\author{
Universidade de São Paulo \\ Escola de Engenharia de São Carlos \\ Departamento de Engenharia Elétrica
}

Antonio Helson Mineiro Soares

\title{
Metodologia Computacional para Coordenação Automática de Dispositivos de Proteção contra Sobrecorrente em Sistemas Elétricos Industriais
}





\section{Antonio Helson Mineiro Soares}

\section{Metodologia Computacional para Coordenação Automática de Dispositivos de Proteção contra Sobrecorrente em Sistemas Elétricos Industriais}

Dissertação apresentada à Escola de Engenharia de São Carlos da Universidade de São Paulo, como parte dos requisitos para obtenção do título de Mestre em Engenharia Elétrica

Área de Concentração: Sistemas Elétricos de Potência

Orientador: Prof. Dr. José Carlos de Melo Vieira Júnior

São Carlos

2009 





\section{Dedicatória}

À minha família pelo apoio incondicional, em todos os sentidos, e fé na certeza da realização deste trabalho. 


\section{Agradecimentos}

Ao Prof. Dr. José Carlos de Melo Vieira Júnior, pelo apoio, atenção, disponibilidade, amizade e orientação durante todo o Mestrado.

Aos Colegas do Laboratório de Sistemas de Energia Elétrica pela ajuda na realização deste trabalho.

Ao Departamento de Engenharia Elétrica da Escola de Engenharia de São Carlos da Universidade de São Paulo, pela oportunidade de realização do curso de Mestrado.

Ao Conselho Nacional de Desenvolvimento Científico e Tecnológico - CNPq pela concessão da bolsa de Mestrado. 


\section{Sumário}

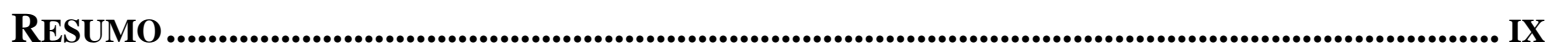

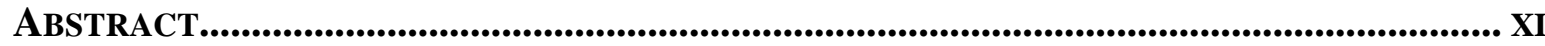

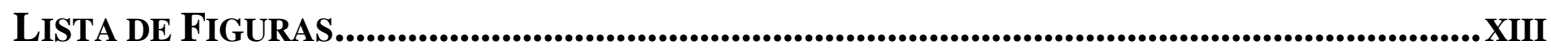

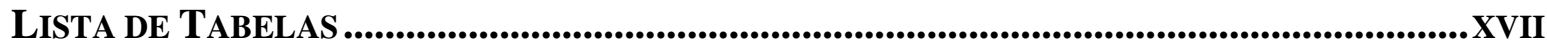

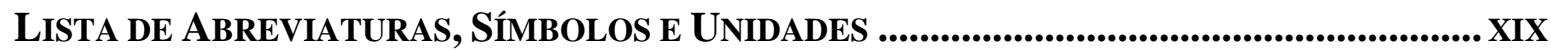

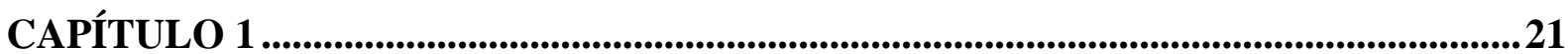

INTRODUÇÃ̃O ..................................................................................................................................21

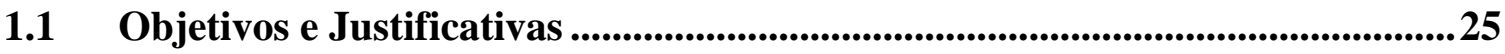

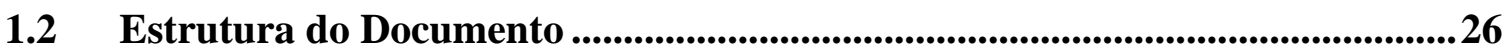

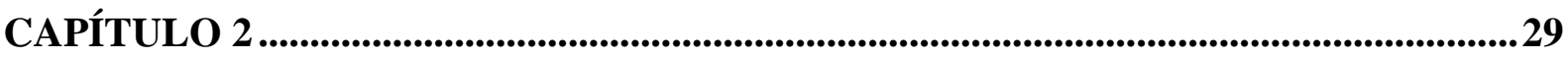

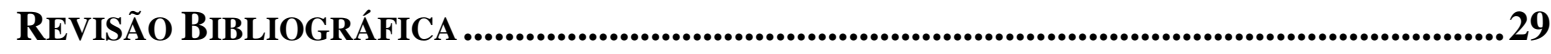

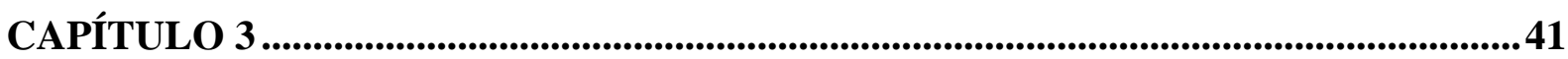

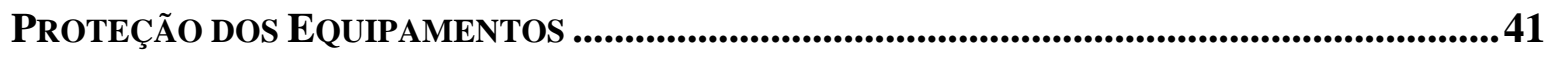

3.1 Dispositivos de Proteção ....................................................................................................... 42

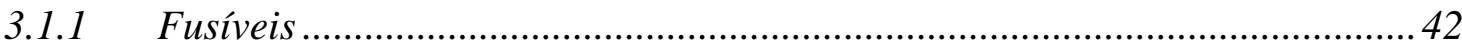

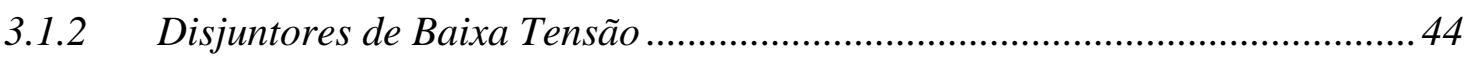

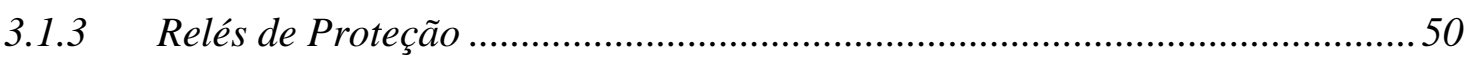

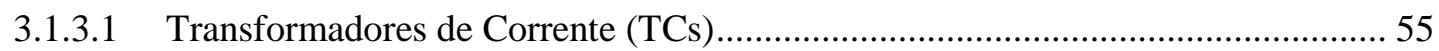

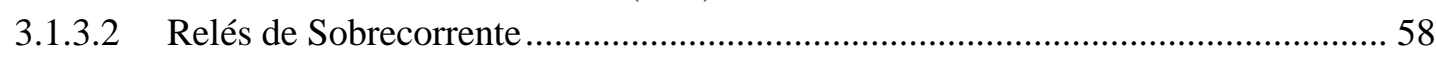

3.1.3.2.1 Curvas de Atuação de Relés de Sobrecorrente ..........................................................................60

3.2 Equipamentos Protegidos .............................................................................69

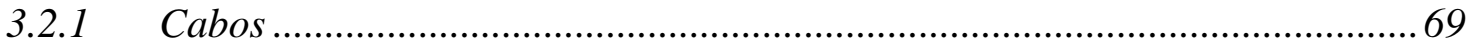

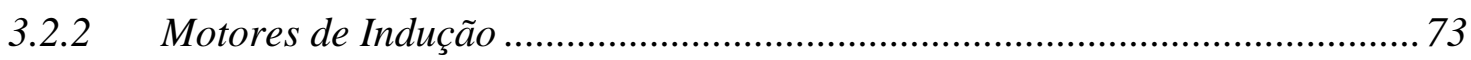

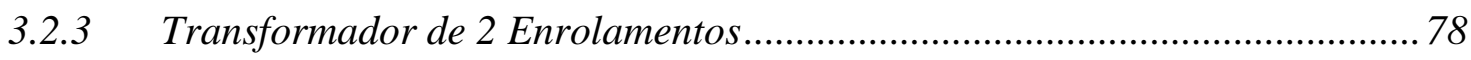

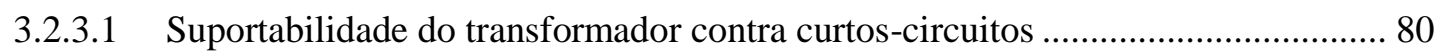

3.3 Considerações Finais.............................................................................................86

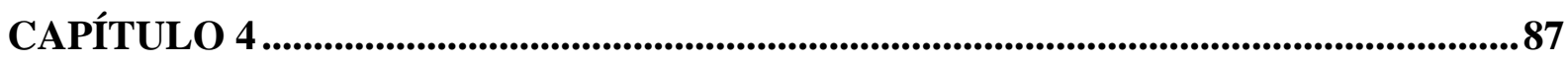

Critérios de CoordenaÇão da Proteção e Seletividade ......................................87

4.1 Correntes de Curto-Circuito .......................................................................8

4.2 Proteção Individual dos Equipamentos .............................................................90

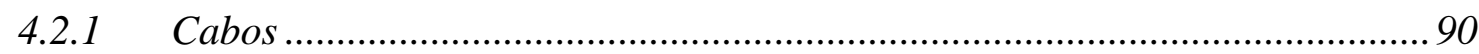

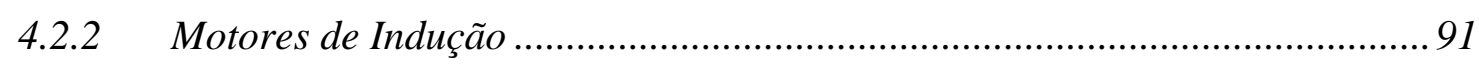

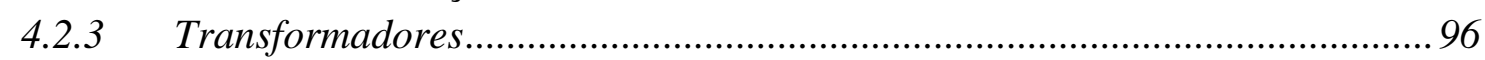


4.3 Coordenação da Proteção e Seletividade ...................................................... 100

4.3.1 Intervalo de Coordenação .......................................................................... 101

4.3.2 O Processo de Coordenação ....................................................................... 102

4.3.3 Solução de Problemas de Coordenação entre Dispositivos de Proteção .... 110

\section{CAPÍTULO 5.}

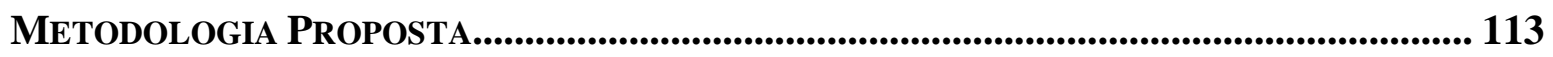

5.1 Dados de Entrada dos Equipamentos ........................................................ 116

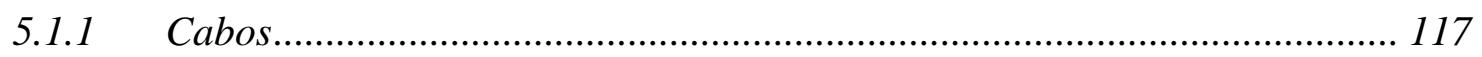

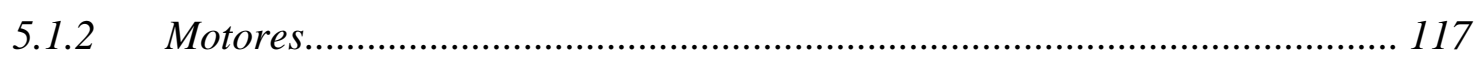

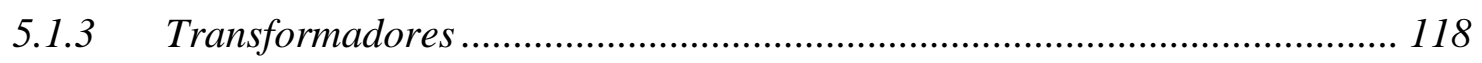

5.2 Tratamento dos Dados dos Equipamentos ...................................................... 119

5.3 Verificação de Consistência dos Dados dos Equipamentos ........................... 120

5.4 Cálculo de Curto-Circuito ........................................................................................ 123

5.5 Dados de Entrada dos Dispositivos de Proteção ................................................ 125

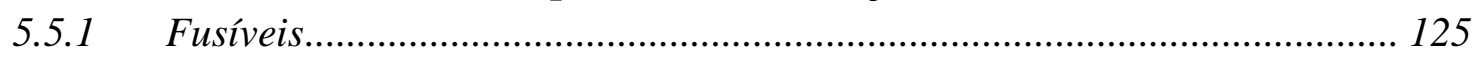

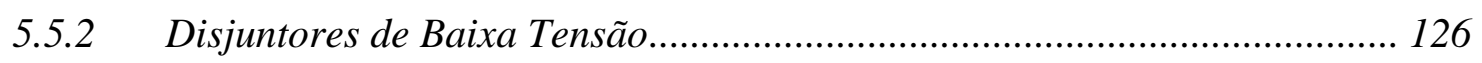

5.5.3 Relé de Sobrecorrente .................................................................................. 126

5.6 Verificação de Consistência dos Dados dos Dispositivos de Proteção ........... 127

5.7 Ajustes Automáticos ......................................................................................... 129

5.7.1 Algoritmo de Definição de Ajustes dos Dispositivos de Proteção ................ 131

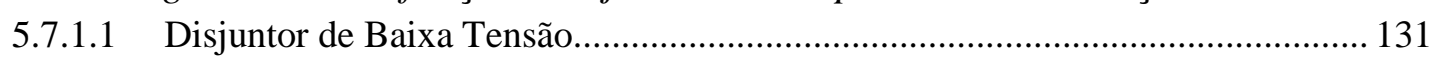

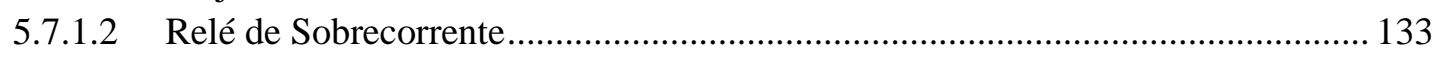

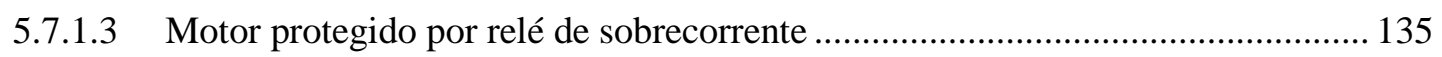

5.7.1.4 Motor protegido por disjuntor de baixa tensão ................................................... 136

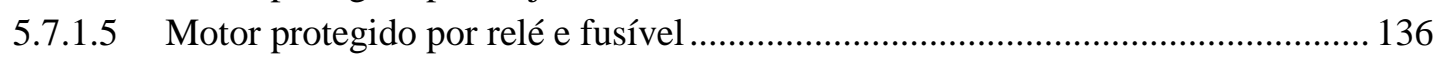

5.7.1.6 Lado secundário do transformador protegido por relé de sobrecorrente. ............. 137

5.7.1.7 Lado secundário do transformador protegido por disjuntor de baixa tensão........ 139

5.7.1.8 Lado secundário do transformador protegido por fusível.................................... 139

5.7.1.9 Lado primário do transformador protegido por relé de sobrecorrente.................. 139

5.7.1.10 Lado primário do transformador protegido por fusível ...................................... 142

5.7.1.11 Barra protegida por qualquer dispositivo de proteção .......................................... 142

5.7.2 Coordenação com o Dispositivo de Proteção da Subestação....................... 143

5.8 Verificação de Sensibilidade dos Dispositivos de Proteção............................... 144

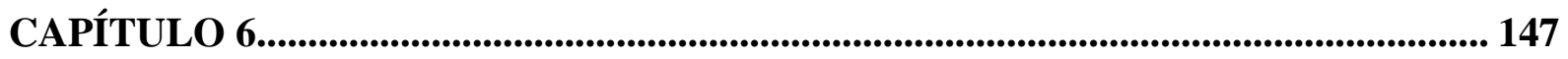

RESULTADOS............................................................................................................... 147

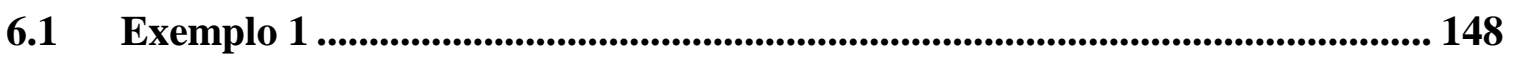

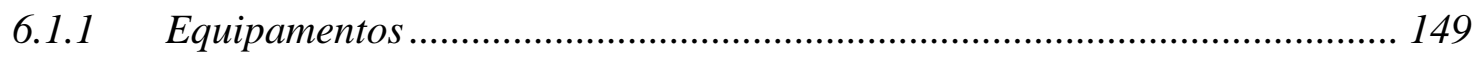

6.1.2 Correntes de Curto-Circuito ........................................................................ 151

6.1.3 Dados de Entrada dos Dispositivos de Proteção ......................................... 152

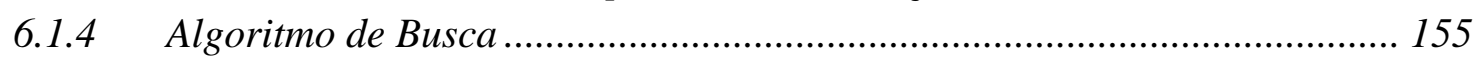

6.1.4.1 Ajuste das Proteções de Fase ............................................................................... 156

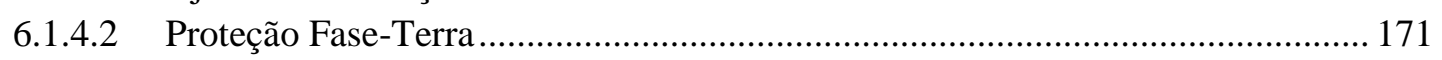


6.2 Exemplo 2 ......................................................................................................................183

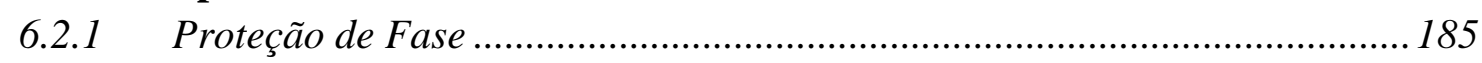

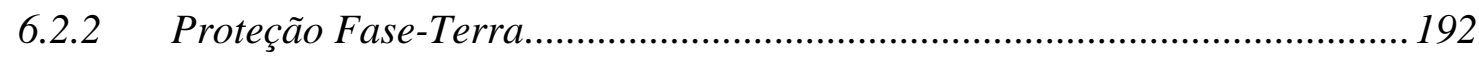

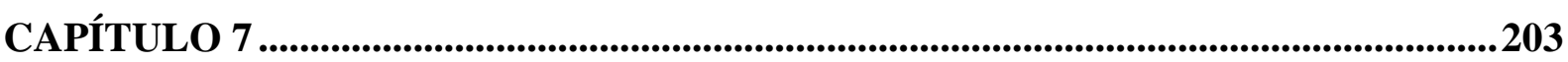

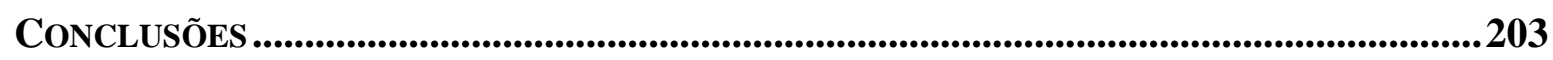

REFERÊNCIAS BIBLIOGRÁFICAS ...........................................................................207

ANEXO A - DADOS DO SISTEMA ELÉTRICO DO EXEMPLO 2 ...............................211

ANEXO B - RESULTADOS COMPLETOS DOS EXEMPLOS........................................221

ANEXO C - PUBLICAÇÕES ..............................................................................................229 


\section{Resumo}

Soares. A. H. M. Metodologia Computacional para Coordenação Automática de Dispositivos de Proteção Contra Sobrecorrente em Sistemas Elétricos Industriais, 2009. 231 f. Mestrado Escola de Engenharia de São Carlos, Universidade de São Paulo, São Paulo.

Este trabalho apresenta uma metodologia computacional para coordenação automática de dispositivos de proteção contra sobrecorrente em sistemas elétricos industriais radiais, tendo como principais vantagens a exatidão nos cálculos dos ajustes e a proposição automática de soluções para eventuais problemas de coordenação, sempre que possível. A metodologia é utilizada tanto para proteção individual contra sobrecorrente dos equipamentos quanto para coordenação dos dispositivos de proteção do sistema. É feito um estudo detalhado dos requisitos de proteção de sobrecorrente dos equipamentos empregados em sistemas elétricos industriais, como motor, cabo e transformador, bem como dos dispositivos mais utilizados, fusível e disjuntor de baixa tensão, com ênfase para a proteção por meio de relés digitais de sobrecorrente. O método é usado para o desenvolvimento de uma ferramenta computacional. Há uma exposição dos algoritmos utilizados para busca e cálculo dos ajustes dos dispositivos de cada equipamento. Por fim é realizado um teste da ferramenta com dois exemplos de sistemas elétricos industriais, mostrando que o mesmo apresenta bom desempenho quanto à exatidão no cálculo dos ajustes e na redução do tempo despendido em estudos de coordenação da proteção e seletividade.

Palavras-Chave: proteção de sistemas elétricos, coordenação da proteção de sobrecorrente, seletividade, relés digitais, curto-circuito, sistemas elétricos industriais. 


\section{Abstract}

Soares. A. H. M. Computational Method for Automatic Overcurrent Coordination of Protection Devices in Industrial Electrical Systems, 2009. 231 p. Master Thesis - Escola de Engenharia de São Carlos, Universidade de São Paulo, São Paulo.

This work presents a computational methodology for automatic overcurrent coordination of protection devices in radial industrial electrical systems, which main advantages are the accuracy in the devices' settings calculation and the automatic proposition of solutions to coordination problems, whenever it is possible. The methodology is used both for equipment individual overcurrent protection and for protection devices coordination. A detailed study of the overcurrent protection requirements of the equipments used in industrial electrical systems, such as motor, cable and transformer is carried out, as well as of the most used protection devices, fuses and low voltage circuit breaker, with emphasis on the protection by means of overcurrent digital relays. The method is used to develop a computational tool. There is an explanation of the search and settings calculation algorithms applied to the devices of each equipment. Finally, two examples of industrial electrical systems are used to assess the performance of the proposed methodology. It is shown that it presents good performance on the accuracy in the calculation of the devices settings and on amount of time spent on protection coordination and selectivity studies.

Index Terms: power systems protection, overcurrent protection coordination, selectivity, digital relays, short circuit, industrial electrical systems. 


\section{Lista de Figuras}

Figura 1.1 - Zonas de proteção. 23

Figura 1.2 - Exemplo de coordenograma mostrando a coordenação entre dois relés. 24

Figura 3.1 - Características de atuação para fusíveis de alta tensão. .44

Figura 3.2 - Exemplos de curvas de atuação de disjuntores de baixa tensão termomagnéticos.

Figura 3.3 - Exemplos de curvas de atuação de disjuntores de baixa tensão de disparo eletrônico.

Figura 3.4 - Exemplos de curva de atuação da proteção contra faltas fase-terra de disjuntores de baixa tensão.

Figura 3.5 - Diagrama funcional de blocos de um relé digital. .52

Figura 3.6 - Esquema de ligação dos TCs para proteção de sobrecorrente fase e de neutro.

Figura 3.7 - Esquema de ligação dos TCs para proteção de sobrecorrente de fase e de terra.

Figura 3.8 - Curva de sobrecorrente a tempo definido. 61

Figura 3.9 - Curva de sobrecorrente a tempo inverso. 62

Figura 3.10 - Curva de atuação moderadamente inversa padrão ANSI (U1). 63

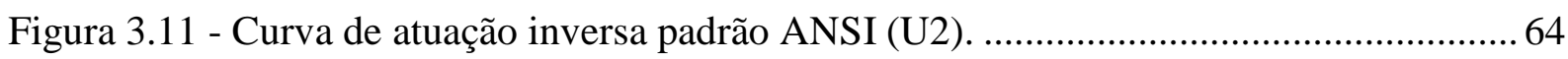

Figura 3.12 - Curva de atuação muito inversa padrão ANSI (U3) ........................................ 64

Figura 3.13 - Curva de atuação extremamente inversa padrão ANSI (U4)............................ 65

Figura 3.14 - Curva de atuação inversa de tempo curto padrão ANSI (U5). ........................... 65

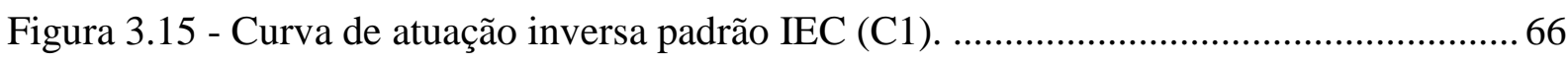

Figura 3.16 - Curva de atuação muito inversa padrão IEC (C2) .......................................... 67

Figura 3.17 - Curva de atuação extremamente inversa padrão IEC (C3)............................... 67

Figura 3.18 - Curva de atuação inversa de tempo longo padrão IEC (C4)............................. 68

Figura 3.19 - Curva de atuação inversa de tempo curto padrão IEC (C5). ............................. 68

Figura 3.20 - Curva do limite térmico de cabo de cobre com conexões prensadas.................. 71

Figura 3.21 - Regiões de ajuste, de alerta e de dano dos cabos.............................................. 73

Figura 3.22 - Curva de partida do motor de indução............................................................... 76

Figura 3.23 - Regiões de ajuste e de dano do motor de indução............................................ 78

Figura 3.24 - Característica de suportabilidade contra curto-circuito de um transformador delta-estrela pertencente à categoria II.

Figura 3.25 - Regiões de dano e de ajuste para o transformador trifásico de dois enrolamentos.

Figura 4.1 - Exemplo de proteção dos cabos realizada por relé 51/50. 
Figura 4.2 - Proteção de motor de média tensão por relé 50 e 51 ..........................................95

Figura 4.3 - Proteção de motor de média tensão por relé 51 e fusível......................................95

Figura 4.4 - Proteção de motor de baixa tensão por disjuntor de baixa tensão (DBT).............96

Figura 4.5 - Proteção de transformador de dois enrolamentos realizada por relés 50 e 51 ...100

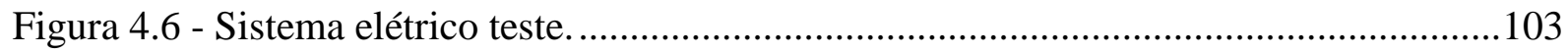

Figura 4.7 - Ajuste das proteções individuais do motor M1 - proteção de fase......................104

Figura 4.8 - Ajuste das proteções individuais do motor M1 - proteção de neutro..................105

Figura 4.9 - Coordenação do relé R2 com o relé R1 - proteção de fase.................................107

Figura 4.10 - Coordenação do relé R2 com o relé R1 - proteção de terra...............................107

Figura 4.11 - Coordenação do relé R3 com o relé R2 - proteção de fase...............................109

Figura 4.12 - Ajuste da função de proteção de neutro do relé R3 ..........................................109

Figura 4.13 - Coordenação entre os relés R1, R2 e R3 - proteção de fase..............................110

Figura 4.14 - Exemplo de problema de proteção .................................................................112

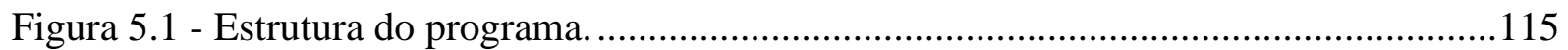

Figura 5.2 - Estrutura geral da entrada de dados e saída de resultados do programa. ............116

Figura 5.3 - Verificação de consistência dos dados do sistema elétrico. ...............................121

Figura 5.4 - Algoritmo para a distinção entre barras e terminais..........................................123

Figura 5.5 - Verificação de consistência dos dispositivos de proteção...................................128

Figura 5.6 - Estrutura do algoritmo "Ajustes". ......................................................................129

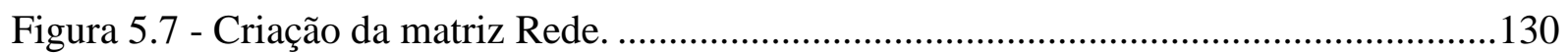

Figura 5.8 - Algoritmo para definição de ajustes de disjuntor de baixa tensão. .....................133

Figura 5.9 - Algoritmo para definição de ajustes dos relés de sobrecorrente de tempo

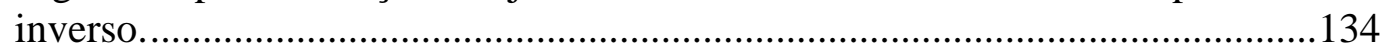

Figura 6.1 - Diagrama unifilar do sistema elétrico do Exemplo 1........................................148

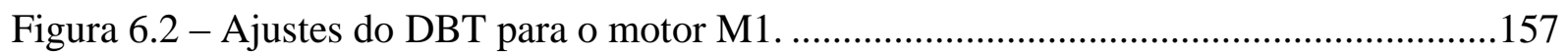

Figura 6.3 - Coordenação entre os dispositivos de proteção do transformador T2 e motor

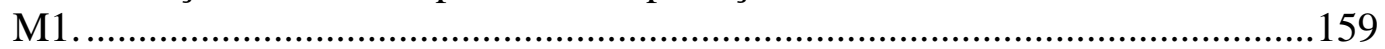

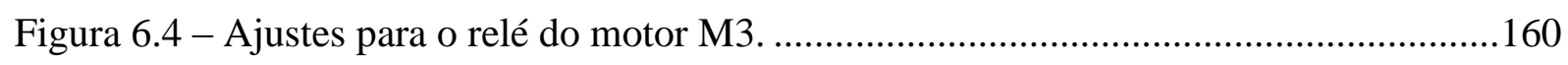

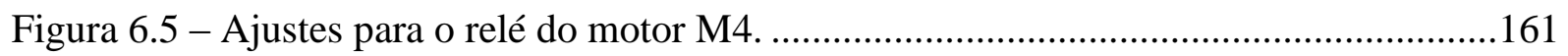

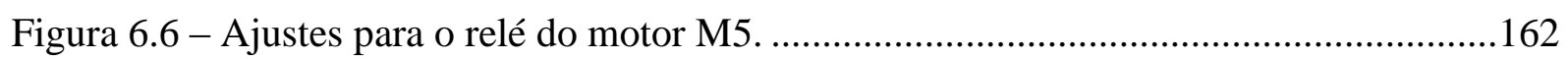

Figura 6.7 - Ajustes para o relé do motor M6. …...............................................................163

Figura 6.8 - Verificação de ajustes do DBT do motor M7 .................................................164

Figura 6.9 - Verificação de ajustes do DBT do motor M8 .................................................165

Figura 6.10 - Ajustes para o Relé-Painel(B04). ................................................................166

Figura 6.11 - Coordenação entre os dispositivos de proteção do transformador T4 e motor M3 
Figura 6.12 - Coordenação entre os dispositivos de proteção do transformador T5 e motor M5.

Figura 6.13 - Coordenação entre os dispositivos de proteção do transformador T6 e motor M8.

Figura 6.14 - Coordenação entre o relé do primário do transformador T5 e os relés associados ao transformador T1.

Figura 6.15 - Verificação da coordenação com o relé da subestação

Figura 6.16 - Ajuste da proteção de terra do DBT para o motor M1

Figura 6.17 - Coordenação da proteção fase-terra do secundário do transformador T2 e motor M1.

Figura 6.18 - Ajustes para o relé de terra do primário do transformador T2........................ 174

Figura 6.19- Ajustes para o relé de terra do motor M3 ...................................................... 175

Figura 6.20- Ajuste do terra do DBT para o motor M7 ..................................................... 176

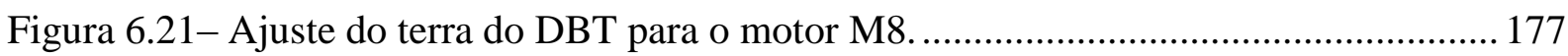

Figura 6.22 - Coordenação da proteção do relé primário do transformador T2 com o relé do painel B04.

Figura 6.23 - Coordenação da proteção do motor M3 com a do lado secundário do transformador T4.

Figura 6.24 - Ajustes do rele de terra do transformador T4.

Figura 6.25 - Coordenação da proteção do motor M8 com a do lado secundário do transformador T6.

Figura 6.26 - Ajustes do relé de terra do transformador T6.

Figura 6.27 - Coordenação da proteção do lado primário do transformador T4 com o lado secundário do transformador $\mathrm{T} 1$.

Figura 6.28 - Ajustes do relé de terra do transformador T1.

Figura 6.29 - Verificação da proteção de terra primário do transformador T1 com a proteção de terra da subestação.

Figura 6.30 - Diagrama unifilar do sistema elétrico do Exemplo 2.

Figura 6.31 - Coordenação entre os dispositivos de proteção do transformador T33 e carga $\mathrm{C} 10$.

Figura 6.32 - Ajustes do relé da barra B20 coordenado com fusível do primário do transformador T33.

Figura 6.33 - Coordenação entre as proteções da barra B20 e B18...................................... 188

Figura 6.34 - Coordenação entre as proteções das barras B20, B18 e B15........................... 188

Figura 6.35 - Coordenação entre as proteções das barras B18, B15 e B12 ........................... 189

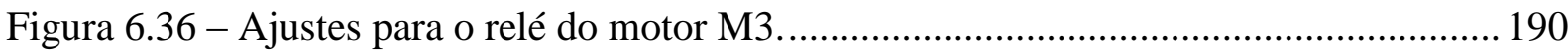

Figura 6.37 - Verificação da coordenação entre os dispositivos do motor M3 e transformador T16. 
Figura 6.38 - Ajustes do relé da barra B25 coordenados com o fusível do primário do transformador T16.

Figura 6.39 - Coordenação entre os dispositivos de proteção do transformador T1 e barra B25.

Figura 6.40 - Coordenação entre o terra do DBT do secundário do transformador T33 com a proteção da carga $\mathrm{C} 10$.

Figura 6.41 - Ajustes do rele de terra da barra B20 com fusível do transformador T33. .......194

Figura 6.42 - Coordenação entre as proteções de terra das barras B20 e B18........................195

Figura 6.43 - Coordenação entre as proteções de terra das barras B20, B18 e B15...............195

Figura 6.44 - Coordenação entre as proteções de terra das barras B18, B15 e B12...............196

Figura 6.45- Ajustes para a proteção de terra do motor M3 ................................................197

Figura 6.46 - Ajustes do rele de terra da barra B25 com o fusível do transformador T16. ....198

Figura 6.47 - Coordenação entre as proteções de terra das barras B15, B12 do secundário do transformador $\mathrm{T} 1$.

Figura 6.48 - Ajustes do relé de terra do primário do transformador T1

Figura 6.49 - Verificação da proteção do primário do transformador T1 com o relé da subestação.

Figura 6.50 - Verificação da proteção de terra primário do transformador T1 com a proteção de terra do relé subestação. 


\section{Lista de Tabelas}

Tabela 3.1 - Constantes das curvas de atuação associadas ao padrão ANSI........................... 63

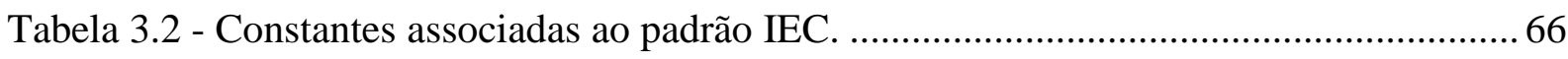

Tabela 3.3 - Valores de $\mathrm{T}_{1}$ e $\mathrm{T}_{2}$ para cabos de cobre e alumínio........................................... 70

Tabela 3.4 - Categoria dos transformadores conforme IEEE Std. C57.12.00 ....................... 81

Tabela 3.5 - Limite térmico de transformadores imersos em óleo isolante............................. 82

Tabela 3.6 - Limite mecânico de transformadores de dois enrolamentos. ............................... 84

Tabela 3.7 - Limite térmico de transformadores a seco. ..................................................... 85

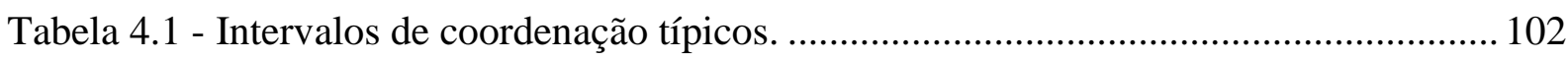

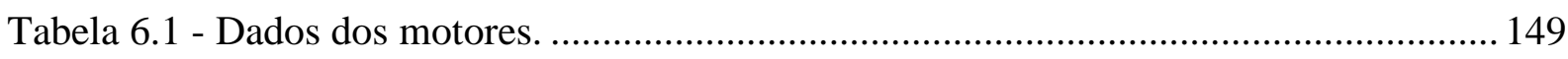

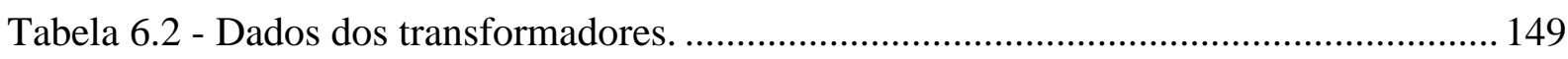

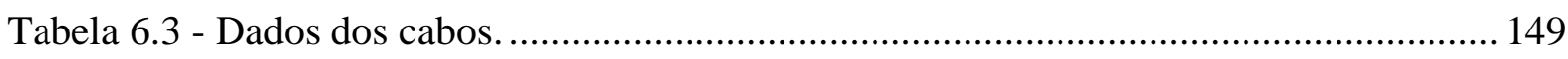

Tabela 6.4 - Impedâncias equivalentes dos cabos. ........................................................... 150

Tabela 6.5 - Corrente nominal e de partida dos motores. .................................................. 150

Tabela 6.6 - Corrente nominal e características da corrente de magnetização dos

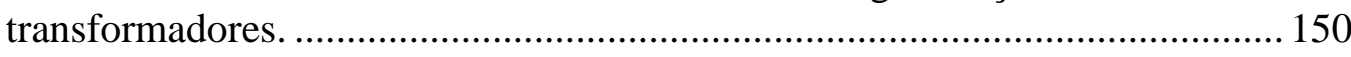

Tabela 6.7 - Ampacidade equivalente dos cabos........................................................ 151

Tabela 6.8 - Correntes de curto-circuito. ........................................................................ 152

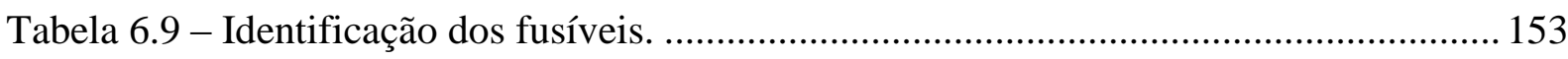

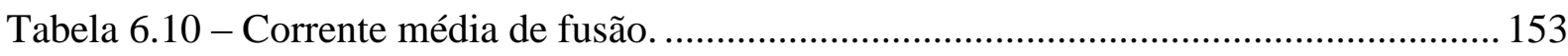

Tabela 6.11 - Tempo de fusão correspondente à corrente média. ........................................ 153

Tabela 6.12 - Identificação dos disjuntores de baixa tensão.............................................. 153

Tabela 6.13 - Parâmetros de ajuste dos disjuntores de baixa tensão. .................................... 154

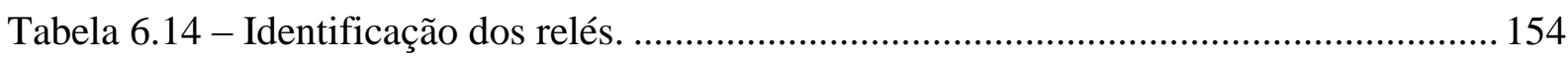

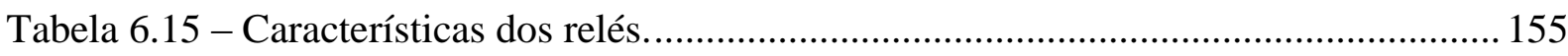

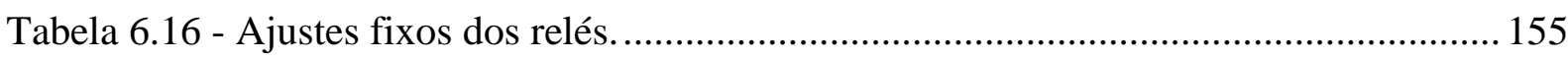

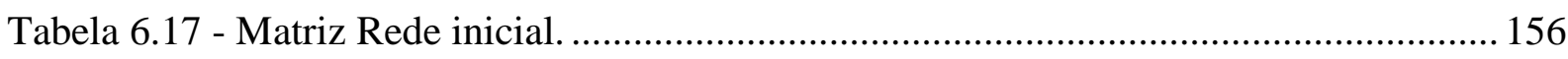

Tabela 6.18 - Matriz Rede para o segundo passo. ............................................................ 158

Tabela 6.19 - Matriz Rede para o terceiro passo. ............................................................... 165

Tabela 6.20 - Matriz Rede para o último passo................................................................. 169

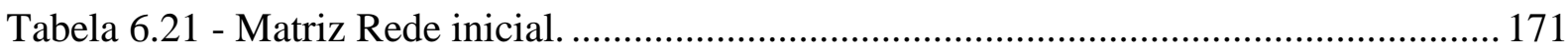

Tabela 6.22 - Matriz Rede para o segundo passo............................................................ 173

Tabela 6.23 - Matriz Rede para o terceiro passo............................................................... 177

Tabela 6.24 - Matriz Rede para o último passo.............................................................. 181 


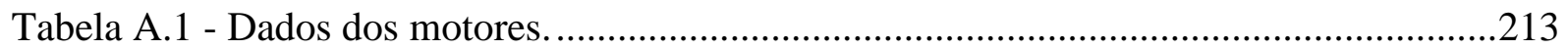

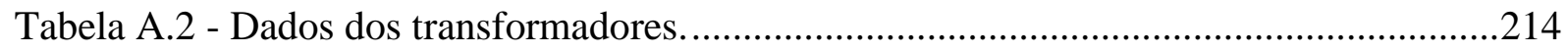

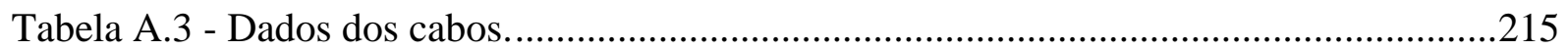

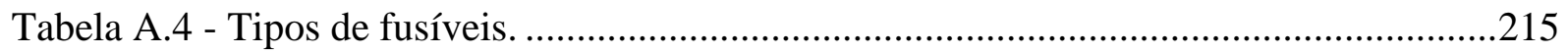

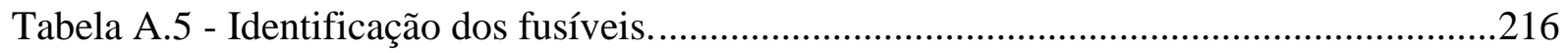

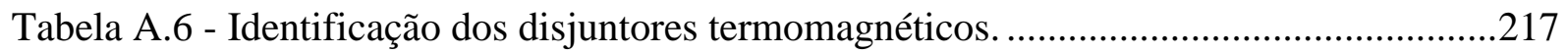

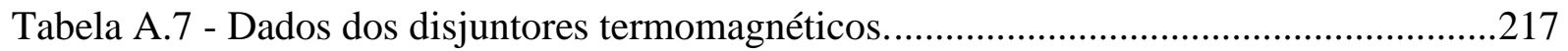

Tabela A.8 - Identificação dos disjuntores de baixa tensão.................................................218

Tabela A.9 - Parâmetros para todos os disjuntores de baixa tensão. .......................................218

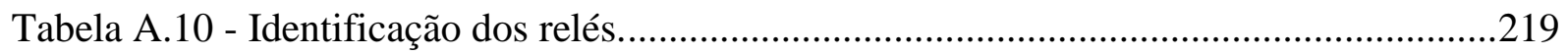

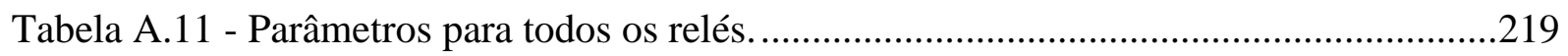

Tabela B.1 - Ajustes dos disjuntores de baixa tensão (Exemplo 1) ……...............................223

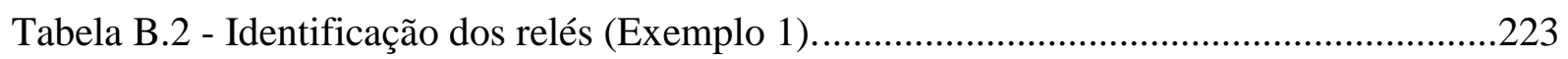

Tabela B.3 - Ajustes dos relés para proteção de fase (Exemplo 1)........................................224

Tabela B.4 - Ajustes dos relés para proteção de terra (Exemplo 1) .......................................224

Tabela B.5 - Ajustes dos disjuntores de baixa tensão (Exemplo 2)......................................225

Tabela B.6 - Identificação dos relés (Exemplo 2).................................................................226

Tabela B.7 - Ajustes dos relés para proteção de fase (Exemplo 2) ........................................226

Tabela B.8 - Ajustes dos relés para proteção de terra (Exemplo 2)......................................227 


\section{Lista de Abreviaturas, Símbolos e Unidades}

A/D - Analógico/Digital.

ANSI - American National Standards Institute.

AT - Atraso de tempo de proteção fase-terra do disjuntor de baixa tensão.

ATC - Atraso de tempo curto.

ATL - Atraso de tempo longo.

CC - Curto-circuito.

CCC - Corrente de curto-circuito.

CPU - Unidade Central de Processamento.

DBT - Disjuntor de Baixa Tensão.

EPROM - Erasable Programmable Read-Only Memory.

IEC - International Electrotechnical Commission.

IED - Intelligent Electronic Device.

IEEE - Institute of Electrical and Electronics Engineers.

$\mathrm{I}_{\mathrm{C}}-$ Corrente de tempo curto.

$\mathrm{I}_{\mathrm{L}}-$ Corrente de tempo longo.

$\mathrm{I}_{\mathrm{N}}$ - Corrente nominal do disjuntor, em Ampère.

M - Múltiplo da corrente de ajuste.

$\mathrm{M}_{\text {inst }}-$ Multiplicador da corrente instantânea.

MT - Multiplicador da corrente de proteção fase-terra do disjuntor de baixa tensão.

MTC - Multiplicador de tempo curto.

MTL - Multiplicador de tempo longo.

NBR - Norma da Associação Brasileira de Normas Técnicas.

RAM - Random Access Memory. 
ROM - Read Only Memory.

SCADA - Supervisory Data and Control Acquisition.

TDS - Multiplicador do ajuste de tempo do relé.

TC - Transformador de Corrente.

$\mathrm{T}_{\mathrm{op}}$ - Tempo de Operação do relé, em segundos.

TP - Transformador de Potencial.

$\Delta-$ Enrolamento em Delta

Y - Enrolamento em Estrela

A - Ampère

$\mathrm{Hz}-$ Hertz

$\mathrm{kV}$ - kilovolt

$\mathrm{mm}^{2}$ - Milímetro Quadrado

ms - Milissegundo

$\mathrm{s}-$ Segundo

${ }^{0} \mathrm{C}-$ Celsius

$\mathrm{kW}$ - kilowatt

VA - Volt-Ampère

MVA - Mega Volt-Ampère

$\Omega / \mathrm{km}-\mathrm{Ohms}$ por quilômetro 


\section{Capítulo 1}

\section{Introdução}

Não obstante a todos os programas computacionais existentes para coordenação da proteção de sistemas elétricos de potência, o papel importante é sem dúvida do engenheiro de proteção, que com sua experiência, terá sensibilidade para projetar um sistema de proteção eficiente, bem como definir os ajustes dos dispositivos de proteção visando satisfazer os seguintes requisitos:

- Seletividade: na ocorrência de distúrbios no sistema elétrico, somente deve ser isolada a parte defeituosa do mesmo, mantendo em operação as demais partes;

- Rapidez: os dispositivos de proteção devem atuar num menor tempo possível, a fim de evitar a propagação do defeito para outras partes do sistema e minimizar ou evitar os danos aos equipamentos e às pessoas envolvidas em sua operação;

- Sensibilidade: a proteção deve ser sensível aos defeitos que possam ocorrer no sistema; 
- Segurança: o sistema de proteção deve ser projetado de forma a distinguir as condições de defeito e não-defeito, de forma a operar corretamente quando solicitado e não operar indevidamente;

- Economia: a implantação do sistema de proteção deve ser economicamente viável.

A segurança de um sistema de proteção é definida em termos de regiões do sistema de energia elétrica, que são chamadas de zonas de proteção, pelas quais um determinado relé ou dispositivo de proteção é responsável. Um dispositivo de proteção será considerado seguro se operar apenas para distúrbios que ocorram dentro de sua zona de proteção. Todos os componentes do sistema de energia elétrica devem estar dentro de pelo menos uma zona de proteção (Figura 1.1), sendo que uma filosofia adotada é garantir que os componentes mais importantes estejam incluídos em pelo menos duas zonas de proteção, isto é, que o componente seja protegido por dois sistemas de proteção. As zonas de proteção devem se sobrepor para garantir que nenhum equipamento fique desprotegido, mesmo que o dispositivo principal responsável pela sua proteção falhe. Neste contexto surgem os conceitos de proteção primária e proteção de retaguarda. O sistema de proteção principal para uma dada zona de proteção é chamado de sistema de proteção primária, cuja responsabilidade é operar no tempo mais rápido possível e retirar de operação a menor quantidade de componentes. Por outro lado, a proteção de retaguarda deve operar caso o sistema de proteção primária falhe. Por exemplo, na Figura 1.1 se houver a falha da proteção primária de um motor (zona de proteção 5) na ocorrência de um curto-circuito, a proteção do barramento (zona de proteção 2) deve atuar, às custas de desligar também o outro motor, sacrificando a seletividade. Esta, por sua vez, para ser atingida depende da correta coordenação dos ajustes dos dispositivos de proteção primária e de retaguarda. 
1 - Proteção da Subestação.

2 - Proteção de Barramento.

3 - Proteção de Transformador.

4 - Proteção de Cabo.

5 - Proteção de Motor.

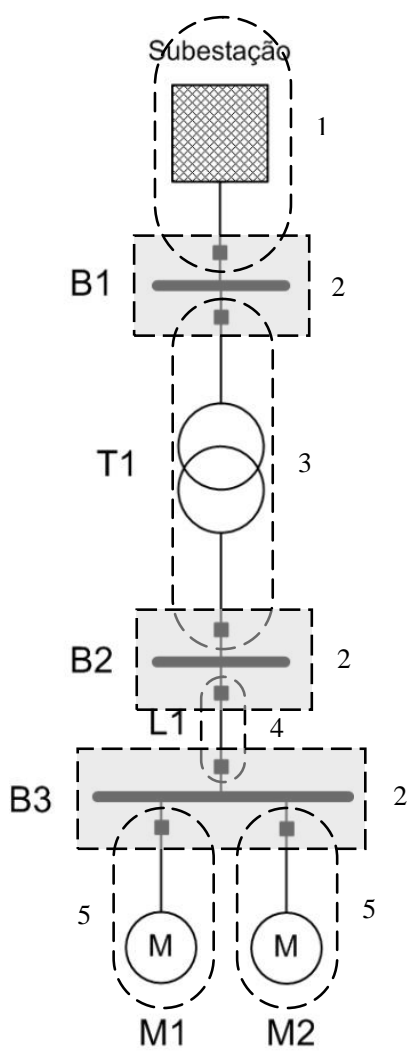

Figura 1.1 - Zonas de proteção.

Em se tratando de proteção contra sobrecorrente - tema abordado neste trabalho existem vários critérios para ajustar os dispositivos de proteção de forma coordenada (CAMINHA, 1977; IEEE Std. 242, 2001). O processo de coordenação de dispositivos de proteção é realizado com o auxílio de coordenogramas, os quais contêm as curvas tempo versus corrente de atuação dos dispositivos de proteção. Em linhas gerais, os dispositivos estão coordenados quando as curvas de atuação da proteção primária estiverem abaixo da curva de atuação da proteção de retaguarda, em todo o trecho protegido, para as correntes de curto-circuito e sobrecarga. A Figura 1.2 ilustra um coordenograma em que o Relé 1 é o dispositivo de proteção primária e o Relé 2, o de retaguarda. Estes estão coordenados, sendo que os ajustes de cada um e o intervalo de tempo que define a "distância" entre as curvas dependem das características dos equipamentos protegidos e dos dispositivos de proteção, conforme será adequadamente abordado nos capítulos 3 e 4 deste documento. 


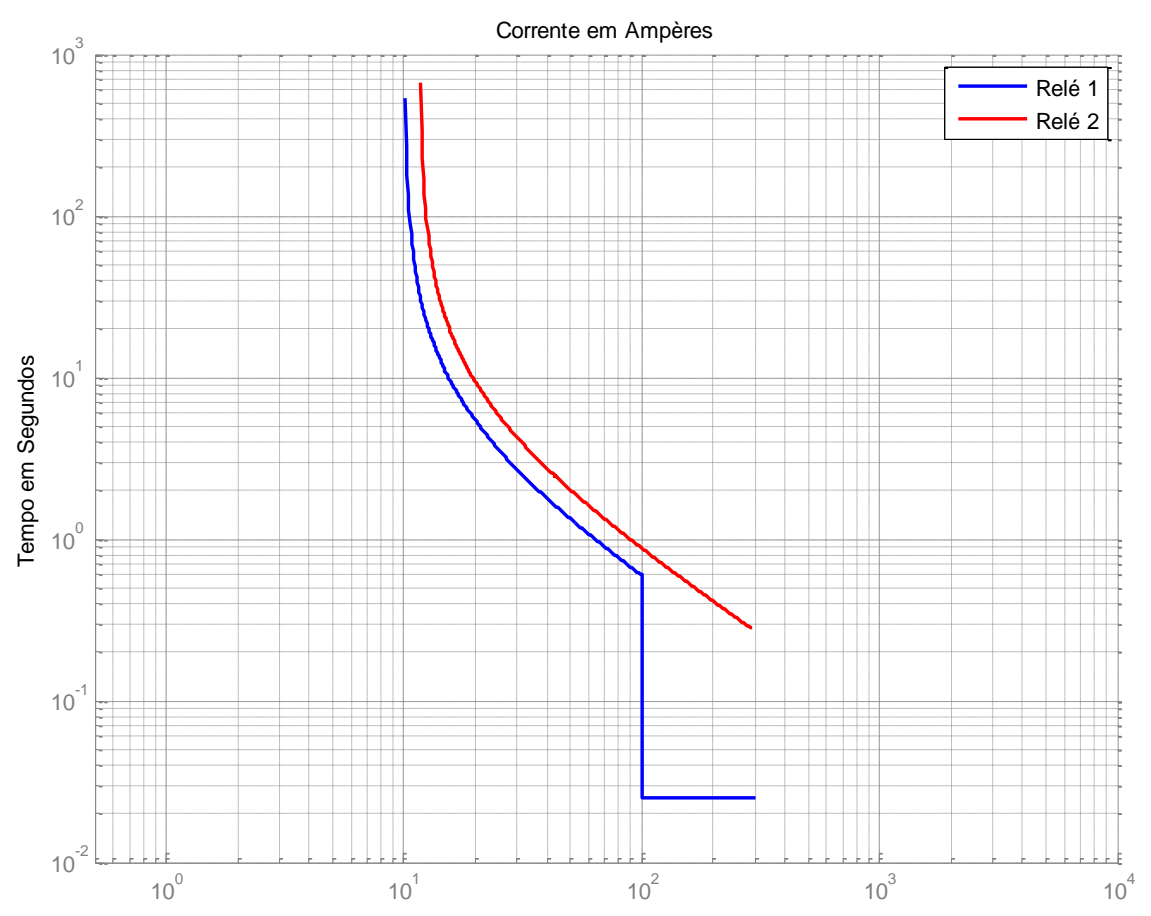

Figura 1.2 - Exemplo de coordenograma mostrando a coordenação entre dois relés.

Estudos de coordenação da proteção e seletividade de dispositivos de proteção contra sobrecorrente são necessários antes da implantação de novos sistemas elétricos e quando ocorre a alteração de sistemas elétricos existentes, sobretudo a instalação de novos motores e geradores. Tais estudos envolvem o conhecimento de todos os critérios de coordenação e de proteção individual de equipamentos, as características dos dispositivos de proteção e os valores das correntes de curto-circuito medidas por todos esses dispositivos. Nota-se, portanto, que a execução dos estudos é um processo trabalhoso que pode demandar muito tempo na medida em que aumenta a complexidade do sistema elétrico sob análise e a diversidade dos tipos de dispositivos de proteção. No caso de sistemas elétricos industriais, a questão de lidar com vários tipos de equipamentos a serem protegidos e de dispositivos de proteção merece destaque, uma vez que podem ser encontrados diferentes tipos de disjuntores de baixa tensão, fusíveis, relés eletromecânicos e digitais. Essa diversidade de dispositivos de 
proteção eleva a complexidade dos estudos de coordenação, pois podem existir curvas de atuação com padrões bastante distintos.

\subsection{Objetivos e Justificativas}

Uma vez verificada a importância e complexidade da execução de estudos de coordenação da proteção e seletividade abordadas anteriormente, este trabalho tem como meta principal o desenvolvimento de uma metodologia computacional capaz de definir automaticamente os ajustes dos dispositivos de proteção contra sobrecorrente em sistemas industriais, de forma a garantir a coordenação entre os mesmos, sempre que possível, agilizando a realização deste tipo de tarefa. A opção por abordar sistemas elétricos industriais deve-se à diversidade dos equipamentos a serem protegidos e dos dispositivos de proteção, visto que existe uma grande quantidade de critérios de proteção a serem considerados, tornando o problema uma tarefa difícil e lenta, se realizada sem o auxílio de ferramentas automáticas. Além disso, o foco do trabalho são sistemas elétricos industriais radiais, sem geradores próprios e se admitem conhecidos o tipo e local de instalação dos dispositivos de proteção e a topologia do sistema elétrico.

Como objetivos principais do trabalho, destacam-se:

- Executar a coordenação automática dos dispositivos de sobrecorrente contra sobrecarga, curtos-circuitos entre fases e curtos-circuitos entre fases envolvendo a terra;

- Reduzir o tempo de execução de estudos de coordenação da proteção e seletividade, tornando-se uma ferramenta muito útil ao engenheiro de proteção. Ressalta-se que não se tem a pretensão de substituir o engenheiro na execução dessa tarefa, pois ele será o responsável por avaliar os resultados 
fornecidos pela metodologia e adaptá-los, se necessário, a particularidades que existam no sistema elétrico da indústria;

- Propor soluções para problemas de coordenação que por ventura possam existir no sistema elétrico sob análise. Esta característica se destaca como diferencial da metodologia proposta em relação a outras encontradas na literatura.

\subsection{Estrutura do Documento}

A disposição dos capítulos e conteúdos se desenvolve da seguinte forma:

- Capítulo 2: apresenta um levantamento bibliográfico sobre o tema do trabalho, mostrando as principais contribuições sobre coordenação automática de dispositivos de proteção contra sobrecorrente;

- Capítulo 3: descreve os dispositivos de proteção e equipamentos utilizados no trabalho, apresentando as características destes que devem ser analisadas em estudos de coordenação de proteção;

- Capítulo 4: apresenta todos os critérios de proteção, tanto para proteção individual dos equipamentos quanto para realizar a coordenação entre os dispositivos, baseando-se na norma IEEE Std. 242 (2001);

- Capítulo 5: descreve de forma detalhada a metodologia computacional proposta para a coordenação automática dos dispositivos de proteção de sistemas elétricos industriais radiais;

- Capítulo 6: apresenta a aplicação da metodologia proposta considerando dois sistemas elétricos;

- Capítulo 7: apresenta as principais conclusões deste trabalho;

- Referências bibliográficas; 
- Anexo A: apresenta os dados de um dos sistemas elétricos analisados neste trabalho;

- Anexo B: apresenta os resultados completos da aplicação da metodologia em dois sistemas elétricos distintos;

- Anexo C: apresenta as publicações resultantes deste trabalho até o momento. 


\section{Capítulo 2}

\section{Revisão Bibliográfica}

Pesquisas relacionadas à busca de metodologias rápidas e eficientes para a definição dos ajustes dos dispositivos de proteção contra sobrecorrente tiveram um avanço significativo com o surgimento do microcomputador, uma vez que este poderia realizar todos os cálculos necessários de forma rápida e confiável, em substituição ao processo manual, o qual demandava bastante tempo e atenção do engenheiro de proteção. Assim, visando prover agilidade e maior precisão nos cálculos para a realização de estudos de coordenação da proteção e seletividade, diversas abordagens podem ser encontradas na literatura. Estas podem ser classificadas basicamente em dois grupos (FLORES E PEREIRA, 1995). No primeiro deles encontram-se os trabalhos em que o objetivo foi a modelagem computacional e representação gráfica dos dispositivos de proteção contra sobrecorrente e suas curvas de atuação. Com isso, a realização de estudos de coordenação da proteção e seletividade tornouse mais rápida, pois a confecção manual realizada em papel foi sendo progressivamente abandonada. No segundo grupo de abordagens encontram-se as metodologias para automatizar o processo de definição dos ajustes com o objetivo de aumentar ainda mais a agilidade e exatidão dos estudos de coordenação da proteção e seletividade. Dentro deste grupo, existem opiniões divergentes quanto ao grau de interatividade entre os programas 
computacionais e o engenheiro de proteção, (KLOCK Jr., 2002). Alguns pesquisadores defendem a idéia de que o grau de interação deva ser elevado para aproveitar a experiência do engenheiro de proteção, ou seja, para que o usuário possa interferir nas decisões do programa em tempo de execução. Por outro lado, outros pesquisadores desenvolveram métodos computacionais com um mínimo de interação com o usuário do programa, sendo que seu papel fica restrito a avaliar a qualidade dos ajustes definidos pelo programa. Entenda-se por “qualidade dos ajustes" o atendimento dos quatro critérios definidos no capítulo anterior: seletividade, rapidez, sensibilidade e segurança.

No contexto exposto anteriormente, este capítulo visa discutir as principais abordagens computacionais encontradas na literatura sobre a definição dos ajustes de dispositivos de proteção contra sobrecorrente, quer sejam por metodologias automáticas ou não. Procura-se aqui abordar desde trabalhos pioneiros até os mais atuais relacionados à automatização dos ajustes dos relés de sobrecorrente.

No trabalho pioneiro de Albrecht et al. (1964), os autores descrevem um programa para realizar a verificação da coordenação e seletividade entre relés direcionais e de sobrecorrente, fusíveis e religadores, cujo foco foi a proteção contra curtos-circuitos entre fases (curtos-circuitos trifásicos e bifásicos). A proposta do trabalho é a seguinte: dada uma topologia conhecida de um sistema elétrico, executar os cálculos necessários para ajustar e verificar a coordenação entre os dispositivos considerados, e também verificar os tempos de atuação dos mesmos para diferentes valores de corrente de falta. O programa computacional desenvolvido permite ainda selecionar o relé mais adequado para a proteção de determinado circuito de acordo com sua curva de atuação. Além disso, o usuário pode fixar o ajuste de determinado dispositivo e requerer a coordenação com os demais ou deixar que o programa determine automaticamente todos os ajustes. A estratégia para coordenar os dispositivos de proteção proposta pelos autores é identificar aqueles com função de proteção de retaguarda e 
então procurar os dispositivos de proteção primária analisando o circuito e o sentido da corrente de falta. Para tanto, o usuário deve fornecer o tipo do dispositivo de proteção (relé, fusível ou religador) e a sua localização. No caso de o programa selecionar o melhor ajuste, a metodologia proposta pelos autores determina vários tempos de atuação do dispositivo de proteção primária em função de correntes de curto-circuito calculadas e em circunstâncias específicas, envolvendo tanto as máximas quanto as mínimas correntes de falta. A esses tempos de atuação são adicionados os intervalos de coordenação. O programa então identifica para cada ajuste de corrente do relé de retaguarda o valor do multiplicador de tempo que satisfaz os critérios de coordenação para todos os valores de corrente. O ajuste do relé de retaguarda que atende os critérios de proteção e com o menor tempo de operação é o selecionado. Nesse trabalho, o programa calcula os ajustes de corrente dos dispositivos de proteção de forma que os mesmos sejam inferiores aos limites de sobrecarga dos circuitos protegidos. Ressalta-se que na época em que o trabalho foi desenvolvido, os relés eram do tipo eletromecânico e possuíam apenas um tipo de curva de atuação.

Com uma proposta ligeiramente diferente de Albrecht et. al. (1964), Langhans e Ronat (1980) descrevem um programa para executar a coordenação automática de dispositivos de proteção contra curto-circuito através da utilização de coordenogramas. O programa contém armazenados os critérios para a realização da coordenação da proteção entre relés de sobrecorrente, disjuntores de baixa tensão e fusíveis. A estratégia proposta para a seleção dos ajustes dos relés de sobrecorrente consiste em iniciar a análise com o dispositivo de proteção das cargas, sendo que o ajuste, no caso de relé e disjuntor de baixa tensão, é calculado para atender aos requisitos da carga. No caso de motores, tais requisitos são a corrente nominal, corrente de partida, tempo de partida e tempo de rotor bloqueado. Em seguida, para ajustar o dispositivo de proteção a montante, o programa inicia com o menor ajuste de corrente e realiza os seguintes testes: 
(a) Se não houver coordenação entre os dispositivos para o tempo de atuação igual a 10 ou 100 segundos, o ajuste de corrente é aumentado;

(b) Se não houver coordenação entre os dispositivos para a corrente de curto-circuito máxima, o multiplicador de tempo é aumentado.

O algoritmo proposto pelos autores repete os itens (a) e (b) até que a coordenação seja conseguida. Uma vez encontrado algum problema na coordenação entre os dispositivos de proteção, o mesmo é revelado ao usuário para que este tome as medidas necessárias para resolvê-lo. Logo, o algoritmo proposto não tenta solucionar os problemas de coordenação. Uma característica importante do programa é que ele considera fixos os ajustes do relé localizado na entrada da instalação analisada (subestação), portanto todos os outros relés devem estar coordenados com ele. Este procedimento é válido, uma vez que os ajustes desse relé normalmente são definidos pela concessionária local de distribuição e/ou transmissão de energia elétrica. Portanto, não existe a flexibilidade de alterá-lo, exceto em casos específicos em que a coordenação dos dispositivos de proteção dentro de uma instalação industrial, por exemplo, seja impossível sem que se possa alterar os ajustes do relé na entrada da indústria. Os resultados apresentados no artigo referem-se apenas à proteção contra curtos-circuitos trifásicos e bifásicos e não há menção alguma sobre a coordenação dos dispositivos de proteção contra faltas fase-terra.

Primando pela interatividade em tempo de execução entre usuário e programa, Flores e Pereira (1995) apresentam os principais aspectos técnicos de um programa interativo que permite calcular os ajustes das unidades temporizada e instantânea de relés de sobrecorrente em sistemas elétricos. O foco do trabalho é a modelagem das curvas de atuação de relés não padronizadas, aproximando-as por polinômios de terceira ordem. A interação do programa com o usuário é realizada através de "menus" de opções e janelas que incluem rotinas para calcular a relação do transformador de corrente, modelar as curvas de atuação dos relés, 
calcular o ajuste de corrente e do multiplicador de tempo dos relés e verificar a sensibilidade dos mesmos para os níveis de curto-circuito informados. A metodologia utilizada baseia-se em normas técnicas para promover a escolha dos ajustes dos relés, mas também permite que o usuário incorpore sua própria experiência durante o processo de coordenação. De acordo com a proposta dos autores, o programa não analisa a coordenação de todos os relés em um mesmo circuito automaticamente. Para coordenar um relé com outro a jusante, é necessário que o usuário tenha ajustado este dispositivo previamente, usando o programa. Após isso, o usuário fornece o intervalo de coordenação e os ajustes do relé de interesse são determinados. Logo, cada relé deve ser ajustado separadamente.

Brown e Parker (1988) implementaram um programa computacional para executar de forma rápida e precisa estudos de coordenação da proteção e seletividade em sistemas de distribuição de energia elétrica radiais. O foco dos autores foi definir um banco de dados para armazenar ponto a ponto as características (curvas) de atuação dos dispositivos de proteção e desenvolver rotinas de manipulação das mesmas. Dessa forma, o usuário pode facilmente selecionar e testar as curvas que atendam às suas necessidades, sendo capaz de alterar os ajustes de corrente e o multiplicador de tempo dos relés, quando necessário. Segundo os autores, o programa calcula os pontos de coordenação, indicando-os ao usuário. A este cabe a função de selecionar a curva de atuação mais adequada, usando os pontos de coordenação para avaliar sua escolha, ou seja, a curva de atuação adequada será aquela que contenha ou que esteja ligeiramente acima desses pontos. Nesse trabalho os autores permitem ainda que os usuários desenvolvam rotinas de programação para auxiliar a verificação da coordenação e seletividade entre os dispositivos de proteção nos casos em que a análise é repetitiva, como por exemplo, um sistema elétrico que contenha vários circuitos semelhantes.

Yinhong et. al. (2001) descrevem sucintamente as características de um programa computacional capaz de realizar a coordenação dos dispositivos de proteção contra 
sobrecorrente automaticamente. Segundo os autores, uma característica marcante da ferramenta desenvolvida é que ela integra cinco módulos, a saber: (i) módulo de coordenação dos relés, (ii) módulo de cálculo de curto-circuito, (iii) módulo de gerenciamento das funções gráficas, (iv) módulo de gerenciamento de dados e (v) módulo de funções adicionais. O primeiro módulo contém funções de execução automática da coordenação entre os dispositivos de proteção e algoritmos para identificar os dispositivos que devem ser coordenados em sistemas elétricos com topologia em anel. O segundo módulo contém rotinas de cálculo dos diversos tipos de curto-circuito: trifásico, bifásico, bifásico-terra e fase-terra. $\mathrm{O}$ módulo de gerenciamento das funções gráficas (módulo 3) inclui a possibilidade de confecção do diagrama unifilar do sistema elétrico sob estudo e a construção dos coordenogramas. O quarto módulo contém todos os dados do sistema elétrico e dos dispositivos de proteção organizados em um banco de dados relacional e utilizando estruturas orientadas a objetos. Finalmente, o quinto módulo abrange funções como impressão dos resultados na forma de coordenogramas ou tabelas, conversão dos dados no formato original para o formato empregado no programa entre outras. A grande contribuição desse artigo, como foi publicado, é sugerir a estrutura de um programa computacional integrado para realizar a coordenação entre dispositivos de proteção contra sobrecorrentes. Não há detalhamento sobre a modelagem dos dispositivos de proteção, sobre como os coordenogramas são construídos e sobre os critérios de coordenação da proteção e seletividade empregados.

Klock Jr. (2002) apresenta um programa computacional voltado para a verificação da coordenação da proteção de relés direcionais de sobrecorrente de neutro de linhas de transmissão de energia elétrica. A verificação da coordenação e seletividade para qualquer curto-circuito fase-terra é feita apenas para um par de relés de proteção primária/retaguarda definido pelo usuário e não para o sistema elétrico inteiro, sendo que suas curvas de atuação são analisadas em diversos pontos. O programa conta com uma rotina de cálculo automático 
dos ajustes do relé de retaguarda, no entanto, o usuário pode alterar os ajustes determinados automaticamente, caso julgue necessário. Além disso, existe um módulo de cálculo de curtocircuito integrado ao módulo de verificação da coordenação, o qual fornece diretamente a corrente de curto-circuito que circula por cada relé para diferentes tipos de faltas determinadas pelo usuário. Segundo os autores, o foco de sua proposta é priorizar a interação do engenheiro de proteção com o programa desenvolvido, de forma que este não interfira nos ajustes, mas sim atue como uma ferramenta de apoio na realização de estudos de coordenação da proteção e seletividade.

Seguindo a estrutura do programa de coordenação proposto em Yinhong et. al. (2001), Yang et. al. (2007) propuseram um algoritmo flexível de coordenação automática de dispositivos de proteção contra sobrecorrente utilizados em linhas de transmissão de energia elétrica. O algoritmo é classificado como flexível, pois analisa diferentes condições operativas do sistema elétrico que resultem em alterações topológicas no mesmo, permite que o usuário defina fatores de segurança e de sensibilidade diferentes para os dispositivos de proteção e possibilita a criação de novos critérios de proteção. Esta característica torna-se útil em situações especiais, em que os critérios de proteção a serem utilizados podem diferir daqueles comumente recomendados na maioria das condições normais de operação. Os autores apenas descrevem as funcionalidades do programa desenvolvido e afirmam que o mesmo está sendo utilizado em algumas concessionárias de transmissão de energia elétrica na China. Resultados de estudos de coordenação da proteção com o emprego do programa desenvolvido não são apresentados no trabalho.

Voltando-se aos sistemas de distribuição de energia elétrica, Comassetto et. al. (2008) desenvolveram uma ferramenta computacional denominada Análise de Sistemas de Proteção (ASP) para determinar automaticamente os ajustes dos dispositivos de proteção desses sistemas, de forma que a coordenação entre eles e a seletividade sejam atingidas. O objeto de 
análise do trabalho consiste nos alimentadores primários, iniciando-se no lado secundário dos transformadores da subestação de distribuição de energia. A estratégia proposta pelos autores envolve a execução de um programa de fluxo de carga em condição de máximo carregamento do sistema de distribuição para determinar os valores mínimos dos fusíveis e ajustes de corrente de relés e religadores. Em seguida, baseando-se em tabelas de seletividade entre fusíveis, o algoritmo proposto seleciona os fusíveis nos trechos de circuito analisados, de forma que eles sejam seletivos e apresentem corrente nominal superior à máxima corrente determinada pela execução do fluxo de carga. Finalmente, procede-se à definição dos ajustes dos religadores e relés. Neste caso, uma vez determinada a mínima corrente de ajuste desses dispositivos, varia-se a temporização das curvas até que o intervalo de coordenação seja respeitado. Caso essa variação não seja suficiente para garantir a seletividade, aumenta-se o valor da corrente de ajuste do relé e/ou religador e varia-se novamente o valor da temporização de forma a tentar obter ajustes seletivos. Esse processo se repete até que a seletividade seja garantida. Depois de terminado o processo para todos os trechos, caso se verifique que há muitos fusíveis em série de forma que a seletividade não seja alcançada, os autores desenvolveram um algoritmo de otimização que determina quais dispositivos de proteção devem ser removidos ou realocados de forma que haja coordenação em todos os trechos de circuito. Esse algoritmo de otimização se baseia na minimização da potência não suprida devido à atuação do dispositivo de proteção.

Além desses trabalhos encontrados na literatura, existem alguns programas disponíveis comercialmente que contêm funções específicas para a realização de estudos de coordenação e seletividade de dispositivos de sobrecorrente. Dentre eles, podem-se citar os seguintes:

- DIgSILENT PowerFactory (DIgSILENT, 2009): desenvolvido pela empresa alemã DIgSILENT GmbH. O módulo de proteção deste programa possibilita 
criar modelos de diversos tipos de dispositivos de proteção, além de facilmente representar as curvas de atuação em coordenogramas. O cálculo de curtocircuito é integrado a esse módulo. Com recursos de manipulação das curvas de atuação, o usuário pode ajustar graficamente os dispositivos de proteção. Esse programa não dispõe de rotinas para realizar automaticamente a coordenação dos dispositivos de proteção;

- CAPTOR (SKM, 2009): desenvolvido pela empresa SKM System Analysis Inc., o programa possui funções de cálculo de curto-circuito e verificação gráfica da coordenação e seletividade dos dispositivos de proteção de sobrecorrente. Esse programa também não dispõe de procedimentos automáticos para efetuar a coordenação;

- ASPEN One-Liner (ASPEN, 2009): desenvolvido pela empresa Advanced Systems for Power Engineering, Inc. esse programa computacional possui as mesmas funcionalidades mencionadas para os dois programas anteriores, com a vantagem de verificar, automaticamente, se os ajustes dos dispositivos de proteção determinados pelo usuário do programa estão devidamente coordenados;

- NEPLAN (BCP SWITZERLAND, 2009): desenvolvido pela BCP Switzerland, esse programa também conta com as mesmas funcionalidades apresentadas para os programas anteriores, sendo que as funções automáticas de definição de ajustes se restringem apenas a relés de distância;

- EASYPOWER (EASYPOWER, 2009): esse programa é desenvolvido pela empresa ESA Inc. e além de conter as funcionalidades apresentadas pelos programas anteriores, ele conta com um módulo de ajuste automático dos dispositivos de proteção. Este módulo fornece automaticamente os ajustes dos 
relés de fase e de neutro, obedecendo aos intervalos de coordenação definidos pelo usuário e às características de suportabilidade contra altas correntes nos equipamentos protegidos. De acordo com o algoritmo empregado para a coordenação automática, o programa não tenta solucionar os casos em que não há a coordenação entre dois dispositivos, ele apenas emite uma notificação ao usuário deixando-o ciente do problema. Além disso, no caso de relés de sobrecorrente que dispõem de várias curvas de atuação, ele não seleciona a curva mais adequada, mas sim realiza a coordenação automática a partir do tipo de curva já selecionado pelo usuário.

Analisando os trabalhos anteriormente apresentados, observa-se que existem várias abordagens para agilizar e tornar mais preciso o processo de coordenação de dispositivos de proteção contra sobrecorrente. Observa-se que as abordagens cuja proposta é a coordenação automática apresentam particularidades que, às vezes, restringem sua aplicação somente a tipos específicos de sistemas de energia elétrica, como por exemplo, Klock Jr. (2002), cujo foco são as linhas de transmissão e Comassetto et. al. (2008), cuja proposta é voltada para sistemas de distribuição de energia. Com uma abordagem mais generalista, ou seja, que permite analisar diferentes tipos de sistemas elétricos e dispositivos de proteção, encontram-se os trabalhos de Albrecht et. al. (1964), Langhans e Ronat (1980), Brown e Parker (1988), além do programa EASYPOWER apresentado na seção anterior. Seguindo esta abordagem generalista, também podem ser incluídos Yinhong et. al. (2001) e Yang et. al. (2007). No entanto, estes trabalhos não detalham a metodologia empregada na determinação automática dos ajustes dos dispositivos de proteção.

A proposta apresentada nesta dissertação de Mestrado é baseada no trabalho de Langhans e Ronat (1980) e no programa EASYPOWER (EASYPOWER, 2009), com o diferencial de suprir certas carências não apresentadas por esses trabalhos. Inicialmente, 
ressalta-se que nenhum deles apresenta com clareza todas as metodologias empregadas para coordenar os dispositivos de proteção. Logo, todas as estratégias de coordenação apresentadas nesta dissertação foram desenvolvidas buscando a obediência à norma IEEE Std. 242 (2001) e a eliminação do curto-circuito no menor tempo possível, considerando tanto os dispositivos de proteção de fase quanto os de neutro. Como diferenciais da proposta deste trabalho destacam-se o emprego dos relés microprocessados de sobrecorrente os quais, pelo fato de contar com vários tipos de curvas padronizadas, permitem a seleção da curva mais adequada para atingir a coordenação e a indicação, sempre que possível, da solução dos problemas de coordenação que possam ocorrer, baseando-se nas recomendações da IEEE Std. 242 (2001). 


\section{Capítulo 3}

\section{Proteção dos Equipamentos}

A ocorrência de curtos-circuitos nos sistemas elétricos pode promover o aparecimento de correntes elétricas de intensidade elevada, as quais, por sua vez, podem trazer efeitos danosos tanto mecânicos como térmicos aos equipamentos conectados ao circuito sob falta. Os efeitos mecânicos podem deformar condutores, enrolamentos dos transformadores e provocar outros danos físicos. Já os efeitos térmicos estão ligados ao tempo de permanência da falta e ao valor eficaz da corrente, e podem produzir um aquecimento excessivo dos materiais condutores e isolantes, com sua consequiente deterioração. Além disso, a circulação de elevadas correntes pode provocar quedas de tensão excessivas causando o desligamento indesejado de outros equipamentos do sistema elétrico e, no local de incidência do curtocircuito, pode ocorrer a liberação de energia em forma de arco elétrico, resultando em incêndios (IEEE Std. 242, 2001). Outro ponto relevante é que um curto-circuito severo, se não eliminado rapidamente, pode causar a perda da estabilidade do sistema elétrico de um modo geral. Isso implica em perda de sincronismo dos geradores síncronos presentes no sistema que, por sua vez, provoca oscilações nas tensões, correntes e freqüência elétrica podendo causar desligamentos em cascata dos equipamentos, resultando em colapso de tensão (KUNDUR, 1994). 
Os esforços dos engenheiros de proteção são orientados no sentido de minimizar os efeitos nocivos que os curtos-circuitos podem causar aos equipamentos e às pessoas que trabalham no ambiente em que estão instalados. Para tanto, o curto-circuito deve ser eliminado o mais rápido possível por meio de dispositivos capazes de detectar as elevadas correntes e interromper sua circulação. Os dispositivos de proteção mais empregados em instalações elétricas industriais e que serão abordados nesta dissertação são relacionados a seguir:

- Fusíveis: podem ser de baixa ou alta tensão;

- Disjuntores de baixa tensão (DBT);

- Relés de sobrecorrente.

De acordo com o exposto, este capítulo visa descrever as características dos dispositivos de proteção citados anteriormente e apresentar os principais fatores relacionados à proteção dos equipamentos do sistema elétrico.

\subsection{Dispositivos de Proteção}

Os fusíveis, disjuntores de baixa tensão e relés de sobrecorrente abordados neste trabalho possuem curvas de atuação ou curvas de proteção que relacionam a intensidade da sobrecorrente com seu tempo de operação. Quanto maior a corrente, menor o tempo que o dispositivo deve atuar. Disjuntores de baixa tensão e relés podem ainda contar com unidades que atuam instantaneamente para valores de corrente muito elevados. Essas e outras características dos dispositivos de proteção são abordadas a seguir.

\subsubsection{Fusíveis}

Fusível pode ser definido como um dispositivo de proteção de sobrecorrente que consiste de um filamento ou lâmina de um metal ou liga metálica (elo) de baixo ponto de 
fusão que se intercala em um ponto da rede elétrica para que se funda, por efeito Joule, quando a intensidade de corrente elétrica superar, devido a um curto-circuito ou sobrecarga, um determinado valor capaz de danificar a integridade física dos equipamentos da rede. Em sistemas industriais, sua aplicação se dá principalmente na proteção de motores, outros tipos de cargas conectadas em baixa tensão e transformadores.

Existem vários tipos de fusíveis, que variam de acordo com o tipo de aplicação, curvas de atuação, correntes e tensões nominais. Inicialmente, existem duas grandes classes nas quais os fusíveis podem ser classificados (IEEE Std. 242, 2001): fusíveis de baixa tensão (para classe de tensão inferior a $1 \mathrm{kV}$ ) e fusíveis de alta tensão (para classes de tensão superior a 1 kV). Embora haja tais diferenças, as seguintes características são comuns aos diversos tipos:

- As funções de detectar a sobrecorrente e provocar a abertura do circuito sob falta são feitas em um mesmo dispositivo;

- Podem ter atuação retardada, cujo tempo de fusão é inversamente proporcional à corrente de curto-circuito;

- São dispositivos monofásicos, logo, caso haja sobrecorrente em apenas uma das fases, esta será interrompida, ao passo que as outras fases nada sofrerão;

- Após a interrupção da sobrecorrente, os fusíveis que atuaram devem ser substituídos.

Em relação às curvas de proteção, os fusíveis normalmente apresentam uma faixa de tolerância determinada por sua corrente de mínima e máxima fusão para cada tempo de atuação. Essa tolerância, definida pelo fabricante do dispositivo, é expressa em porcentagem em torno de um valor médio de corrente também definido pelo fabricante, por exemplo, existem fusíveis cuja tolerância varia de $-15 \%$ (curva de mínima fusão) até $+15 \%$ (curva de máxima fusão) (IEEE Std. 242, 2001). A Figura 3.1 apresenta exemplos de três curvas de atuação de fusíveis de alta tensão, para diferentes valores de corrente nominal. As curvas são 
apresentadas em escala logarítmica para ambos os eixos, sendo que a curva tracejada representa a curva de mínima fusão e a desenhada em linha cheia representa a curva de máxima fusão. Elas foram obtidas admitindo-se, para cada tempo de atuação, um percentual de $\pm 10 \%$ em torno de um valor médio de corrente. Em termos conceituais, a curva de mínima fusão visa oferecer máxima proteção sem atuação desnecessária, obedecidas todas as características de operação dos equipamentos protegidos, ou seja, na proteção de motores, por exemplo, a corrente de partida do motor não deve provocar a atuação do fusível. Por outro lado, a máxima corrente de fusão é utilizada para a coordenação do fusível com outros dispositivos de proteção instalados a montante dele.

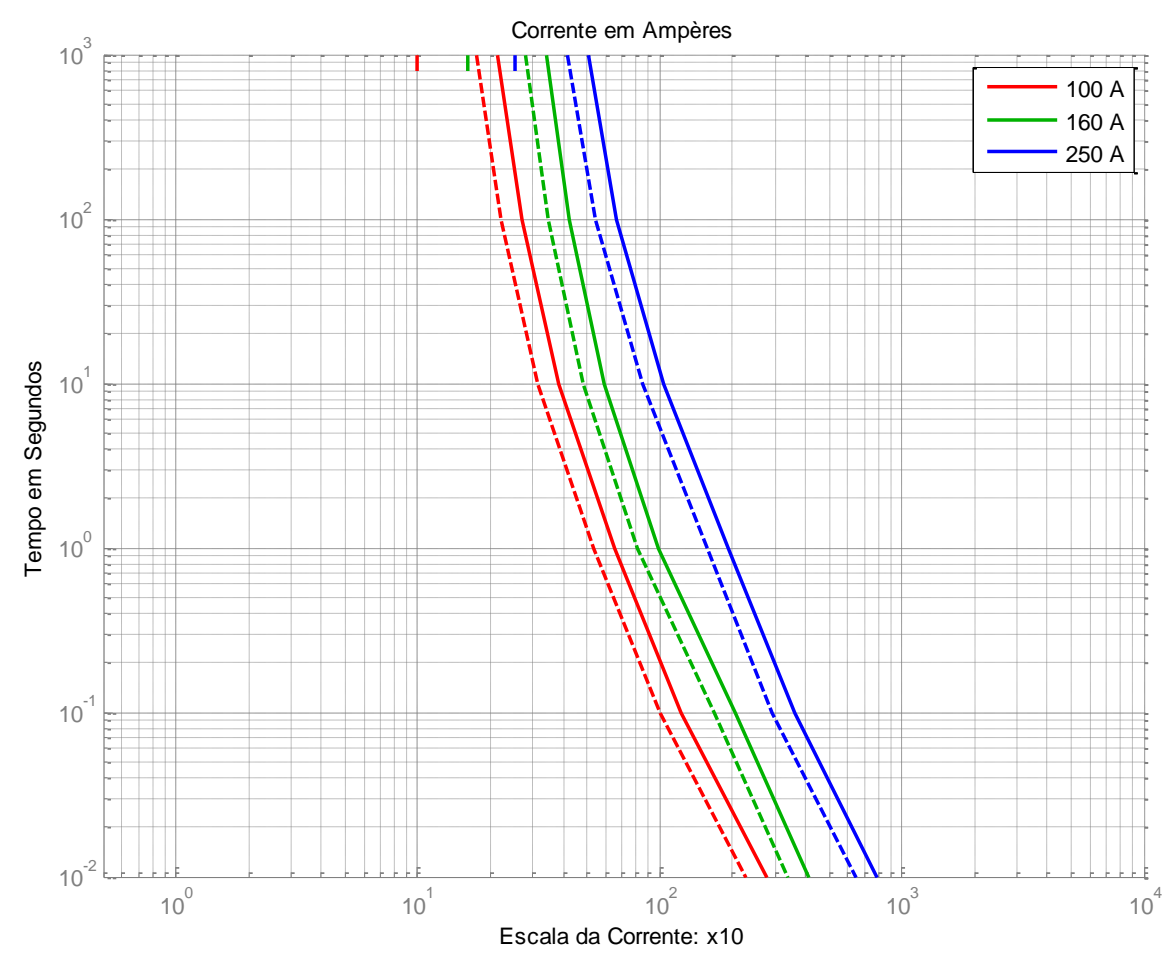

Figura 3.1 - Características de atuação para fusíveis de alta tensão.

\subsubsection{Disjuntores de Baixa Tensão}

Disjuntores de baixa tensão são dispositivos de proteção de sistemas elétricos destinados a abrir e fechar circuitos elétricos por meios não automáticos, e abrir automaticamente sob determinadas condições de falta ou sobrecarga, sem que haja danos em 
si próprios quando devidamente aplicados, respeitando sua classe de tensão e sua corrente nominal (IEEE Std. 242, 2001). Sua principal característica é a capacidade de se rearmar (manual ou eletricamente) quando algum defeito ocorre, diferindo do fusível que se torna inutilizado depois de atuar. Como função principal no caso de curtos-circuitos, o disjuntor de baixa tensão deve ser capaz de interromper a corrente elétrica elevada antes que os efeitos térmicos e mecânicos desta possam se tornar perigosos aos equipamentos da rede elétrica.

Para desempenhar as funções de proteção, os disjuntores de baixa tensão contam com características de disparo ou curvas de atuação, as quais são fornecidas pelos fabricantes. Portanto, o dispositivo que detecta a sobrecorrente e o que secciona o circuito estão acoplados dentro do disjuntor. As curvas de atuação podem ser muito diferentes em função do modelo e fabricante do disjuntor de baixa tensão. Nesta dissertação serão abordados um tipo de disjuntor de baixa tensão termomagnético e um tipo de disjuntor de baixa tensão com disparador eletrônico.

Os disjuntores termomagnéticos são os mais utilizados em redes de baixa tensão e as curvas típicas de atuação referentes a dois tipos de disjuntores são apresentadas na Figura 3.2.

Eles possuem basicamente três funções:

- Manobra - abertura ou fechamento voluntário do circuito;

- Proteção contra curto-circuito - esta função é desempenhada por um atuador magnético (ex: solenóide), que efetua a abertura do disjuntor com o aumento instantâneo da corrente elétrica da rede protegida. Na Figura 3.2 esta função corresponde à curva de atuação instantânea. O elemento do disjuntor responsável por essa função pode permitir ou não o ajuste dos valores de corrente de atuação. Neste último caso, o valor é fixo;

- Proteção contra sobrecarga - é realizada por meio de um atuador bi-metálico, que é sensível ao calor e provoca a abertura quando a corrente elétrica 
permanece, por um determinado período, acima da corrente nominal do disjuntor. Na Figura 3.2 esta função corresponde à curva a tempo inverso apontada como "atuação temporizada". Tal como explicado para a função de proteção contra curto-circuito, o elemento responsável pela atuação temporizada pode permitir ou não o ajuste da corrente e do tempo de atuação.

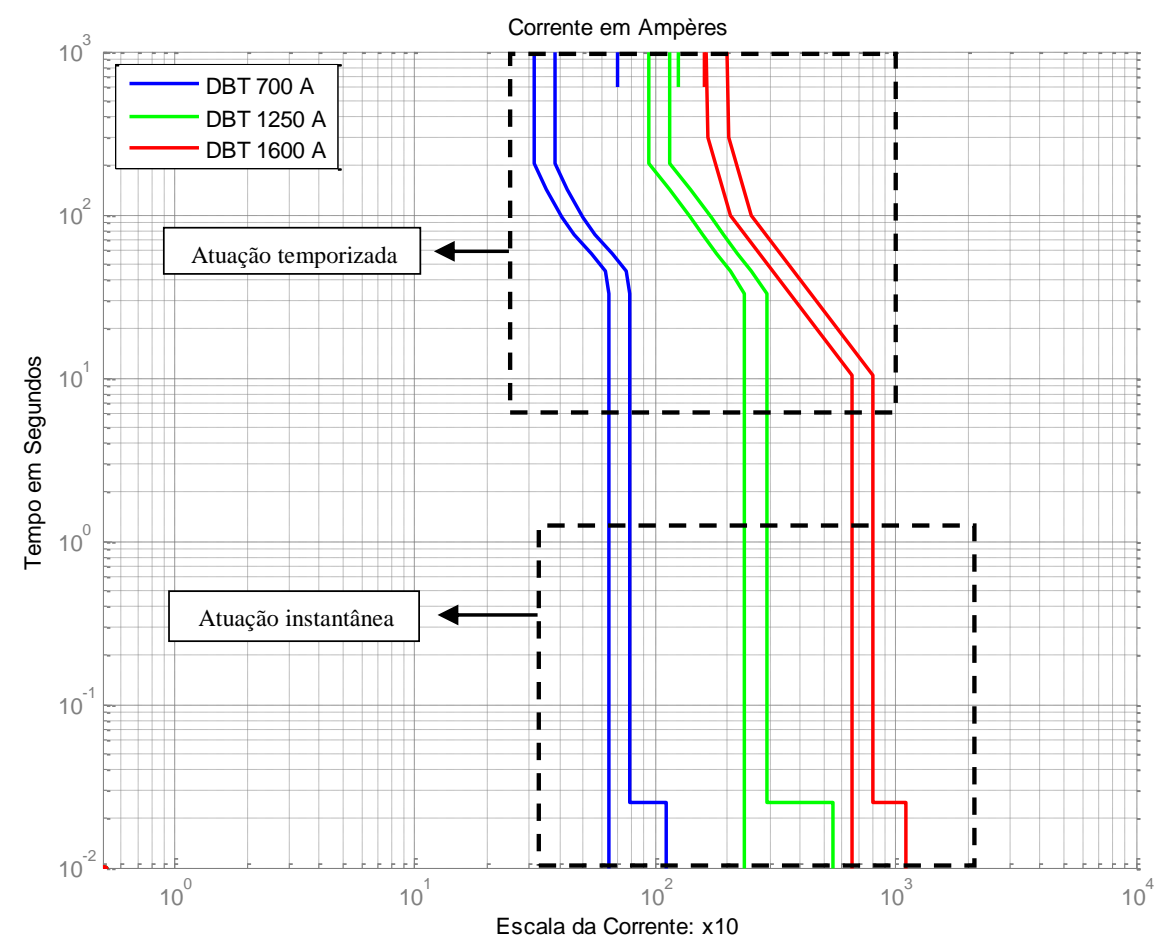

Figura 3.2 - Exemplos de curvas de atuação de disjuntores de baixa tensão termomagnéticos.

O disjuntor de baixa tensão com disparador eletrônico utilizado nas análises desta dissertação possui curva de atuação dividida em quatro funções de proteção (IEEE Std. 242, 2001):

- Proteção de tempo longo: mais adequada para proteção contra sobrecarga, é caracterizada pelo tempo de atuação na ordem de minutos, podendo atingir uma ou duas horas, a depender da capacidade e intensidade de corrente que flui pelo disjuntor. Este comportamento é definido por uma curva a tempo inverso dependente da corrente, em que quanto maior a corrente mais rápida é a atuação 
do disjuntor. Normalmente, para ajustar a unidade de tempo longo é necessário definir a corrente de atuação (ou disparo), conhecida como corrente de tempo longo, e o tempo de atuação, conhecido como atraso de tempo longo (ATL). A expressão (3.1) define o ajuste de tempo longo:

$$
I_{L}=M T L \times I_{N}
$$

Sendo:

$\mathrm{I}_{\mathrm{L}}$ : corrente de tempo longo.

MTL: multiplicador de tempo longo.

$\mathrm{I}_{\mathrm{N}}$ : corrente nominal do disjuntor, em Ampère.

O atraso de tempo longo (ATL) é o tempo de atuação definido para uma corrente seis vezes superior à corrente nominal do disjuntor.

- Proteção de tempo curto: proteção de curto-circuito, definida pela corrente de atuação de tempo curto de acordo com a expressão (3.2) e atraso de tempo curto. A atuação ocorre em tempos na ordem de segundos ou dezenas de segundos.

$$
I_{c}=M T C \times I_{L}
$$

Sendo:

$\mathrm{I}_{\mathrm{C}}$ : corrente de tempo curto.

MTC: multiplicador de tempo curto.

O atraso de tempo curto (ATC) é o tempo de atuação da unidade de tempo curto do disjuntor de baixa tensão e normalmente é ajustável em até 0,4 segundo.

- Proteção instantânea: juntamente com a proteção de tempo curto compõe a proteção de curto-circuito, definida pela corrente de atuação instantânea, de acordo com a expressão (3.3).

$$
I_{\text {inst }}=\text { MInst } \times I_{N}
$$

Sendo MInst o multiplicador da corrente instantânea de disparo do disjuntor. 
- Proteção contra faltas fase-terra: um sensor eletrônico mede a corrente de seqüência zero no ramo do equipamento protegido e comanda a abertura do disjuntor caso esta corrente ultrapasse o valor ajustado no relé. Esta função de proteção é caracterizada por uma curva a tempo definido, logo o tempo também pode ser ajustado. A expressão (3.4) define a corrente de atuação da proteção contra faltas fase-terra.

$$
I_{\text {terra }}=M T \times I_{N}
$$

Sendo $M T$ o multiplicador da corrente de disparo da unidade de proteção contra faltas fase-terra.

De forma semelhante aos fusíveis, as curvas de atuação dos disjuntores de baixa tensão também são representadas por uma faixa de tolerância em torno de um valor médio de corrente. Neste trabalho, a tolerância admitida para os disjuntores de baixa tensão foi de $\pm 10 \%$, valor obtido após a análise de diversos catálogos de fabricantes. A Figura 3.3 ilustra as curvas de atuação de três disjuntores com correntes nominais diferentes. Nesta figura observa-se que para os disjuntores de 100 e $300 \mathrm{~A}$, os ajustes dos multiplicadores de tempo curto e instantâneo são iguais. Logo, a curva que representa a atuação de tempo curto é sobreposta pela curva de atuação instantânea. Isso já não ocorre para o disjuntor de 2000 A. Na Figura 3.4 apresentam-se as curvas a tempo definido da unidade de proteção contra faltas fase-terra de dois disjuntores de baixa tensão ajustadas em $10 \%$ das respectivas correntes nominais, com tempos de atuação ajustados em 0,1 e 0,4 segundo. 


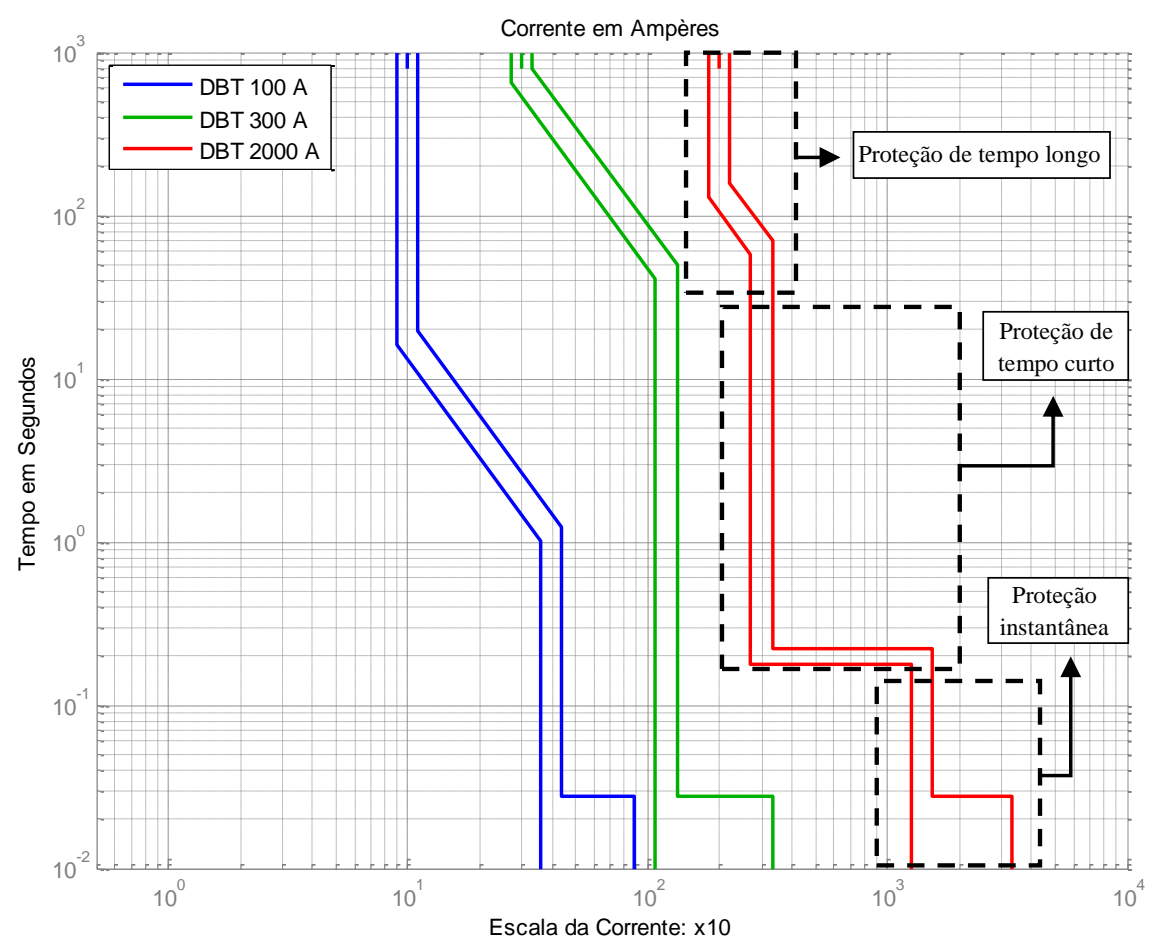

Figura 3.3 - Exemplos de curvas de atuação de disjuntores de baixa tensão de disparo eletrônico.

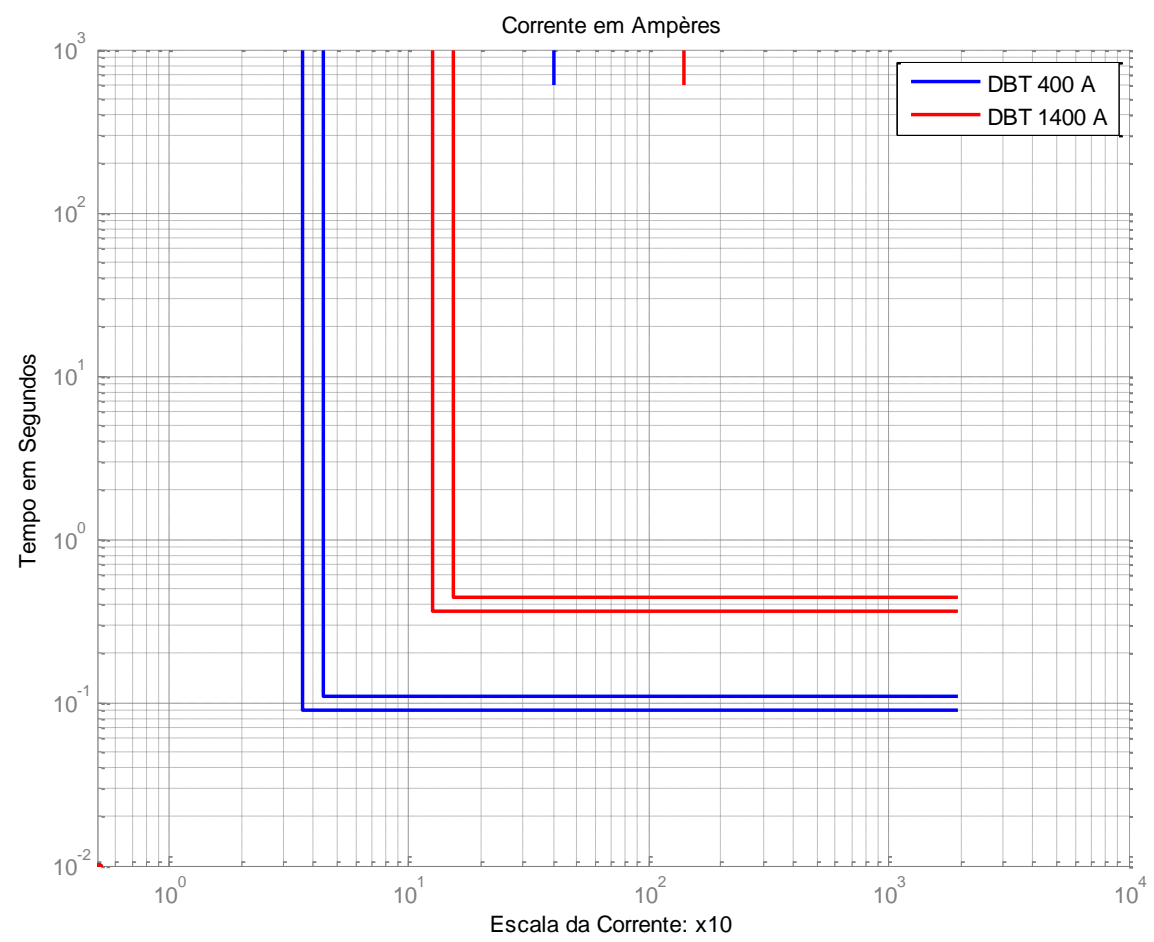

Figura 3.4 - Exemplos de curva de atuação da proteção contra faltas fase-terra de disjuntores de baixa tensão. 


\subsubsection{Relés de Proteção}

De uma maneira geral, os relés de proteção são dispositivos que monitoram determinadas grandezas e detectam anormalidades decorrentes de falhas nos sistemas elétricos. Essas grandezas podem ser corrente, tensão, freqüência etc. Caso seja detectada alguma falha no sistema, o relé opera enviando um sinal para a abertura do disjuntor, isolando somente o trecho defeituoso visando a melhor forma de suprir a demanda e restaurar a normalidade do sistema o mais rápido possível. Sua aplicação abrange desde a proteção de motores em sistemas elétricos industriais, transformadores, linhas de transmissão de energia elétrica e geradores de grande porte, podendo ser empregados como proteção primária ou de retaguarda.

Com os avanços tecnológicos na área de eletrônica e de processamento de sinais, surgiram os relés de proteção digitais, que são relés eletrônicos gerenciados por microprocessadores, em que os valores das grandezas monitoradas e as atuações podem ser registrados e as parametrizações podem ser realizadas através de programas computacionais.

A proteção digital de sistemas elétricos de potência surgiu nas décadas de 60 e 70, quando pesquisadores desenvolveram diferentes algoritmos para relés de distância para proteção de linhas de transmissão (COURY et al., 2007). A técnica de proteção digital está atualmente consolidada, mas continua sendo uma área de muitas pesquisas, tendo em vista o constante desenvolvimento dos microprocessadores.

A mais recente geração de relés digitais microprocessados é dedicada à realização das funções de proteção, medição, controle e comunicação com outros dispositivos. Essa versatilidade conferida aos relés digitais microprocessados originou uma nova denominação para esse tipo de equipamento, pois o termo "relé de proteção" tem sido considerado restritivo por alguns autores (HEWITSON et al., 2004). Dessa forma, esses dispositivos têm sido denominados dispositivos eletrônicos inteligentes, do inglês Intelligent Electronic Devices 
(IEDs). Em linhas gerais um IED pode ser definido como um dispositivo que agrega diferentes funções de proteção, funções de controle inteligentes, capacidade de monitoramento e comunicação com outros dispositivos ou sistemas do tipo SCADA (Supervisory Data and Control Aquisition), incluindo a possibilidade de aplicar técnicas de inteligência artificial (HEWITSON et al., 2004; COURY et al., 2007).

As principais vantagens do emprego de IEDs em sistemas elétricos, com foco voltado à proteção desses sistemas, são (ALMEIDA, 2000; COURY et al., 2007):

- Maior confiabilidade devido às facilidades de autodiagnóstico;

- Integração com outros equipamentos através de suas portas de comunicação possibilitando ajuste, medições de dados, registro de curtos-circuitos de forma remota, além da possibilidade da implementação de esquemas sofisticados envolvendo o emprego de técnicas inteligentes de controle e adaptação como, por exemplo, redes neurais e lógica fuzzy;

- Flexibilidade: um único tipo de dispositivo de hardware pode ser utilizado para diversos tipos de relés, havendo diferenças apenas no programa computacional que pode ser incluído facilmente sem prejudicar as funções de proteção, tais como localização de faltas, registro de eventos, medições de demanda, estimação de temperatura etc;

- Modularidade: funções de controle, proteção e comunicação podem ser adicionadas ao dispositivo por meio da aquisição de módulos específicos. Tais módulos são facilmente incorporados ao dispositivo.

As principais desvantagens dos relés digitais fazem menção aos circuitos integrados e abrangem aspectos como baixa vida útil (15 anos), susceptibilidade à interferência eletromagnética e rápida depreciação do dispositivo, posto que rapidamente pode se tornar obsoleto devido ao avanço da tecnologia empregada. 
A Figura 3.5 apresenta a arquitetura de um relé digital. Nele se aplicam sinais analógicos provenientes dos transdutores de corrente e de tensão, conhecidos como transformadores de corrente (TCs) e transformadores de potencial (TPs). A função desses transdutores é reduzir os valores das correntes e tensões, respectivamente, a valores compatíveis com os suportados pelos relés.

Observa-se também na Figura 3.5 que o relé dispõe de uma entrada de sinais digitais, que podem receber sinais tais como o estado de disjuntores, chaves e outros relés. Estes sinais são pré-processados antes de entrarem na unidade central de processamento (CPU) que constitui o "cérebro" do relé. Como saída, os relés digitais dispõem de portas seriais e paralelas para comunicação com outros equipamentos, mostrador de informações (display) e saída de sinais digitais dos quais o principal é o sinal de disparo ou de trip, que enviado a um disjuntor provoca o seccionamento de parte do sistema elétrico ou de equipamentos específicos.

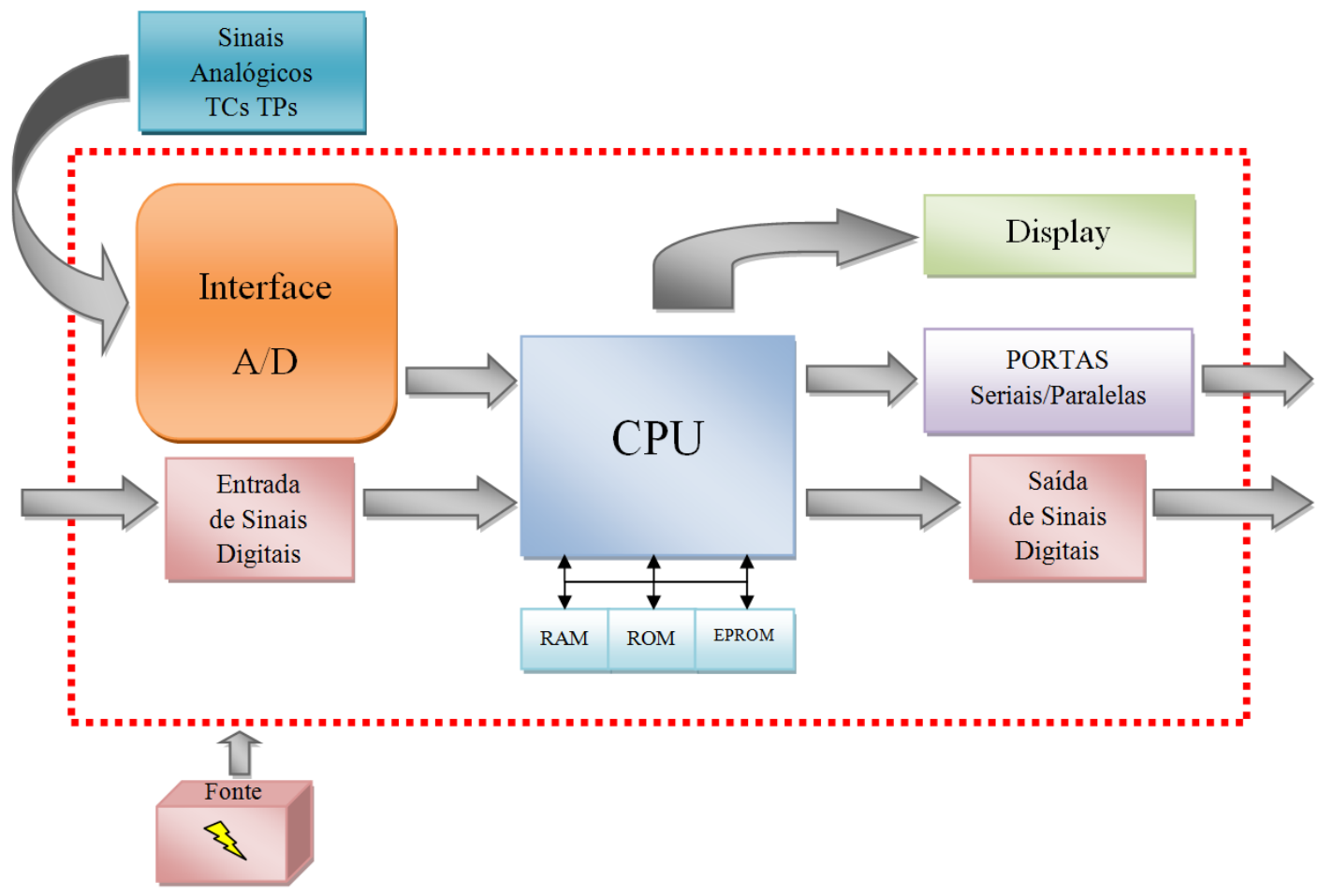

Figura 3.5 - Diagrama funcional de blocos de um relé digital. 
Da Figura 3.5 tem-se que os principais componentes da arquitetura de um relé digital são (COURY et al., 2007):

- Sinais analógicos: os sinais analógicos devem ser reduzidos aos níveis compatíveis com o circuito eletrônico do relé por meio dos TCs e TPs. Em seguida esses sinais devem ser filtrados antes de serem amostrados. Essa filtragem normalmente é realizada por meio de filtros passa-baixa com o objetivo de remover componentes de alta frequiência do sinal a ser amostrado. Tal característica é de grande importância para evitar erros no processamento digital do sinal. Esses filtros também são conhecidos como filtros anti-aliasing, pois são eles os responsáveis em eliminar o efeito da sobreposição dos espectros (ou aliasing). Para tanto, a freqüência de corte deve ser igual à metade da taxa amostral utilizada pelos conversores analógico-digitais. Isto está de acordo com o teorema da amostragem, o qual declara que a reconstituição completa de uma determinada freqüência do sinal analógico $f_{1}$ deve ser realizada com uma freqüência de amostragem no processo de digitalização igual a, no mínimo, o dobro de $f_{l}$;

- Interface analógico/digital (A/D): recebe os sinais analógicos já filtrados e executa os processos de amostragem através de dispositivos Sample and Hold (S/H), multiplexação e conversão analógico/digital por meio de um sinal de sincronização (clock) que determina a freqüência de amostragem. Para cada sinal amostrado há a conversão do valor instantâneo do sinal analógico em uma palavra digital, que fica disponível para o microprocessador;

- Unidade central de processamento (CPU): os sinais digitais provenientes de disjuntores, relés ou outros equipamentos são pré-processados para sua aplicação na CPU. A CPU executa os programas de proteção, o controle de 
diversas funções de tempo e realiza tarefas de autodiagnóstico e de comunicação com os periféricos;

- Memórias: são três as principais memórias em um relé digital, descritas a seguir.

- Memória de acesso aleatório, mais conhecida por memória RAM (Random Access Memory). Esse tipo de memória permite tanto a leitura como a gravação e regravação de dados. É utilizada como armazenamento temporário dos valores de entrada, para acumular resultados intermediários dos programas de proteção e para armazenar dados a serem guardados posteriormente na memória não volátil.

- Memória somente de leitura ou memória ROM (Read Only Memory). Esse tipo de memória só permite leitura e é utilizada para armazenagem permanente de programas do relé digital, de onde são executados.

- Memória somente de leitura eletricamente programável, ou EPROM (Electrically Programmable Read Only Memory): utilizada para armazenagem de variáveis ou parâmetros de ajustes do relé ou outros dados que não são modificados com grande freqüência.

- Mostrador ou display: mostra todas as informações sobre o estado do dispositivo. Pode ser empregado na parametrização do relé;

- Saída de sinais digitais: meio pelo qual o relé digital envia seus principais sinais de comando para um ou mais dispositivos de proteção. Esses sinais podem ser utilizados como sinal de alarme ou de disparo;

- Portas seriais e paralelas: as portas seriais permitem a troca de informações remotas ou locais para tarefas de ajustes dos valores dos parâmetros e leitura 
de registros de faltas. As portas paralelas permitem o intercâmbio de informações em tempo real com outros equipamentos.

Para aumentar a confiabilidade de operação, os relés necessitam de uma fonte de alimentação independente da rede elétrica, geralmente do tipo comutada, que pode ser ligada a baterias.

Este trabalho está focado na aplicação de relés digitais de sobrecorrente e informações adicionais sobre seus predecessores, ou seja, os relés eletromecânicos e relés estáticos, podem ser encontradas em Caminha (1977) e IEEE Std. 242 (2001), respectivamente.

A seguir serão brevemente apresentadas as principais características dos transformadores de corrente. Os transformadores de potencial (TP) não serão tratados neste trabalho porque eles não são necessários nas funções de proteção de sobrecorrente. Informações mais detalhadas sobre os mesmos podem ser encontradas em Caminha (1977), Coury et al. (2007) e em IEEE Std. 242 (2001).

\subsubsection{Transformadores de Corrente (TCs)}

As principais funções de um transformador de corrente são evitar a conexão direta de relés e medidores na rede elétrica e adaptar as grandezas a serem medidas aos valores compatíveis com a capacidade desses equipamentos.

Os TCs são equipamentos monofásicos e podem ser encontrados sob diversos tipos (MAMEDE FILHO, 2005): barra, enrolado, toroidal (ou janela), bucha, núcleo dividido, múltiplos enrolamentos primários, múltiplos núcleos secundários, múltiplos enrolamentos secundários e derivação no secundário. O detalhamento de todos os tipos de TC não é fundamental para o entendimento desta dissertação e maiores informações sobre todos eles podem ser encontradas em Mamede Filho (2005). No entanto, os TCs tipo enrolado e toroidal serão brevemente apresentados a seguir. O primeiro será apresentado porque se admite neste trabalho que todos os relés com proteção de sobrecorrente de fase são conectados a TCs 
daquele tipo. O segundo será referenciado como alternativa de ligação da função de sobrecorrente de terra, conforme será abordado na seção 3.1.3.2.

Um TC do tipo enrolado apresenta o enrolamento primário com uma ou mais espiras envolvendo o núcleo do transformador, ao passo que o enrolamento secundário tem um número maior de espiras. A ele podem ser conectados diversos relés e/ou medidores.

TCs do tipo toroidal ou janela não possuem um primário fixo e apresentam uma abertura por onde passa o condutor que forma o circuito primário. São empregados quando se deseja medir pequenas ou médias correntes ou quando não se deseja seccionar o condutor para instalar o transformador de corrente.

Independente do tipo, as principais características de um TC, segundo a NBR 6856, são as seguintes (CAMINHA, 1977; MAMEDE FILHO, 2005):

- Corrente e relação de transformação nominal: as correntes nominais primárias padronizadas, dadas em Ampère, são 5, 10, 15, 20, 25, 30, 40, 50, 60, 75, 100, $125,150,200,250,300,400,500,600,800,1000,1200,1500,2000,2500$, 3000, 4000, 5000, 6000, 8000. As correntes nominais secundárias são geralmente iguais a 5 A. Contudo, quando os relés de proteção estão instalados distantes do transformador de corrente, pode-se usar corrente nominal de $1 \mathrm{~A}$ para reduzir a queda de tensão nos cabos de ligação;

- Classe de tensão de isolamento nominal: definida pela tensão do circuito ao qual o TC será conectado;

- Freqüência nominal: 50 ou $60 \mathrm{~Hz}$;

- Classe de exatidão nominal: valor máximo do erro, expresso em \%, que pode ser introduzido pelo TC no relé e/ou medidor em condições especificadas. Para um TC empregado na proteção, este erro é $2,5 \%$ ou $10 \%$ admitindo que o mesmo esteja suprindo à carga uma corrente vinte vezes maior que a sua 
corrente nominal secundária. Já as classes de exatidão para os TCs empregados na medição são: $0,3-0,6-1,2 \%$;

- Carga nominal: a carga secundária de um TC corresponde ao valor ôhmico das impedâncias formadas pelos diferentes equipamentos conectados no seu secundário, incluindo-se os condutores de interligação. A carga nominal é aquela que corresponde à potência em que a exatidão do TC é garantida. A carga que os medidores e relés representam para os TCs é fornecida pelos fabricantes desses equipamentos;

- Fator de sobrecorrente nominal ou fator de segurança: é o fator pelo qual se deve multiplicar a corrente nominal do TC, resultando na máxima corrente com a qual o TC mantém sua classe de exatidão. Usualmente, esse fator é igual a 20 ;

- Fator térmico nominal: é o fator pelo qual se deve multiplicar a corrente primária nominal do TC, a fim de obter a máxima corrente que o mesmo pode suportar, em regime permanente e operando em condições normais, sem que os limites de temperatura especificados pela sua classe de isolação sejam violados. Esse fator pode ser igual a: 1,0 - 1,3 - 1,5 - 2,0;

- Limite de curta duração para efeito térmico: é o valor eficaz simétrico da corrente primária que o $\mathrm{TC}$ pode suportar por um determinado tempo (normalmente 1 segundo) sem que os limites de temperatura sejam violados, estando ele com o enrolamento secundário em curto-circuito;

- Limite de curta duração para efeito dinâmico: é o valor eficaz simétrico da corrente primária que o TC pode suportar durante aproximadamente 0,1 segundo, estando o enrolamento secundário curto-circuitado, sem se danificar mecanicamente em razão das forças eletromagnéticas resultantes. 
Todas as características apresentadas anteriormente são especificadas pelo fabricante do TC.

\subsubsection{Relés de Sobrecorrente}

As funções de proteção características em relés de sobrecorrente digitais são as seguintes:

- Sobrecorrente de fase: atua baseada na medição das correntes das fases A, B e C, bastando em uma das fases a corrente exceder o valor ajustado no relé para que o mesmo atue. Pode ter atuação instantânea ou temporizada, sendo que o ajuste do elemento instantâneo é completamente independente do elemento temporizado. Este, por sua vez, disponibiliza curvas a tempo dependente, ou tempo inverso, e curvas a tempo definido. Maiores detalhes serão abordados na subseção seguinte. Os elementos temporizado e instantâneo da proteção de sobrecorrente de fase são codificados segundo os padrões do ANSI (American National Standards Institute) da seguinte maneira: a proteção temporizada de sobrecorrente de fase é representada pelo código ANSI 51, ou simplesmente 51, e a instantânea, por 50 (CAMINHA, 1977; IEEE Std. 242, 2001);

- Sobrecorrente de neutro: atua baseada na corrente calculada a partir da soma vetorial das três correntes de fase medidas pelo relé. Elementos instantâneos $(50 \mathrm{~N})$ e temporizados $(51 \mathrm{~N})$ estão disponíveis;

- Sobrecorrente de terra: atua baseada na corrente medida por um TC toroidal (IEEE Std. 242, 2001). Essa função de proteção pode ser programada para atuação instantânea (ANSI 50G) e temporizada (ANSI 51G).

Em alguns relés digitais, existem entradas analógicas diferentes para a proteção de sobrecorrente de terra e de neutro, sendo que aquela pode apresentar uma faixa de ajustes mais sensíveis que esta. Quando o relé não possui essas duas entradas diferenciadas, apresenta 
apenas a entrada de neutro, a qual pode ser alimentada também por um TC tipo toroidal. A Figura 3.6 mostra como os TCs são conectados em um relé digital para prover a proteção de sobrecorrente de fase e de neutro. Os TCs das fases A, B e C estão conectados em estrela (Y) alimentando as entradas analógicas de fase (IA, IB e IC) do relé. A entrada analógica correspondente à corrente de neutro (IN) recebe o somatório fasorial das correntes nas três fases. Esse tipo de conexão dos TCs para prover a corrente de neutro denomina-se conexão residual. O código 52 corresponde à representação do disjuntor.

A Figura 3.7 apresenta o esquema de ligação dos TCs de fase e de um TC toroidal para a realização da proteção de sobrecorrente de fase e de terra, respectivamente. Observa-se que o TC toroidal enlaça as três fases e alimenta a entrada analógica do relé correspondente à proteção de terra (entrada IN do relé).

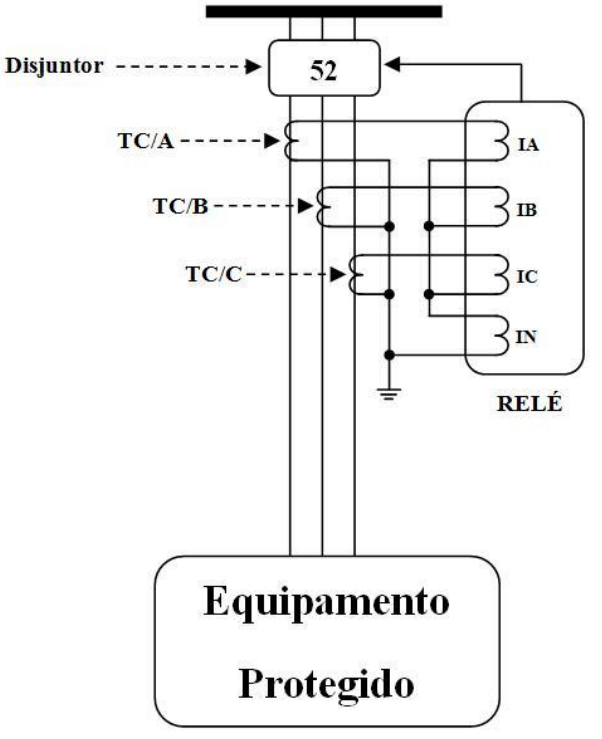

Figura 3.6 - Esquema de ligação dos TCs para proteção de sobrecorrente fase e de neutro. 


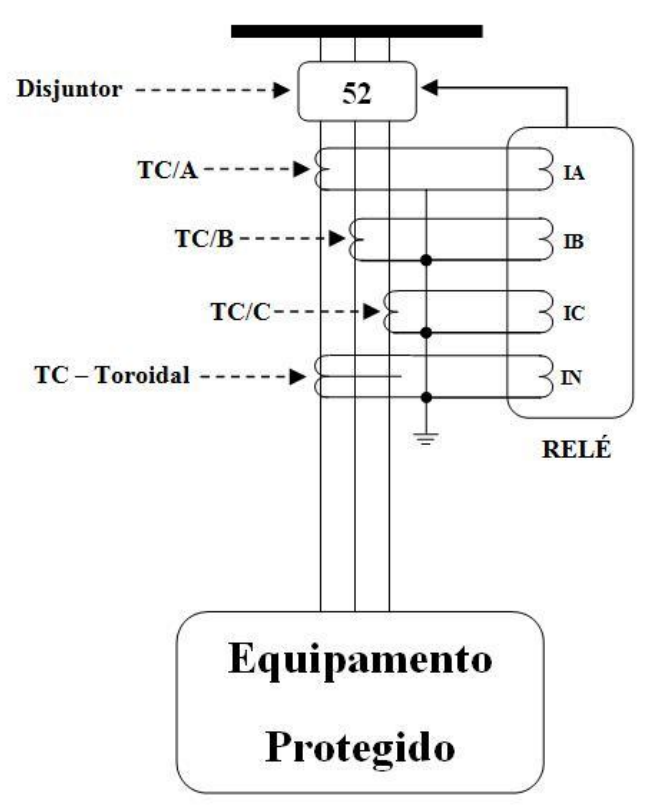

Figura 3.7 - Esquema de ligação dos TCs para proteção de sobrecorrente de fase e de terra.

\subsection{Curvas de Atuação de Relés de Sobrecorrente}

As características de proteção ou curvas de atuação de relés de sobrecorrente aplicamse nos elementos temporizados da proteção de fase, de terra e de neutro. Elas podem ser dependentes da corrente, chamadas de tempo dependente ou tempo inverso, ou terem seu tempo de atuação especificado, como é o caso das características a tempo definido.

No caso das curvas a tempo definido, o relé envia o sinal de disparo para qualquer corrente maior ou igual à corrente de ajuste $\left(\mathrm{I}_{\mathrm{up}}\right)$, que tenha duração superior a um dado tempo estabelecido $\left(\mathrm{T}_{\mathrm{up}}\right)$. O termo corrente de ajuste também é sinônimo de corrente de disparo, corrente de partida ou corrente de pick up. A Figura 3.8 ilustra uma curva de atuação a tempo

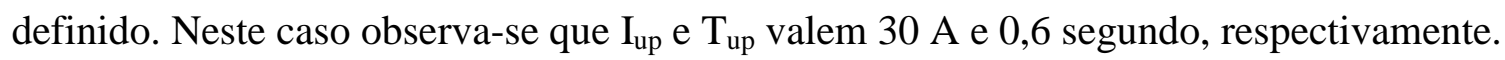




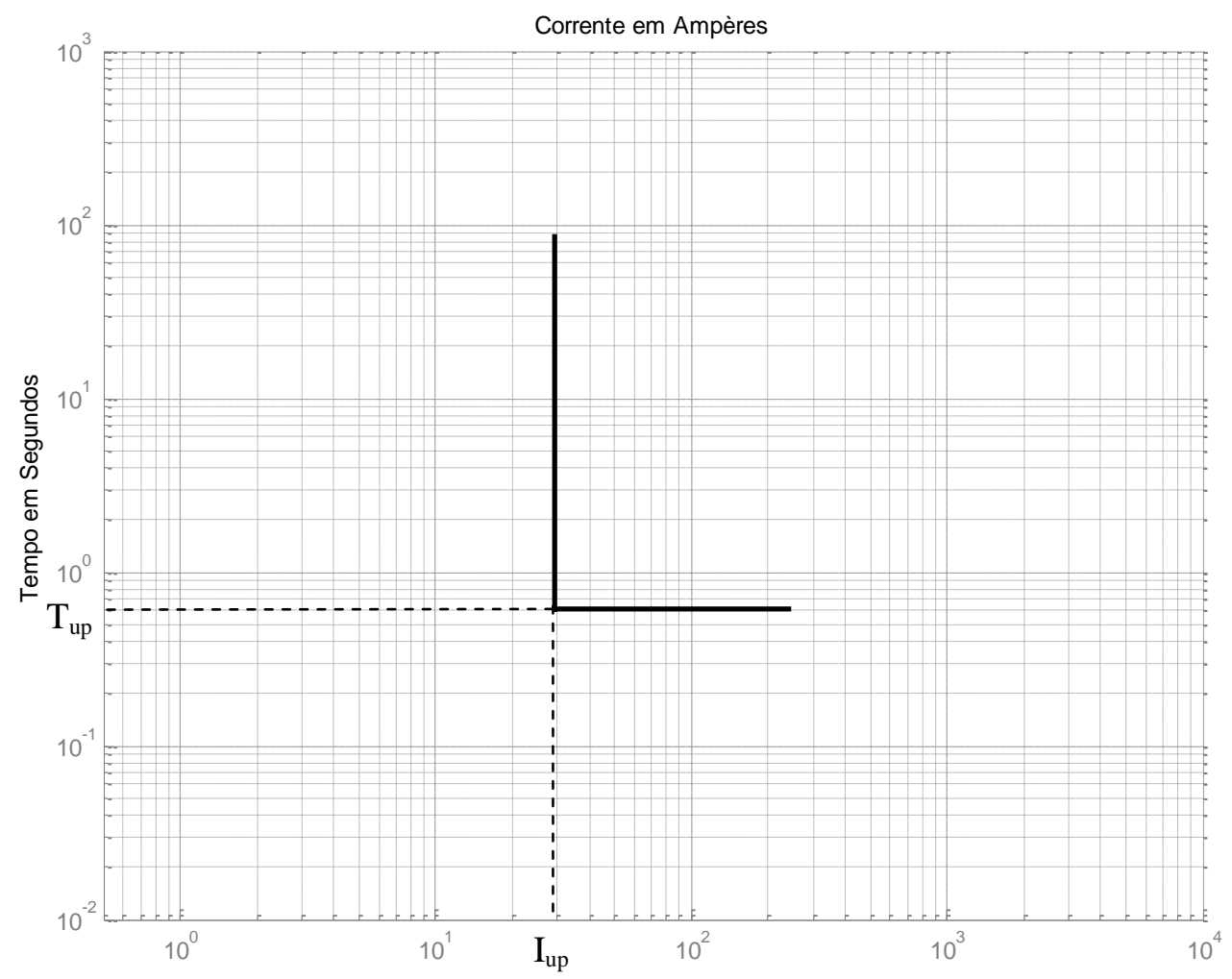

Figura 3.8 - Curva de sobrecorrente a tempo definido.

No caso das curvas de atuação a tempo dependente ou tempo inverso, o tempo de atuação é inversamente proporcional ao valor da corrente. Isto é, o relé atuará em tempos decrescentes para valores de corrente maiores ou iguais à corrente de ajuste $\left(\mathrm{I}_{\text {up }}\right)$. A Figura 3.9 ilustra um exemplo de curva de atuação a tempo inverso. Na verdade existem famílias de curvas a tempo inverso, podendo ser padronizadas ou não. As curvas padronizadas obedecem a equações estabelecidas pelo instituto ANSI ou pelo IEC (International Electrotechnical Comission). As curvas não padronizadas são definidas pelo fabricante do relé de proteção. Neste capítulo apenas as curvas de atuação padronizadas serão detalhadas. Nos modernos relés digitais o engenheiro de proteção pode escolher entre ambos os padrões, visto que os mesmos já se encontram programados nesses relés. 


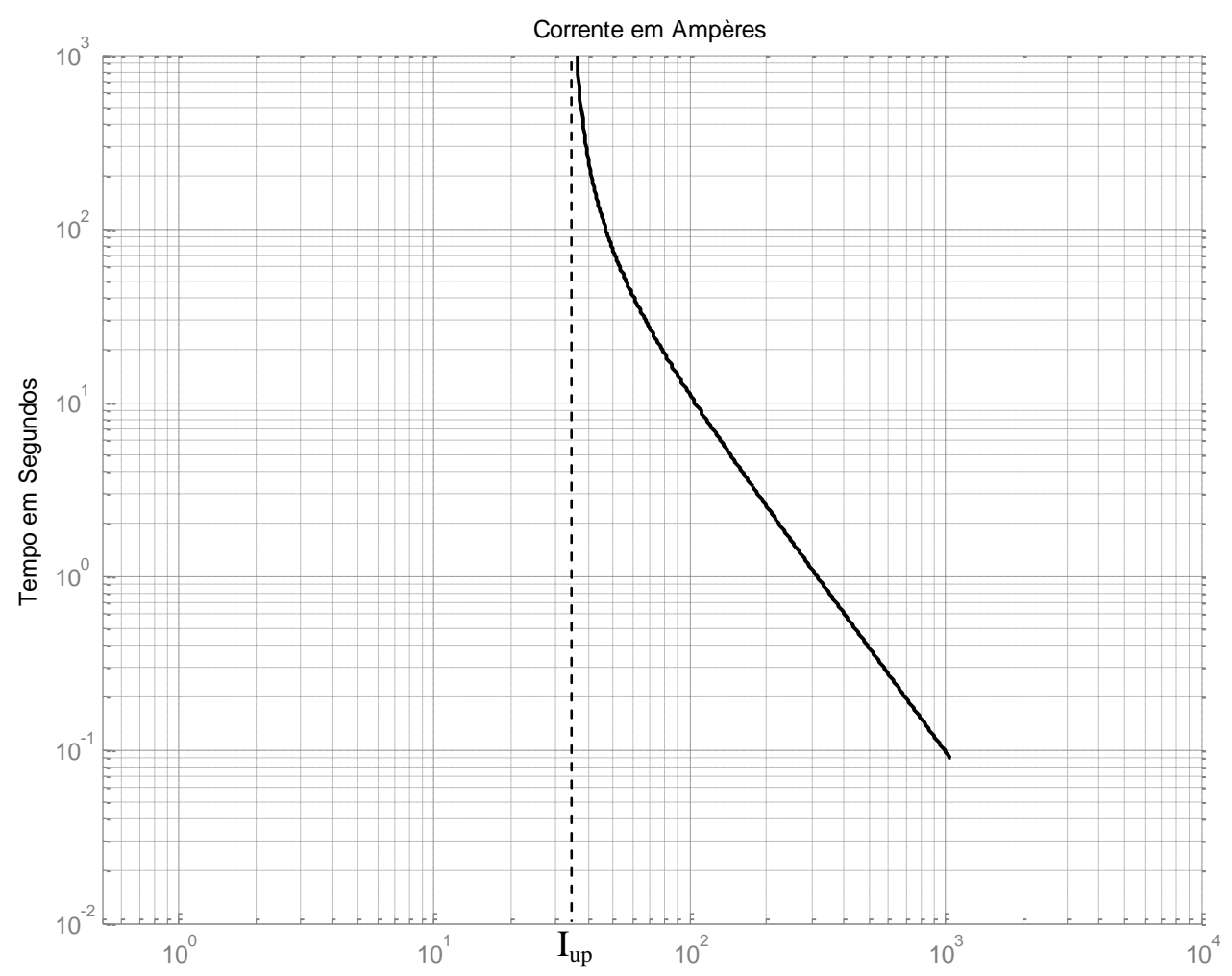

Figura 3.9 - Curva de sobrecorrente a tempo inverso.

\section{Curvas de atuação - padrão ANSI}

As curvas de atuação a tempo inverso do padrão ANSI são definidas na norma IEEE

Std. C37.112 (1996). O tempo de operação do relé é fornecido pela expressão geral (3.4).

$$
T_{o p}=T D S \times\left(K_{1}+\frac{K_{2}}{\left(M^{K_{3}}-1\right)}\right)
$$

Sendo:

$\mathrm{T}_{\mathrm{op}}$ : Tempo de operação do relé, em segundos.

TDS: Multiplicador do ajuste de tempo do relé.

M: Múltiplo da corrente de ajuste.

$\mathrm{K}_{1}, \mathrm{~K}_{2}, \mathrm{~K}_{3}$ : Constantes definidas de acordo com o tipo de curva.

A Tabela 3.1 apresenta os valores das constantes $K_{1}$ a $K_{3}$ para os diferentes tipos de curvas de atuação do padrão ANSI: moderadamente inversa, inversa, muito inversa, 
extremamente inversa e inversa de tempo curto. Esses tipos são referenciados por um código iniciado pela letra "U”, conforme se observa na primeira coluna da Tabela 3.1.

Tabela 3.1 - Constantes das curvas de atuação associadas ao padrão ANSI.

\begin{tabular}{|c|c|c|c|}
\hline Tipo de Curva & $\mathbf{K}_{\mathbf{1}}$ & $\mathbf{K}_{\mathbf{2}}$ & $\mathbf{K}_{\mathbf{3}}$ \\
\hline Moderadamente Inversa (U1) & 0,0226 & 0,0104 & 0,0200 \\
\hline Inversa (U2) & 0,1800 & 5,9500 & 2,0000 \\
\hline Muito Inversa (U3) & 0,0963 & 3,8800 & 2,0000 \\
\hline Extremamente Inversa (U4) & 0,0352 & 5,6700 & 2,0000 \\
\hline Inversa de Tempo Curto (U5) & 0,00262 & 0,00342 & 0,0200 \\
\hline
\end{tabular}

Os cinco tipos de curvas de atuação, segundo o padrão ANSI, são mostrados na Figura 3.10 à Figura 3.14, para o múltiplo da corrente de disparo (ou partida) variando de 1 a 30. Observa-se que o multiplicador do ajuste de tempo (TDS) provoca um deslocamento vertical nas curvas de atuação. Normalmente, o valor de TDS para as curvas do padrão ANSI varia de 0,5 a 15, sendo o passo dessa variação dependente do modelo do relé.

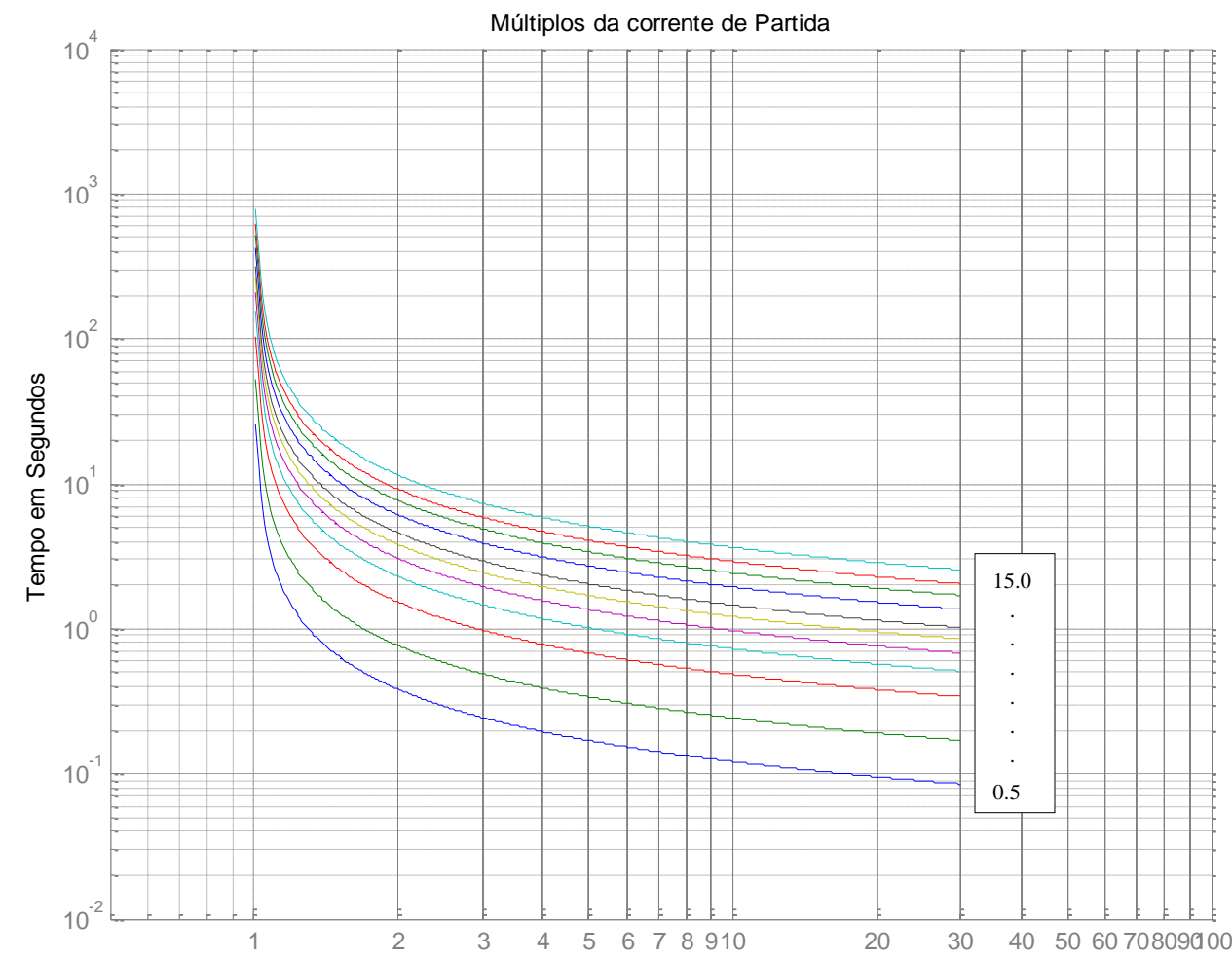

Figura 3.10 - Curva de atuação moderadamente inversa padrão ANSI (U1). 


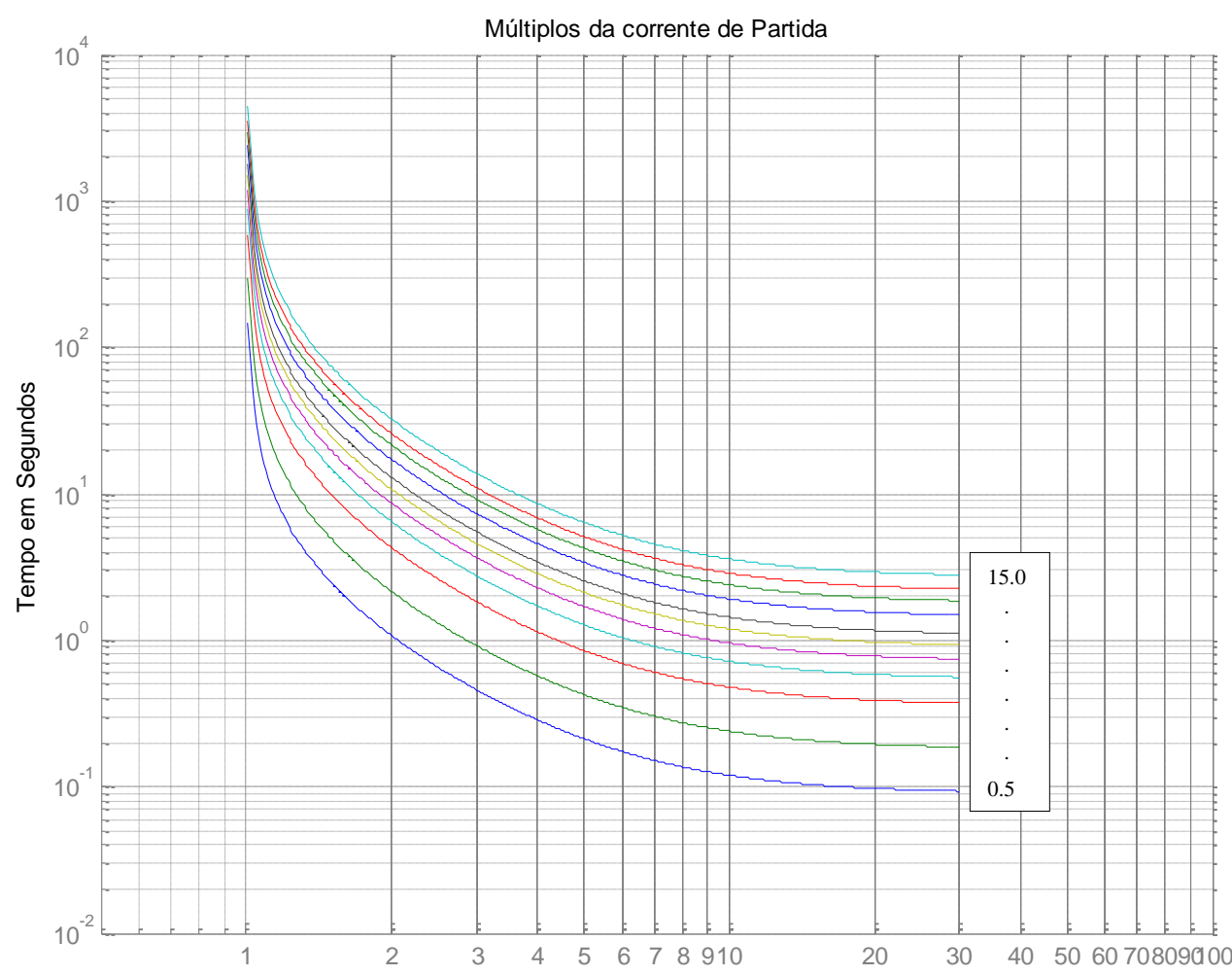

Figura 3.11 - Curva de atuação inversa padrão ANSI (U2).

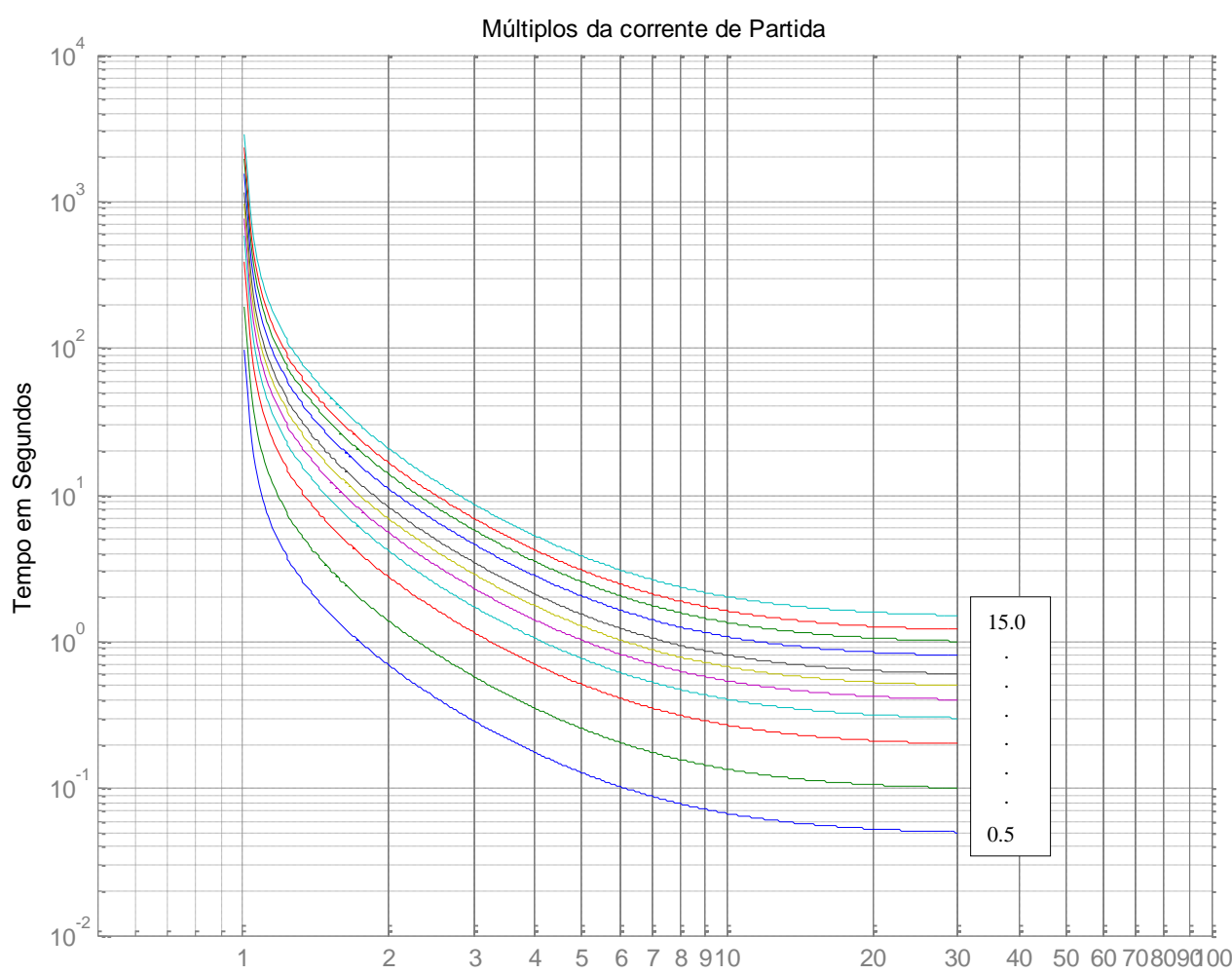

Figura 3.12 - Curva de atuação muito inversa padrão ANSI (U3). 


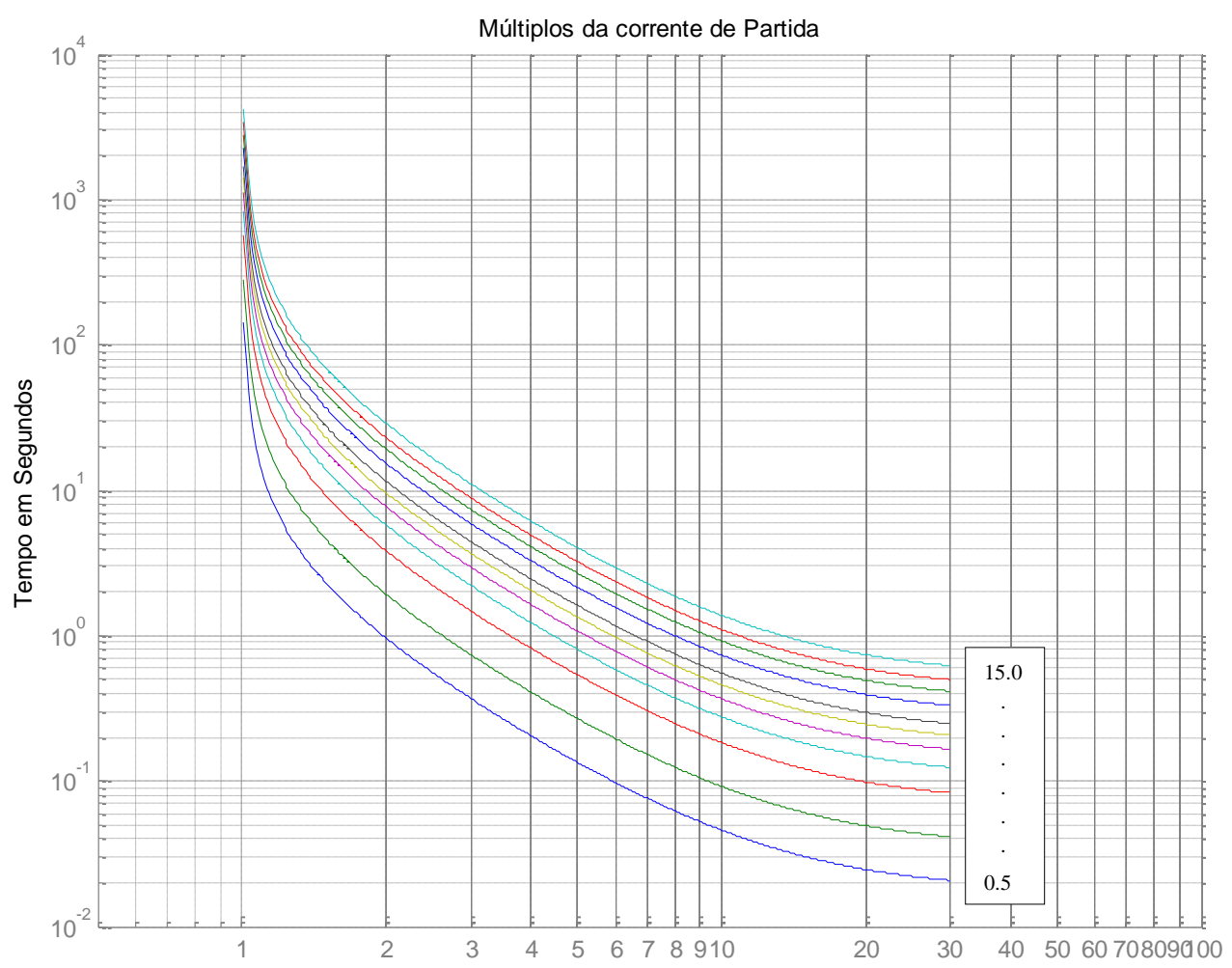

Figura 3.13 - Curva de atuação extremamente inversa padrão ANSI (U4).

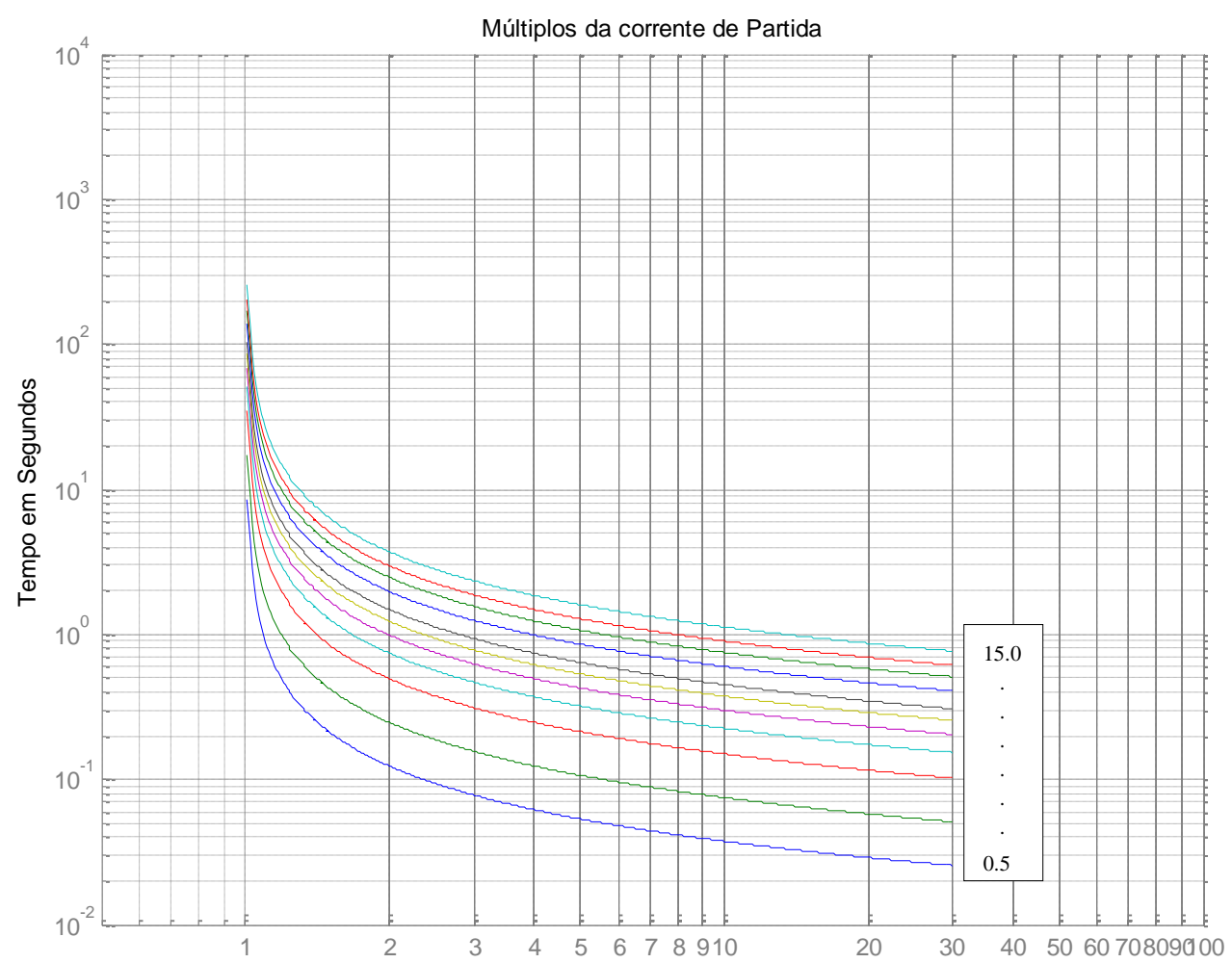

Figura 3.14 - Curva de atuação inversa de tempo curto padrão ANSI (U5). 


\section{Curvas de atuação - padrão IEC}

As curvas de atuação segundo o padrão IEC também são definidas pela expressão (3.4). No entanto os valores das constantes $K_{1}$ a $K_{3}$ são dados na Tabela 3.2 (IEC 60255-3, 1989; SCHWEITZER ENGINEERING LABORATORIES, 2007).

Tabela 3.2 - Constantes associadas ao padrão IEC.

\begin{tabular}{|c|c|c|c|}
\hline Tipo de Curva & $\mathbf{K}_{\mathbf{1}}$ & $\mathbf{K}_{\mathbf{2}}$ & $\mathbf{K}_{\mathbf{3}}$ \\
\hline Inversa (C1) & 0 & 0,14 & 0,02 \\
\hline Muito Inversa (C2) & 0 & 13,50 & 1,00 \\
\hline Extremamente Inversa (C3) & 0 & 80,00 & 2,00 \\
\hline Inversa de Tempo Longo (C4) & 0 & 120,00 & 1,00 \\
\hline Inversa de Tempo Curto (C5) & 0 & 0,05 & 0,04 \\
\hline
\end{tabular}

De acordo com o padrão IEC, o multiplicador de ajuste de tempo do relé varia de 0,05 até 1. Novamente o passo dessa variação depende do modelo do relé de sobrecorrente. Da Figura 3.15 à Figura 3.19 mostram-se os diferentes tipos de curvas de atuação, de acordo com o padrão IEC.

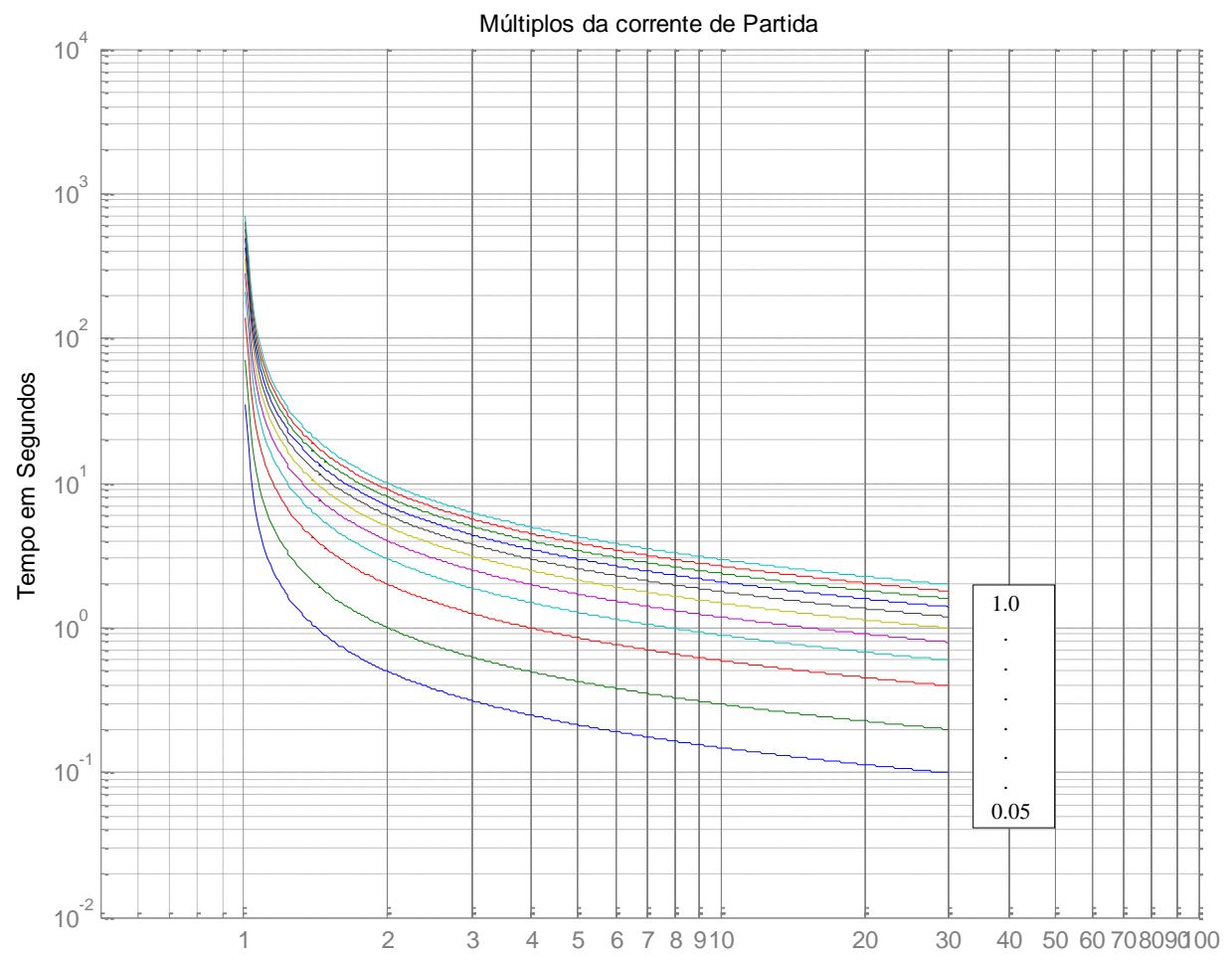

Figura 3.15 - Curva de atuação inversa padrão IEC (C1). 


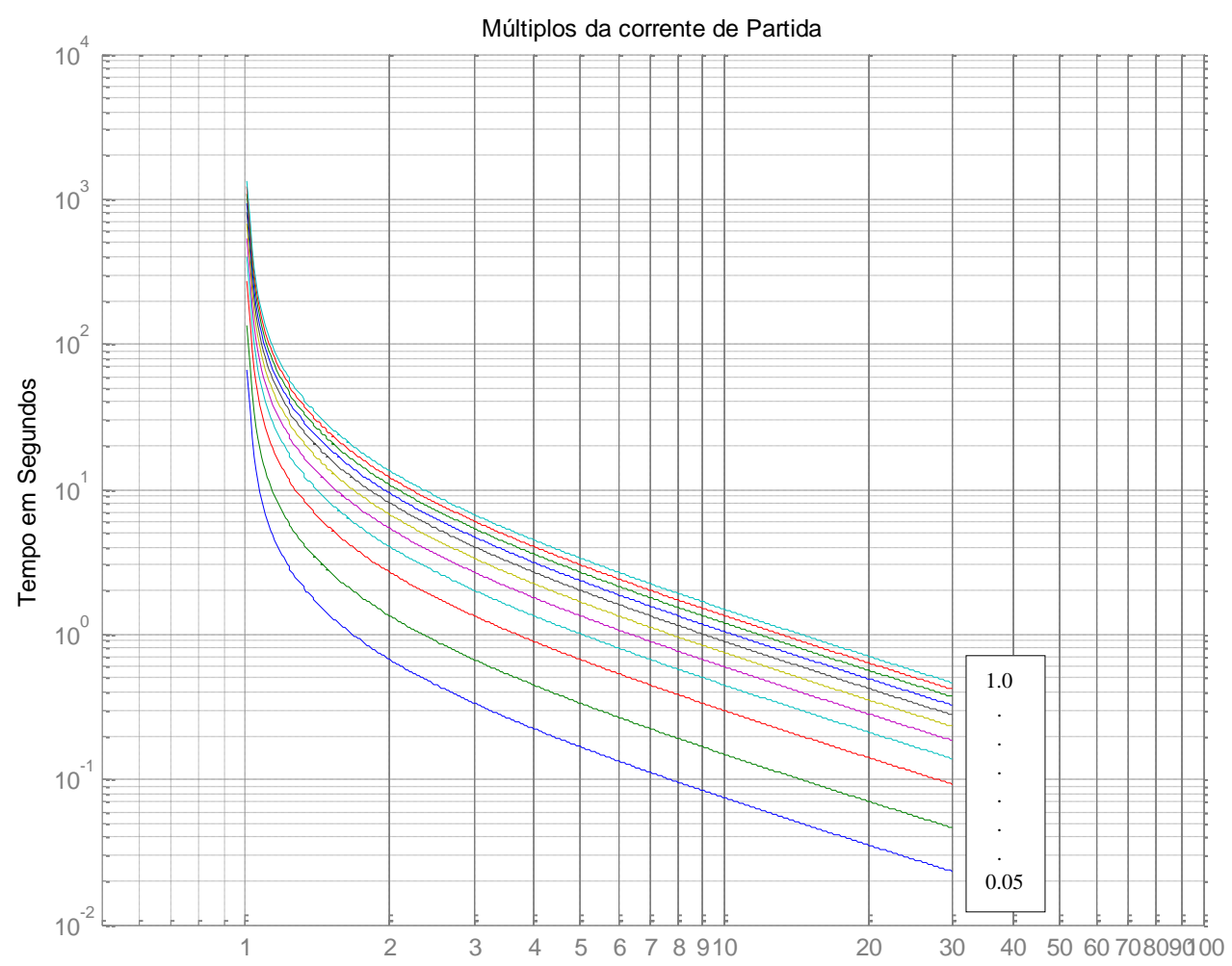

Figura 3.16 - Curva de atuação muito inversa padrão IEC (C2).

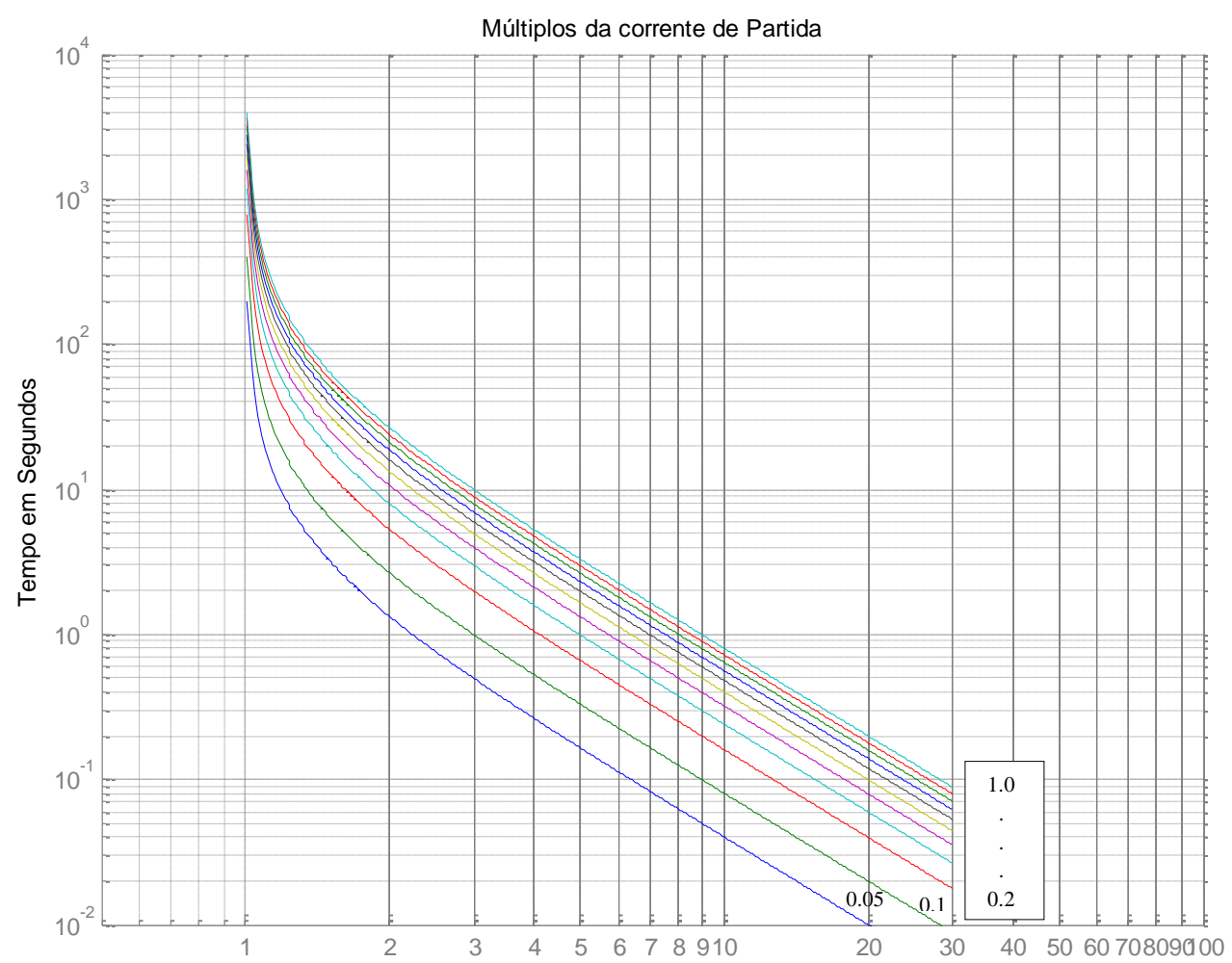

Figura 3.17 - Curva de atuação extremamente inversa padrão IEC (C3). 


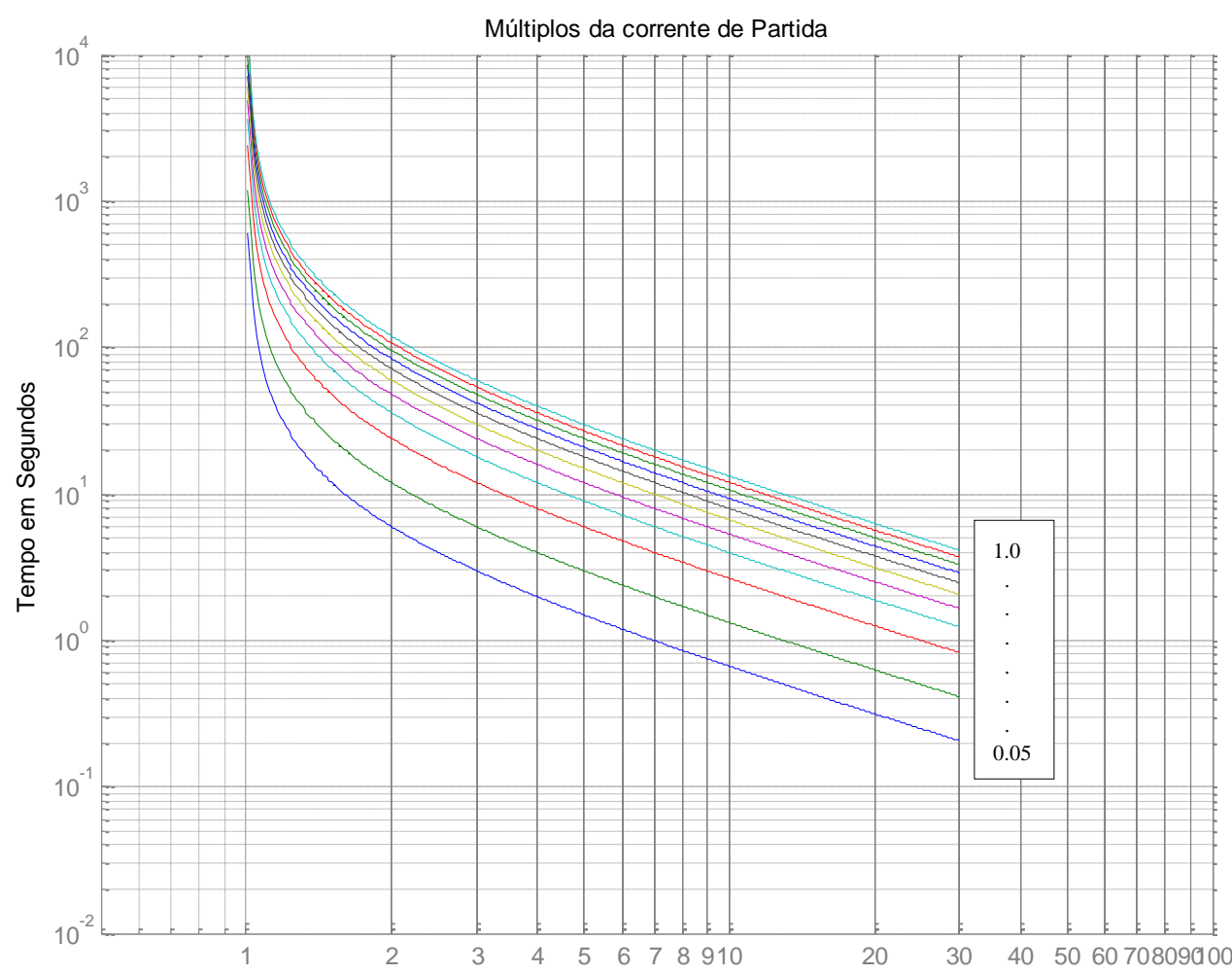

Figura 3.18 - Curva de atuação inversa de tempo longo padrão IEC (C4).

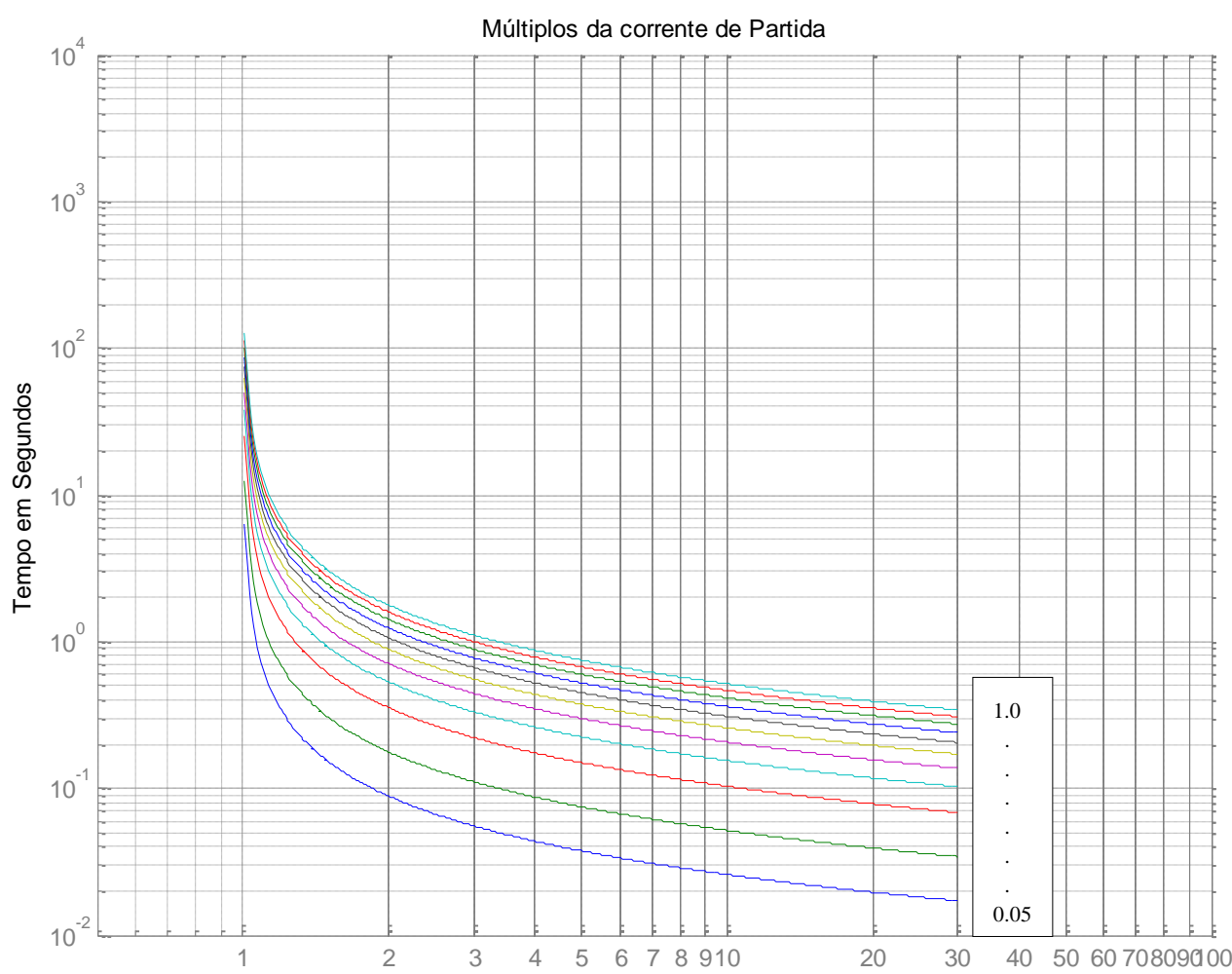

Figura 3.19 - Curva de atuação inversa de tempo curto padrão IEC (C5). 


\subsection{Equipamentos Protegidos}

As características nominais dos equipamentos protegidos, bem como seus limites térmico e mecânico, são de suma importância na definição dos ajustes dos dispositivos de proteção de sobrecorrente. Devido ao fato do trabalho abordar sistemas elétricos industriais, três principais equipamentos serão analisados:

- Cabos;

- Motores de indução com rotor gaiola de esquilo. Deste ponto em diante, esses motores serão referenciados no texto apenas como "motores de indução";

- Transformadores de dois enrolamentos. Este termo será referenciado apenas como "transformadores" no restante deste documento.

\subsection{1 $\underline{\text { Cabos }}$}

Os cabos necessitam ser protegidos contra sobreaquecimento causado pelas excessivas correntes de curto-circuito que circulam nos condutores. Durante um curto-circuito, a energia devida ao efeito Joule causa inicialmente a elevação da temperatura dos condutores, seguida do material isolante. Como conseqüência, tem-se que caso o defeito não seja interrompido rapidamente, o aquecimento poderá danificar o cabo. Admitindo-se que o curto-circuito seja eliminado instantaneamente ou em um curto intervalo de tempo após o instante de sua incidência, a quantidade de calor transferida do condutor metálico para o material isolante é pequena. Portanto, considera-se que todo o calor produzido por efeito Joule está confinado dentro do condutor (IEEE Std 242, 2001). Logo, a estratégia empregada na proteção dos cabos é baseada na energia térmica armazenada no material condutor e no limite máximo de temperatura admitida pela isolação, ou seja, em situações de curto-circuito a temperatura do condutor pode aumentar até certo limite, de maneira a não causar danos ao material isolante. 
Para aplicar a estratégia mencionada anteriormente podem ser empregadas duas equações para relacionar a elevação da temperatura do condutor com a intensidade da corrente que circula por ele. Uma para o condutor de cobre (expressão (3.5)) e a outra para condutor de alumínio (expressão (3.6)) (PRYSMIAN CABLES AND SYSTEMS, 2008).

$$
\begin{gathered}
\left(\frac{I}{S}\right)^{2} \times t=115.679 \times \log _{10}\left(\frac{T_{2}+234}{T_{1}+234}\right) \\
\left(\frac{I}{S}\right)^{2} \times t=48.686 \times \log _{10}\left(\frac{T_{2}+228}{T_{1}+228}\right)
\end{gathered}
$$

Sendo:

$\mathrm{I}=$ corrente de curto-circuito (A)

$\mathrm{S}=$ seção transversal $\left(\mathrm{mm}^{2}\right)$

$\mathrm{t}=$ tempo de duração do curto-circuito $(\mathrm{s})$

$\mathrm{T}_{1}$ = máxima temperatura admissível no condutor em operação normal $\left({ }^{\circ} \mathrm{C}\right)$

$\mathrm{T}_{2}=$ máxima temperatura admitida para o condutor no curto-circuito $\left({ }^{\circ} \mathrm{C}\right)$

Geralmente a temperatura inicial do condutor não é precisamente conhecida, pois depende da carga do cabo e das condições ambientais. Por motivos de segurança deve-se admitir a máxima temperatura permitida no condutor, nas condições normais de trabalho do cabo. Na instalação dos cabos em sistemas de potência existe a possibilidade de que a conexão do mesmo seja feita por meio de solda estanho-chumbo, cujas características são depreciadas com o aumento da temperatura. Neste caso, recomenda-se que a temperatura não ultrapasse $160^{\circ} \mathrm{C}$. Esta recomendação não se aplica para conexões prensadas ou parafusadas (PRYSMIAN CABLES AND SYSTEMS, 2008). A Tabela 3.3 apresenta os valores típicos de $\mathrm{T}_{1}$ e $\mathrm{T}_{2}$ para condutores de cobre e alumínio, considerando o tipo da conexão.

Tabela 3.3 - Valores de $T_{1}$ e $T_{2}$ para cabos de cobre e alumínio.

\begin{tabular}{|c|c|c|c|c|}
\hline \multirow{2}{*}{$\mathbf{T}_{\mathbf{1}}\left({ }^{\mathbf{0}} \mathbf{C}\right)$} & \multicolumn{3}{|c|}{$\mathbf{T}_{\mathbf{2}}\left({ }^{\mathbf{0}} \mathbf{C}\right)$} \\
\cline { 2 - 5 } & \multicolumn{2}{|c|}{ Condutor de Cobre } & \multicolumn{2}{c|}{ Condutor de Alumínio } \\
\cline { 2 - 5 } & Conexão Prensada & Conexão Soldada & Conexão Prensada & Conexão Soldada \\
\hline 90 & 250 & 160 & 250 & 160 \\
\hline 105 & \multirow{2}{*}{250} & & & \\
\hline
\end{tabular}


As expressões (3.5) e (3.6) possibilitam obter uma curva indicando o limite térmico do cabo para diferentes valores de corrente de curto-circuito. A Figura 3.20 ilustra a curva de limite térmico obtida para um cabo de cobre com conexões prensadas. A curva de limite térmico do cabo normalmente é definida até o tempo de 10 segundos (IEEE Std. 242, 2001).

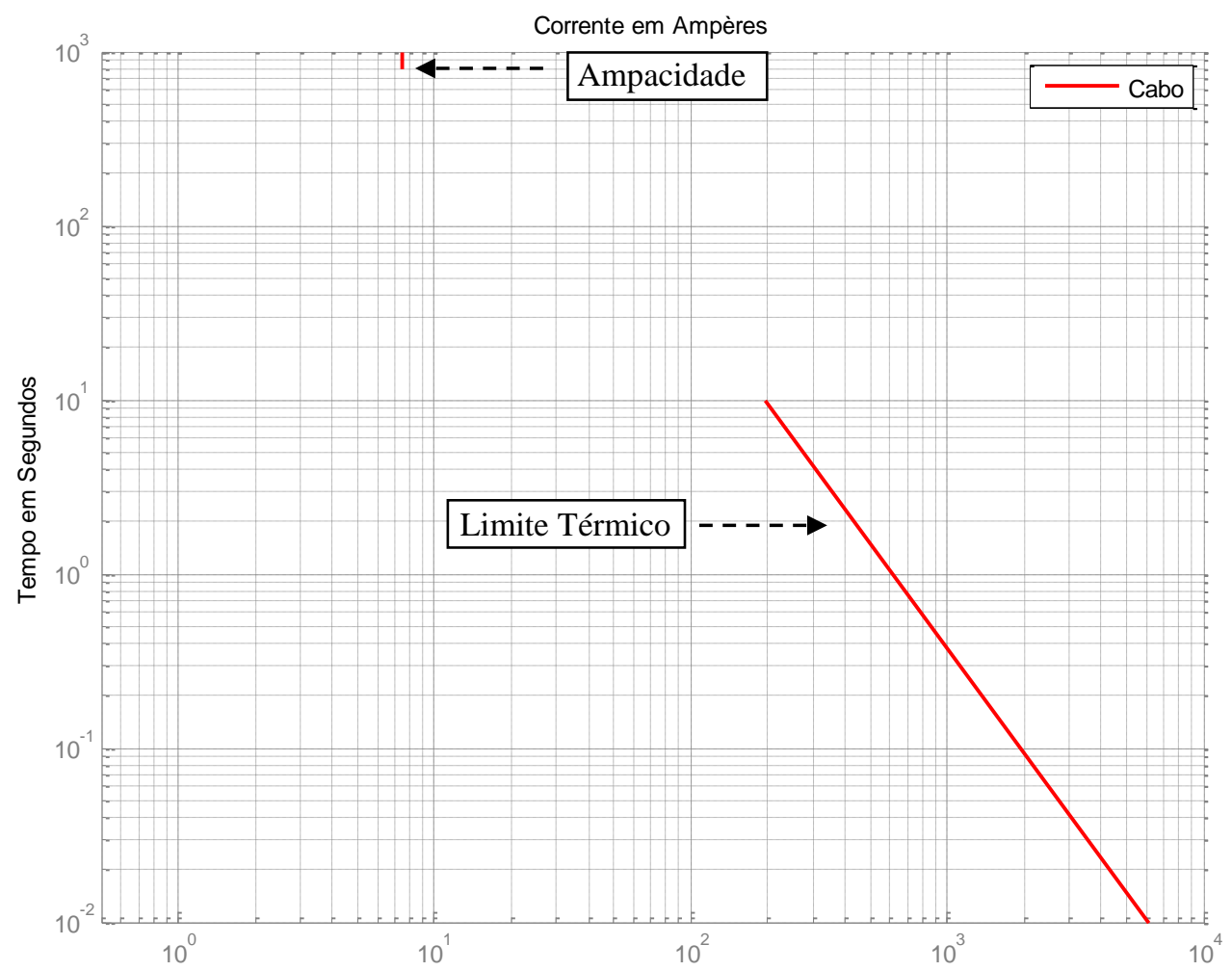

Figura 3.20 - Curva do limite térmico de cabo de cobre com conexões prensadas.

Na Figura 3.20 mostra-se também a ampacidade do cabo que é definida como a capacidade máxima de corrente elétrica nos condutores em regime. Conforme a corrente aumenta, a temperatura se eleva e os condutores se dilatam devido ao efeito Joule, elevando a resistência do cabo que altera a própria corrente. Se um condutor é carregado continuamente acima de sua ampacidade, os limites do projeto da temperatura do condutor e da isolação estarão excedidos, causando redução da vida útil do cabo. Eventualmente o cabo pode operar em regime de emergência, com sobrecarga, o que é previsto em projeto, mas isso não deve ocorrer com freqüência. 
Fazendo o uso da Figura 3.20 para ajustar os dispositivos de proteção contra sobrecorrente, a ampacidade está relacionada à proteção contra sobrecarga. Logo a corrente de ajuste dos relés, dos DBT e a corrente nominal dos fusíveis devem, sempre que possível, menores ou iguais à ampacidade do cabo, porém superiores à corrente nominal da carga que o circuito alimenta. Para ajustar a proteção instantânea contra curtos-circuitos, parte-se do princípio que para a máxima corrente de curto-circuito, a atuação do dispositivo de proteção que protege o cabo deve ocorrer em um tempo inferior àquele obtido pela curva do limite térmico para a mesma corrente (IEEE Std. 242, 2001). Com essas informações, podem-se estabelecer as regiões de ajuste, de alerta e de dano para os cabos, conforme ilustrado na Figura 3.21 e explicadas a seguir:

- Região de Ajuste: região correspondente à área abaixo da curva de limite térmico do cabo. Para defini-la pode-se prolongar a curva de limite térmico até 1000 segundos ou mais, a depender do valor máximo da escala de tempo mostrada no gráfico. Nota-se também que essa região compreende valores de corrente superiores à ampacidade do cabo. De fato, embora não recomendada, a operação dos cabos com valores de corrente superiores à sua ampacidade é permitida em condições transitórias, porém ocorre a redução de sua vida útil. As curvas dos dispositivos de proteção devem estar nessa região;

- Região de Alerta: indica os valores de corrente em que o cabo pode operar provisoriamente, em caso de emergência;

- Região de Dano: as curvas dos dispositivos de proteção não podem estar localizadas nessa região. A violação desta determinação pode ocasionar danos irreversíveis aos cabos. 


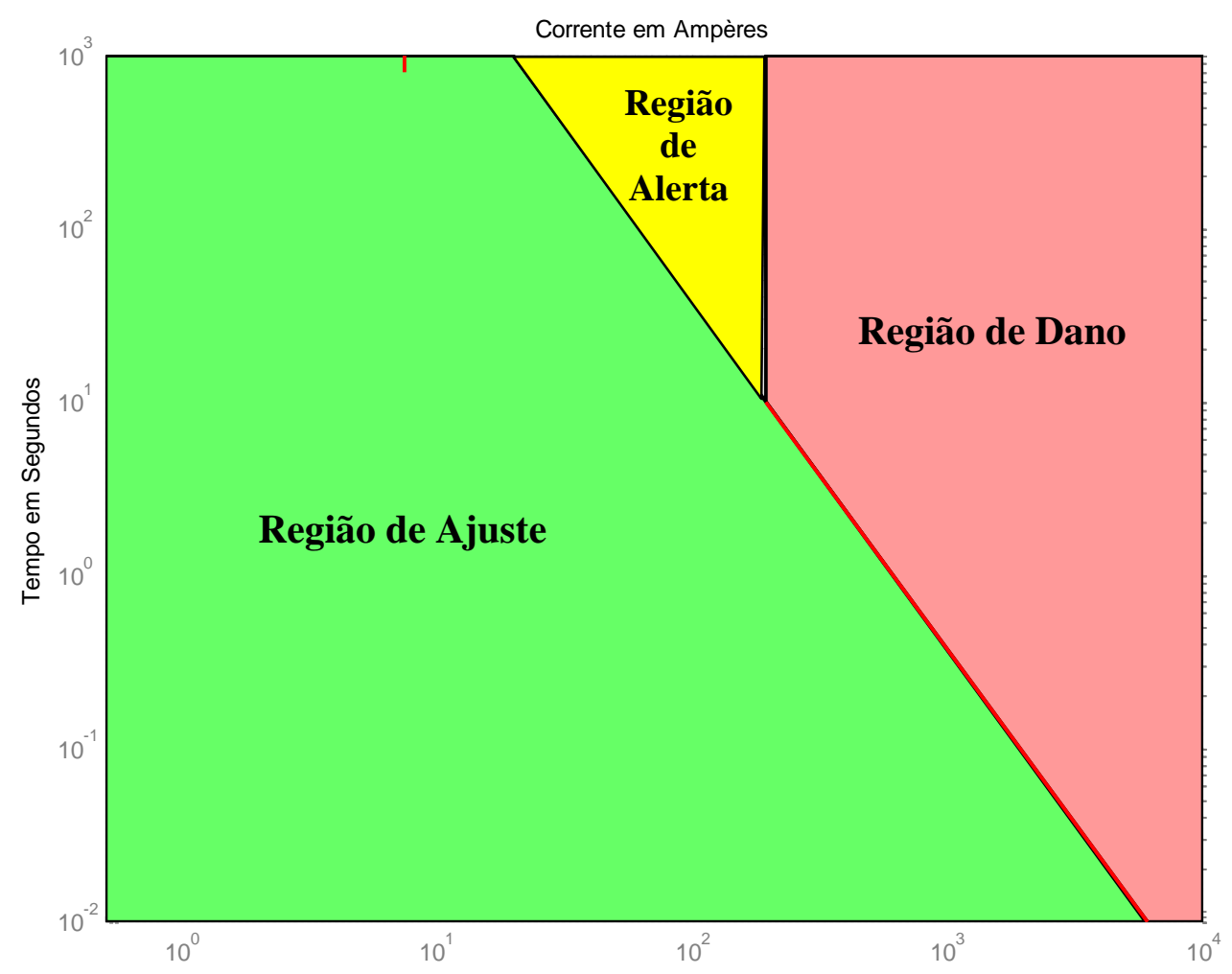

Figura 3.21 - Regiões de ajuste, de alerta e de dano dos cabos.

\subsubsection{Motores de Indução}

Em relação à proteção contra sobrecorrente de motores de indução, dispositivos de atuação instantânea devem ser empregados na proteção contra curtos-circuitos, ao passo que dispositivos com atuação temporizada devem ser empregados na proteção contra sobrecarga. Embora essa filosofia de proteção seja aplicada tanto em motores de baixa quanto de média tensão, existem algumas diferenças nos esquemas de proteção contra sobrecorrente de motores pertencentes a essas distintas classes de tensão.

Em se tratando de motores de baixa tensão (tensão inferior a $1000 \mathrm{~V}$ ), a proteção contra sobrecarga normalmente é provida por relés térmicos ou disjuntores de baixa tensão com sensores eletrônicos (IEEE Std. 242, 2001), como é o caso da atuação de tempo longo presente nos disjuntores de baixa tensão apresentados na seção 3.1.2. Por outro lado, a 
proteção contra curtos-circuitos entre fases (trifásico e bifásico) pode ser realizada por disjuntores de baixa tensão contendo unidades termomagnéticas ou eletrônicas para prover rápida atuação, e por fusíveis. Já no caso de curtos-circuitos fase-terra ou bifásico-terra, alguns modernos disjuntores de baixa tensão contam com unidades de operação específicas para esta finalidade.

No caso dos motores de indução de média tensão é comum que a proteção contra sobrecorrente seja feita por um dos seguintes esquemas (IEEE Std. 242, 2001):

- Esquema 1: relé de sobrecorrente com curva a tempo inverso para proteção contra sobrecarga e relé de sobrecorrente com atuação instantânea para proteção contra curtos-circuitos entre fases e entre fases envolvendo a terra;

- Esquema 2: relé de sobrecorrente com curva a tempo inverso para proteção contra sobrecarga e fusível para proteção contra curtos-circuitos.

Ressalta-se que para motores de média tensão e elevada potência utiliza-se também relé diferencial para protegê-los contra curtos-circuitos internos, cuja atuação deve ser instantânea. Neste caso, o relé diferencial representa a proteção primária do motor, ao passo que o relé de sobrecorrente com função instantânea ou o fusível representa a proteção de retaguarda. No entanto, esses dois dispositivos não precisam estar coordenados entre si, uma vez que protegem o mesmo equipamento. Logo, em se tratando de faltas internas ao motor, qualquer dispositivo de proteção a montante que esteja coordenado com o relé de sobrecorrente ou fusível, também está coordenado com o relé diferencial. Assim, é desnecessário representar o relé diferencial em estudos de coordenação da proteção e seletividade e por isso, tal dispositivo não será explicitamente abordado neste trabalho.

O esquema 1 mencionado anteriormente é utilizado quando os relés comandam um disjuntor de média tensão, ao passo que o esquema 2 é usando quando o relé de sobrecarga comanda um contator. Neste caso, o fusível visa proteger também o contator, pois o mesmo 
pode ser danificado se operar interrompendo elevadas correntes de curto-circuito. Já os disjuntores de média tensão são capazes de suportar essas elevadas correntes (IEEE Std. 242, 2001). Ainda no caso do esquema 1, as funções de sobrecorrente temporizada e instantânea (51 e 50) estão contidas em um mesmo relé digital multifunção. Alguns relés digitais específicos para a proteção de motores de indução de média tensão contam com uma função de sobrecorrente temporizada específica para sobrecarga (código ANSI 49), na qual a curva de atuação não é padronizada.

Independente do esquema de proteção utilizado, a definição dos ajustes de proteção de sobrecorrente de motores de indução devem se basear nas seguintes grandezas:

- Corrente nominal: corrente na qual se dá a operação normal do motor. Pode ser corrigida pelo fator de serviço, o qual multiplica a corrente nominal e permite uma ligeira sobrecarga no motor;

- Corrente de partida: é o valor eficaz da corrente de energização do motor, quando partindo diretamente conectado na rede elétrica. Seu valor varia de 5 a 8 vezes a corrente nominal da máquina (IEEE Std. 242, 2001);

- Tempo de aceleração: é o tempo para o motor deixar a condição de repouso e atingir a condição normal de operação. Durante a maior parte desse período, a corrente que o motor exigirá do sistema elétrico é a corrente de partida;

- Tempo de rotor bloqueado: é o máximo período de tempo que o motor pode permanecer com o rotor travado sem violar os limites de temperatura recomendados para sua operação. Durante a partida, caso o tempo de aceleração seja superior ao tempo de rotor bloqueado, existe o risco de o motor se danificar.

As grandezas anteriores podem ser representadas no plano tempo versus corrente pela curva apresentada na Figura 3.22, denominada curva de partida do motor de indução. Na 
prática, o ponto definido pela corrente de partida e tempo de aceleração não é tão bem determinado quanto apresentado na Figura 3.22. De fato, essa curva é arredondada nessa região e pode variar conforme mudam as características nominais do motor. No entanto, por simplicidade e pelo fato de se obter resultados mais conservadores, a curva de partida mostrada na Figura 3.22 será considerada neste trabalho. Essa abordagem conservadora também é utilizada por alguns programas computacionais disponíveis comercialmente, como é o caso do DIgSILENT PowerFactory (DIgSILENT, 2009).

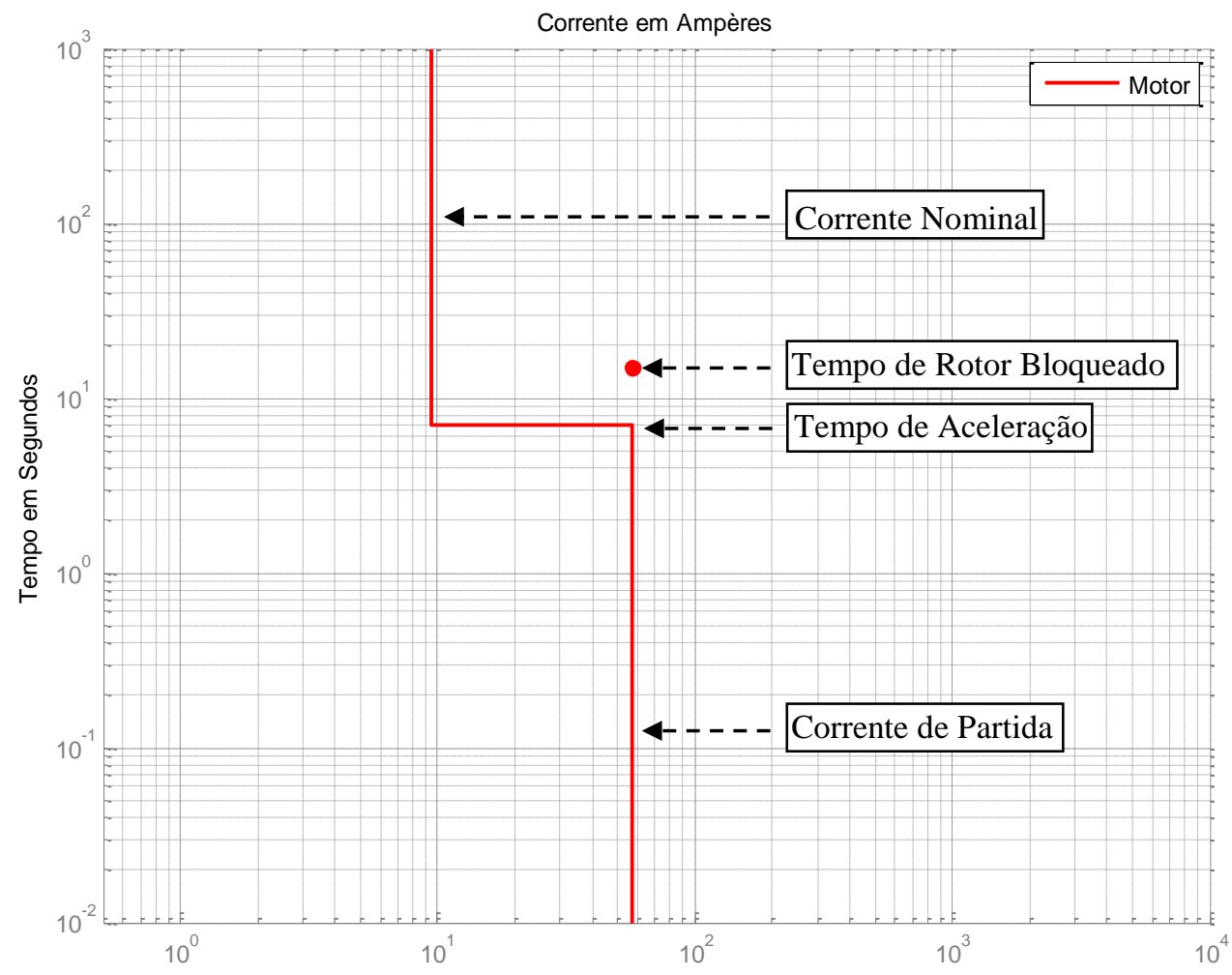

Figura 3.22 - Curva de partida do motor de indução.

A curva de partida do motor de indução é fundamental para definir os ajustes dos dispositivos de proteção contra sobrecorrente, quaisquer que sejam eles. O ajuste de corrente do dispositivo que o protegerá contra sobrecarga deve ser superior à corrente nominal do motor, considerando o fator de serviço, e deve ser temporizado para permitir que ocorra a partida da máquina. No entanto, esse ajuste deve provocar a atuação da proteção em um 
tempo inferior ao tempo de rotor bloqueado se correntes elevadas persistirem por períodos de tempo superiores ao tempo de aceleração. Isso significa que as curvas temporizadas dos dispositivos de proteção (relé de sobrecorrente, fusível e/ou disjuntor de baixa tensão) devem ser posicionadas na região marcada em verde na Figura 3.23, denominada Região de Ajuste. No entanto, a curva de atuação temporizada não deve ficar muito próxima do tempo de partida, pois se a tensão aplicada ao motor for inferior à nominal, ele pode demorar mais tempo para partir e então o relé pode atuar indevidamente. Para solucionar este problema, considera-se uma margem de segurança para ajustar o multiplicador de tempo da curva temporizada do relé. A escolha desse ajuste depende do julgamento do engenheiro de proteção e/ou de ensaios do fabricante do motor, especificando o tempo de aceleração no caso de partida com tensão reduzida. Ainda na Figura 3.23, observa-se a existência de uma região de dano definida por correntes superiores à corrente de partida do motor e cuja duração seja superior ao tempo de rotor bloqueado. Caso os dispositivos de proteção do motor permitam que ele opere na região de dano, o mesmo poderá sofrer sérios danos físicos.

Outro ponto importante na proteção do motor de indução é a definição do ajuste do dispositivo de proteção contra curto-circuito, o qual deve ter atuação instantânea. Deve-se lembrar que a corrente de partida de um motor de indução é assimétrica, sendo que o valor de pico pode provocar a atuação indevida do dispositivo de sobrecorrente com atuação instantânea (IEEE Std. 242, 2001). Portanto, o valor do ajuste da proteção instantânea deve ser superior à corrente de partida assimétrica. No caso de a proteção do motor ser feita por fusíveis, o mesmo deve ser escolhido de forma a obedecer tal critério. 


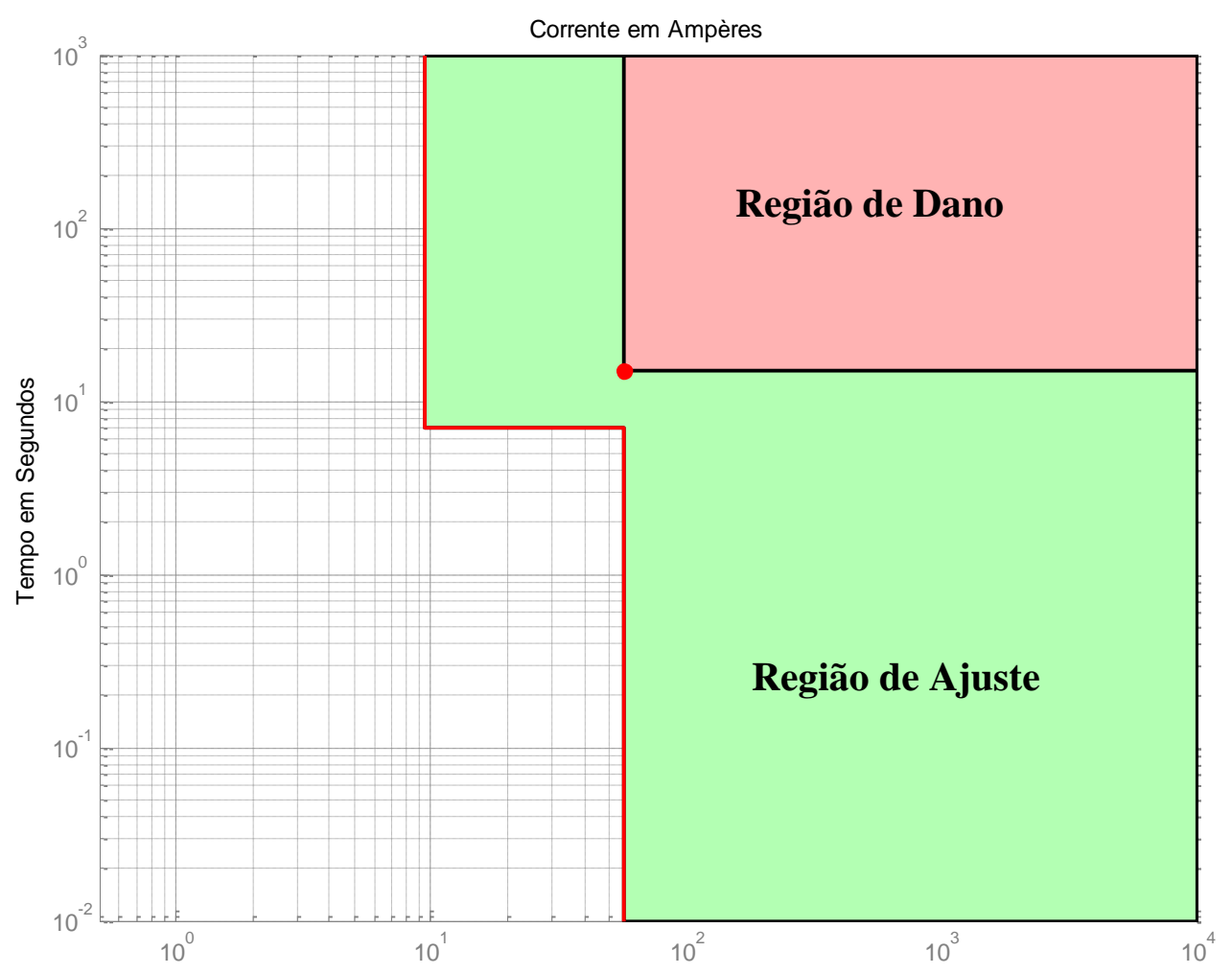

Figura 3.23 - Regiões de ajuste e de dano do motor de indução.

\subsubsection{Transformador de 2 Enrolamentos}

A especificação e os ajustes dos dispositivos de proteção dos transformadores devem considerar as suas características nominais, a intensidade e duração de sua corrente de energização, os valores máximos das correntes de curto-circuito nos lados primário e secundário e os limites térmicos dos mesmos. Nesta seção serão abordados os aspectos relevantes a serem considerados na definição apenas dos ajustes das proteções contra sobrecorrente dos transformadores.

A proteção contra sobrecorrente de transformadores pode ser realizada considerando diferentes esquemas de proteção. De maneira geral, é realizada por um dispositivo de proteção instalado no lado primário dos mesmos, que pode ser fusível ou disjuntor, sendo que este deve ser comandado por relés. No entanto, pode apresentar dispositivos de proteção tanto no lado primário quanto no secundário, a depender da classe de tensão, potência nominal e 
importância do transformador para o sistema industrial (IEEE Std. 242, 2001). Em relação à proteção contra sobrecarga realizada por dispositivos de sobrecorrente, relés com curva a tempo inverso são muito empregados como proteção no lado primário do transformador. A curva a tempo inverso torna-se importante para a coordenação com os dispositivos de proteção a jusante e a montante. Outro esquema consiste em instalar fusíveis ou disjuntores (com relés associados) em ambos os lados do transformador, sendo que se a tensão do lado de baixa tensão for inferior a $1 \mathrm{kV}$, é comum utilizar disjuntores de baixa tensão. Quando há dispositivos de sobrecorrente instalados em ambos os lados do transformador, recomenda-se que a proteção contra sobrecarga seja realizada preferencialmente pelo dispositivo localizado no lado secundário, deixando como proteção de retaguarda o dispositivo localizado no lado primário, com o intuito de prover uma atuação mais rápida, se necessário (IEEE Std 242, 2001).

Em relação à proteção contra curtos-circuitos, existem dois grupos de dispositivos utilizados para esta finalidade: (i) os que detectam a formação de gases no interior do transformador, e (ii) os que detectam a sobrecorrente (IEEE Std. 242, 2001). O primeiro grupo de dispositivos é aplicado em transformadores imersos em óleos isolantes, cujo material isolante (óleo) pode ser decomposto devido às elevadas temperaturas causadas pelas correntes de curto-circuito, originando gases no interior do tanque do transformador. $\mathrm{O}$ segundo grupo de dispositivos é composto por fusíveis, disjuntores e relés de sobrecorrente, os quais podem ser mais facilmente coordenados com outros dispositivos de proteção contra sobrecorrente. Para proteção contra curtos-circuitos internos ao transformador, é comum utilizar relés diferenciais com atuação instantânea para transformadores importantes (normalmente de elevada capacidade), tendo os outros dispositivos de proteção contra sobrecorrente como proteção de retaguarda (IEEE Std 242, 2001). 
Independente do esquema de proteção utilizado, os ajustes devem ser definidos de forma a permitir a operação do transformador em condições nominais, não atuar para a corrente de energização do mesmo e promover a atuação dos dispositivos de proteção antes que a condição anormal do sistema elétrico provoque a violação dos limites térmico e mecânico do transformador. Estes limites são definidos pela característica de suportabilidade do transformador contra curtos-circuitos (IEEE Std. C57.109, 1993; IEEE Std. C57.12.00, 2006; IEEE Std. 242, 2001).

\subsubsection{Suportabilidade do transformador contra curtos-circuitos}

A característica de suportabilidade contra curtos-circuitos do transformador representa os limites dos esforços térmicos e mecânicos suportáveis pelo equipamento, na ocorrência de um curto-circuito no lado secundário. O limite mecânico tem ganhado grande importância recentemente (IEEE Std. 242, 2001) e está relacionado não só ao valor da intensidade e duração da corrente de defeito, mas também à freqüência com que ocorrem os curtoscircuitos, pois alguns efeitos mecânicos apresentam natureza cumulativa. Logo a ocorrência de repetidos curtos-circuitos pode acelerar o processo de danos no transformador, caso este não esteja devidamente protegido. Tendo em vista a existência desses limites, a característica de suportabilidade pode ser composta por duas curvas: a que representa o limite térmico, comumente conhecida como curva ANSI, e a que representa o limite mecânico.

A característica de suportabilidade depende, entre outros fatores, da potência nominal do transformador. Neste sentido, os transformadores foram agrupados em quatro categorias, conforme apresentado na Tabela 3.4 (IEEE Std. C57.12.00, 2006). 
Tabela 3.4 - Categoria dos transformadores conforme IEEE Std. C57.12.00.

\begin{tabular}{|c|c|c|}
\hline Categoria & Monofásico (kVA) & Trifásico (kVA) \\
\hline I & 5 a 500 & 15 a 500 \\
\hline II & 501 a 1.667 & 501 a 5.000 \\
\hline III & 1.668 a 10.000 & 5.001 a 30.000 \\
\hline IV & Acima de 10.000 & Acima de 30.000 \\
\hline
\end{tabular}

A Figura 3.24 apresenta a característica de suportabilidade de um transformador conectado em delta no lado primário e estrela no secundário, pertencente à Categoria II (Tabela 3.4). Nessa figura também está representada a corrente de magnetização do transformador. Cada item pertencente à figura será detalhado a seguir.

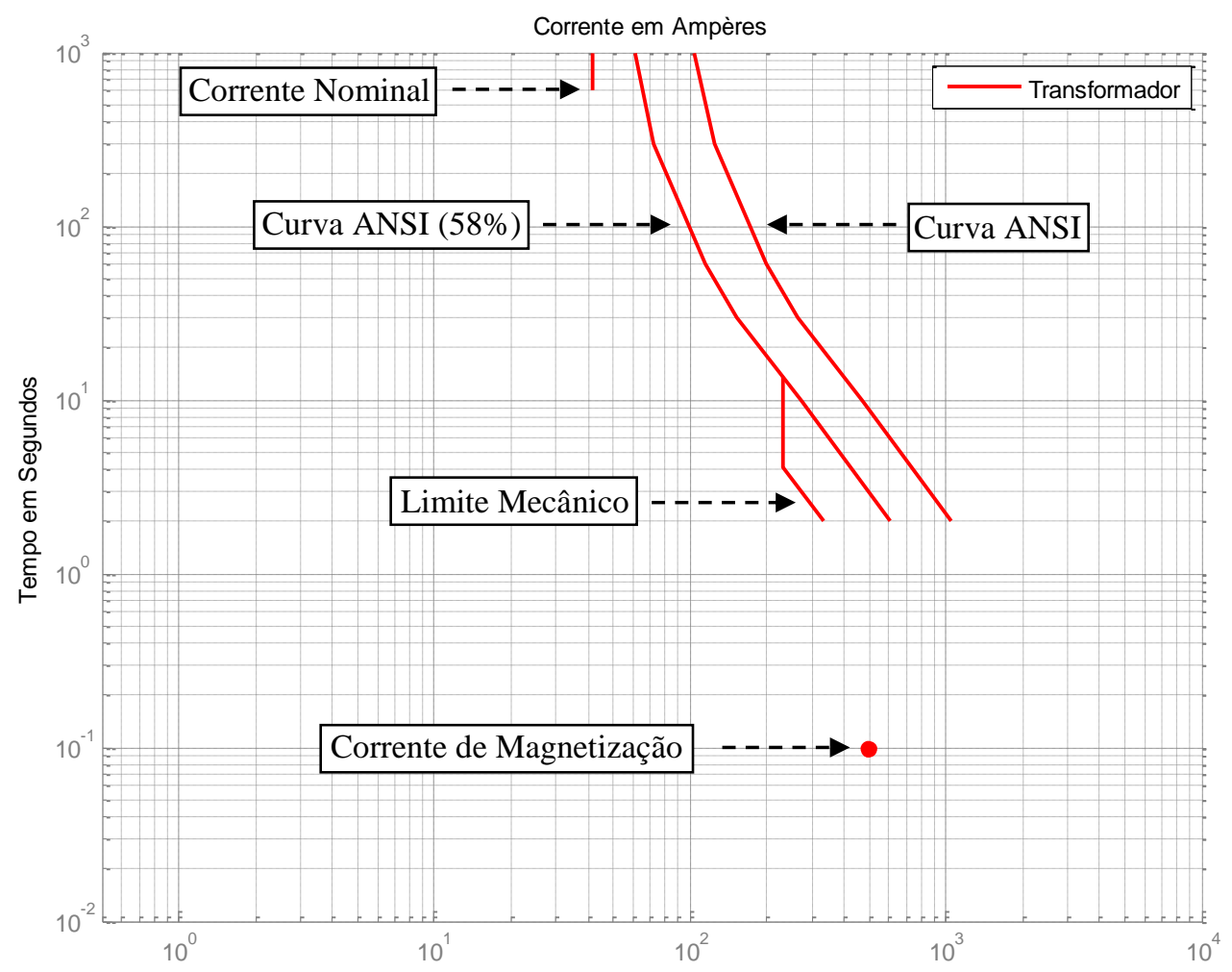

Figura 3.24 - Característica de suportabilidade contra curto-circuito de um transformador delta-estrela pertencente à categoria II. 
- Corrente nominal: representa a condição nominal de operação do transformador. Os dispositivos de proteção contra sobrecorrente não devem atuar para este valor de corrente;

- Corrente de Magnetização: é a corrente de energização do transformador. Sua intensidade, em valor eficaz, varia de 8 a 12 vezes a corrente nominal do transformador, e atribui-se sua duração de até 0,10 segundo (IEEE Std. 242, 2001). A proteção primária do transformador, caso tenha atuação instantânea, deve ser ajustada de forma que o valor da corrente de ajuste seja superior à corrente de magnetização;

- Curva ANSI: representa o limite térmico do transformador e é mostrada a partir de 2 segundos. Para transformadores imersos em óleo isolante, a curva ANSI é construída com base nas informações da Tabela 3.5;

Tabela 3.5 - Limite térmico de transformadores imersos em óleo isolante.

\begin{tabular}{|c|c|}
\hline Múltiplo da Corrente Nominal & Tempo (s) \\
\hline 2,00 & 1.800 \\
\hline 3,00 & 300 \\
\hline 4,75 & 60 \\
\hline 6,30 & 30 \\
\hline 11,30 & 10 \\
\hline 25,00 & 2 \\
\hline
\end{tabular}

- Curva ANSI (58\%): esta curva é utilizada quando o transformador em análise é do tipo delta-estrela com neutro solidamente aterrado. Neste tipo de transformador, um curto-circuito fase-terra no lado secundário provoca uma circulação de corrente nas outras duas fases do lado primário igual a 58\% da corrente total de defeito no secundário, referida ao primário. Portanto, para 
prover uma proteção contra curto-circuito mais eficaz, desloca-se a curva ANSI para a esquerda em 58\% (IEEE Std. 242, 2001);

- Limite mecânico: para transformadores da Categoria I a curva ANSI é suficiente para representar os limites térmico e mecânico (IEEE Std. C57.109, 1993). Para transformadores da categoria II, o limite mecânico dependerá da frequiência de ocorrência das faltas. Caso seja estimado que determinado transformador esteja sujeito a curtos-circuitos freqüentes (tipicamente mais de 10 em toda a vida útil do transformador) considera-se o limite mecânico. Caso contrário, a característica de suportabilidade será representada apenas pela curva ANSI (IEEE C57.109, 1993). No caso de curtos-circuitos freqüentes foi estabelecido que o limite térmico é obtido considerando uma corrente que varia de $70 \%$ a $100 \%$ da máxima corrente de defeito. Para transformadores da categoria III, estabeleceu-se que a curva do limite mecânico é obtida para correntes acima de $50 \%$ da máxima corrente de curto-circuito. Além disso, estima-se que o transformador estará sujeito a curtos-circuitos freqüentes se ocorrerem mais de 5 faltas em toda a sua vida útil - neste caso representa-se o limite mecânico. Para os transformadores da categoria IV, a faixa de correntes utilizada para obter a curva do limite mecânico é a mesma dos transformadores da categoria III. No entanto, como transformadores da categoria IV são de elevada potência, recomenda-se a representação do limite mecânico tanto para curtos-circuitos freqüentes quanto para os não freqüentes. $O$ processo de obtenção da curva do limite mecânico faz o uso da Tabela 3.6, de acordo com as recomendações de IEEE Std. C57.109 (1993). Na primeira coluna, calculam-se os múltiplos da corrente nominal do transformador considerando porcentagens máxima e mínima da máxima corrente simétrica de curto-circuito 


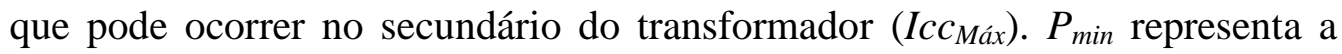
porcentagem mínima (70\% para transformadores da classe II e 50\% para transformadores das classes III e IV), e $P_{\max }$ representa a máxima porcentagem (100\% para as categorias de II a IV). Z representa a impedância porcentual do transformador e $k$ é uma constante definida pelo produto $\boldsymbol{I C C}_{\boldsymbol{M a ́} \boldsymbol{x}} \times \boldsymbol{t}$, sendo $t=2$ segundos.

Tabela 3.6 - Limite mecânico de transformadores de dois enrolamentos.

\begin{tabular}{|c|c|}
\hline Múltiplo da Corrente Nominal & Tempo (s) \\
\hline$\frac{P_{\min }}{Z}$ & $k \times\left(\frac{Z}{P_{\min }}\right)^{2}$ \\
\hline$\frac{P_{\min }}{Z}$ & $2 \times\left(\frac{P_{\max }}{P_{\min }}\right)^{2}$ \\
\hline$\frac{P_{\max }}{Z}$ & 2 \\
\hline
\end{tabular}

Conhecidas as características de suportabilidade do transformador contra correntes de curto-circuito e o ponto que define a corrente de magnetização, é possível definir as regiões de ajuste e de dano para o transformador. Essas regiões são mostradas na Figura 3.25. Observa-se que a região de ajuste é delimitada pela corrente nominal do transformador, corrente de magnetização, tempo de energização do equipamento e pela curva de suportabilidade contra curtos-circuitos. Tal como apresentado para os motores e cabos, as curvas dos dispositivos de proteção devem estar localizadas dentro da região de ajuste. Já a Região de Dano compreende os pontos tempo $x$ corrente situados acima da curva de suportabilidade contra curtos-circuitos. Caso o transformador opere em qualquer condição dentro da região de dano, poderá sofrer sérios danos físicos.

Para transformadores cujos enrolamentos são conectados em delta no lado primário e estrela no secundário e que tenham neutro solidamente aterrado, a curva ANSI (58\%) e a 
curva ANSI podem ser representadas simultaneamente, tal como na Figura 3.24. Neste caso, a curva ANSI representa o limitante máximo para o ajuste dos dispositivos de proteção, pois em algumas condições a depender do julgamento do engenheiro de proteção, admite-se que a região de dano delimitada pela curva ANSI (58\%) seja violada.

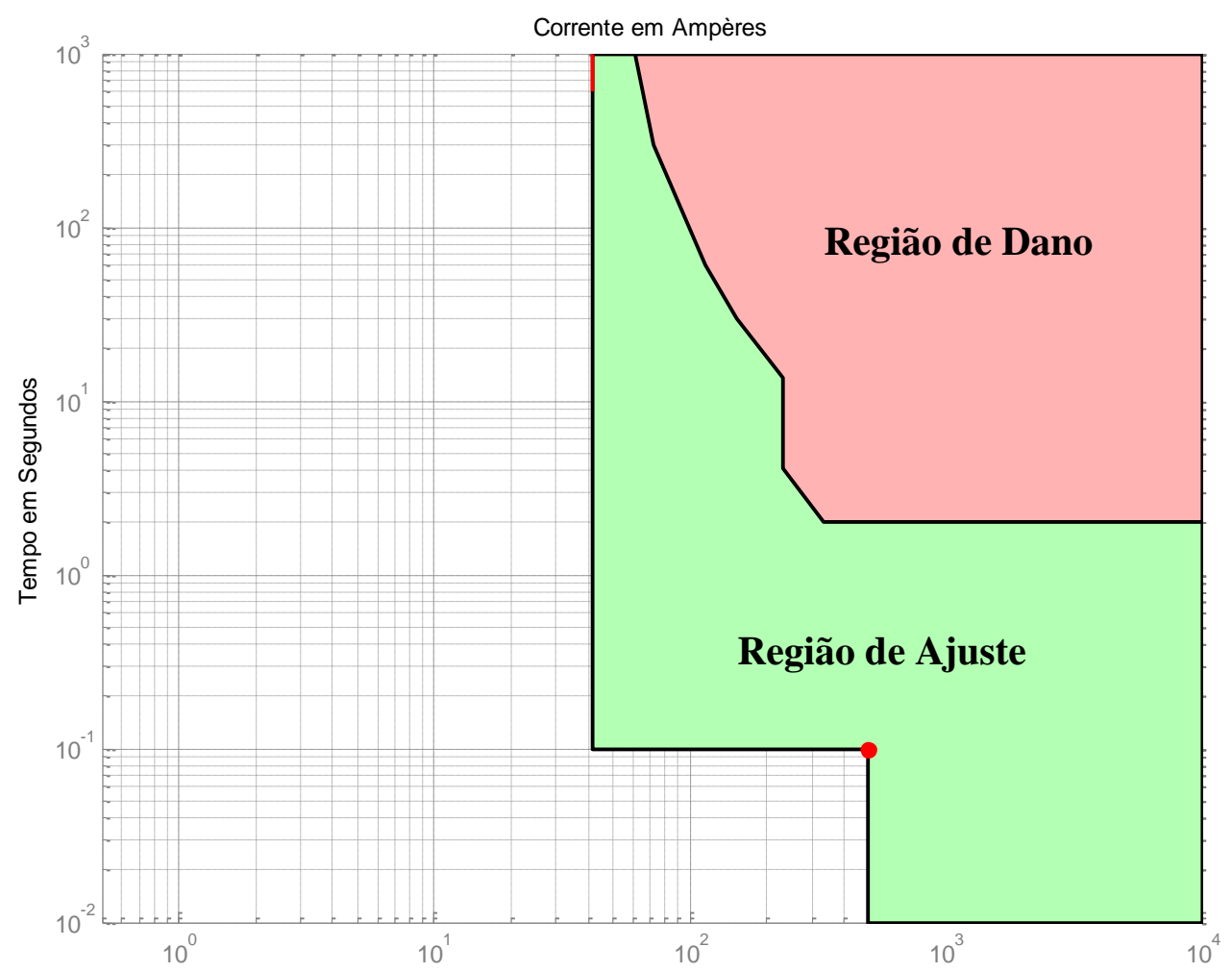

Figura 3.25 - Regiões de dano e de ajuste para o transformador trifásico de dois enrolamentos.

A curva ANSI de transformadores a seco é semelhante à dos transformadores imersos em óleo isolante e o limite mecânico também obedece às mesmas regras mencionadas anteriormente. A Tabela 3.7 apresenta o limite térmico para esse tipo de transformador (IEEE Std. C57.12.59, 2001; IEEE Std. C57.12.01, 2005).

Tabela 3.7 - Limite térmico de transformadores a seco.

\begin{tabular}{|c|c|}
\hline Múltiplo da Corrente Nominal & Tempo (s) \\
\hline 3,50 & 100 \\
\hline 11,20 & 10 \\
\hline 25,00 & 2 \\
\hline
\end{tabular}




\subsection{Considerações Finais}

Este capítulo visou introduzir as curvas de atuação a tempo inverso dos dispositivos de proteção contra sobrecorrente utilizados neste trabalho, e também as características que definem as condições normais e proibitivas de operação dos equipamentos protegidos. Foram apresentadas as regiões de ajuste e de dano dos equipamentos protegidos considerados nesta dissertação. As regiões de ajuste e de dano se aplicam para ajustar os dispositivos de proteção contra curtos-circuitos entre fases (trifásico e bifásico) e contra sobrecarga. No entanto, essas regiões não são necessárias para ajustar a proteção contra curtos-circuitos fase-terra, pois geralmente os níveis de corrente de falta envolvidas nesses casos são inferiores aos observados no caso de faltas entre fases, fazendo com que os critérios de proteção sejam mais simples.

Uma apresentação detalhada de todos os critérios de proteção, tanto para proteção individual dos equipamentos quanto para realizar a coordenação entre os dispositivos, será apresentada no Capítulo 4. 


\section{Capítulo 4}

\section{Critérios de Coordenação da Proteção e Seletividade}

Uma vez apresentados os dispositivos de proteção e os equipamentos a serem protegidos no Capítulo 3, este capítulo apresenta os critérios de proteção usados no trabalho para ajustar os dispositivos de proteção de cada equipamento e os critérios empregados para coordená-los. Todos os critérios de proteção utilizados neste trabalho são recomendados pela norma IEEE Std. 242 (2001).

Antes de proceder à determinação dos ajustes dos dispositivos de proteção contra sobrecorrente é necessário realizar um estudo de curto-circuito para calcular todas as correntes de falta de interesse. Portanto, antes de abordar em detalhes os critérios de proteção, será apresentada uma breve descrição das correntes de curto-circuito a serem consideradas no ajuste dos dispositivos de proteção contra sobrecorrente.

\subsection{Correntes de Curto-Circuito}

Os tipos de curto-circuito que podem ocorrer nos sistemas elétricos são o curtocircuito trifásico, bifásico (fase-fase), bifásico-terra (fase-fase-terra) e monofásico (fase-terra). Pode haver uma impedância entre o ponto de defeito e a terra, conhecida como impedância de 
falta, a qual limita o valor da corrente de curto-circuito quando comparada ao valor da corrente de um curto-circuito franco ou sólido, ou seja, sem impedância de falta. Normalmente, a intensidade da corrente devido a um curto-circuito trifásico é muito maior do que as intensidades associadas aos curtos-circuitos bifásico e bifásico-terra, as quais, por sua vez, são maiores do que a corrente de curto-circuito fase-terra. No entanto, existem alguns casos em que a corrente de curto-circuito devido a uma falta monofásica é igual ou ligeiramente maior do que a de um curto-circuito trifásico. Isso pode acontecer quando o curto-circuito monofásico ocorrer no lado de baixa tensão de um transformador conectado em delta-estrela com neutro solidamente aterrado (IEEE Std. 242, 2001). Em linhas gerais, para coordenar dois dispositivos de proteção contra sobrecorrente, utilizam-se os valores de corrente correspondentes ao curto-circuito mais severo, ou seja, o curto-circuito trifásico ou, quando for o caso, o fase-terra. Este procedimento garante a coordenação entre dois dispositivos de proteção para uma larga faixa de correntes de curto-circuito.

É bem conhecido que a corrente de curto-circuito é composta de dois componentes (STEVENSON Jr., 1978; IEEE Std. 242, 2001):

- Um componente de corrente alternada simétrica de curto-circuito;

- Um componente de corrente contínua (componente CC) cujo valor inicial é elevado, mas diminui gradativamente ao longo do tempo.

O valor do componente CC é fortemente relacionado ao instante de ocorrência do curto-circuito e à relação entre a resistência e reatância equivalentes do circuito em relação ao ponto em que ocorre a falta. Logo, para os estudos de proteção, convém admitir que o componente CC é máximo, a fim de que os resultados do estudo estejam a favor da segurança. A taxa de decrescimento do componente $\mathrm{CC}$ depende da relação entre a resistência e a reatância do circuito equivalente calculada a partir do local de ocorrência do curto-circuito (STEVENSON Jr., 1978; IEEE Std. 242, 2001). Além disso, ela também depende da natureza 
da fonte. Geradores e motores síncronos, devido ao seu sistema de excitação controlado, conseguem impor um decaimento gradual à medida que o curto-circuito persiste. Por outro lado, motores de indução contribuem para a corrente de curto-circuito somente nos instantes iniciais, sendo que seu valor rapidamente cai a zero após esse instante. Neste contexto, podese dividir a corrente de curto-circuito em três partes, relacionadas a seguir por ordem de magnitude decrescente:

- Corrente subtransitória: valor eficaz da corrente de curto-circuito inicial;

- Corrente transitória: valor eficaz da corrente de curto-circuito calculado alguns ciclos após a ocorrência do curto-circuito. O instante no qual ela é calculada varia conforme o método do cálculo de curto-circuito. Neste trabalho, o programa DIgSILENT PowerFactory será utilizado para efetuar os cálculos de curto-circuito e nele a corrente transitória de curto-circuito é calculada considerando 100 ms após a incidência do defeito (DIgSILENT, 2009);

- Corrente permanente: valor eficaz da corrente de curto-circuito após o decaimento completo do componente contínuo. Seu valor pode ser da mesma ordem de grandeza da corrente nominal do circuito elétrico ou equipamento protegido e normalmente não é utilizada para definir os ajustes dos dispositivos de proteção contra sobrecorrente.

O valor máximo da corrente subtransitória é utilizado para ajustar e avaliar a resposta de dispositivos com atuação instantânea, como os fusíveis, disjuntores de baixa tensão e relés equipados com elementos de atuação instantânea.

O valor máximo da corrente transitória é utilizado para coordenar os dispositivos de proteção quando pelo menos um deles possui atuação temporizada, seja por tempo definido ou por curva a tempo inverso. 
A fim de avaliar a sensibilidade dos dispositivos de proteção deve ser usado o valor eficaz da mínima corrente de curto-circuito estimada para o sistema elétrico sob análise. Não existe um procedimento padrão para determinar a mínima corrente de curto-circuito (IEEE Std. 242, 2001) e neste trabalho admite-se que essa corrente corresponde à calculada para um curto-circuito bifásico sem impedância de falta, desprezando os motores de indução. Este é um procedimento aceitável, pois leva a valores de correntes de falta com intensidade muito inferior à intensidade da corrente para um curto-circuito trifásico franco.

\subsection{Proteção Individual dos Equipamentos}

Nesta seção serão definidos todos os critérios de proteção utilizados no ajuste das proteções individuais de cabos, motores de indução e transformadores.

\subsection{1 $\underline{\text { Cabos }}$}

Não existem critérios rígidos para definir os ajustes dos dispositivos de sobrecorrente que protegem os cabos. Os requisitos gerais orientam para que a corrente de ajuste da proteção temporizada deva ser inferior à ampacidade do cabo e que o ajuste de corrente da proteção instantânea deva ser inferior à máxima corrente de curto-circuito que pode fluir no cabo (IEEE Std. 242, 2001). Os valores exatos desses ajustes e do ajuste de tempo da proteção temporizada são definidos em função da coordenação com outros dispositivos de proteção a jusante.

A Figura 4.1 ilustra um exemplo da aplicação em um relé digital com unidades de proteção temporizada e instantânea ajustadas para proteger o cabo. Nota-se que toda curva de proteção (temporizada e instantânea) encontra-se à esquerda da curva de limite térmico. A seta na parte inferior do gráfico indica o valor da máxima corrente de curto-circuito. 


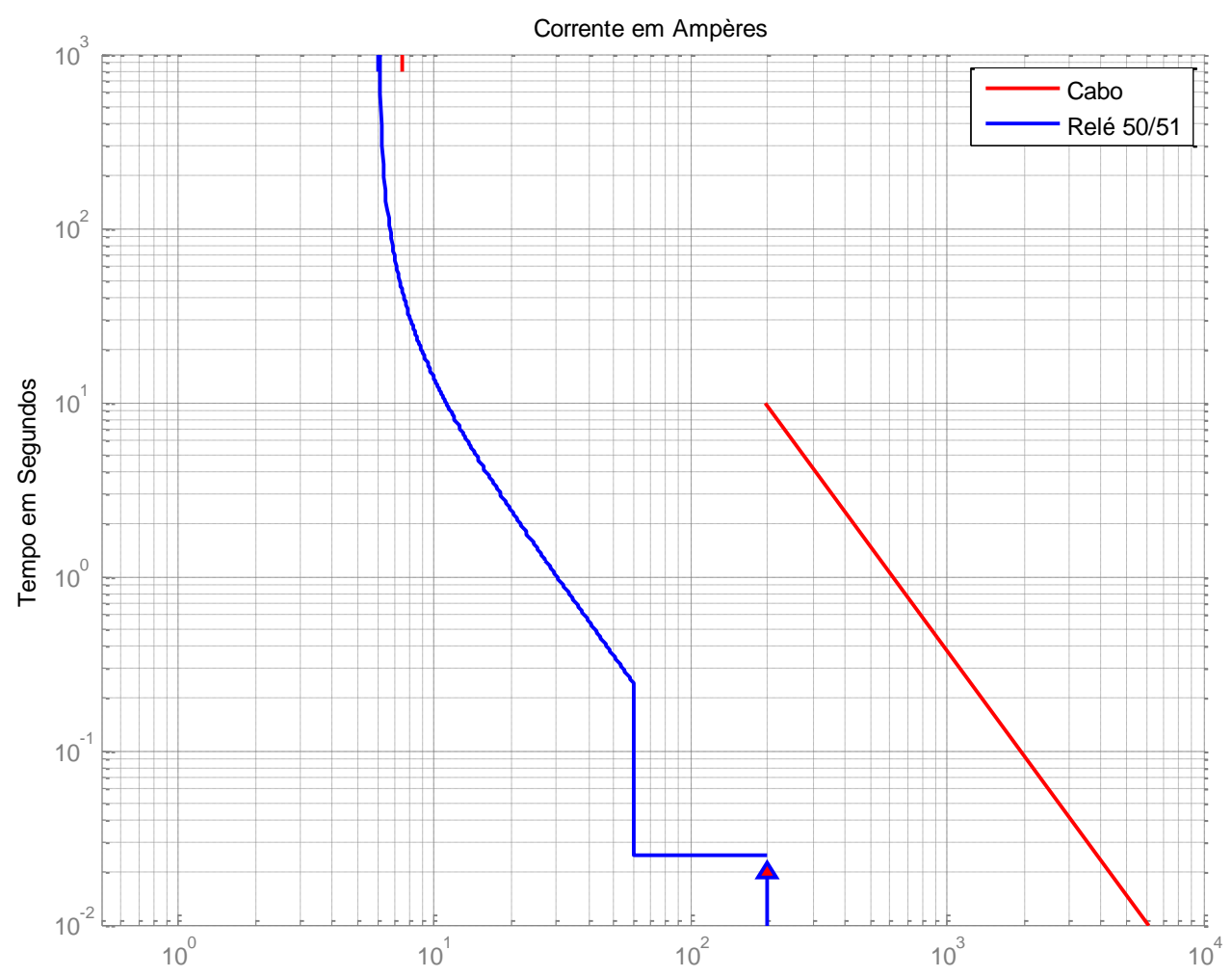

Figura 4.1 - Exemplo de proteção dos cabos realizada por relé 51/50.

\subsubsection{Motores de Indução}

Os ajustes da proteção individual dos motores de indução devem ser realizados tendo como referência sua curva de partida. Neste trabalho está-se considerando que a proteção dos motores de baixa tensão pode ser feita por disjuntores de baixa tensão ou fusíveis, e que a proteção dos motores de média tensão é feita por relés de sobrecorrente com ajustes temporizados e instantâneos ou por relé de sobrecorrente temporizado e fusível. Ressalta-se que pode haver outras combinações de dispositivos de proteção para esta finalidade, mas os critérios a serem obedecidos são os mesmos apresentados nesta seção. Esses outros dispositivos podem ser os seguintes (IEEE Std. C37.96, 2000; IEEE Std. 242, 2001):

- Motores de baixa tensão: combinação de relé térmico e disjuntor de baixa tensão com unidade instantânea, somente. Esta combinação não foi 
explicitamente tratada neste trabalho porque sua modelagem computacional se assemelha à do disjuntor de baixa tensão previamente apresentada;

- Motores de média tensão: alguns relés específicos para a proteção de motores fornecem, além das curvas de proteção padronizadas, curvas especiais para a proteção contra sobrecarga baseada na imagem térmica do motor.

Os critérios de proteção utilizados neste trabalho são apresentados a seguir e são aplicáveis tanto aos motores de baixa tensão quanto aos de média tensão:

- O ajuste de corrente da unidade de sobrecorrente temporizada do relé ou da unidade de tempo longo do disjuntor de baixa tensão deve ser admitido em $105 \%$ da corrente nominal do motor já considerando o fator de serviço do motor, se houver. Essa margem de $105 \%$ foi admitida como fator de segurança neste trabalho. Qualquer que seja a curva escolhida para o relé ou para o disjuntor de baixa tensão, a mesma não deve interceptar a curva de partida da máquina e tampouco se situar acima do tempo de rotor bloqueado. Admitiu-se uma margem de segurança de 2 a 10 segundos além do tempo de partida do motor. Esta margem mínima de 2 segundos é desprezada somente no caso de disjuntor de baixa tensão, quando o tempo de rotor bloqueado estiver situado dentro da faixa de tolerância da curva do disjuntor. Neste caso, a borda inferior da curva, não deve interceptar a curva de partida do motor. Caso a margem de 2 segundos seja desprezada e mesmo assim o tempo de rotor bloqueado continue dentro da faixa de imprecisão da curva do disjuntor, o ajuste será considerado aceitável, pois mesmo com essa violação o motor estará parcialmente protegido. Recomenda-se, entretanto, a adequação dos dispositivos de proteção nesses casos. Por questão de simplicidade, a unidade 
de tempo curto do disjuntor pode ser ajustada no mesmo valor da unidade instantânea, caso o modelo do disjuntor utilizado permita;

- As unidades de sobrecorrente instantânea do relé e do disjuntor de baixa tensão devem ser capazes de atuar para curtos-circuitos severos. No entanto, não podem atuar na partida da máquina. Para tanto, devem ser ajustadas em um valor de corrente superior ao valor assimétrico da corrente de partida do motor, que pode variar de $165 \%$ a $250 \%$ do valor eficaz simétrico da corrente de partida. O valor típico utilizado é 176\% (IEEE Std. 242, 2001), contudo para dispositivos de proteção insensíveis aos valores de pico da corrente e com filtro de componente contínuo, pode-ser admitir uma margem menor. Neste trabalho, admite-se que o ajuste de corrente da unidade instantânea do relé de sobrecorrente é $165 \%$ da corrente de partida, valor eficaz simétrico. Para fusíveis e disjuntores de baixa tensão, o fator de 176\% será empregado;

- A unidade de sobrecorrente de terra do relé ou disjuntor de baixa tensão deve ser ajustada de modo que a proteção seja sensível o suficiente para detectar curtos-circuitos fase-terra, porém não deve operar na operação normal do motor ou durante sua energização. Por esse motivo, admitiu-se um valor da corrente de ajuste de $10 \%$ da corrente nominal do TC, no caso de a proteção ser feita por relés de sobrecorrente. Este valor foi escolhido como fator de segurança para que a corrente de ajuste seja superior à corrente devida ao erro nominal dos TCs, o qual é $10 \%$ na maioria dos TCs de proteção. Neste trabalho, padronizou-se que as curvas de proteção das unidades de proteção contra curtos-circuitos fase-terra sejam do tipo tempo definido, a fim de prover uma rápida atuação e devido à simplicidade de ajuste. Como tempo de ajuste, definiu-se o valor de $100 \mathrm{~ms}$ para que a proteção não atue no caso de 
transitórios rápidos que provoquem desequilíbrios de corrente. Em Hewitson et al. (2004) recomenda-se que os valores de ajuste de corrente e de tempo devam ser os mínimos que o relé permita, no entanto esta recomendação não será seguida, a fim de tornar o sistema de proteção confiável, mas ainda rápido. Em relação aos disjuntores de baixa tensão, não há um critério específico para o ajuste da unidade instantânea - apenas recomenda-se configurar para os mínimos valores possíveis do dispositivo de proteção. Neste trabalho, inicialmente serão admitidos os valores de $10 \%$ da corrente nominal do disjuntor, com tempo de atuação de 100 ms e curva a tempo definido. Ressaltase, no entanto, que esses valores foram escolhidos em favor da segurança e que podem ser alterados conforme a experiência do engenheiro de proteção e particularidades do sistema elétrico.

Como exemplo da aplicação dos critérios de proteção anteriores, a Figura 4.2, Figura 4.3 e Figura 4.4 mostram as curvas de proteção das três combinações de dispositivos empregados para a proteção de motores de indução contra curtos-circuitos entre fases. Nessas figuras mostra-se também o valor da máxima corrente de curto-circuito (curto-circuito trifásico), representada por uma seta em azul desenhada na parte inferior do coordenograma, cujo valor é 300 A. Observa-se que todas as curvas de proteção das três figuras permanecem dentro da área de ajuste definida para a proteção de motores. 


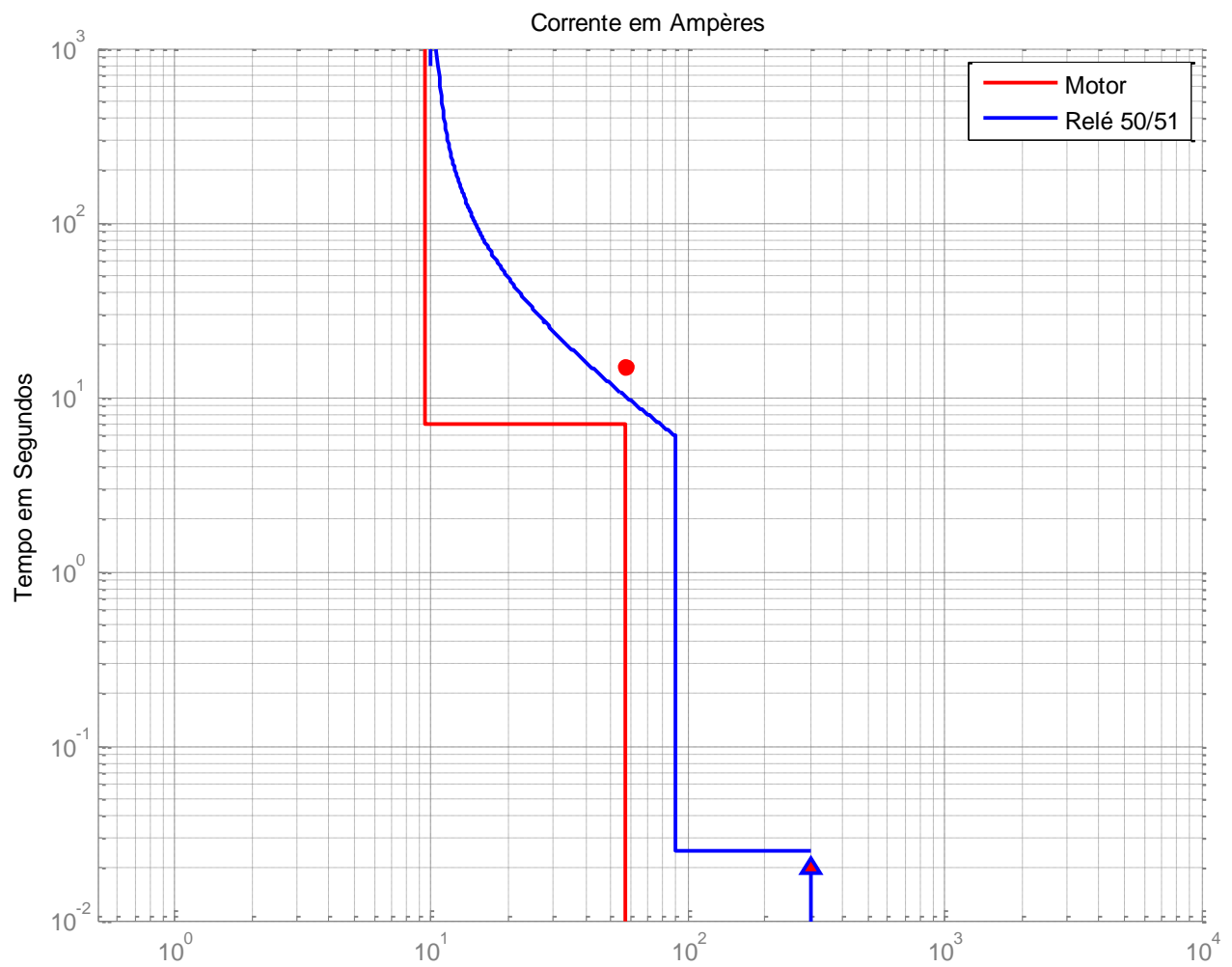

Figura 4.2 - Proteção de motor de média tensão por relé 50 e 51 .

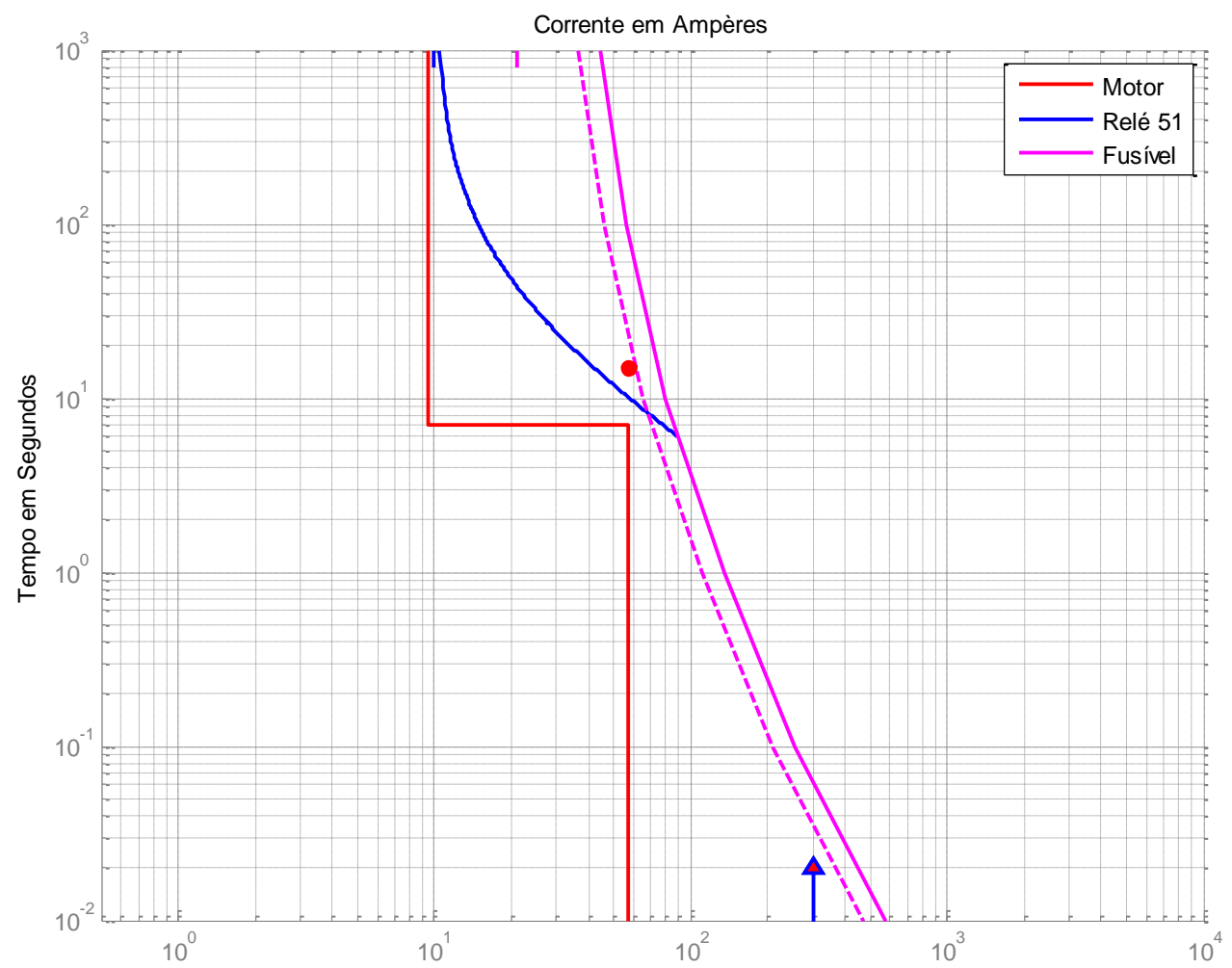

Figura 4.3 - Proteção de motor de média tensão por relé 51 e fusível. 


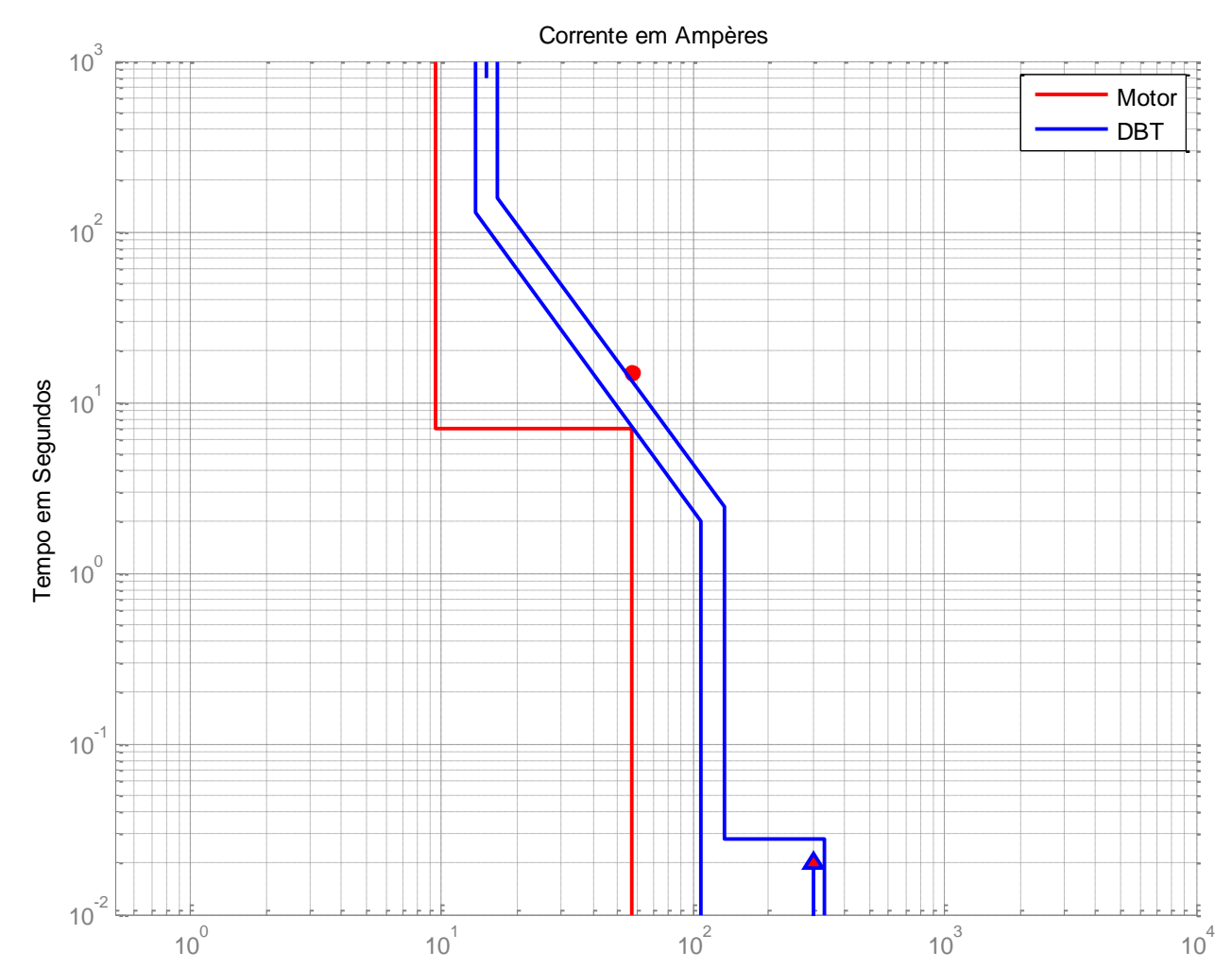

Figura 4.4 - Proteção de motor de baixa tensão por disjuntor de baixa tensão (DBT).

\subsection{3 $\underline{\text { Transformadores }}$}

Os ajustes dos dispositivos de proteção do transformador devem ser definidos de tal forma que as curvas de proteção estejam situadas dentro da região de ajuste. Os critérios são os seguintes (IEEE Std. C57.109, 1993; IEEE Std. 242, 2001; IEEE Std. C57.12.00, 2006):

- Proteção contra sobrecarga: caso haja dispositivo de proteção instalado no lado secundário do transformador, seu ajuste de corrente deve estar entre $125 \%$ e $300 \%$ da corrente nominal do equipamento. Recomenda-se que ele seja ajustado em $125 \%$, se possível, para prover uma proteção mais eficiente contra sobrecarga. Caso não haja dispositivo de proteção no secundário, o dispositivo localizado no primário deve ter sua corrente de ajuste definida entre $125 \%$ e 
$400 \%$ da corrente nominal do transformador. Admite-se que o dispositivo de proteção instalado no lado primário viole a região de dano para pequenos valores de corrente (IEEE Std. 242, 2001). No entanto, para prover uma proteção eficaz, a filosofia adotada neste trabalho estabelece que a curva de proteção do dispositivo localizado no lado primário poderá ultrapassar a curva ANSI no tempo igual a 1000 segundos, até o limite de $+3 \%$ do valor da corrente do limite térmico definida para este tempo. Ressalta-se que para transformadores delta-estrela com neutro solidamente aterrado, utiliza-se a curva ANSI (58\%) como referência. Essa medida é válida, pois, em se tratando de relés digitais, existe uma tolerância nas curvas de cerca de 3\%, como pode ser observado em Schweitzer Engineering Laboratories (2008). Além disso, a adoção dessa tolerância proporciona uma maior flexibilidade à metodologia automática de ajuste, evitando que situações dentro dos limites de tolerância sejam consideradas como inadequadas;

- Proteção contra curtos-circuitos entre fases: o ajuste do dispositivo de proteção do lado secundário do transformador, se houver, deve ter sua unidade de atuação instantânea bloqueada para possibilitar a coordenação com os dispositivos de proteção localizados a jusante do mesmo. O ajuste da proteção instantânea do relé instalado no lado primário do transformador deve ser superior ao valor assimétrico da máxima corrente de curto-circuito no secundário e também da corrente de magnetização. A estimativa do valor de pico dessas correntes será feita, neste trabalho, pela aplicação de fatores de assimetria sobre os valores eficazes, conforme recomendado por normas (IEEE Std. 242, 2001). Caso o dispositivo de proteção seja fusível, o fator de assimetria será $176 \%$ sobre os valores eficazes de ambas correntes. Caso seja 
relé digital, pode-se empregar um menor fator, que neste trabalho será admitido igual a 120\% (CEE RELAYS Ltd., 2009).

- Proteção contra curtos-circuitos fase-terra: em relação ao lado secundário do transformador, só deve haver dispositivo de proteção para enrolamento conectado em Y solidamente aterrado ou aterrado por impedância. Neste caso, adotam-se os mesmos critérios empregados na proteção contra faltas fase-terra do motor, ou seja, corrente de ajuste em $10 \%$ da corrente nominal do TC ou disjuntor e tempo de atuação igual a $100 \mathrm{~ms}$, com curva a tempo definido. Caso o enrolamento primário do transformador seja conectado em delta ou Y com neutro isolado, não é necessário coordenar os dispositivos de proteção contra curtos-circuitos fase-terra do primário com o secundário, pois não haverá circulação da corrente de falta em ambos os relés simultaneamente para faltas fase-terra no secundário do transformador. Logo, aplicam-se os mesmos critérios empregados na proteção do secundário. Por outro lado, caso seja necessário coordenar o relé do primário com o dispositivo de proteção do secundário, também será utilizada curva a tempo definido, corrente de ajuste em $10 \%$ da corrente nominal do TC e tempo de atuação respeitando o intervalo de coordenação apresentado na Tabela 4.1 da seção seguinte.

$\mathrm{Na}$ ocorrência de curtos-circuitos bifásicos no secundário de um transformador deltaestrela, a corrente em uma das fases do lado primário é cerca de $16 \%$ maior do que a corrente que flui no secundário, referida ao primário (IEEE Std. 242, 2001). Por isso, ao se ajustar o elemento temporizado do relé do primário, deve-se, preferencialmente, definir um valor de corrente de ajuste de $116 \%$ do valor da corrente de ajuste do elemento temporizado do dispositivo de proteção do secundário. Para outras conexões dos enrolamentos dos 
transformadores, a corrente de ajuste do elemento temporizado do relé do primário pode ser igual ou superior à corrente de ajuste do dispositivo de proteção do secundário.

A Figura 4.5 apresenta um exemplo de ajuste de relés de sobrecorrente (50/51) localizados no primário e secundário de um transformador delta-estrela com neutro solidamente aterrado. Observa-se que a composição das curvas temporizada e instantânea satisfaz todos os critérios de proteção, ou seja, as curvas estão dentro da região de ajuste definida para transformadores de dois enrolamentos. Ainda nessa figura, observa-se que dois valores de correntes de curto-circuito são apresentados: um valor igual a 550 A e outro igual a 4500 A. O primeiro corresponde à máxima corrente de curto-circuito no secundário do transformador - observa-se que o ajuste do relé instantâneo está ajustado em cerca de $120 \%$ do seu valor. O segundo valor de corrente de curto-circuito corresponde à máxima corrente de curto-circuito que o relé do primário detecta. Finalmente, o ajuste de corrente da curva temporizada do relé do primário é igual a $116 \%$ do ajuste do relé do secundário, conforme recomendam os critérios de proteção para esse tipo de transformador.

Deve-se atentar ao fato de que para selecionar a curva adequada do dispositivo de proteção do secundário do transformador (se houver), é necessário considerar o comportamento da carga que o mesmo alimenta. Por exemplo, se a carga for composta de vários motores, a curva de proteção do dispositivo no lado secundário do transformador deve estar acima do ponto definido pela corrente de partida do maior motor somada à corrente nominal dos demais motores. Isso garante que o dispositivo do secundário do transformador não atuará caso todas as cargas estejam ligadas e ocorra a partida do maior motor. Não há uma regra geral para definição desse critério, visto que existe uma diversidade na operação das cargas conectadas a um barramento, já que as cargas não atingem sua capacidade máxima em um mesmo instante, tampouco todos os motores partirão em um mesmo instante. Logo, 
julga-se que esse critério é adequado e conservador na definição do ajuste de sobrecarga do dispositivo de proteção instalado no lado secundário do transformador.

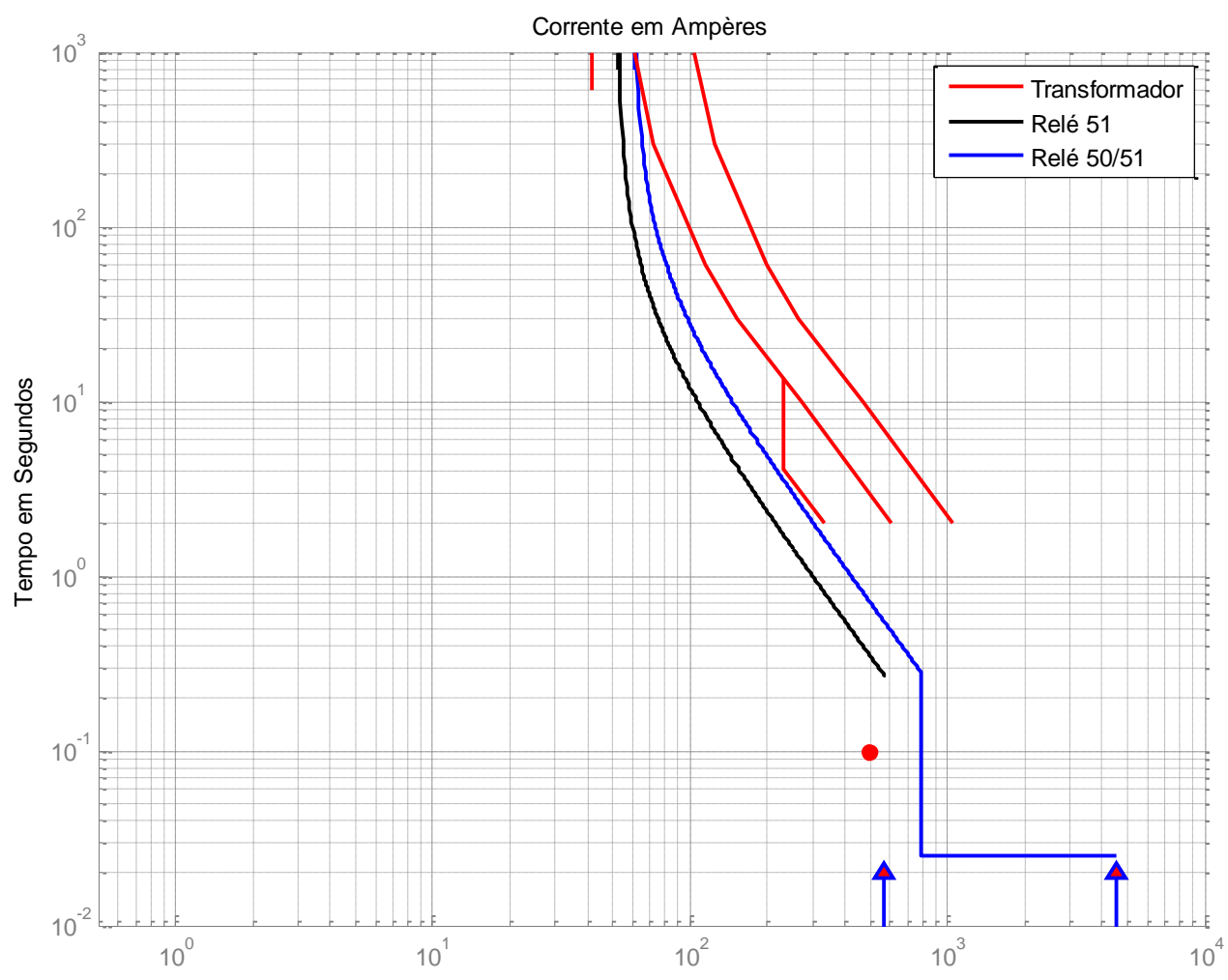

Figura 4.5 - Proteção de transformador de dois enrolamentos realizada por relés 50 e 51.

\subsection{Coordenação da Proteção e Seletividade}

O processo de coordenação dos dispositivos de proteção contra sobrecorrente é iniciado após a determinação das correntes máximas e mínimas de curto-circuito e da determinação das capacidades nominais de todos os equipamentos. Normalmente, inicia-se com a definição dos ajustes das cargas e então se percorre o sistema elétrico em direção à subestação de entrada da indústria, realizando a coordenação entre todos os dispositivos de proteção existentes nesse caminho.

Para definir os critérios de coordenação, deve-se entender o conceito de intervalo de coordenação, o qual está abordado na seção seguinte. 


\subsubsection{Intervalo de Coordenação}

O intervalo de coordenação é o mínimo intervalo de tempo a ser aplicado entre duas curvas de dispositivos de proteção contra sobrecorrente, para que os mesmos estejam coordenados de forma a garantir a seletividade. Ou seja, a proteção mais próxima do defeito deve operar com garantia que o dispositivo de proteção a montante não opere. O intervalo de coordenação depende dos tipos dos dispositivos de proteção. Por exemplo, os tempos de atuação das curvas dos relés não incluem as tolerâncias fornecidas pelo fabricante e nem o tempo de abertura do disjuntor associado. No caso dos fusíveis e disjuntores de baixa tensão, em que as curvas de proteção são representadas por faixas de imprecisão, as tolerâncias e o tempo de abertura (ou fusão no caso de fusíveis) estão considerados.

Para relés digitais, o intervalo de coordenação varia de 200 ms a 300 ms (IEEE Std. 242, 2001). Os responsáveis por esse atraso são os seguintes fatores:

- Tempo de abertura do disjuntor: entre 5 e 8 ciclos (80 ms a $133 \mathrm{~ms}$ );

- Tolerância dos ajustes do relé: 170 ms desprezando a calibração do relé e $120 \mathrm{~ms}$, considerando que o mesmo fora calibrado em campo.

Para relés eletromecânicos, aos fatores anteriores adicionam-se 100 ms referentes ao movimento devido à inércia do disco de indução depois que a sobrecorrente cessa.

A Tabela 4.1 fornece os intervalos típicos de coordenação admitidos. A rigor não é necessário aplicar intervalos de coordenação entre as curvas dos fusíveis e disjuntores de baixa tensão, pois todas as tolerâncias já estão consideradas. No entanto, neste trabalho será admitido um intervalo de coordenação entre esses dispositivos igual a $120 \mathrm{~ms}$, como fator de segurança e um intervalo de $250 \mathrm{~ms}$ quando houver relé a jusante como resultado do somatório dos intervalos de tempo desde a detecção da condição anormal até a devida abertura do disjuntor. 
Tabela 4.1 - Intervalos de coordenação típicos.

\begin{tabular}{|c|c|c|c|}
\hline \multirow{2}{*}{ Dispositivo a jusante } & Fusível & $\begin{array}{c}\text { Disjuntor de baixa } \\
\text { tensão }\end{array}$ & Relé digital \\
\cline { 2 - 4 } & $120 \mathrm{~ms}$ & $120 \mathrm{~ms}$ & $120 \mathrm{~ms}$ \\
\hline Fusível & $120 \mathrm{~ms}$ & $120 \mathrm{~ms}$ & $120 \mathrm{~ms}$ \\
\hline $\begin{array}{c}\text { Disjuntor de baixa } \\
\text { tensão }\end{array}$ & $250 \mathrm{~ms}$ & $250 \mathrm{~ms}$ & $250 \mathrm{~ms}$ \\
\hline Relé digital & &
\end{tabular}

\subsubsection{O Processo de Coordenação}

A aplicação dos critérios de proteção e dos intervalos de coordenação será ilustrada por meio de um exemplo. Considere o trecho de um sistema elétrico apresentado na Figura 4.6 e que as barras B1 e B3 possuem tensões nominais de 13,8 kV e 4,16 kV, respectivamente. $\mathrm{Na}$ primeira está conectado o cabo L1, que por sua vez se conecta ao primário do transformador T1. Este alimenta dois motores de indução trifásicos M1 e M2. Admite-se que o motor M1 tem maior capacidade que M2. Os retângulos em branco apresentados na figura referem-se às posições dos relés R1, R2 e R3. Neste exemplo, por simplicidade, a coordenação será demonstrada com relés de sobrecorrente. No entanto os procedimentos se aplicam aos outros tipos de dispositivos de proteção. Os dados nominais dos elementos desse sistema elétrico são:

- Cabo L1: cabo de cobre com conexões prensadas, seção transversal de $95 \mathrm{~mm}^{2}$, ampacidade igual a 251 A e classe de tensão igual a $20 \mathrm{kV}$;

- Transformador T1: capacidade nominal de 3 MVA, 13,80/4,16 kV, com impedância percentual igual a 7,61\%;

- Motor M1: potência mecânica igual a $450 \mathrm{~kW}$, tensão igual a 4,16 kV, rendimento igual a $90 \%$, fator de potência nominal de 0,91 , fator de serviço igual a 1, tempo de aceleração igual a 7 segundos, tempo de rotor bloqueado 
igual a 15 segundos e corrente de partida igual a 6 vezes a corrente nominal do motor;

- Motor M2: potência mecânica igual a $355 \mathrm{~kW}$, tensão igual a 4,16 kV, rendimento igual a 93\%, fator de potência nominal de 0,91 , fator de serviço igual a 1, tempo de aceleração igual a 6 segundos, tempo de rotor bloqueado igual a 10 segundos e corrente de partida igual a 6 vezes a corrente nominal do motor.

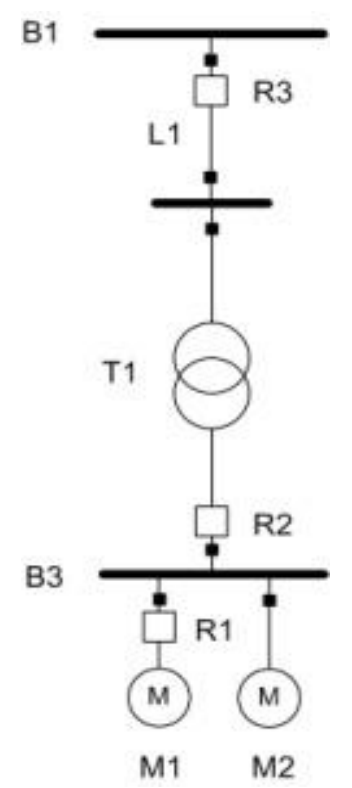

Figura 4.6 - Sistema elétrico teste.

Os procedimentos apresentados a seguir referem-se à coordenação do relé de proteção do motor M1 com os outros relés a montante. Em uma situação prática, os ajustes de todas as cargas do barramento devem ser analisados.

1. Iniciando da barra de carga - B3 - ajustam-se os dispositivos de proteção de todas as cargas. Neste exemplo, as proteções de sobrecorrente do motor M1 serão analisadas. Seu esquema de proteção é composto por relé digital multifuncional com as unidades temporizada (51), instantânea (50) e temporizada de neutro (51N). Os TCs utilizados neste exemplo são de 100/5A e 50/5A para as proteções de fase e de terra, respectivamente. Os ajustes das funções de proteção 51 e 50 do relé motor são apresentados na Figura 4.7. 
Observa-se que todos os critérios de proteção apresentados nas seções anteriores foram aplicados. O encontro da curva de proteção temporizada com a instantânea define o “joelho" da curva de proteção. Este novo elemento será de grande importância para coordenar os relés de proteção do motor M1 com os relés a montante. Neste trabalho, a escolha da curva de atuação do relé 51 do motor, quando não especificada, é feita considerando aquela que intercepta a curva de proteção instantânea no menor tempo possível, respeitando a margem mínima de 2 segundos do tempo de aceleração. Observase ainda que a máxima corrente de curto-circuito trifásico é da ordem de $5000 \mathrm{~A}$, significando que o elemento instantâneo do relé conseguirá detectar uma larga faixa de correntes de defeito. O ajuste para proteção fase-terra é apresentado na Figura 4.8, seguindo os critérios das seções anteriores, ou seja, corrente de partida ajustada em $10 \%$ da corrente nominal do TC e curva a tempo definido com temporização ajustada em 0,1 segundo;

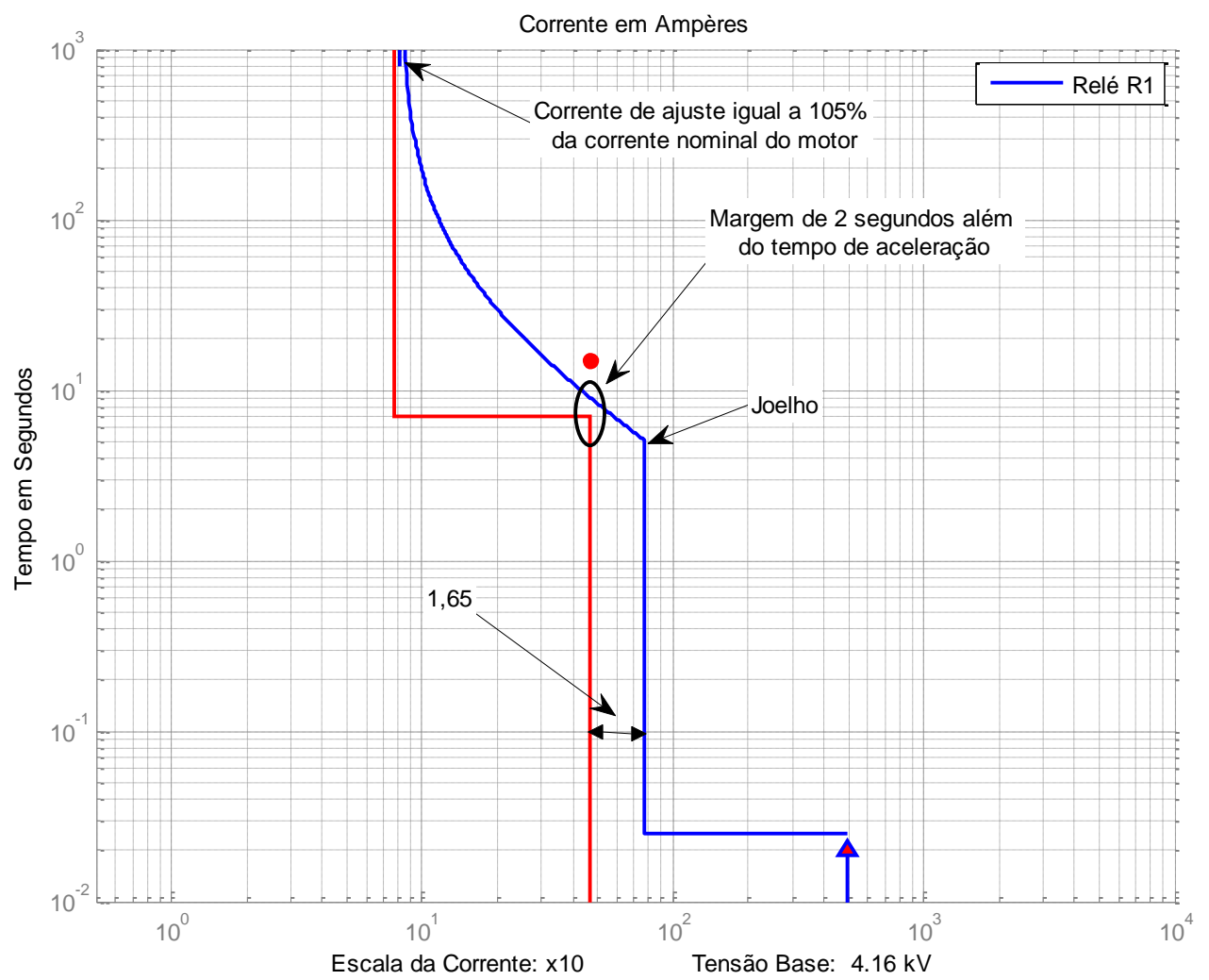

Figura 4.7 - Ajuste das proteções individuais do motor M1 - proteção de fase. 


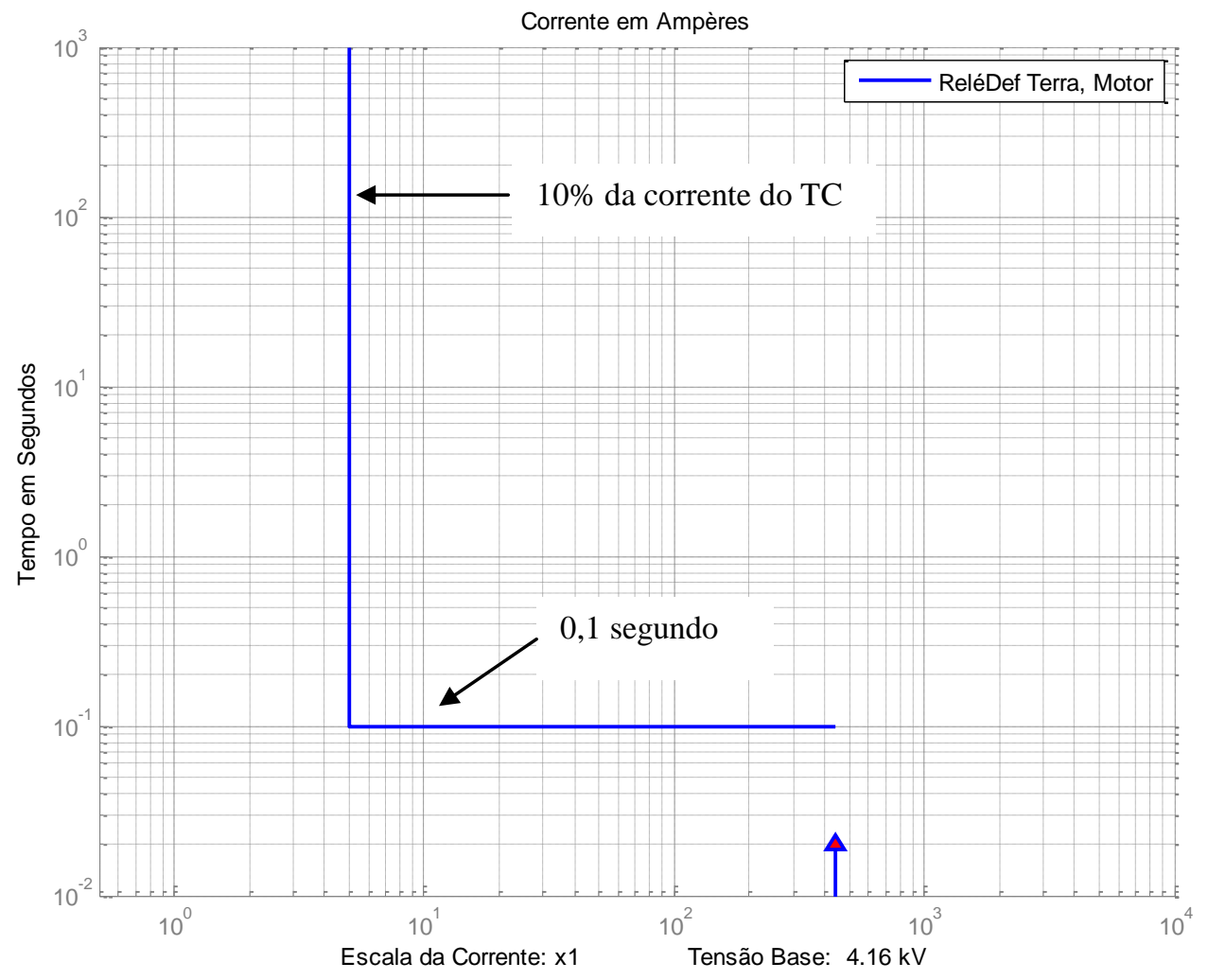

Figura 4.8 - Ajuste das proteções individuais do motor M1 - proteção de neutro.

2. Após ajustar todos os dispositivos de proteção da barra de carga, identifica-se aquele que possui os ajustes mais elevados (normalmente é o que protege a maior carga) para realizar a coordenação com o relé de proteção a montante. No caso deste exemplo, a maior carga é o motor M1;

3. Para determinar o ajuste de corrente do relé 51 instalado no secundário do transformador, deve-se identificar o ponto definido pelo somatório da corrente de partida do maior motor com as correntes nominais das outras cargas e o tempo de aceleração do maior motor ponto identificado em verde na Figura 4.9. Ao tempo de operação da unidade instantânea do relé R1 definido pelo valor da máxima corrente transitória de curto-circuito no motor deve-se adicionar o intervalo de coordenação de $250 \mathrm{~ms}$ para ajustar a unidade temporizada do relé R2. Ao joelho da curva de proteção do relé R1 também se deve adicionar $250 \mathrm{~ms}$ para ajustar a curva de atuação do relé R2. Portanto, para o relé R2 
deve-se escolher uma curva cujo ajuste de corrente seja maior ou igual a $125 \%$ da corrente nominal do transformador e que esteja localizada à direita e acima, porém o mais próximo possível das três referências, ou pontos de decisão, citadas anteriormente: corrente de partida de M1 adicionada às correntes nominais das outras cargas conectadas na barra B2, intervalo de coordenação adicionado ao joelho da curva de proteção do relé R1 e intervalo de coordenação adicionado à operação da proteção instantânea do relé R1 devido à máxima corrente transitória de curto-circuito no motor. Observa-se que aparentemente a curva do relé R2 não está respeitando o intervalo de coordenação com o joelho da curva do relé R1, no entanto há mais de 250 ms entre essas curvas, e não se consegue perceber isso por causa da escala de tempo da ordem de segundos e não milissegundos. Destaca-se que esse nível de precisão na definição dos ajustes é uma grande vantagem do programa de ajuste automático proposto nesta dissertação. Ainda na Figura 4.9 nota-se que o elemento instantâneo do relé R2 não está representado. Na verdade ele deve ser bloqueado para que haja coordenação do relé R2 com o relé R1. Uma vez definido um padrão de curva (ANSI ou IEC) e um tipo (normal inversa, muito inversa etc.) para o dispositivo de proteção do secundário do transformador, recomenda-se selecionar o mesmo padrão e tipo para o relé de proteção a montante dele, com a finalidade de facilitar a coordenação entre os dispositivos. O ajuste da proteção de terra do lado secundário do transformador depende do tipo das conexões do enrolamento. Para este exemplo, o enrolamento secundário do transformador está conectado em estrela com neutro solidamente aterrado. Os ajustes da função de proteção de neutro têm que coordenar com aqueles do relé de proteção a jusante, seguindo o critério de $10 \%$ da corrente do TC, que neste caso é de 50/5A, com curva a tempo definido temporizada em $350 \mathrm{~ms}$. Esses ajustes são apresentados na Figura 4.10. Observa-se que as duas proteções estão no mesmo ajuste de 
corrente, isso acontece porque os TCs correspondentes têm a mesma relação de transformação;

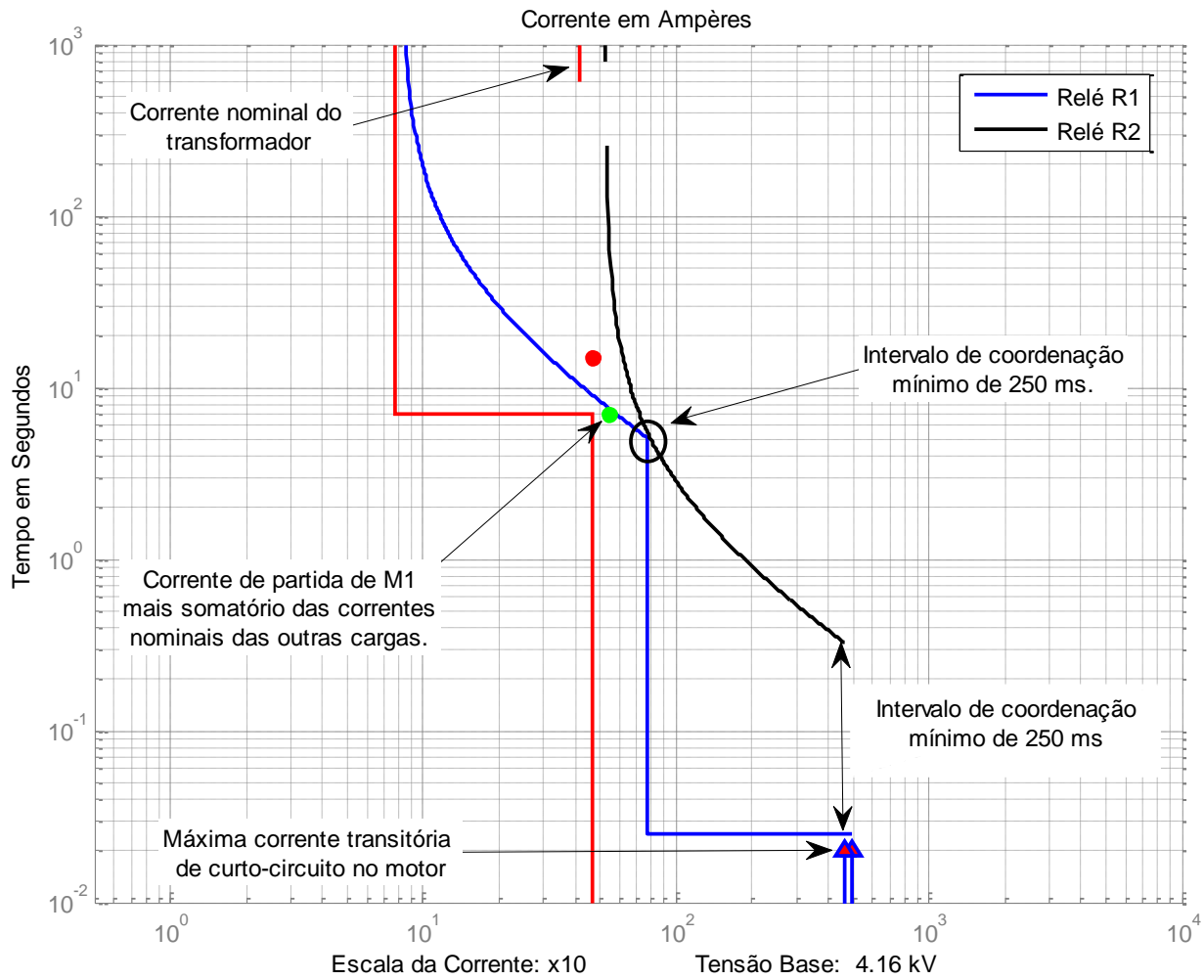

Figura 4.9 - Coordenação do relé R2 com o relé R1 - proteção de fase.

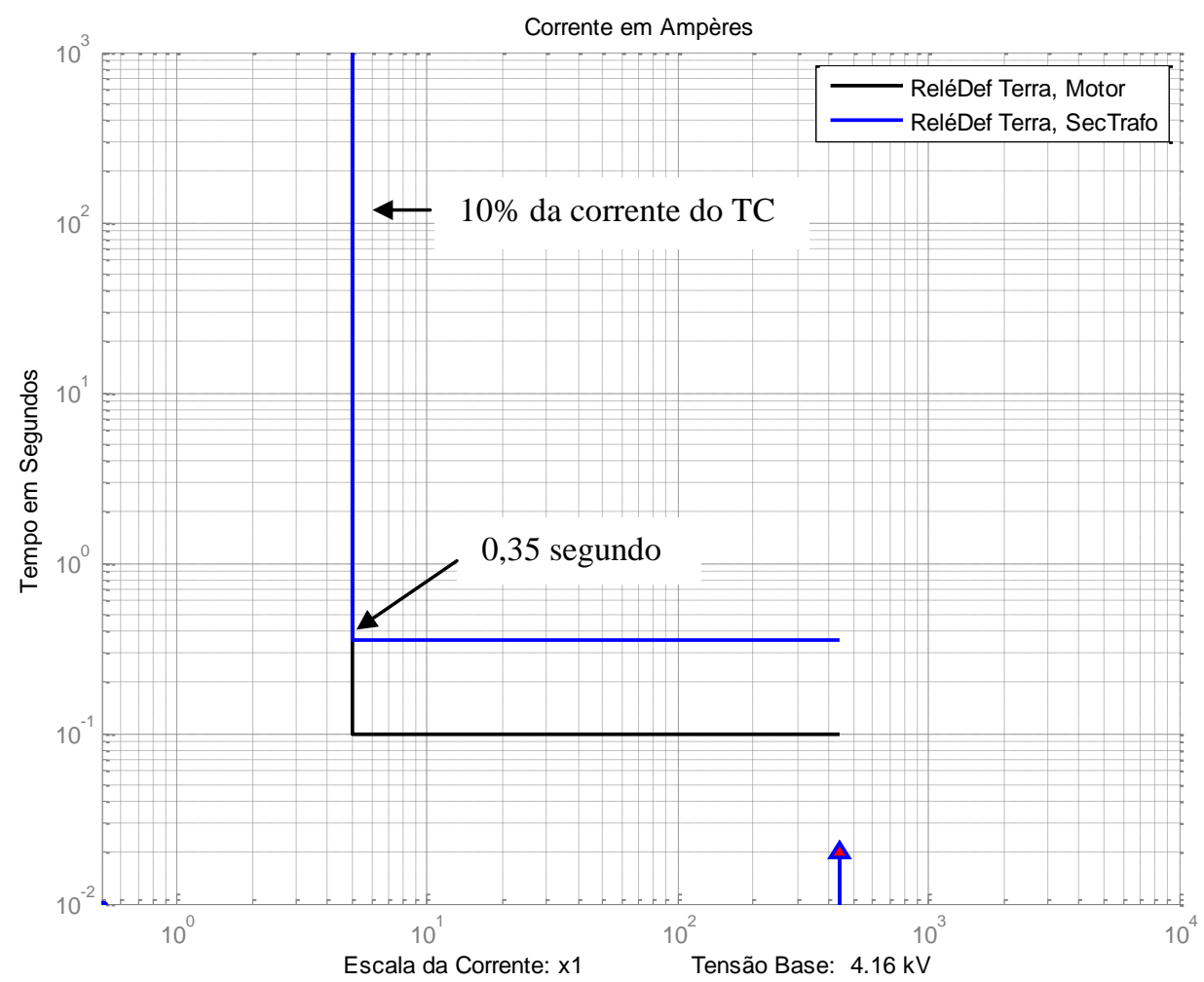

Figura 4.10 - Coordenação do relé $\mathbf{R} 2$ com o relé $\mathbf{R} 1$ - proteção de terra. 
4. O ajuste da unidade temporizada do relé R3, localizado no primário do transformador é calculado inicialmente definindo a corrente de ajuste igual a $116 \%$ do valor ajustado no relé R2, pois o transformador em questão é do tipo delta-estrela. Em seguida, ao tempo de atuação do relé R2 para a máxima corrente de curto-circuito transitório, adiciona-se o intervalo de coordenação de 250 ms, definindo um ponto de referência, e então se ajusta o multiplicador de tempo da curva temporizada do relé R3 para que a mesma esteja imediatamente acima daquele ponto de referência. Esses procedimentos são apresentados na Figura 4.11. Observa-se nesta figura que a unidade instantânea do relé R3 está ajustada em cerca de $125 \%$ da corrente de magnetização do transformador e da máxima corrente subtransitória de curto-circuito no secundário do transformador. Nota-se também que o cabo e o transformador estão adequadamente protegidos. Para proteção de terra do lado primário do transformador, há de se verificar o tipo do enrolamento, o qual está conectado, no exemplo, em delta. Portanto a proteção de terra não precisa coordenar com a proteção a jusante, ficando o ajuste de tempo em 0,1 segundos e corrente de partida a $10 \%$ do TC, que neste caso é de 50/5A. Esses ajustes são apresentados na Figura 4.12.

5. O coordenograma completo com os ajustes das funções de proteção de fase de todos os dispositivos existentes no sistema elétrico da Figura 4.6 é apresentado na Figura 4.13. Não se faz necessário apresentar um coordenograma semelhante para as funções de proteção de neutro, pois a do relé R3 não precisa estar coordenada com a do relé R2, conforme explicado em seções anteriores. 


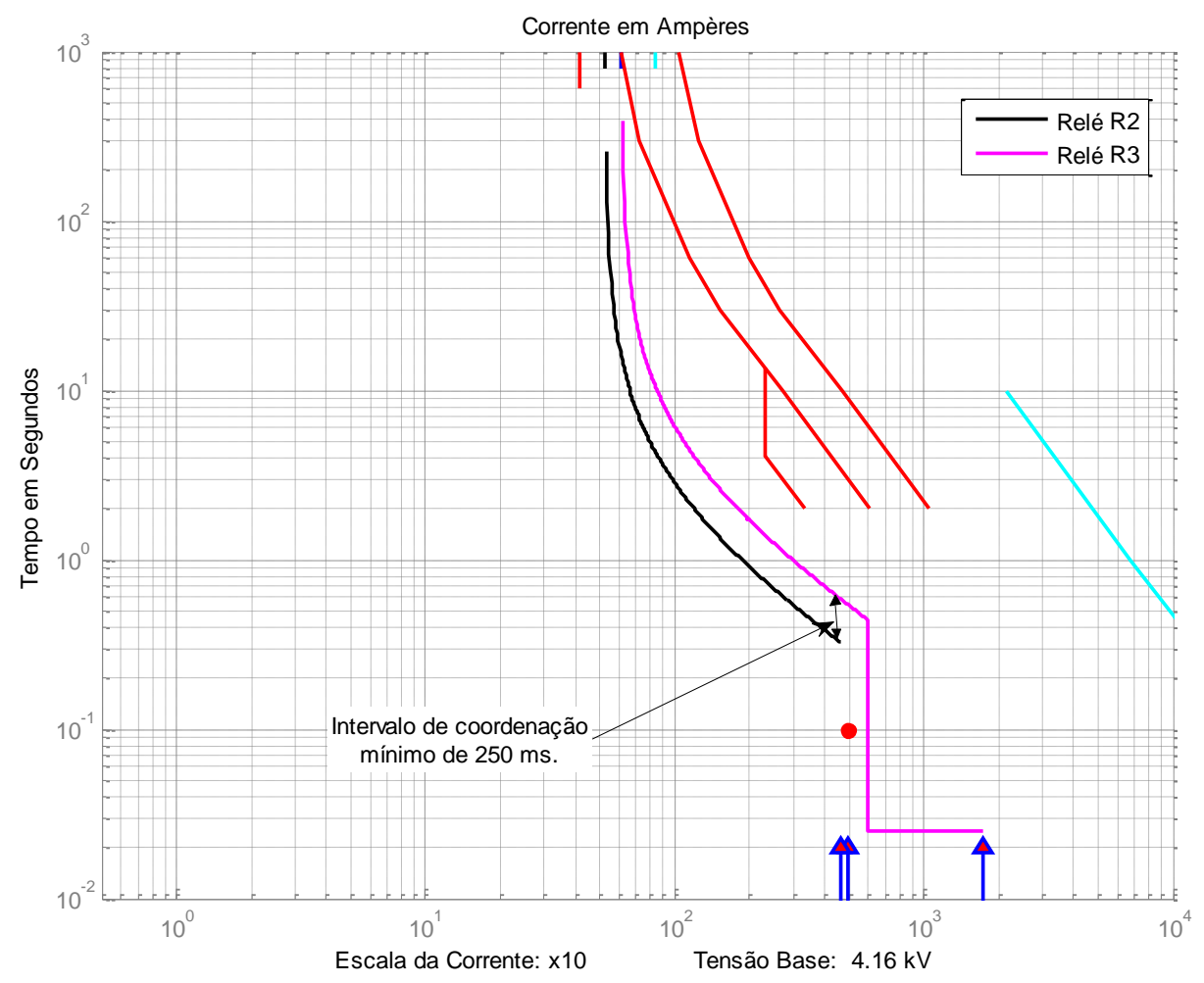

Figura 4.11 - Coordenação do relé $\mathbf{R 3}$ com o relé $\mathbf{R 2}$ - proteção de fase.

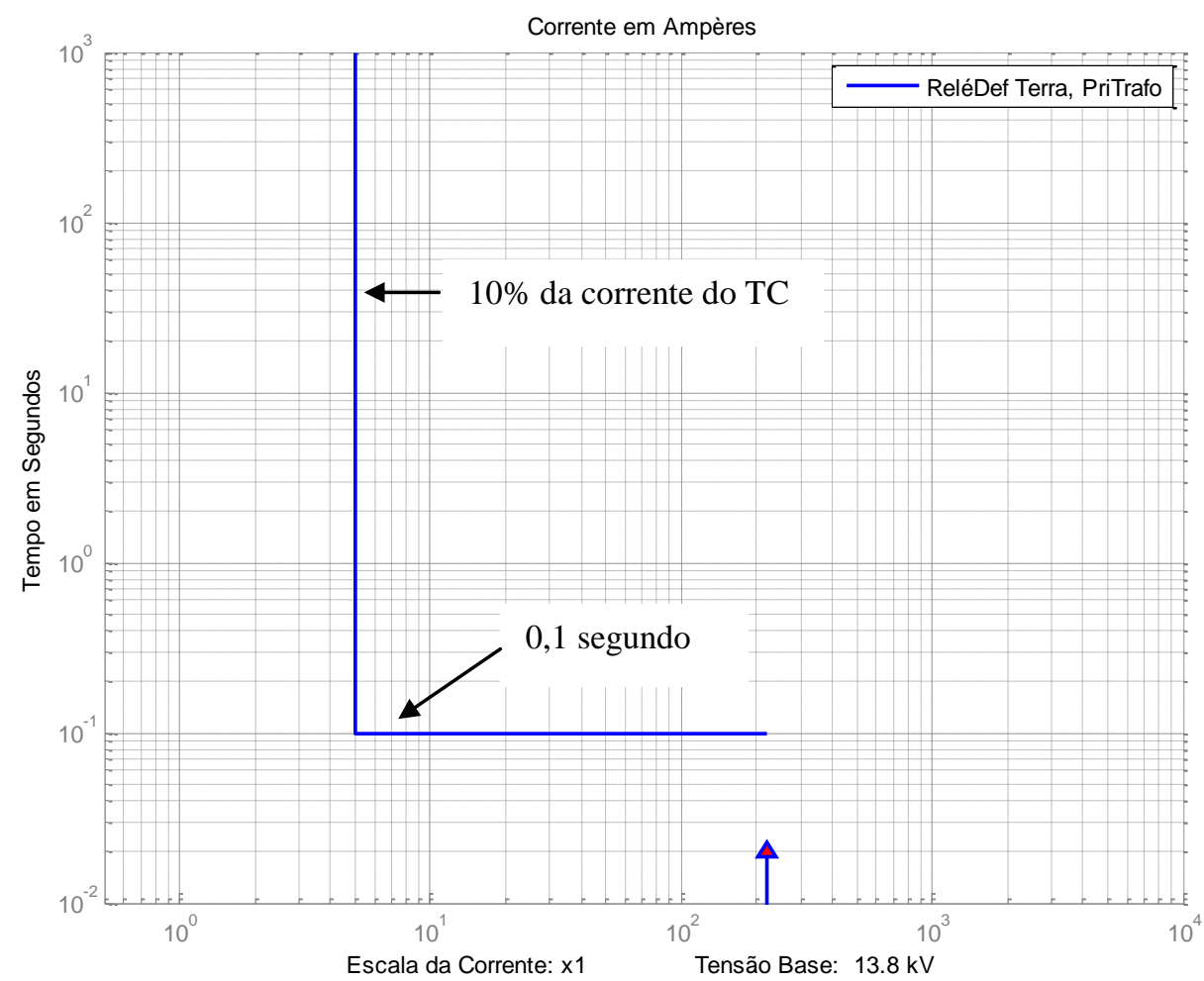

Figura 4.12 - Ajuste da função de proteção de neutro do relé R3. 


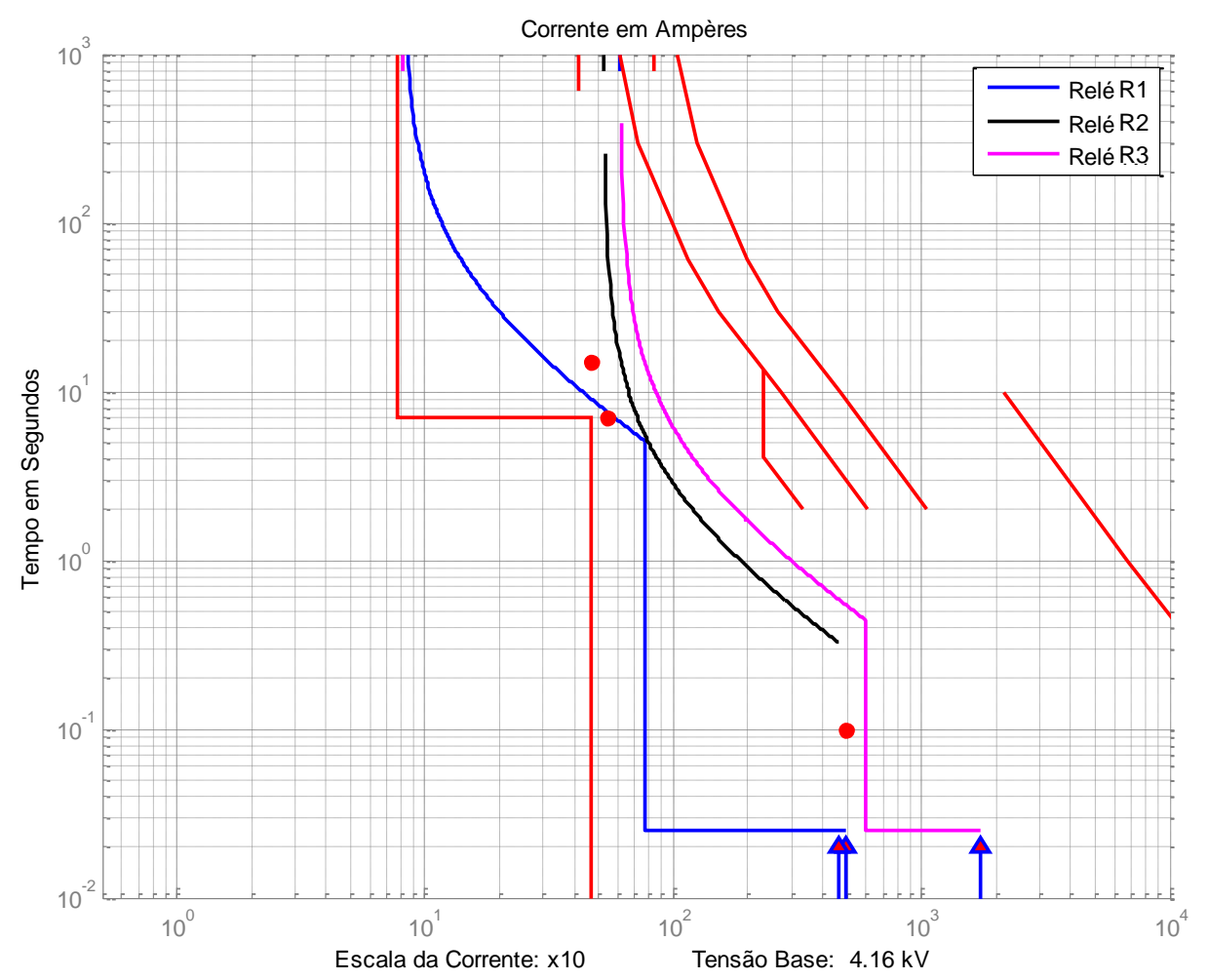

Figura 4.13 - Coordenação entre os relés R1, R2 e R3 - proteção de fase.

O processo de coordenação segue até que todas as cargas sejam analisadas e até chegar ao relé instalado na entrada da indústria (subestação). Um estudo completo de coordenação dos dispositivos de sobrecorrente de fase e de neutro ou terra é apresentado no Capítulo 6.

\subsubsection{Solução de Problemas de Coordenação entre Dispositivos de Proteção}

$\mathrm{Na}$ realização de estudos de coordenação da proteção e seletividade é comum encontrar situações em que a coordenação e seletividade são impossíveis de serem alcançadas, ou são possíveis desde que se permita que as regiões de danos dos equipamentos sejam violadas. Logo, a determinação dos ajustes é uma solução de compromisso entre seletividade e proteção. Neste trabalho, a idéia defendida é a priorização da proteção em detrimento da coordenação e seletividade sempre que necessário. 
Problemas de coordenação e de proteção podem acontecer com dispositivos de curva fixa, ou seja, sem ajustes, como fusíveis e alguns tipos de disjuntores termomagnéticos, na ocasião desses dispositivos não terem sido adequadamente dimensionados e violem a região de dano dos equipamentos protegidos. Em situações desta natureza a estratégia adotada na metodologia proposta consiste em considerar apenas a parte da curva que eficazmente protege o equipamento, desconsiderando para efeito de coordenação o restante da curva. A Figura 4.14 é exemplo desse problema. Nesta figura tem-se um transformador alimentando uma carga em que sua proteção e a proteção do lado secundário do transformador é realizada por disjuntores de baixa tensão, e a proteção do primário por fusível. Observa-se que a curva de proteção do fusível intercepta a curva ANSI do transformador, deixando-o desprotegido para uma faixa de valores de corrente. Neste caso, a recomendação é a substituição do fusível por relé de sobrecorrente ou por outro cuja curva de proteção se adéquie ao transformador. Neste trabalho, a metodologia proposta não prevê a substituição de dispositivos de proteção, portanto situações desse tipo serão apenas identificadas como casos de perda de coordenação.

Em alguns problemas de coordenação, admite-se que ajustes dos dispositivos de proteção instalados no mesmo ramo sejam feitos iguais. Este procedimento garante rapidez na proteção, caso o dispositivo a jusante falhe. Os dispositivos a serem afetados por essa medida são aqueles instalados nos lados primário e secundário de transformadores e também no início e fim de cabos. Esse procedimento está de acordo com as recomendações de IEEE Std. 242 (2001). 


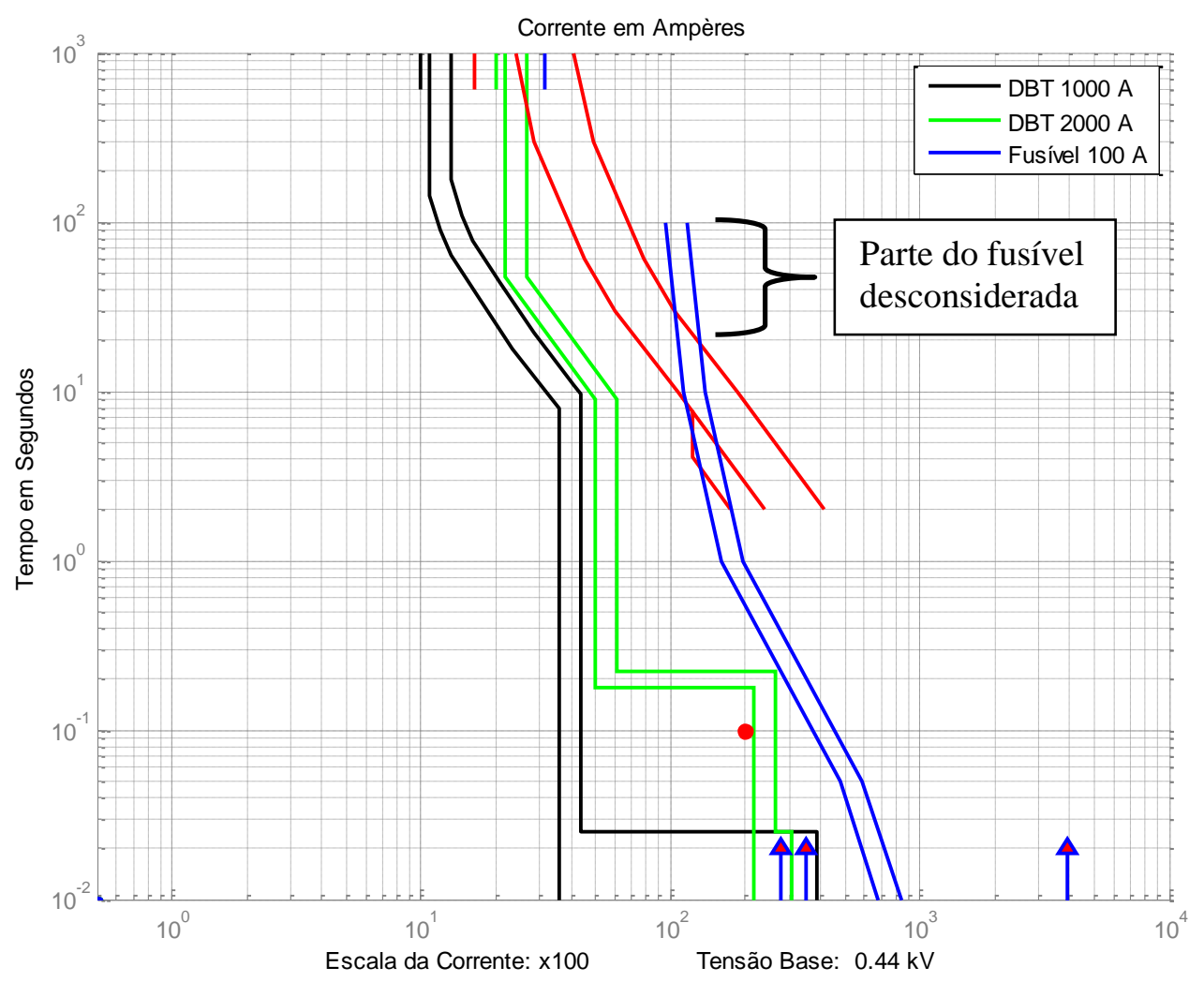

Figura 4.14 - Exemplo de problema de proteção

Finalmente, um ponto que merece atenção se refere aos ajustes do relé de proteção instalado na entrada da indústria (subestação), os quais são definidos pela concessionária de energia elétrica. Exceto em situações específicas, esses ajustes não podem ser alterados. Esta será a idéia adotada neste trabalho. O método computacional proposto determina um algoritmo de ajuste automático, coordenando todos os dispositivos de proteção desde o mais baixo nível de tensão até o dispositivo de proteção da entrada da indústria. Ao final é verificada a coordenação entre a proteção da entrada da indústria com o primeiro dispositivo da rede. Caso ocorram problemas de coordenação, inicia-se um processo de correção de ajustes aplicando os procedimentos explicados anteriormente, ou seja, os dispositivos de proteção instalados em um mesmo ramo são ajustados nos mesmos valores de corrente e de multiplicador de tempo. Este procedimento está explicado detalhadamente no Capítulo 5. 


\section{Capítulo 5}

\section{Metodologia Proposta}

Este capítulo descreve a metodologia proposta por meio do desenvolvimento de um programa computacional para coordenação automática dos dispositivos de proteção de sistemas elétricos industriais radiais. O programa foi estruturado na forma de diagrama de blocos, conforme ilustra a Figura 5.1. De maneira sucinta, cada um dos blocos será apresentado a seguir e, nas seções subseqüentes, eles serão descritos em detalhe.

- Dados dos Equipamentos: características dos equipamentos do sistema elétrico industrial, bem como sua configuração topológica. Esses equipamentos são barras, terminais, cabos, transformadores e motores;

- Tratamento de Dados: a partir dos dados de entrada dos equipamentos, este bloco calcula as correntes nominais dos equipamentos, correntes de partida dos motores, correntes de magnetização dos transformadores e curvas de danos. Essas informações serão utilizadas para a definição das regiões de dano e de ajuste dos equipamentos;

- Verificação de Consistência dos Equipamentos: o algoritmo desenvolvido verifica se há equipamentos desconectados, formando ilhas. Em caso positivo, uma mensagem de erro é fornecida ao usuário, e o programa tem sua execução interrompida; 
- Cálculo de Curto-Circuito: as correntes de curto-circuito importantes ao estudo de coordenação da proteção e seletividade são fornecidas ao programa por meio de arquivo no modo texto. Elas são calculadas por outro programa computacional - o DIgSILENT PowerFactory - conforme será explicado posteriormente;

- Dados dos Dispositivos de Proteção: informações sobre os dispositivos de proteção. Neste bloco estão contemplados os TCs, relés, disjuntores de baixa tensão e fusíveis. Há informações sobre os tipos de curvas disponíveis, as faixas de ajuste dos elementos temporizado e instantâneo (quando aplicáveis) e sua localização;

- Verificação de Consistência dos Dados dos Dispositivos: nesta etapa do programa, o algoritmo analisa se há equipamentos sem dispositivos de proteção associados. Em caso positivo, a execução do programa é interrompida;

- Ajustes: este é o principal bloco do programa, em que é executado o algoritmo de definição automática dos ajustes dos dispositivos de proteção, respeitando os critérios de proteção individual e coordenada dos equipamentos.

- Saída dos Resultados: ao final do programa todos os ajustes dos dispositivos são salvos numa tabela em um arquivo-texto e em forma gráfica, por meio dos coordenogramas.

A Figura 5.2 mostra um diagrama de blocos em que todos os arquivos de entrada de dados e as formas de saída dos resultados são apresentados. Como pode ser observado, o programa necessita de sete arquivos de entrada de dados: Motores, Trafos, Cabos, CCCs (Correntes de Curtos-Circuitos), Relés, DBTs e Fusíveis, os quais correspondem às informações de motores de indução, transformadores, cabos, correntes de curto-circuito, relés, 
disjuntores de baixa tensão e fusíveis, respectivamente. Já a saída do programa consiste em um arquivo texto Ajustes, contendo todos os ajustes dos dispositivos de proteção e Gráficos, representando todos coordenogramas.

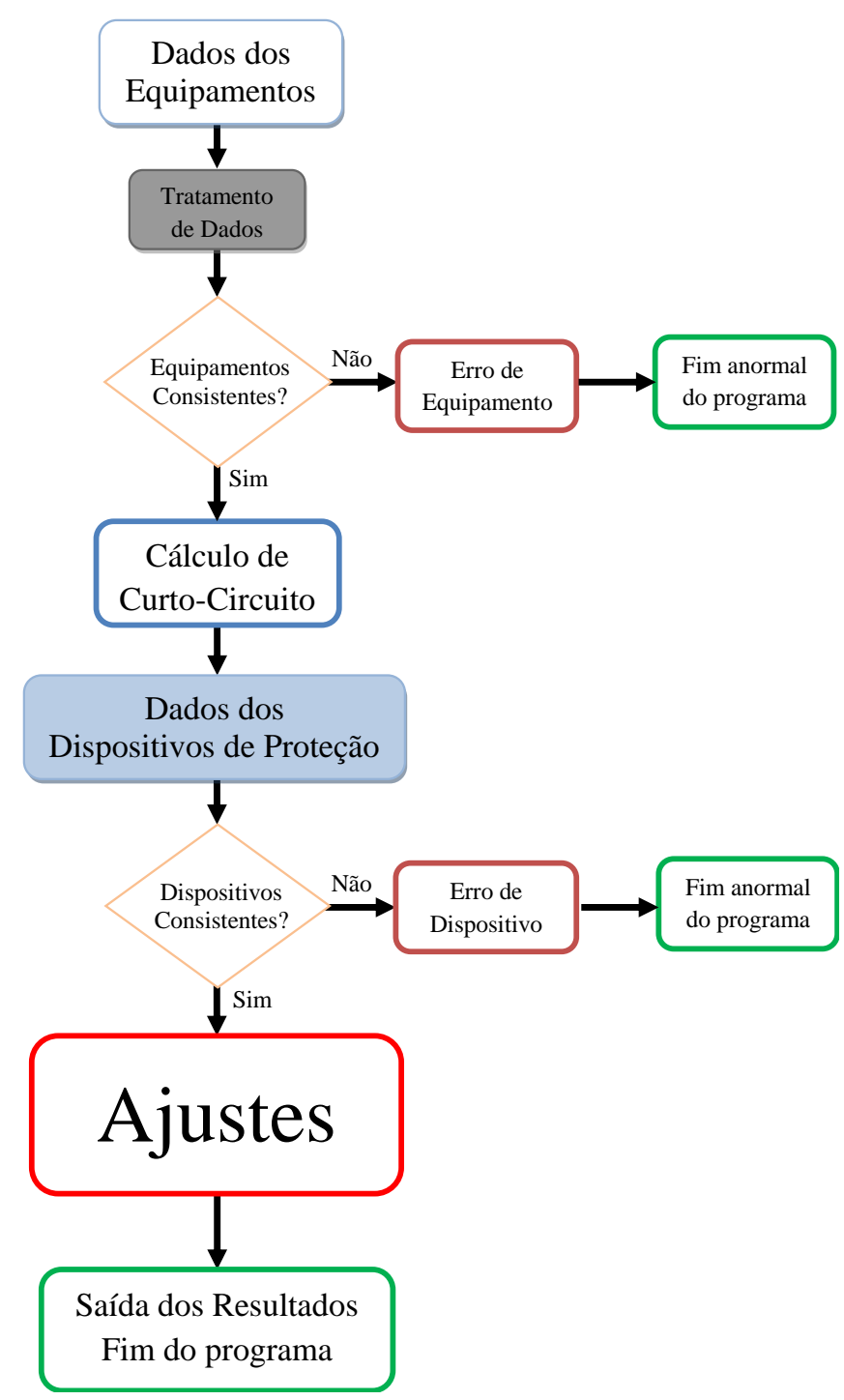

Figura 5.1 - Estrutura do programa.

O programa foi desenvolvido em ambiente Matlab (Mathworks, 2009) para aproveitar as suas facilidades em relação à construção dos coordenogramas, contudo salienta-se que o mesmo foi estruturado de maneira que a transposição para outra linguagem de programação seja um procedimento simples. Por isso, procurou-se empregar o mínimo possível de comandos próprios da linguagem do Matlab. 


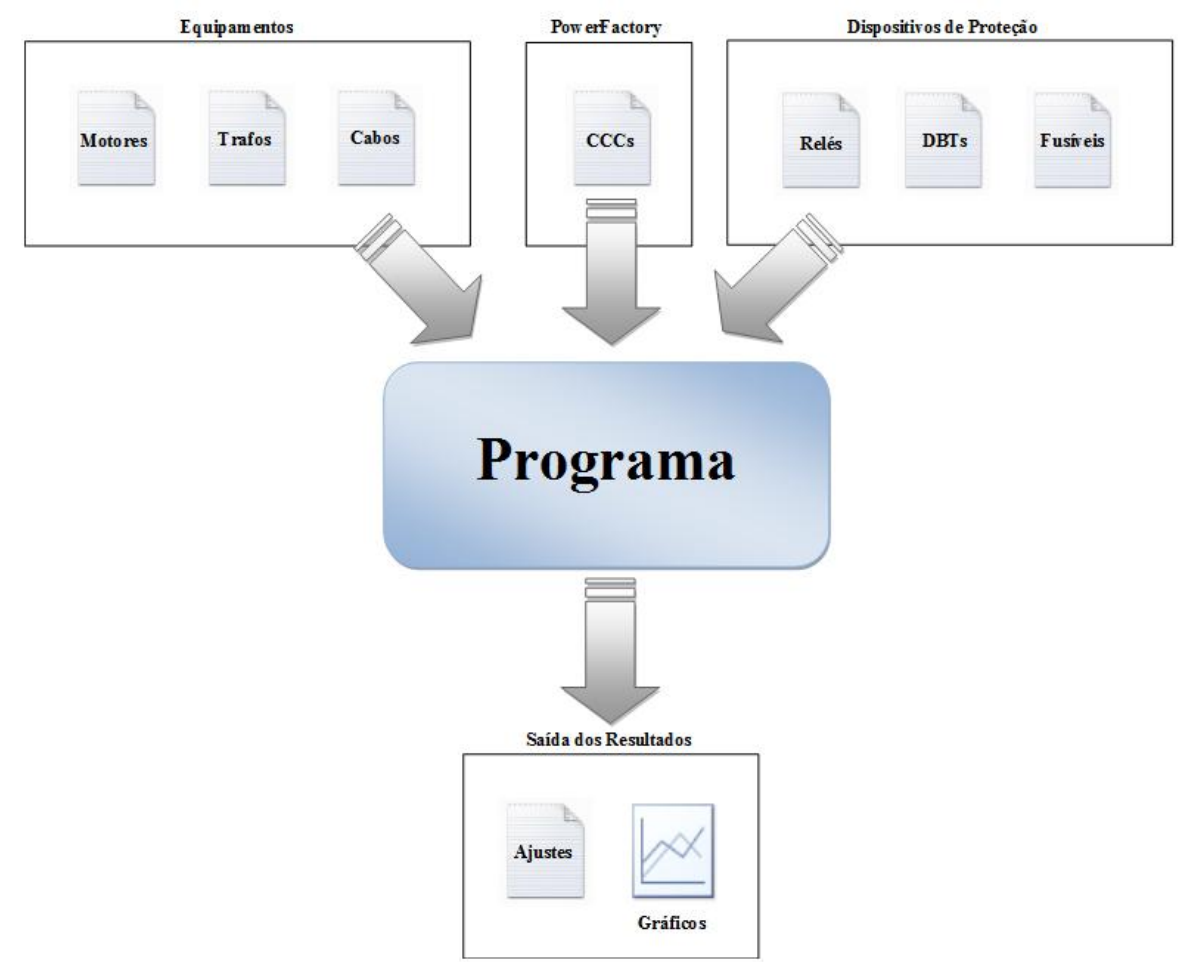

Figura 5.2 - Estrutura geral da entrada de dados e saída de resultados do programa.

\subsection{Dados de Entrada dos Equipamentos}

Os dados de entrada dos equipamentos estão na forma de arquivos-texto tabulados.

Nas subseções seguintes são apresentados os dados necessários e no Capítulo 6 são apresentados os padrões de formatação dos dados.

Os equipamentos utilizados neste trabalho foram: cabos, motores de indução e transformadores, cada qual com suas particularidades, cujas informações foram organizadas em arquivos-texto diferentes. Os dados de cada equipamento necessários para a execução do programa são apresentados a seguir. 


\subsection{1 $\underline{\text { Cabos }}$}

Os dados dos cabos são os seguintes:

- Um índice para a identificação do cabo;

- Número da barra conectada ao início do cabo;

- Número da barra conectada ao final do cabo;

- Tipo de cabo:

○ 1, para cobre.

○ 2, para alumínio.

- Tensão nominal no cabo em kV;

- Número de condutores no cabo;

- Área de seção transversal do condutor, em $\mathrm{mm}^{2}$;

- Temperatura normal de funcionamento, em graus Celsius;

- Temperatura máxima permitida no cabo, em graus Celsius;

- Ampacidade em Ampère;

- Comprimento, em km;

- Impedância (resistência e reatância) de seqüência positiva em $\Omega / \mathrm{km}$.

\subsubsection{Motores}

Para os motores de indução, o usuário deve fornecer os seguintes dados:

- Um índice para identificação do motor;

- O número da barra a qual está conectado;

- Potência nominal em VA;

- Tensão nominal em kV;

- Fator de potência nominal; 
- Fator de Serviço do Motor;

- Múltiplo da corrente nominal para cálculo da corrente de partida;

- Tempo de aceleração do motor, em segundos;

- Tempo de rotor bloqueado do motor, em segundos;

- Margem de segurança sobre o tempo de aceleração, em segundos.

\subsubsection{Transformadores}

Para os transformadores de dois enrolamentos, as informações necessárias são as seguintes:

- Um índice para a identificação do equipamento;

- A barra conectada ao lado primário do transformador;

- A barra conectada ao lado secundário do transformador;

- Tipo de isolação do transformador:

○ 1, para líquido imerso.

- 2, para seco.

- Tipo de enrolamento do lado secundário:

○ 1, delta;

○ 2, estrela;

○ 3, estrela com neutro aterrado por impedância;

- 4, estrela com neutro solidamente aterrado.

- Tipo de enrolamento do lado primário:

○ Mesma codificação do lado secundário.

- Potência nominal em MVA;

- Frequiência estimada para a ocorrência de faltas:

○ 0 para faltas não freqüentes; 
- 1 para faltas freqüentes.

- Tensão do lado primário, em kV;

- Tensão do lado secundário, em kV;

- Multiplicador para obter a corrente de Magnetização;

- Impedância percentual do transformador.

\subsection{Tratamento dos Dados dos Equipamentos}

Uma vez carregados os dados de entrada no programa, procede-se à execução do algoritmo de tratamento dessas informações, conforme apresentado em seguida.

- Cabos: a partir dos dados de entrada calcula-se a ampacidade equivalente, a qual é obtida multiplicando o número de condutores pela ampacidade fornecida nos dados de entrada. Nas fórmulas para a determinação da curva de dano dos cabos (expressões 3.5 e 3.6), multiplica-se o número de condutores pela área de seção transversal de cada um, a fim de considerar cabos compostos por mais de um condutor;

- Motor: a partir dos dados de entrada, são calculadas, para cada motor, a corrente nominal $\left(\mathrm{I}_{\mathrm{N}}\right)$ e a corrente de partida $\left(\mathrm{I}_{\mathrm{P}}\right)$, conforme as expressões $(5.1)$ e (5.2) (SEN, 1997).

$$
\begin{gathered}
I_{N}=F S \times \frac{P_{N}}{\sqrt{3} \times V} \quad \text { Ampère } \\
I_{P}=M \times I_{N} \quad \text { Ampère }
\end{gathered}
$$

Sendo:

FS: Fator de Serviço.

$\mathrm{P}_{\mathrm{N}}$ : Potência nominal, em VA.

V: Tensão de linha nominal, em V.

M: Múltiplo da corrente nominal. 
- Transformador: a partir dos dados de entrada são calculadas, para cada transformador, a corrente nominal $\left(\mathrm{I}_{\mathrm{N}}\right)$, corrente de magnetização $\left(\mathrm{I}_{\mathrm{SH}}\right)$ e obtidas a curva ANSI e a curva de limite mecânico, caso se aplique. A corrente nominal e a corrente de magnetização são calculadas conforme as expressões (5.3) e (5.4) (SEN, 1997), respectivamente.

$$
\begin{gathered}
I_{N}=\frac{P_{N}}{\sqrt{3} \times V} \text { Ampère } \\
I_{S H}=M_{S H} \times I_{N} \quad \text { Ampère }
\end{gathered}
$$

Sendo:

$\mathrm{P}_{\mathrm{N}}$ : Potência nominal, em VA;

V: Tensão de linha nominal, em V;

$\mathrm{M}_{\mathrm{SH}}$ : multiplicador para obter $\mathrm{I}_{\mathrm{SH}}$. Varia entre 8 e 12.

Aplicam-se também, neste módulo do programa, os procedimentos para se obter as curvas ANSI e a curva do limite mecânico, conforme explicado na seção 3.2.3.1.

\subsection{Verificação de Consistência dos Dados dos Equipamentos}

Após o tratamento dos dados dos equipamentos, há a necessidade de verificação de consistência dos dados do sistema elétrico. Logo foi desenvolvido um algoritmo que procura falhas na topologia do mesmo. O algoritmo percorre toda a rede elétrica partindo de cada motor até atingir a barra de entrada da indústria, ou barra da subestação, como esta será referida neste trabalho. Caso o algoritmo encontre trechos isolados do restante do sistema elétrico, ocorre um indicativo de erro e recomenda-se uma revisão dos dados de entrada, pois a metodologia proposta não abrange esses casos. O algoritmo que desempenha esta função está apresentado no fluxograma da Figura 5.3. 


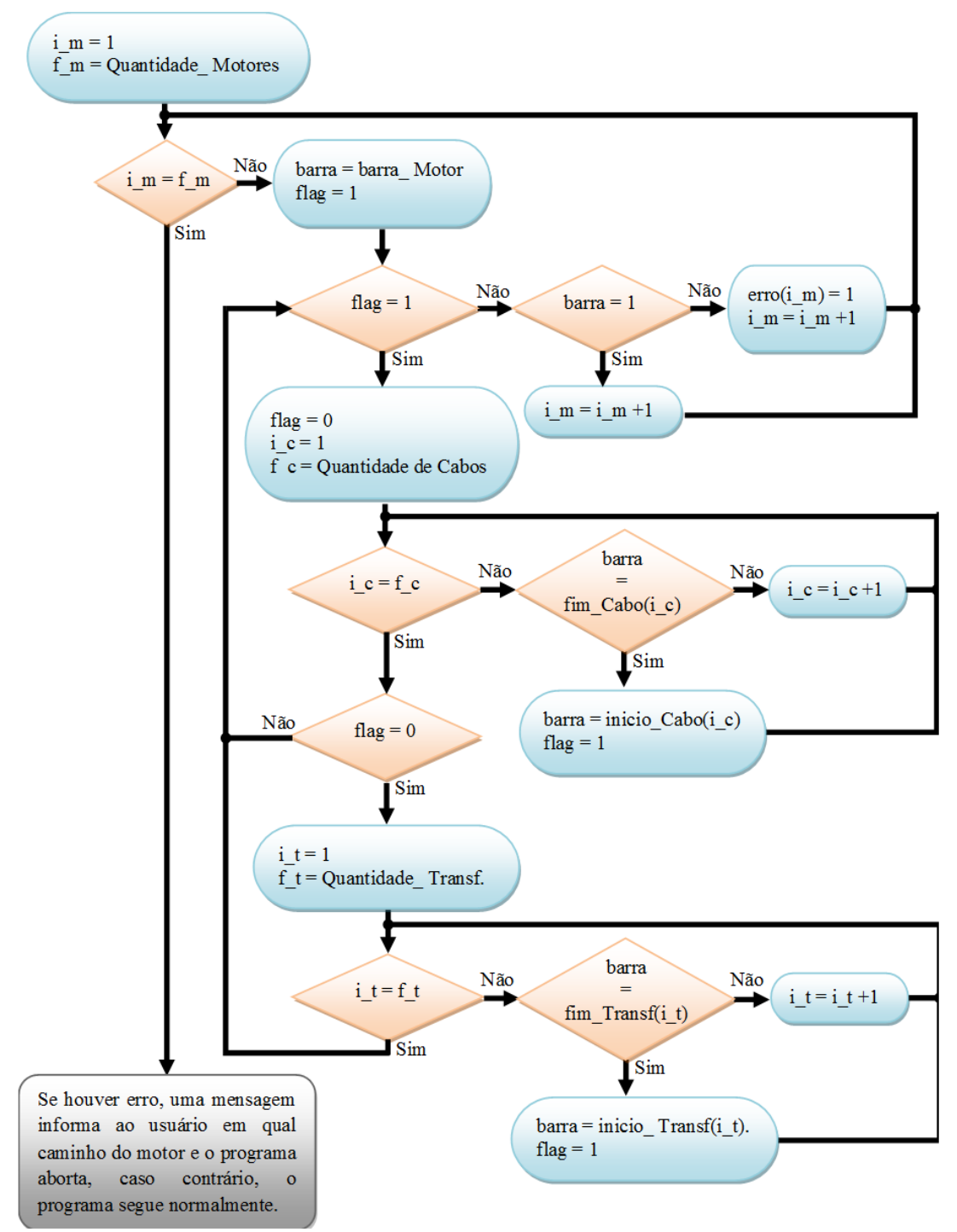

Figura 5.3 - Verificação de consistência dos dados do sistema elétrico.

Sendo:

cont: contador do laço.

Term(cont): vetor de terminais.

i_t : contador do laço contendo o valor dos índices dos transformadores.

f_t: quantidade de transformadores da rede.

i_m : contador do laço com o valor dos índices dos motores.

f_m: quantidade de motores da rede.

i_c : contador do laço contendo o valor dos índices dos cabos. 
f_c: quantidade de cabos da rede.

fim_Cabo(i_c): vetor que armazena a barra final de um cabo.

início_Cabo(i_c): vetor que armazena a barra inicial de um cabo.

fim_Transf(i_t $)$ : vetor que armazena a barra inicial de um transformador.

início_Transf(i_t): vetor que armazena a barra final de um transformador.

barra_Motor(i_m): vetor que armazena a barra que liga o motor.

Neste ponto, torna-se importante definir os conceitos de "barra" e de "terminal" utilizados neste trabalho. Uma barra é definida como um nó elétrico onde são conectados um ou vários circuitos elétricos, tanto na entrada quanto na saída da mesma. O terminal é uma barra com apenas uma entrada e uma saída, utilizado como nó auxiliar para interligar cabos aos lados primário e secundário de transformadores, e a motores. A importância da distinção desses elementos deve-se ao fato de que todos os algoritmos apresentados deste ponto em diante são baseados na identificação das barras, sendo os terminais considerados como parte integrante dos primários e secundários de transformadores e de motores.

O fluxograma da Figura 5.4 apresenta os procedimentos utilizados para diferenciar barras de terminais. Inicialmente, verifica-se em todos os transformadores se eles têm cabos associados tanto no lado primário quanto no lado secundário. Se na barra que conecta transformador e cabo não houver outro equipamento, esta barra será considerada como um terminal.

No fluxograma da Figura 5.4 as variáveis ainda não definidas têm o seguinte significado:

barra: variável de decisão contendo o número das barras dos equipamentos.

flag: marcador que identifica o fim do caminho de cada motor, desde a barra na qual ele está conectado até a barra da subestação. 
erro(i_m): vetor identificador de falhas no caminho de cada motor.

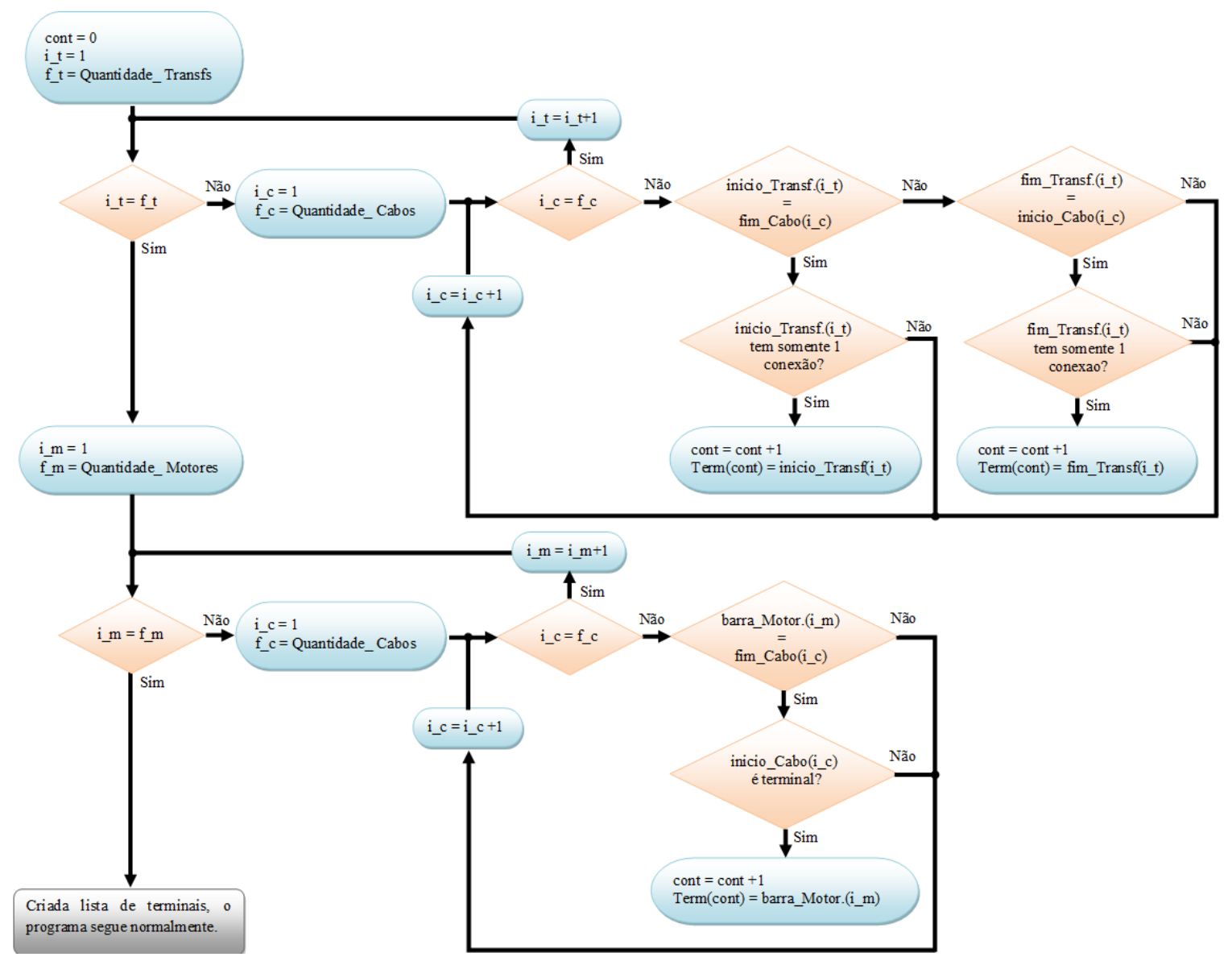

Figura 5.4 - Algoritmo para a distinção entre barras e terminais.

\subsection{Cálculo de Curto-Circuito}

Para compor o arquivo de entrada dos dispositivos de proteção é necessário conhecer as correntes de curto-circuito medidas por eles. Neste trabalho as correntes de curto-circuito são tratadas como dados de entrada, calculadas pelo programa DIgSILENT PowerFactory (DIgSILENT, 2009), no entanto qualquer outro programa pode ser empregado. Os dados necessários são os seguintes:

- Um índice para identificação das correntes;

- Um índice identificador do local da ocorrência do curto-circuito. Os valores das correntes de curto-circuito a serem inseridos no programa são aqueles que 
fluem pelos dispositivos de proteção e não o valor total da corrente de curtocircuito nas barras. Seguindo essa idéia, idealizou-se uma codificação para identificar o local da ocorrência da falta ou tipo de equipamento protegido, conforme apresentado em seguida:

○ 1, para dispositivo instalado em motores;

○ 2, para dispositivos instalados no lado primário de transformadores;

○ 3, para dispositivos instalados no lado secundário de transformadores;

○ 4, para dispositivos instalados no início de cabos;

- 5, para dispositivos instalados no final de cabos;

○ 6, para o dispositivo de proteção da subestação;

○ 7, para dispositivos instalados em cargas em geral.

- O índice do equipamento correspondente à codificação apresentada no item anterior;

- A mínima corrente de curto-circuito trifásico, valor eficaz simétrico em Ampère;

- A máxima corrente transitória de curto-circuito trifásico, valor eficaz simétrico em Ampère;

- A máxima corrente subtransitória de curto-circuito trifásico, valor eficaz simétrico em Ampère;

- A máxima corrente de curto-circuito fase-terra, valor eficaz simétrico em Ampère. Ressalta-se que a forma como está organizado o arquivo de entrada das correntes de curto-circuito está apresentada no Capítulo 6 (Tabela 6.8). 


\subsection{Dados de Entrada dos Dispositivos de Proteção}

Os dados dos dispositivos de proteção foram dispostos em arquivos-texto diferentes. São comuns a todos eles:

- Um índice para identificação do dispositivo;

- Índice que define a localização dos dispositivos, conforme codificação a seguir:

- 1, para dispositivo instalado em motores;

○ 2, para dispositivos instalados no lado primário de transformadores;

○ 3, para dispositivos instalados no lado secundário de transformadores;

○ 4, para dispositivos instalados no início de cabos;

○ 5, para dispositivos instalados no final de cabos;

○ 6, para o dispositivo de proteção da subestação;

○ 7, para dispositivos instalados em cargas em geral.

- Índice do equipamento protegido;

- Índice das correntes de curto-circuito associadas ao dispositivo de proteção;

- Intervalo de coordenação com o dispositivo a montante, em ms.

Nas subseções seguintes são apresentados os dados necessários e no Capítulo 6 são apresentados os padrões de formatação dos dados.

\subsubsection{Fusíveis}

As seguintes informações são necessárias para definir um fusível:

- Corrente nominal; 
- Pontos (corrente, tempo): esses pontos definirão a corrente média de fusão do elo fusível. Sobre essa corrente média é aplicada a margem de tolerância, que neste trabalho será admitida igual a $\pm 10 \%$.

\subsubsection{Disjuntores de Baixa Tensão}

Para os disjuntores de baixa tensão, devem ser fornecidos os seguintes dados:

- Corrente nominal;

- Faixas de ajustes: multiplicador de tempo longo (MTL); atraso de tempo longo (ATL); multiplicador de tempo curto (MTC); atraso de tempo curto (ATC); multiplicador para ajuste instantâneo (MInst); multiplicador de terra (MT); atraso de terra (AT). O usuário deve fornecer o limite inferior, o passo da variação e o limite superior da faixa de ajuste;

\subsubsection{Relé de Sobrecorrente}

O modelo do relé digital de sobrecorrente considerado como padrão nesta dissertação, compreende um dispositivo com as unidades temporizada e instantânea tanto para proteção de fase (curto-circuito trifásico e outros tipos envolvendo apenas as fases) quanto de terra (curtocircuito envolvendo fase e terra). Além disso, considera-se que a unidade temporizada apresente as curvas de atuação dos padrões ANSI e IEC. Para esses relés, os dados de entrada são os seguintes:

- Faixa de ajuste do multiplicador de tempo do relé (TDS) para cada padrão de curva (ANSI ou IEC): a metodologia faz uso do limite inferior, do passo da variação e do limite superior da faixa de ajuste;

- Faixa de valores da corrente de ajuste de partida do relé: limite inferior, passo e limite superior; 
- Faixa de valores da corrente de ajuste da unidade instantânea do relé: limite inferior, passo e limite superior;

- Relação de transformação do transformador de corrente:

○ Corrente nominal do enrolamento primário;

○ Corrente nominal do enrolamento secundário.

- Ajustes fixos de relé: a metodologia prevê a realização da coordenação caso os ajustes de determinado dispositivo de proteção necessitem ser fixados. Para tanto, as seguintes informações devem ser fornecidas:

○ Índice do relé;

- Padrão da curva da unidade temporizada:

- 1, para ANSI;

- 2, para IEC.

○ Tipo da curva:

- Pode variar de 1 a 5, fazendo relação com o padrão.

○ TDS (multiplicador de tempo do relé) dependente do padrão;

- Corrente de ajuste da unidade temporizada, considerando a relação de transformação do TC e os valores da faixa de ajustes;

○ Corrente de ajuste da unidade instantânea, considerando a relação de transformação do TC e os valores da faixa de ajustes.

\subsection{Verificação de Consistência dos Dados dos Dispositivos de Proteção}

Os dados de entrada dos dispositivos de proteção são verificados de maneira a garantir uma completa proteção da rede, ou seja, garantindo uma proteção a todos os equipamentos sempre que possível. Se o algoritmo encontrar algum equipamento não protegido, é fornecida 
uma mensagem informando o usuário sobre o problema, e o programa tem sua execução interrompida, pois caso contrário os resultados da coordenação ficarão comprometidos.

A Figura 5.5 apresenta o fluxograma desse algoritmo. Inicialmente, verifica-se se cada motor é protegido por fusível, DBT ou relé. Caso não seja identificado nenhum dispositivo de proteção, um vetor de erro armazena essa informação. Em seguida são testados todos os transformadores (lado primário) e os motores e, constatada a ausência de dispositivos de proteção nesses equipamentos, atualiza-se o vetor de erro. Em alguns sistemas industriais, a instalação de dispositivos de proteção no lado secundário de transformadores pode não ser requerida. Em razão disso, o algoritmo verifica apenas o lado primário dos transformadores.

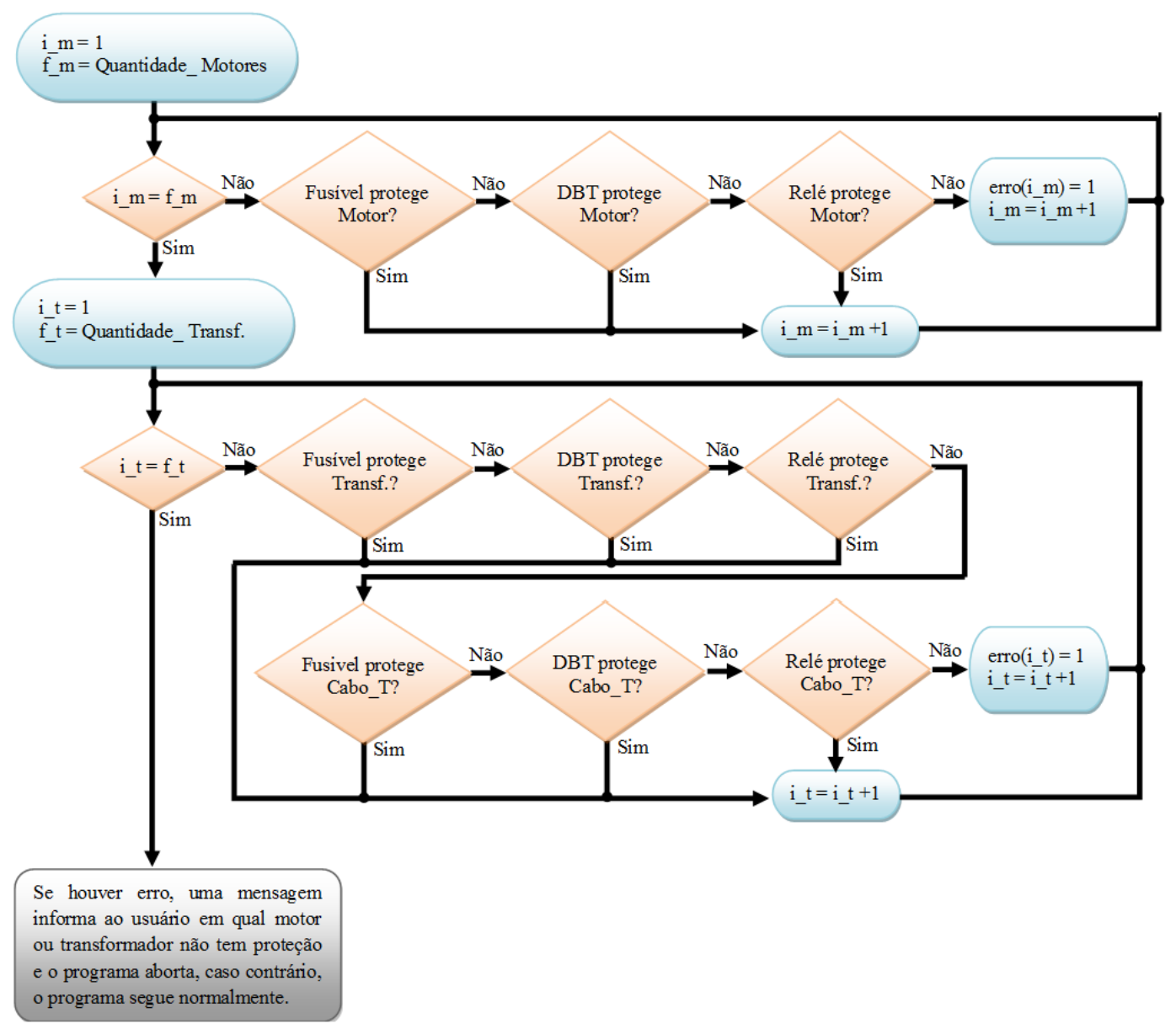

Figura 5.5 - Verificação de consistência dos dispositivos de proteção. 


\subsection{Ajustes Automáticos}

Com os dados dos equipamentos e dos dispositivos de proteção verificados, o programa inicia um algoritmo denominado “Ajustes”, que é o responsável pela aplicação dos critérios de proteção individual e de coordenação. Pode-se considerar esta etapa como a mais importante da metodologia de coordenação proposta. A explicação detalhada inicia-se com a apresentação de um algoritmo, cuja estrutura é apresentada na Figura 5.6.

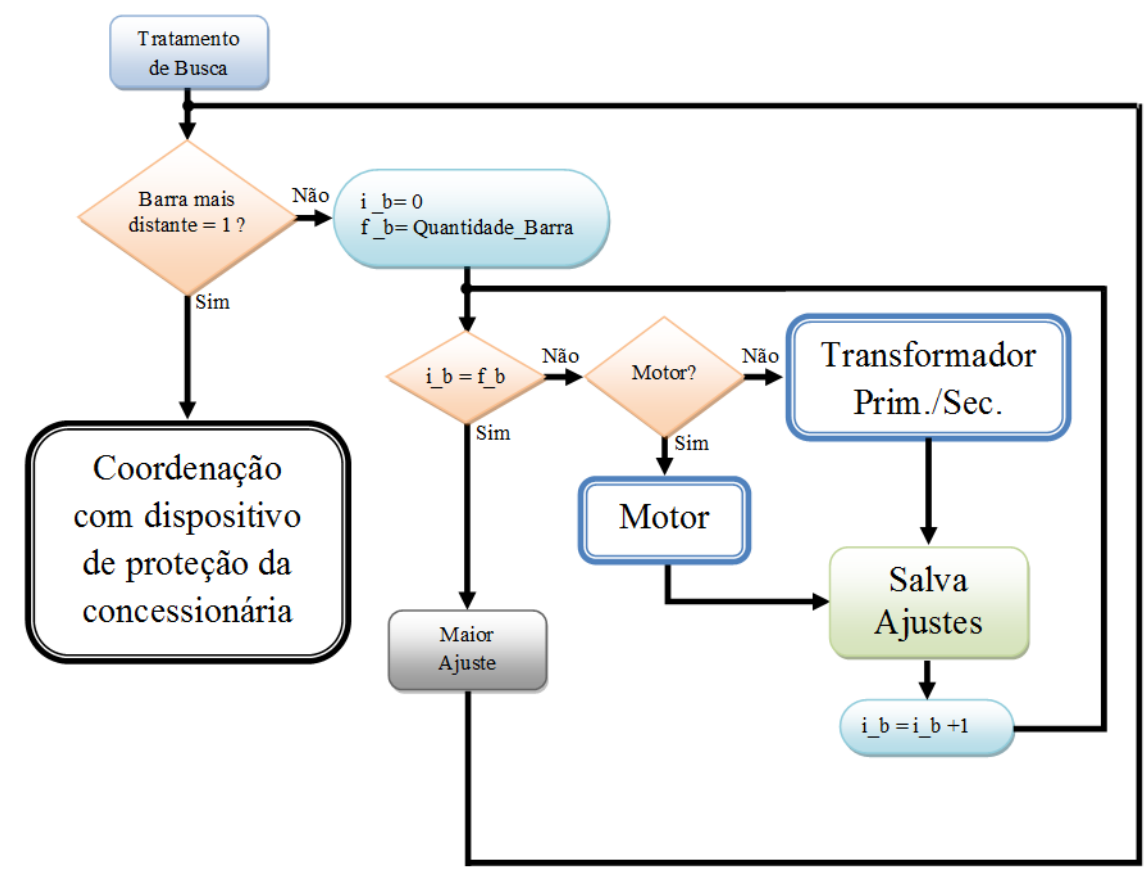

Figura 5.6 - Estrutura do algoritmo "Ajustes".

Na Figura 5.6 as variáveis apresentadas são as seguintes:

i_b : contador do laço.

f_b: quantidade de barras da matriz "Rede".

A idéia básica do algoritmo "Ajustes" é a seguinte. Entendendo a rede elétrica como uma árvore, o algoritmo procura a maior folha no ramo mais distante da raiz, ou seja, ele busca o dispositivo de maior ajuste que protege o equipamento mais distante eletricamente da barra da subestação. No início da execução do algoritmo, os dispositivos mais distantes são aqueles relacionados à proteção das cargas, no caso, motores de indução. 
Para a execução dessa busca faz-se necessário criar a matriz "Rede" contendo todas as barras e equipamentos no trajeto desde cada motor até a barra da subestação. A criação da matriz "Rede" está apresentada no fluxograma da Figura 5.7, sendo:

Rede(i_m, cont): Matriz contendo todas as barras de cada motor até a barra da subestação.

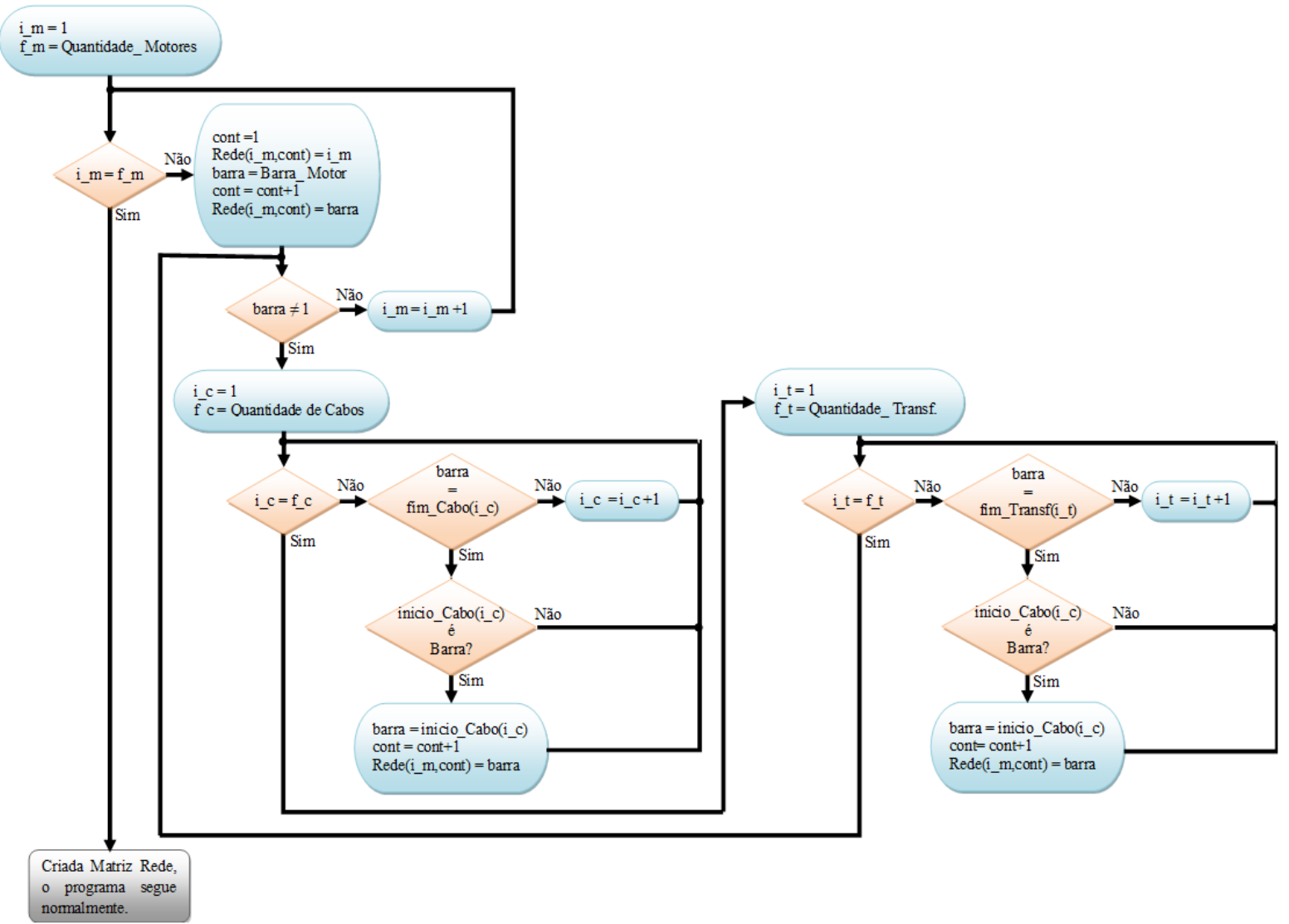

Figura 5.7 - Criação da matriz Rede.

Uma vez construída a matriz "Rede", inicia-se o processo de definição dos ajustes. Buscam-se as barras mais distantes eletricamente da barra da subestação e se executa o algoritmo que definirá os ajustes dos dispositivos de proteção de todos os equipamentos conectados a essas barras, aplicando-se os critérios de proteção e salvando em seguida os ajustes encontrados na matriz "Proteção". Em seguida, as cargas das barras mais distantes são processadas com o objetivo de identificar qual dispositivo de proteção possui o maior ajuste. Este e os elementos que definem seu trajeto até a barra da subestação permanecem na matriz 
"Rede", ao passo que todo o trajeto dos outros dispositivos de proteção é eliminado da matriz "Rede". Com isso, finaliza-se o processamento das barras mais distantes. O próximo passo é efetuar outra busca das barras mais distantes da barra da subestação, desconsiderando as barras já processadas. Analogamente ao explicado anteriormente, os dispositivos de proteção de todas as cargas e saídas para transformadores e cabos são ajustados aplicando-se os critérios de proteção individual dos equipamentos e também os critérios de coordenação, pois os ajustes dos dispositivos de proteção a jusante estão armazenados na matriz "Proteção". E assim, esses processos de busca e execução do algoritmo de ajustes se repetem até que reste apenas a barra da subestação.

\subsubsection{Algoritmo de Definição de Ajustes dos Dispositivos de Proteção}

Uma vez identificado o equipamento protegido, o algoritmo verifica quais dispositivos de proteção estão instalados. No caso de o equipamento protegido ser um motor, são três as configurações de dispositivos de proteção abordadas neste trabalho: relé, disjuntor de baixa tensão e relé associado com fusível.

Para o caso de transformador, pode haver relé, disjuntor de baixa tensão e fusível no lado secundário, e relé ou fusível no lado primário.

Lembrando que os cabos são equipamentos associados aos motores e transformadores, sendo sua proteção realizada em conjunto com estes.

Identificados o equipamento protegido e o dispositivo de proteção, algoritmos específicos para cada dispositivo são empregados.

\subsubsection{Disjuntor de Baixa Tensão}

Para disjuntores de baixa tensão, o algoritmo representado pelo diagrama de blocos da Figura 5.8 é executado. Inicialmente, define-se a corrente de tempo longo como apresentado no capítulo anterior. Essa corrente é uma porcentagem da corrente nominal do disjuntor e seu 
valor depende do equipamento protegido. Em seguida é calculado o atraso de tempo longo, definido para uma corrente seis vezes superior à corrente nominal do disjuntor, respeitando o intervalo de coordenação com qualquer dispositivo de proteção a jusante e os limites da região de ajuste. Para a corrente de ajuste da unidade de tempo curto há de se verificar a coordenação e ajustes a jusante. Ela é calculada como uma porcentagem da corrente de tempo longo. $\mathrm{O}$ atraso de tempo curto é definido a partir do dispositivo a jusante, respeitando o intervalo de coordenação. Caso não exista dispositivo a jusante, esse atraso é definido no limite inferior da faixa de ajustes. Para a unidade instantânea do disjuntor, é necessário verificar o tipo de equipamento protegido. Se for motor, deve ser ajustado respeitando a corrente de partida. Além disso, a corrente de tempo curto e a corrente da unidade instantânea podem ser ajustadas no mesmo valor, se possível, com atraso de tempo curto no seu valor mínimo. Por outro lado, caso o disjuntor de baixa tensão esteja instalado no secundário de transformador, sua unidade instantânea deve ser ajustada no limite superior de sua faixa de ajustes de corrente, a fim de evitar ou minimizar a perda de coordenação com o dispositivo de proteção a jusante para elevados valores de corrente de curto-circuito. Se o limite superior da faixa de ajustes for menor do que a máxima corrente de curto-circuito na carga, não se conseguirá evitar essa perda de coordenação, no entanto a faixa de valores de corrente em que esse problema ocorre será reduzida. Finalmente, é efetuado o ajuste da proteção contra faltas fase-terra (blocos Corrente de Terra e Atraso de Terra), respeitando os critérios definidos no capítulo anterior. 


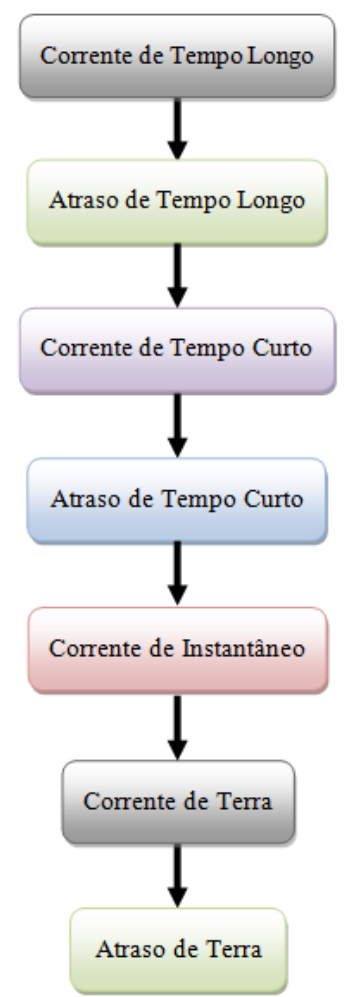

Figura 5.8 - Algoritmo para definição de ajustes de disjuntor de baixa tensão.

\subsubsection{Relé de Sobrecorrente}

Para relés de sobrecorrente, o algoritmo representado no fluxograma da Figura 5.9 é executado. A corrente de ajuste, referente à unidade temporizada do relé, é definida com base nos critérios de ajuste abordados no capítulo anterior. Em seguida, o algoritmo define os pontos de decisão, que são os pontos no plano tempo versus corrente sobre os quais os fatores de segurança e intervalos de coordenação devem ser aplicados e respeitados. No bloco denominado "Preview" o algoritmo identifica todos os tipos de curvas configurados no modelo do relé, para toda a faixa de ajustes do multiplicador de tempo (TDS), mas restringindo-se ao ajuste de corrente definido previamente. O algoritmo "Preview" faz com que a busca pelas melhores curvas se inicie a partir dos pontos de decisão. Neste caso, as melhores curvas são aquelas que não violam os critérios de proteção. Esse procedimento visa reduzir o esforço computacional do programa, uma vez que não analisa as curvas que violam os critérios de proteção. Se não existirem curvas que atendam os critérios de proteção, o 
programa pode executar duas ações distintas. A primeira delas é recalcular os ajustes do relé e do dispositivo a jusante, sacrificando a seletividade em função de rapidez na proteção. Esta ação será executada se os dispositivos estiverem instalados no lado primário e secundário do transformador, respectivamente. Maiores detalhes são fornecidos na seção 5.7.1.9. A segunda ação é abortar a execução do programa, pois neste caso pode haver problemas na entrada de dados ou mau dimensionamento do sistema de proteção. A continuação do programa a partir deste ponto forneceria ajustes que comprometeriam a eficiência dos sistemas de proteção. Logo, o usuário é encorajado a verificar se os valores dos dados de entrada são coerentes. Desde que haja curvas de atuação possíveis, o algoritmo seleciona aquela que possui menor ajuste de multiplicador de tempo e procede à determinação do ajuste da unidade instantânea do relé. Para o ajuste da função de proteção contra curtos-circuitos fase-terra, os critérios apresentados no capítulo anterior são obedecidos, empregando curva a tempo definido.

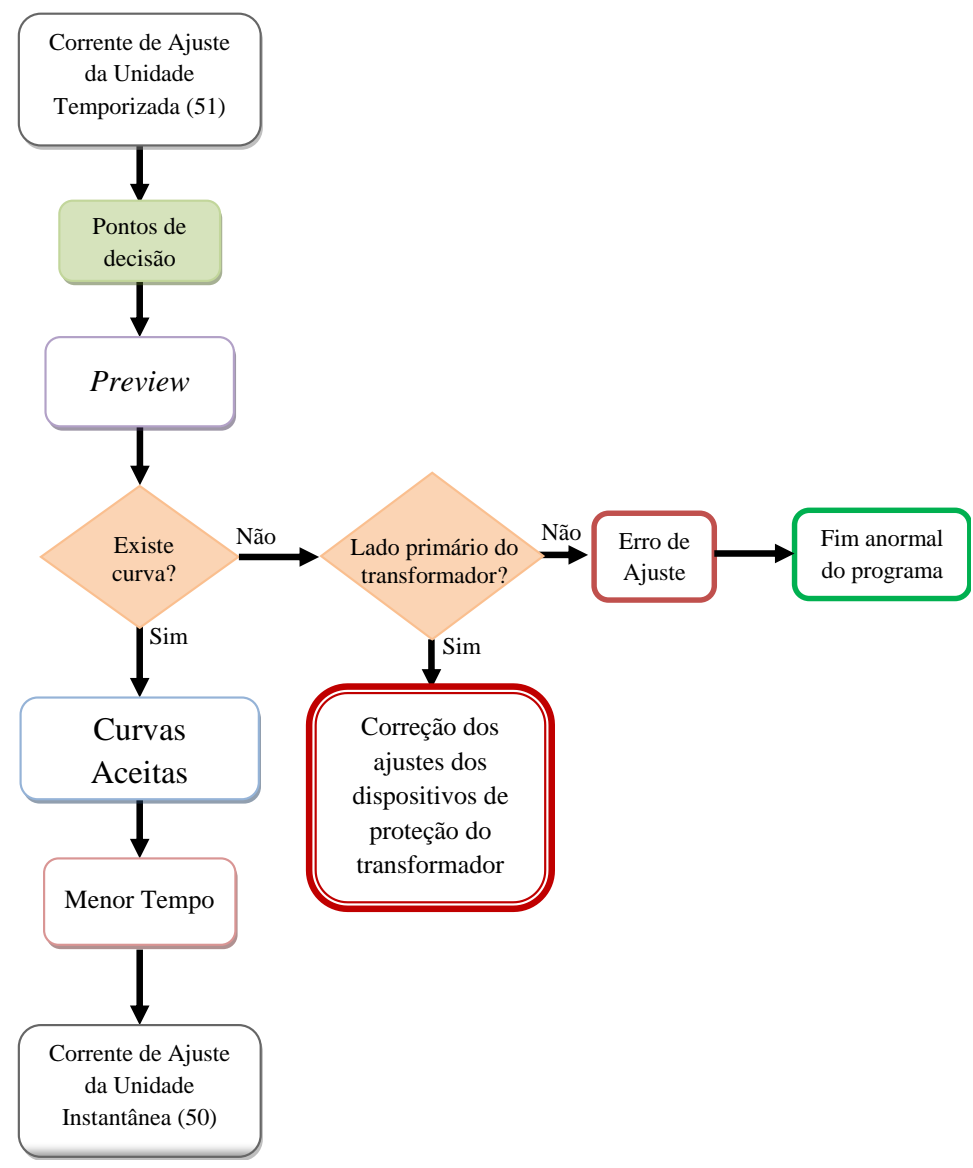

Figura 5.9 - Algoritmo para definição de ajustes dos relés de sobrecorrente de tempo inverso. 
No caso dos fusíveis, o programa apenas verificará se o mesmo não viola as regiões de dano do motor ou do transformador que o mesmo protege. Havendo violação, uma mensagem de erro é fornecida ao usuário, mas o programa não sugere um novo fusível. Ressalta-se que a idéia original não é especificar novos dispositivos de proteção, mas sim executar a coordenação entre eles, admitindo-os conhecidos.

\subsubsection{Motor protegido por relé de sobrecorrente}

Inicialmente determina-se a corrente de ajuste do relé, considerando a corrente nominal do motor corrigida pelo fator de serviço. Para determinar a corrente de ajuste, considerou-se, neste trabalho, uma margem de $105 \%$ da corrente nominal do motor corrigida pelo fator de serviço, sendo necessário um teste para verificar se a corrente de ajuste está dentro dos limites da faixa de ajustes da unidade temporizada do relé. Em caso negativo, o programa fornece uma mensagem de erro ao usuário informando a impossibilidade da realização do ajuste automático e tem sua execução interrompida.

Uma vez calculada a corrente de ajuste do elemento temporizado do relé, determinamse os pontos de decisão para o ajuste da proteção do motor, baseando-se nos critérios de proteção apresentados no Capítulo 4. Neste caso, o ponto de decisão é o “joelho” determinado pela corrente de partida do motor e o tempo de aceleração, mais a margem de segurança sobre o tempo de aceleração. Em seguida, o programa passa à determinação da curva de atuação mais adequada do relé, executando o algoritmo "Preview" para identificar as possíveis curvas, ou seja, aquelas que se situam entre o ponto de decisão e o tempo de rotor bloqueado. Dentre as curvas válidas é escolhida aquela cujo ajuste do multiplicador de tempo é tal que apresente o menor tempo de atuação para uma corrente de $165 \%$ da corrente de partida do motor. Caso o programa não encontre curvas válidas, é fornecida uma mensagem de erro ao usuário solicitando a verificação dos dados de entrada e então se aborta sua execução. 
O ajuste da função instantânea do relé será $165 \%$ da corrente de partida do motor. Caso este ajuste seja maior que a máxima corrente de curto-circuito no local, a função instantânea do relé será bloqueada.

A proteção fase-terra por relé digital é realizada por uma função independente configurada no próprio dispositivo. Fixa-se a corrente de ajuste em $10 \%$ da corrente nominal do TC e seleciona-se curva a tempo definido com ajuste em 0,1 segundo.

\subsubsection{Motor protegido por disjuntor de baixa tensão}

Para disjuntor de baixa tensão protegendo motor, primeiramente define-se a corrente de tempo longo a $105 \%$ da corrente de partida do motor, verificando se esse valor está dentro dos limites definidos na entrada de dados. Para o atraso de tempo longo o ajuste é calculado de forma que seja maior do que o tempo de aceleração do motor mais o fator de segurança sobre o tempo de aceleração. A corrente de tempo curto é estabelecida a $176 \%$ da corrente de partida do motor, para permitir a partida, e o atraso de tempo curto é fixado no limite mínimo por se tratar de motor, ou seja, não tem curva a jusante. A corrente da unidade instantânea do disjuntor é fixada o mais próximo possível da corrente de tempo curto, devendo respeitar os $176 \%$ da corrente de partida do motor.

Para a proteção fase-terra realizada por disjuntor de baixa tensão de motores, a corrente de ajuste deve ser definida em $10 \%$ da corrente de nominal do disjuntor, temporizada em 0,1 segundo, respeitando sempre os limites do dispositivo.

\subsubsection{Motor protegido por relé e fusível}

Neste caso, o programa executa o mesmo algoritmo do relé, com a diferença de que o fusível substituirá a função instantânea do relé. Dadas as características do fusível, o programa simplesmente testa se seus parâmetros estão dentro da região de ajuste do motor.

Para coordenação de dispositivo de proteção a montante, o programa define como ponto de decisão, a intersecção da curva de atuação temporizada do relé com a curva de 
máxima fusão do fusível. A determinação deste ponto é realizada por meio de interpolação logarítmica.

No caso de fusível, este também desempenhará proteção fase-terra, como dispositivo adicional da proteção do relé.

\subsubsection{Lado secundário do transformador protegido por relé de sobrecorrente.}

Inicialmente determina-se a corrente de ajuste do relé, utilizando a margem de $125 \%$ da corrente nominal do transformador, sendo necessário verificar se esta corrente pertence à faixa de ajustes do relé.

Neste caso a definição dos pontos de decisão depende do esquema de proteção do equipamento a jusante que apresente o maior ajuste:

- Se o maior ajuste é devido ao relé de sobrecorrente, o primeiro ponto de decisão é o joelho formado pela interseção da curva de atuação temporizada e a corrente de ajuste da unidade instantânea do relé, adicionado o intervalo de coordenação. O segundo ponto de decisão é definido pelo tempo de operação da unidade instantânea do relé para a máxima corrente transitória de curtocircuito que ambos os relés medem (relé do equipamento e secundário do transformador), adicionado o intervalo de coordenação (ver Figura 4.9, para exemplo com relé de motor);

- Quando o maior ajuste é devido ao disjuntor de baixa tensão, o primeiro ponto de decisão é o joelho determinado pela intersecção da curva de tempo longo com o ajuste da corrente de tempo curto, adicionado o intervalo de coordenação. O segundo ponto de decisão é definido pela interseção da curva de tempo curto com o ajuste da corrente da unidade instantânea do disjuntor, adicionado o intervalo de coordenação. Finalmente, o terceiro ponto de decisão é determinado pelo tempo de operação da unidade instantânea do disjuntor de 
baixa tensão considerando a máxima corrente transitória de curto-circuito, adicionado o intervalo de coordenação. Em todos esses casos, consideram-se as curvas do disjuntor correspondentes à tolerância máxima;

- Se o maior ajuste é devido ao relé de sobrecorrente e fusível, o primeiro ponto de decisão é determinado pela intersecção da curva de atuação da unidade temporizada com a curva de máxima fusão do fusível. Já o segundo ponto de decisão é determinado pelo tempo de atuação da máxima curva de fusão do fusível, adicionado o intervalo de coordenação correspondente;

- Se o secundário do transformador alimenta uma barra contendo motores, existe ainda um outro ponto de decisão, formado pela soma da corrente de partida do maior motor e a corrente nominal das outras cargas no tempo igual ao tempo de aceleração do maior motor.

Definidos os pontos de decisão, o algoritmo "Preview" testa quais curvas são viáveis para a proteção no secundário do transformador. A curva de atuação escolhida é aquela que esteja situada acima de todos os pontos de decisão e que possua o menor tempo de atuação para a máxima corrente transitória de curto-circuito, desde que o intervalo de coordenação com o dispositivo de proteção a jusante seja respeitado.

A função instantânea do relé de sobrecorrente que protege o secundário do transformador é bloqueada.

Para proteção fase-terra de transformador há de se verificar o tipo da conexão do enrolamento secundário do transformador. Para os casos em que o enrolamento do lado secundário é do tipo estrela com neutro solidamente aterrado ou aterrado por impedância, o ajuste de corrente deve obedecer aos $10 \%$ da corrente nominal do TC e a curva escolhida deve ser curva a tempo definido temporizada de forma a considerar o intervalo de coordenação 
com o dispositivo de proteção a jusante. Para outros tipos de enrolamento do transformador, a proteção contra curtos-circuitos fase-terra não se aplica.

\subsubsection{Lado secundário do transformador protegido por disjuntor de baixa tensão}

Para disjuntor de baixa tensão protegendo o lado secundário de transformador, primeiramente calcula-se a corrente de tempo longo como $125 \%$ da corrente nominal do transformador. O atraso de tempo longo é ajustado de forma a garantir a coordenação com a curva do dispositivo a jusante. Para a corrente de tempo curto há de se verificar o "joelho" da curva a jusante adicionando $10 \%$ da corrente como segurança. O atraso de tempo curto é ajustado de forma a coordenar com a curva a jusante. Para o ajuste da unidade instantânea, o valor é ajustado no limite máximo da faixa de ajuste para garantir coordenação com a curva a jusante.

Verificado o tipo de enrolamento do lado secundário do transformador, este sendo estrela com neutro solidamente aterrado ou aterrado por impedância, o atraso de tempo deve ser tal que haja coordenação com o dispositivo de proteção a jusante, e a corrente ajustada em $10 \%$ da corrente nominal do disjuntor.

\subsubsection{Lado secundário do transformador protegido por fusível}

Dada a curva do fusível, o programa testa se o fusível é adequado ao transformador, ou seja, se está dentro da região de ajuste do transformador e respeita os pontos de decisão definidos na seção 5.7.1.6.

No caso de fusível, este também fará a proteção fase-terra, assim o basta ao programa verificar a coordenação e alertar para um eventual problema.

\subsubsection{Lado primário do transformador protegido por relé de sobrecorrente}

A corrente de ajuste da unidade temporizada do relé terá uma margem de $116 \%$ da corrente de ajuste do relé do secundário ou da corrente nominal do disjuntor de baixa tensão 
para transformadores cuja conexão dos seus enrolamentos é do tipo delta-estrela. Caso contrário, a corrente de ajuste do relé do primário será igual à corrente de ajuste do relé do lado secundário ou da corrente nominal do disjuntor de baixa tensão, sendo necessário verificar se o valor calculado está dentro da faixa de ajustes do relé.

Os pontos de decisão são definidos a depender do dispositivo de proteção a jusante do relé no lado primário do transformador. Assim, as seguintes opções são possíveis:

- Se há relé no lado secundário, o ponto de decisão é definido pelo tempo de operação deste relé para a máxima corrente transitória de curto-circuito no secundário do transformador, adicionado o intervalo de coordenação;

- Se há disjuntor de baixa tensão no lado secundário, o primeiro ponto de decisão é o joelho determinado pela intersecção da curva de tempo longo com o ajuste da corrente de tempo curto, adicionado o intervalo de coordenação. O segundo ponto de decisão é definido pela interseção da curva de tempo curto com o ajuste da corrente da unidade instantânea do disjuntor, adicionado o intervalo de coordenação. Caso o ajuste de corrente da unidade instantânea do disjuntor de baixa tensão seja inferior à máxima corrente de curto-circuito no secundário do transformador, deve-se definir um terceiro ponto de decisão determinado pelo tempo de operação da unidade instantânea do disjuntor de baixa tensão considerando essa máxima corrente de curto-circuito, adicionado o intervalo de coordenação. Em todos esses casos, consideram-se as curvas do disjuntor correspondentes à tolerância máxima;

- Se há fusível no lado secundário, o ponto de decisão é determinado pelo tempo máximo (total) de fusão do fusível para a máxima corrente transitória de curtocircuito, adicionado o intervalo de coordenação correspondente. 
Uma vez identificados os pontos de decisão, executa-se o algoritmo "Preview" para encontrar a melhor curva de atuação, com a seguinte restrição: se o dispositivo de proteção utilizado no lado secundário for relé, só serão testados os tipos de curva do padrão definido para o mesmo. Se o algoritmo "Preview" não encontrar curvas para o relé do lado primário do transformador o programa recalcula o ajuste de corrente da unidade temporizada do relé do lado secundário do transformador adicionando $10 \%$ a esse ajuste e determinando um novo ajuste do multiplicador de tempo. Com isso a melhor curva do secundário deverá definir outros pontos de decisão para o relé do primário, e este processo se repete até que exista uma curva para o primário ou até que a região de dano do transformador seja violada. Nesta condição, priorizando a proteção do transformador, sacrifica-se a coordenação entre os relés do primário e do secundário e ajusta-se a unidade temporizada do relé do primário igual aos ajustes inicias do relé do secundário, de forma que suas curvas de atuação se sobreponham. Esta perda de coordenação entre dispositivos instalados em um mesmo ramo é permitida, conforme abordado na seção 4.3.3.

Novamente, assim como no relé de proteção do motor, o programa executa o algoritmo de melhor curva para função de proteção temporizada do relé, sendo que a melhor curva será aquela que respeite os pontos de decisão e que possua o menor tempo de operação devido à maior corrente entre $120 \%$ da corrente de magnetização e a $120 \%$ da máxima corrente subtransitória de curto-circuito no lado secundário do transformador. Entretanto, este tempo de atuação deve ser maior que o tempo estabelecido como tempo de coordenação de relé.

O ajuste da função instantânea do relé será a maior corrente entre $120 \%$ da corrente de magnetização e a $120 \%$ da máxima corrente de curto-circuito do dispositivo de proteção do secundário. 
Para a proteção contra curtos-circuitos fase-terra deve-se fazer a mesma verificação do tipo de enrolamento feita no lado secundário. Caso não seja estrela com neutro solidamente aterrado ou aterrado por impedância, não é necessário haver coordenação com a curva do dispositivo a jusante e ajusta-se o dispositivo em $10 \%$ da corrente nominal do TC, com curva a tempo definido temporizada em 0,1 segundo. Caso contrário, os dispositivos de proteção de terra do primário e secundário do transformador devem estar devidamente coordenados. Eles podem ser ajustados no mesmo valor de corrente, desde que não inferior a $10 \%$ dos respectivos TCs, e temporizados de maneira a respeitar o intervalo de coordenação entre os mesmos.

\subsubsection{Lado primário do transformador protegido por fusível}

Dada a curva de atuação do fusível, o programa testa se o fusível é adequado ao transformador, ou seja, se está dentro da região de ajuste do transformador, respeitando os pontos de decisão definidos na seção anterior. Caso o fusível não respeite os pontos de decisão, uma mensagem de erro é fornecida ao usuário solicitando a verificação dos dados de entrada do dispositivo de proteção, no entanto o programa não tem sua execução interrompida, pois se pode admitir a perda de coordenação entre os dispositivos de proteção situados no primário e secundário do transformador.

Caso não exista dispositivo de proteção específico para proteger o transformador contra curtos-circuitos fase-terra, o fusível também executará esta função. Logo, basta ao programa verificar a coordenação e alertar para um eventual problema.

\subsubsection{Barra protegida por qualquer dispositivo de proteção}

Esta situação se aplica quando uma barra com várias cargas, incluindo motores e transformadores, é alimentada por um cabo conectado a outra barra. O programa trata os dispositivos de proteção do cabo desta configuração de forma semelhante aos dispositivos de 
proteção instalados no lado secundário de transformadores. Portanto, os procedimentos descritos nas seções 5.7.1.6, 5.7.1.7, 5.7.1.8 são aplicados neste caso.

\subsubsection{Coordenação com o Dispositivo de Proteção da Subestação}

Quando a matriz "Rede" tiver apenas um único caminho, o programa executa a verificação de coordenação com o dispositivo de proteção da subestação, cujos ajustes são dados de entrada do programa.

O teste de verificação de coordenação com o dispositivo de proteção da subestação é simples, bastando verificar se os seguintes critérios são respeitados:

- A curva de atuação do relé de proteção da subestação deve estar, no mínimo $\Delta t$ segundos acima do joelho da curva de proteção do primeiro relé a jusante, sendo $\Delta t$ o intervalo de coordenação correspondente;

- O ajuste de corrente da unidade temporizada do relé da subestação deve ser maior ou igual ao ajuste de corrente da unidade temporizada do primeiro relé a jusante;

- A unidade instantânea do relé da subestação, se houver, deve ter ajuste de corrente maior ou igual ao ajuste definido para a unidade instantânea do primeiro relé a jusante.

No caso de não haver coordenação entre o relé de entrada da indústria com o dispositivo de proteção da subestação o programa fornece uma mensagem de erro ao usuário e executa o algoritmo denominado "Ajustes Iguais", para tentar prover a coordenação entre esses dispositivos. Esse algoritmo busca no sistema elétrico o transformador mais próximo da entrada da indústria com o maior ajuste, e recalcula os ajustes dos dispositivos de proteção do lado primário e secundário, de maneira a deixá-los com os mesmo ajustes. Esta estratégia foi 
admitida neste trabalho como forma de tentar solucionar o problema de falta de coordenação em questão.

Em seguida, o teste de coordenação com o dispositivo de proteção da subestação é realizado novamente, e caso a coordenação ainda não seja possível, executa-se o algoritmo “Ajustes Iguais" até que haja coordenação ou até que todos os relés dos lados secundários e primários dos transformadores tenham sido ajustados com mesmos ajustes. Se mesmo assim a coordenação não for atingida, o programa informa o erro ao usuário e fixa os ajustes dos dispositivos de proteção nos valores anteriores ao início do teste de coordenação com o relé da subestação, pois foram os ajustes definidos pelo programa de forma a garantir proteção rápida e seletiva de todos os equipamentos do sistema elétrico. Em termos práticos, nessas circunstâncias, deve-se procurar os representantes da concessionária para discutir a possibilidade de alteração dos ajustes do relé da subestação.

Caso não se verifique a coordenação entre a unidade instantânea do relé da subestação e da unidade instantânea do relé a jusante, o programa informa o erro ao usuário, mas não executa nenhuma ação corretiva, para não prejudicar a eficácia das proteções definidas para os equipamentos da indústria. Novamente, deve-se discutir com o representante da concessionária a possibilidade de alteração nos ajustes do relé da subestação.

\subsection{Verificação de Sensibilidade dos Dispositivos de Proteção}

A última etapa da metodologia proposta, implementada no programa computacional descrito neste capítulo, é verificar se todos os dispositivos de proteção são sensíveis às mínimas correntes de curto-circuito que podem ocorrer imediatamente a jusante dos mesmos. Nesta etapa realiza-se um teste simples em que se verifica se a mínima corrente de curtocircuito intercepta as curvas de atuação dos dispositivos de proteção correspondentes. Em caso positivo, o programa emite uma mensagem informando que não encontrou problemas. 
Por outro lado, emite-se uma mensagem de erro solicitando que se verifiquem os dados dos equipamentos e topologia do circuito. Neste caso, a metodologia proposta não indica a alteração dos ajustes porque os mesmos foram definidos considerando as margens de segurança recomendadas por normas. Uma alteração dessa natureza poderia causar o desligamento do circuito em condições normais de operação, portanto, é necessário efetuar estudos mais apurados. 


\section{Capítulo 6}

\section{Resultados}

Este capítulo apresenta os resultados da aplicação da metodologia proposta para obter a coordenação dos dispositivos de proteção de dois sistemas elétricos industriais distintos, cujos dados são reais. A aplicação da metodologia se dá por meio da implementação de um programa computacional, conforme abordado no capítulo anterior.

O programa inicia carregando os dados de entrada dos equipamentos da rede elétrica a partir de arquivos-texto tabulados. Em seguida, procede-se ao tratamento desses dados, pois alguns parâmetros necessários durante a execução do programa são calculados a partir dos dados de entrada. Após a leitura dos dados de entrada, faz-se necessária a verificação de consistência dos mesmos para que não haja falhas na rede e para que a execução do programa prossiga normalmente.

Com os dados dos equipamentos carregados, tratados e verificados, estes são repassados ao programa DIgSILENT PowerFactory que calcula as correntes de curto-circuito no sistema elétrico em análise. Ao usuário, caberá construir o arquivo dos dados de entrada das correntes de curto-circuito a partir dos resultados do DIgSILENT PowerFactory. O programa de ajuste automático prossegue carregando os dados dos dispositivos de proteção do 
sistema elétrico e fazendo a verificação de consistência a fim de identificar se existe algum equipamento desprotegido.

\subsection{Exemplo 1}

A Figura 6.1 mostra o diagrama unifilar da rede elétrica usada no teste. O sistema elétrico está dividido em quatro níveis de tensão, a saber:

- $138 \mathrm{kV}$ : barra B01

- 13,8 kV: barras B02, B03, B04, B05, B08, B11, B14 e B16;

- $4,16 \mathrm{kV}$ : barras B12, B13 e B15;

- 0,44 kV: barras B06, B07, B09, B10 e B17.

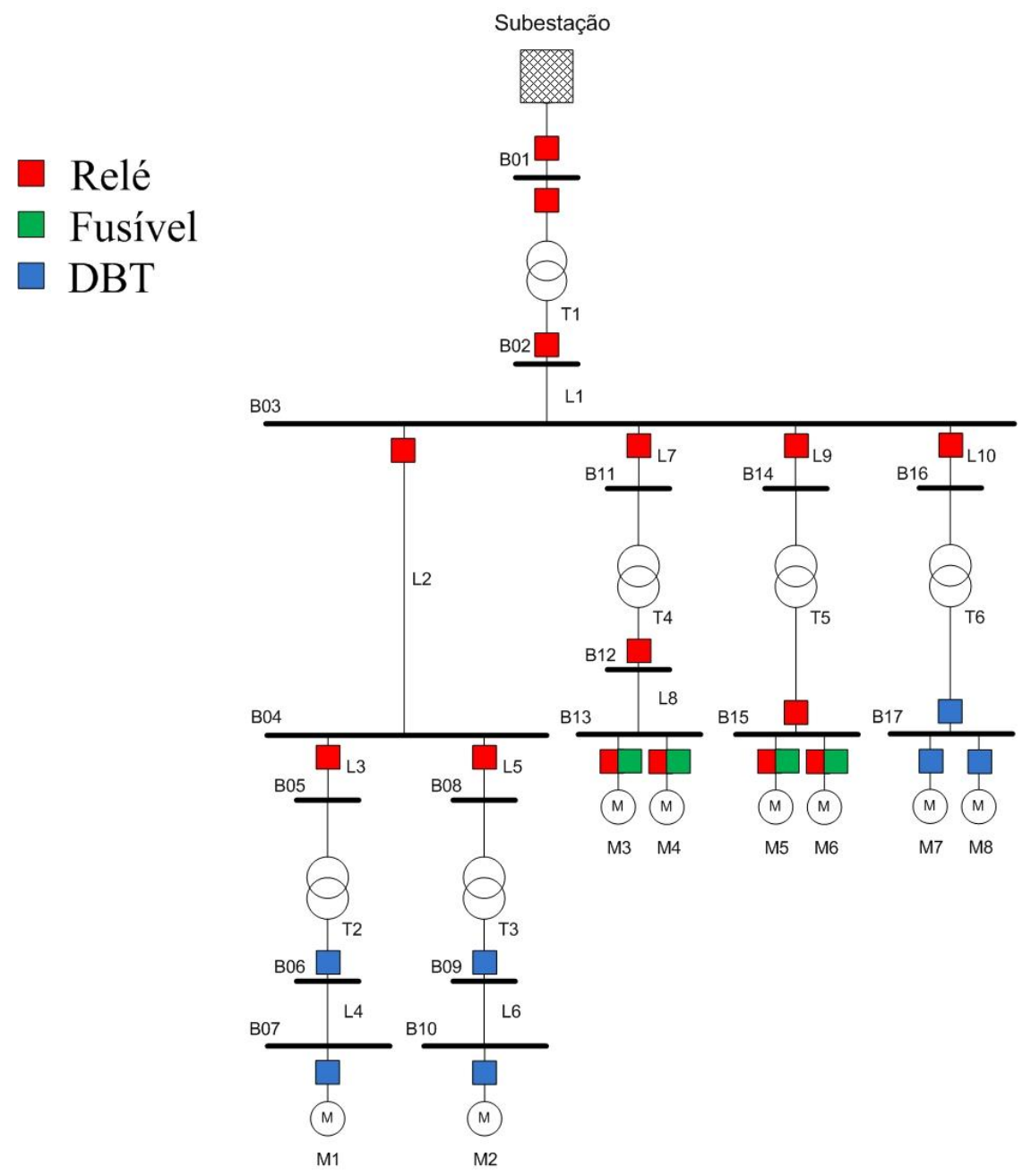

Figura 6.1 - Diagrama unifilar do sistema elétrico do Exemplo 1. 


\subsubsection{Equipamentos}

Os dados dos equipamentos do sistema elétrico são apresentados nas tabelas seguintes.

A Tabela 6.1 mostra os dados de entrada dos motores, a Tabela 6.2 dos transformadores, a

Tabela 6.3 e a Tabela 6.4 dos cabos.

Tabela 6.1 - Dados dos motores.

\begin{tabular}{|c|c|c|c|c|c|c|c|c|c|}
\hline ID & Barra & $\begin{array}{c}\text { Potência } \\
\text { Nominal } \\
(\mathrm{kVA})\end{array}$ & $\begin{array}{c}\text { Tensão } \\
(\mathrm{kV})\end{array}$ & $\begin{array}{c}\text { Fator de } \\
\text { Serviço }\end{array}$ & $\begin{array}{l}\text { Ip/In* } \\
\text { Tempo de } \\
\text { Aceleração } \\
(\mathrm{s})\end{array}$ & $\begin{array}{c}\text { Tempo de } \\
\text { Rotor } \\
\text { Bloqueado } \\
(\mathrm{s})\end{array}$ & $\begin{array}{c}\text { Margem de } \\
\text { Segurança } \\
\text { sobre o } \\
\text { Tempo de } \\
\text { Aceleração } \\
\text { (s) }\end{array}$ & $\begin{array}{c}\text { Fator de } \\
\text { Potência } \\
\text { Nominal }\end{array}$ \\
\hline 1 & 7 & 200,80 & 0,44 & 1,05 & 7,2 & 7 & 11 & 2 & 0,83 \\
\hline 2 & 10 & 200,80 & 0,44 & 1,05 & 7,2 & 7 & 11 & 2 & 0,83 \\
\hline 3 & 13 & 649,02 & 4,16 & 1,05 & 6,0 & 7 & 15 & 2 & 0,89 \\
\hline 4 & 13 & 299,79 & 4,16 & 1,05 & 6,0 & 5 & 12 & 2 & 0,89 \\
\hline 5 & 15 & 531,73 & 4,16 & 1,05 & 6,0 & 7 & 15 & 2 & 0,91 \\
\hline 6 & 15 & 424,13 & 4,16 & 1,05 & 6,0 & 5 & 12 & 2 & 0,90 \\
\hline 7 & 17 & 71,02 & 0,44 & 1,05 & 7,4 & 4 & 10 & 2 & 0,88 \\
\hline 8 & 17 & 147,14 & 0,44 & 1,05 & 8,0 & 6 & 12 & 2 & 0,84 \\
\hline
\end{tabular}

*Ip $=$ corrente de partida; In = corrente nominal.

Tabela 6.2 - Dados dos transformadores.

\begin{tabular}{|c|c|c|c|c|c|c|c|c|c|c|c|}
\hline \multirow{2}{*}{ ID } & \multirow{2}{*}{$\begin{array}{l}\text { Barra } \\
\text { Início }\end{array}$} & \multirow{2}{*}{$\begin{array}{l}\text { Barra } \\
\text { Fim }\end{array}$} & \multirow{2}{*}{$\begin{array}{l}\text { Tipo de } \\
\text { Isolação }\end{array}$} & \multirow{2}{*}{$\begin{array}{l}\text { Potência } \\
\text { (MVA) }\end{array}$} & \multirow{2}{*}{$\begin{array}{c}\text { Tensão } \\
\text { de } \\
\text { Alta } \\
(\mathrm{kV})\end{array}$} & \multirow{2}{*}{$\begin{array}{c}\text { Tensão } \\
\text { de } \\
\text { Baixa } \\
(\mathrm{kV})\end{array}$} & \multirow{2}{*}{$\begin{array}{l}\text { Impedância } \\
(\%)\end{array}$} & \multirow{2}{*}{$\mathrm{M}_{\mathrm{SH}}$} & \multicolumn{2}{|c|}{$\begin{array}{l}\text { Conexão dos } \\
\text { Enrolamentos }\end{array}$} & \multirow{2}{*}{$\begin{array}{c}\text { Freqüência } \\
\text { de Faltas }\end{array}$} \\
\hline & & & & & & & & & Prim & $\mathrm{Sec}$ & \\
\hline 1 & 1 & 2 & 1 & 10,00 & 138,00 & 13,80 & 12,46 & 12 & 1 & 4 & 1 \\
\hline 2 & 5 & 6 & 1 & 0,75 & 13,80 & 0,44 & 5,00 & 12 & 1 & 4 & 1 \\
\hline 3 & 8 & 9 & 1 & 0,75 & 13,80 & 0,44 & 5,00 & 12 & 1 & 4 & 1 \\
\hline 4 & 11 & 12 & 1 & 3,00 & 13,80 & 4,16 & 7,28 & 12 & 1 & 4 & 1 \\
\hline 5 & 14 & 15 & 1 & 3,00 & 13,80 & 4,16 & 7,28 & 12 & 1 & 4 & 1 \\
\hline 6 & 16 & 17 & 1 & 1,00 & 13,80 & 0,44 & 4,76 & 12 & 1 & 4 & 1 \\
\hline
\end{tabular}

Tabela 6.3 - Dados dos cabos.

\begin{tabular}{|c|c|c|c|c|c|c|c|c|c|}
\hline ID & $\begin{array}{c}\text { Barra } \\
\text { Início }\end{array}$ & $\begin{array}{c}\text { Barra } \\
\text { Fim }\end{array}$ & $\begin{array}{c}\text { Tipo de } \\
\text { Cabo }\end{array}$ & $\begin{array}{c}\text { Tensão } \\
\text { Nominal } \\
(\mathrm{kV})\end{array}$ & $\begin{array}{c}\text { Número de } \\
\text { Condutores } \\
\text { por Fase }\end{array}$ & $\begin{array}{c}\text { Seção } \\
\text { Transversal } \\
\left(\mathrm{mm}^{2}\right)\end{array}$ & $\begin{array}{c}\text { T1 } \\
\left({ }^{\circ} \mathrm{C}\right)\end{array}$ & $\begin{array}{c}\text { T2 } \\
\left({ }^{\circ} \mathrm{C}\right)\end{array}$ & $\begin{array}{c}\text { Ampacidade } \\
\text { por } \\
\text { Condutor } \\
(\mathrm{A})\end{array}$ \\
\hline 1 & 2 & 3 & 1 & 13,80 & 2 & 150 & 90 & 250 & 0,320 \\
\hline 2 & 3 & 4 & 1 & 13,80 & 1 & 95 & 90 & 250 & 0,251 \\
\hline 3 & 4 & 5 & 1 & 13,80 & 1 & 95 & 90 & 250 & 0,251 \\
\hline 4 & 6 & 7 & 1 & 0,44 & 4 & 185 & 90 & 250 & 0,363 \\
\hline 5 & 4 & 8 & 1 & 13,80 & 1 & 95 & 90 & 250 & 0,251 \\
\hline 6 & 9 & 10 & 1 & 0,44 & 4 & 185 & 90 & 250 & 0,363 \\
\hline 7 & 3 & 11 & 1 & 13,80 & 1 & 95 & 90 & 250 & 0,251 \\
\hline 8 & 12 & 13 & 1 & 4,16 & 3 & 95 & 90 & 250 & 0,248 \\
\hline 9 & 3 & 14 & 1 & 13,80 & 1 & 95 & 90 & 250 & 0,251 \\
\hline 10 & 3 & 16 & 1 & 13,80 & 1 & 95 & 90 & 250 & 0,251 \\
\hline
\end{tabular}

T1 = máxima temperatura em operação normal; T2= máxima temperatura no curto-circuito. 
Tabela 6.4 - Impedâncias equivalentes dos cabos.

\begin{tabular}{|c|c|c|c|}
\hline ID & $\begin{array}{c}\text { Comprimento } \\
(\mathrm{km})\end{array}$ & $\begin{array}{c}\text { Resistência } \\
(\Omega / \mathrm{km})\end{array}$ & $\begin{array}{c}\text { Reatância } \\
(\Omega / \mathrm{km})\end{array}$ \\
\hline 1 & 0,450 & 0,0804 & 0,0676 \\
\hline 2 & 0,850 & 0,2480 & 0,1440 \\
\hline 3 & 0,025 & 0,2480 & 0,1440 \\
\hline 4 & 0,040 & 0,0425 & 0,0425 \\
\hline 5 & 0,030 & 0,2480 & 0,1440 \\
\hline 6 & 0,021 & 0,0425 & 0,0425 \\
\hline 7 & 0,620 & 0,2480 & 0,1440 \\
\hline 8 & 0,030 & 0,1233 & 0,0633 \\
\hline 9 & 0,040 & 0,2480 & 0,1440 \\
\hline 10 & 0,030 & 0,2480 & 0,1440 \\
\hline
\end{tabular}

A Tabela 6.5 mostra a corrente nominal e corrente de partida calculadas para cada motor a partir dos dados de entrada.

Tabela 6.5 - Corrente nominal e de partida dos motores.

\begin{tabular}{|c|c|c|}
\hline ID & $\begin{array}{c}\text { Corrente Nominal } \\
(\mathrm{A})\end{array}$ & $\begin{array}{c}\text { Corrente de Partida } \\
(\mathrm{A})\end{array}$ \\
\hline 1 & 276,656 & $1.991,921$ \\
\hline 2 & 276,656 & $1.991,921$ \\
\hline 3 & 94,579 & 567,472 \\
\hline 4 & 43,687 & 262,122 \\
\hline 5 & 77,487 & 464,920 \\
\hline 6 & 61,807 & 370,839 \\
\hline 7 & 97,849 & 724,083 \\
\hline 8 & 202,725 & $1.621,798$ \\
\hline
\end{tabular}

A Tabela 6.6 mostra a corrente nominal, a corrente de magnetização e o tempo de duração desta para os transformadores.

Tabela 6.6 - Corrente nominal e características da corrente de magnetização dos transformadores.

\begin{tabular}{|c|c|c|c|c|}
\hline ID & $\begin{array}{c}\text { Corrente } \\
\text { Nominal } \\
(\mathrm{A})\end{array}$ & $\begin{array}{c}\text { Corrente de } \\
\text { Magnetização } \\
(\mathrm{A})\end{array}$ & $\begin{array}{c}\text { Tensão-base } \\
\text { para os cálculos } \\
(\mathrm{kV})\end{array}$ & $\begin{array}{c}\text { Tempo da } \\
\text { Corrente de } \\
\text { Magnetização (s) }\end{array}$ \\
\hline 1 & 418,370 & $5.020,437$ & 13,80 & 0,1 \\
\hline 2 & 984,120 & $11.809,437$ & 0,44 & 0,1 \\
\hline 3 & 985,432 & $11.825,183$ & 0,44 & 0,1 \\
\hline 4 & 416,497 & $4.997,966$ & 4,16 & 0,1 \\
\hline 5 & 416,358 & $4.996,300$ & 4,16 & 0,1 \\
\hline 6 & $1.312,160$ & $15.745,916$ & 0,44 & 0,1 \\
\hline
\end{tabular}


A Tabela 6.7 mostra ampacidade equivalente de cada cabo do sistema elétrico.

Tabela 6.7 - Ampacidade equivalente dos cabos.

\begin{tabular}{|c|c|}
\hline ID & $\begin{array}{c}\text { Ampacidade } \\
\text { Equivalente (A) }\end{array}$ \\
\hline 1 & 0,640 \\
\hline 2 & 0,251 \\
\hline 3 & 0,251 \\
\hline 4 & 1,452 \\
\hline 5 & 0,251 \\
\hline 6 & 1,452 \\
\hline 7 & 0,251 \\
\hline 8 & 0,744 \\
\hline 9 & 0,251 \\
\hline 10 & 0,251 \\
\hline
\end{tabular}

Finalizando o processamento dos dados de entrada, a função representada pelo algoritmo da Figura 5.4 é executada para diferenciar as barras dos terminais. O programa identificou corretamente os nós B02, B05, B06, B08, B09, B11, B12, B14 e B16 como terminais.

\subsubsection{Correntes de Curto-Circuito}

A Tabela 6.8 mostra as correntes de curto-circuito, resultado do programa DIgSILENT PowerFactory, obtidas a partir dos dados dos equipamentos. A coluna "Tipo de Equipamento" apresenta a codificação que identifica o local da corrente de curto-circuito, definida na seção 5.4. Os valores apresentados na tabela são referidos à tensão nominal da barra ou terminal no qual os equipamentos estão conectados. 
Tabela 6.8 - Correntes de curto-circuito.

\begin{tabular}{|c|c|c|c|c|c|c|}
\hline ID & $\begin{array}{c}\text { Tipo de } \\
\text { Equipamento }\end{array}$ & $\begin{array}{c}\text { Índice do } \\
\text { Equipamento }\end{array}$ & $\begin{array}{c}\text { Corrente } \\
\text { Mínima (A) }\end{array}$ & $\begin{array}{l}\text { Máxima Corrente } \\
\text { Transitória (A) }\end{array}$ & $\begin{array}{l}\text { Máxima Corrente } \\
\text { Subtransitória (A) }\end{array}$ & $\begin{array}{c}\text { Máxima Corrente } \\
\text { Fase-Terra (A) }\end{array}$ \\
\hline 1 & 6 & 1 & 1.180 & 1.375 & 1.375 & 510 \\
\hline 2 & 2 & 1 & 1.180 & 1.375 & 1.375 & 504 \\
\hline 3 & 3 & 1 & 3.972 & 4.582 & 4.897 & 220 \\
\hline 4 & 4 & 2 & 3.895 & 4.980 & 5.334 & 220 \\
\hline 5 & 4 & 7 & 3.895 & 4.878 & 5.224 & 220 \\
\hline 6 & 4 & 9 & 3.895 & 4.876 & 5.223 & 220 \\
\hline 7 & 4 & 10 & 3.895 & 5.024 & 5.381 & 220 \\
\hline 8 & 4 & 3 & 3.558 & 4.634 & 4.936 & 220 \\
\hline 9 & 4 & 5 & 3.558 & 4.633 & 4.935 & 220 \\
\hline 10 & 3 & 2 & 14.453 & 17.701 & 18.654 & 21.910 \\
\hline 11 & 1 & 1 & 12.619 & 15.301 & 16.344 & 19.261 \\
\hline 12 & 3 & 3 & 14.452 & 17.679 & 18.653 & 21.920 \\
\hline 13 & 1 & 2 & 13.451 & 16.331 & 17.354 & 20.465 \\
\hline 14 & 3 & 4 & 3.515 & 4.056 & 4.534 & 440 \\
\hline 15 & 1 & 3 & 3.500 & 4.281 & 4.790 & 440 \\
\hline 16 & 1 & 4 & 3.500 & 4.568 & 5.110 & 440 \\
\hline 17 & 3 & 5 & 3.573 & 4.111 & 4.605 & 440 \\
\hline 18 & 1 & 5 & 3.573 & 4.457 & 4.993 & 440 \\
\hline 19 & 1 & 6 & 3.573 & 4.545 & 5.091 & 440 \\
\hline 20 & 3 & 6 & 19.451 & 23.923 & 25.168 & 29.620 \\
\hline 21 & 1 & 7 & 19.451 & 25.376 & 26.696 & 29.620 \\
\hline 22 & 1 & 8 & 19.451 & 24.522 & 25.798 & 29.620 \\
\hline
\end{tabular}

\subsubsection{Dados de Entrada dos Dispositivos de Proteção}

As características dos dispositivos de proteção utilizados no sistema elétrico da Figura 6.1 são apresentadas nas tabelas seguintes de acordo com os itens descritos na seção 5.5.

A Tabela 6.9 mostra os dados de identificação dos fusíveis. A coluna "Tipo de Equipamento" indica o tipo de equipamento protegido, sendo que o código "1" refere-se a motores. Já a coluna “Índice do Equipamento” define qual motor é protegido pelo fusível em questão, de acordo com os índices definidos na Tabela 6.1. A coluna "Índice da Corrente de Curto-Circuito" identifica quais valores das correntes de curto-circuito circulam pelo dispositivo, de acordo com a Tabela 6.8. As duas últimas colunas da Tabela 6.9 indicam a corrente nominal do fusível e o intervalo de coordenação com dispositivos de proteção a montante, respectivamente. 
Tabela 6.9 - Identificação dos fusíveis.

\begin{tabular}{|c|c|c|c|c|c|}
\hline ID & $\begin{array}{c}\text { Tipo de } \\
\text { Equipamento }\end{array}$ & $\begin{array}{c}\text { Índice do } \\
\text { Equipamento }\end{array}$ & $\begin{array}{c}\text { Índice da Corrente } \\
\text { de Curto-Circuito }\end{array}$ & $\begin{array}{c}\text { Corrente } \\
\text { Nominal (A) }\end{array}$ & $\begin{array}{c}\text { Intervalo de } \\
\text { Coordenação (ms) }\end{array}$ \\
\hline 1 & 1 & 3 & 15 & 200 & 120 \\
\hline 2 & 1 & 4 & 16 & 100 & 120 \\
\hline 3 & 1 & 5 & 18 & 150 & 120 \\
\hline 4 & 1 & 6 & 19 & 100 & 120 \\
\hline
\end{tabular}

A Tabela 6.10 e a Tabela 6.11 apresentam os pontos da corrente média de fusão em relação ao tempo de fusão do fusível, para os dispositivos empregados no exemplo. Sobre essa corrente médua deve-se aplicar uma tolerância de $\pm 10 \%$ para obter as curvas mínima e máxima de fusão.

Tabela 6.10 - Corrente média de fusão.

\begin{tabular}{|c|c|c|c|c|c|c|c|}
\hline \multirow{2}{*}{ ID } & \multicolumn{7}{|c|}{ Corrente $(\mathrm{A})$} \\
\cline { 2 - 8 } & $\mathrm{I}(1)$ & $\mathrm{I}(2)$ & $\mathrm{I}(3)$ & $\mathrm{I}(4)$ & $\mathrm{I}(5)$ & $\mathrm{I}(6)$ & $\mathrm{I}(7)$ \\
\hline 1 & 350,00 & 357,14 & 483,00 & 700,00 & $1.277,77$ & $2.400,00$ & $5.000,00$ \\
\hline 2 & 182,14 & 192,85 & 243,75 & 345,45 & 587,50 & $1.110,00$ & $2.500,00$ \\
\hline 3 & 291,66 & 297,61 & 402,5 & 583,33 & $1.064,8$ & 2.000 & $4.166,66$ \\
\hline 3 & 233,33 & 238,09 & 322 & 466,66 & 851,84 & 1.600 & $3.333,33$ \\
\hline
\end{tabular}

Tabela 6.11 - Tempo de fusão correspondente à corrente média.

\begin{tabular}{|c|c|c|c|c|c|c|c|}
\hline \multirow{2}{*}{ ID } & \multicolumn{7}{|c|}{ Tempo (s) } \\
\cline { 2 - 8 } & $\mathrm{T}(1)$ & $\mathrm{T}(2)$ & $\mathrm{T}(3)$ & $\mathrm{T}(4)$ & $\mathrm{T}(5)$ & $\mathrm{T}(6)$ & $\mathrm{T}(7)$ \\
\hline 1 & $3.000,00$ & $1.000,00$ & 100,00 & 10,00 & 1,00 & 0,10 & 0,01 \\
\hline 2 & $3.000,00$ & $1.000,00$ & 100,00 & 10,00 & 1,00 & 0,10 & 0,01 \\
\hline 3 & $3.000,00$ & $1.000,00$ & 100,00 & 10,00 & 1,00 & 0,10 & 0,01 \\
\hline 4 & $3.000,00$ & $1.000,00$ & 100,00 & 10,00 & 1,00 & 0,10 & 0,01 \\
\hline
\end{tabular}

A Tabela 6.12 mostra os dados de entrada dos disjuntores de baixa tensão e a Tabela 6.13 mostra os ajustes disponíveis dos disjuntores utilizados no exemplo.

Tabela 6.12 - Identificação dos disjuntores de baixa tensão.

\begin{tabular}{|c|c|c|c|c|}
\hline ID & $\begin{array}{c}\text { Tipo de } \\
\text { Equipamento }\end{array}$ & $\begin{array}{c}\text { Índice do } \\
\text { Equipamento }\end{array}$ & $\begin{array}{c}\text { Índice da Corrente de } \\
\text { Curto-Circuito }\end{array}$ & $\begin{array}{c}\text { Corrente } \\
\text { Nominal (A) }\end{array}$ \\
\hline 1 & 1 & 1 & 11 & 400 \\
\hline 2 & 1 & 2 & 13 & 400 \\
\hline 3 & 1 & 7 & 21 & 150 \\
\hline 4 & 1 & 8 & 22 & 350 \\
\hline 5 & 3 & 2 & 10 & 1.400 \\
\hline 6 & 3 & 3 & 12 & 1.400 \\
\hline 7 & 3 & 6 & 20 & 1.800 \\
\hline
\end{tabular}


Tabela 6.13 - Parâmetros de ajuste dos disjuntores de baixa tensão.

\begin{tabular}{|c|c|c|c|c|c|c|c|c|c|c|c|c|c|c|c|c|c|c|c|c|c|}
\hline \multirow{2}{*}{ ID } & \multicolumn{3}{|c|}{ MTL (xIn) } & \multicolumn{3}{|c|}{ ATL (s) } & \multicolumn{3}{|c|}{ MTC (xMTL) } & \multicolumn{3}{|c|}{ ATC (s) } & \multicolumn{3}{|c|}{ MInst (xIn) } & \multicolumn{3}{|c|}{ MT (xIn) } & \multicolumn{3}{|c|}{$\mathrm{AT}(\mathrm{s})$} \\
\hline & LI & pas. & LS & $\mathrm{LI}$ & pas. & $\mathrm{LS}$ & LI & pas. & LS & $\mathrm{LI}$ & pas. & LS & LI & pas. & LS & LI & pas. & $\mathrm{LS}$ & LI & pas. & LS \\
\hline 1 & 0,4 & 0,1 & 1,1 & 0,5 & 0,1 & 30 & 0,1 & 0,1 & 0,1 & 0,1 & 0,1 & 0,4 & 2 & 0,1 & 12 & 0,1 & 0,1 & 1 & 0,1 & 0,1 & 0,4 \\
\hline 2 & 0,4 & 0,1 & 1,1 & 0,5 & 0,1 & 30 & 0,1 & 0,1 & 0,1 & 0,1 & 0,1 & 0,4 & 2 & 0,1 & 12 & 0,1 & 0,1 & 1 & 0,1 & 0,1 & 0,4 \\
\hline 3 & 0,4 & 0,1 & 1,1 & 0,5 & 0,1 & 30 & 0,1 & 0,1 & 0,1 & 0,1 & 0,1 & 0,4 & 2 & 0,1 & 12 & 0,1 & 0,1 & 1 & 0,1 & 0,1 & 0,4 \\
\hline 4 & 0,4 & 0,1 & 1,1 & 0,5 & 0,1 & 30 & 0,1 & 0,1 & 0,1 & 0,1 & 0,1 & 0,4 & 2 & 0,1 & 12 & 0,1 & 0,1 & 1 & 0,1 & 0,1 & 0,4 \\
\hline 5 & 0,4 & 0,1 & 1,1 & 0,5 & 0,1 & 30 & 0,1 & 0,1 & 0,1 & 0,1 & 0,1 & 0,4 & 2 & 0,1 & 12 & 0,1 & 0,1 & 1 & 0,1 & 0,1 & 0,4 \\
\hline 6 & 0,4 & 0,1 & 1,1 & 0,5 & 0,1 & 30 & 0,1 & 0,1 & 0,1 & 0,1 & 0,1 & 0,4 & 2 & 0,1 & 12 & 0,1 & 0,1 & 1 & 0,1 & 0,1 & 0,4 \\
\hline 7 & 0,4 & 0,1 & 1,1 & 0,5 & 0,1 & 30 & 0,1 & 0,1 & 0,1 & 0,1 & 0,1 & 0,4 & 2 & 0,1 & 12 & 0,1 & 0,1 & 1 & 0,1 & 0,1 & 0,4 \\
\hline
\end{tabular}

$\mathrm{LI}=$ limite inferior da faixa de ajustes; $\mathrm{LS}=$ limite superior da faixa de ajustes; pas. = passo da variação entre os limites inferior e superior; $\mathrm{In}=$ corrente nominal do disjuntor $(\mathrm{A}) ; \mathrm{MTL}=$ multiplicador de tempo longo; $\mathrm{ATL}=$ atraso de tempo longo; $\mathrm{MTC}=$ multiplicador de tempo curto; $\mathrm{ATC}=$ atraso de tempo curto; MInst = multiplicador de instantâneo; MT = multiplicador da corrente da unidade de proteção de terra; AT = atraso da unidade de proteção de terra; LI = limite inferior; LS = limite superior

A Tabela 6.14 mostra os dados identificadores dos relés de sobrecorrente, ao passo que a Tabela 6.15 mostra os dados de entrada de cada relé. Já a Tabela 6.16 mostra os ajustes daqueles relés escolhidos pelo usuário para terem ajustes fixos. Neste caso em especial, o único relé com ajuste fixo é o relé da subestação, cujos ajustes são determinados pela concessionária de energia elétrica e que devem ser respeitados no resultado final da coordenação dos dispositivos de proteção da indústria. Ressalta-se que todos os relés de sobrecorrente considerados neste trabalho possuem as curvas de atuação definidas nos padrões ANSI e IEC, simultaneamente.

Tabela 6.14 - Identificação dos relés.

\begin{tabular}{|c|c|c|c|}
\hline ID & $\begin{array}{c}\text { Tipo de } \\
\text { Equipamento }\end{array}$ & $\begin{array}{c}\text { Índice do } \\
\text { Equipamento }\end{array}$ & $\begin{array}{c}\text { Índice da Corrente de } \\
\text { Curto-Circuito }\end{array}$ \\
\hline 1 & 6 & 1 & 1 \\
\hline 2 & 2 & 1 & 2 \\
\hline 3 & 3 & 1 & 3 \\
\hline 4 & 4 & 2 & 4 \\
\hline 5 & 4 & 7 & 5 \\
\hline 6 & 4 & 9 & 6 \\
\hline 7 & 4 & 10 & 7 \\
\hline 8 & 4 & 3 & 8 \\
\hline 9 & 4 & 5 & 9 \\
\hline 10 & 3 & 4 & 14 \\
\hline 11 & 1 & 3 & 16 \\
\hline 12 & 1 & 4 & 17 \\
\hline 13 & 3 & 5 & 18 \\
\hline 14 & 1 & 5 & 19 \\
\hline 15 & 1 & 6 & \\
\hline
\end{tabular}

Na Tabela 6.15 são apresentadas as faixas possíveis de ajustes para todas as unidades de proteção dos relés de sobrecorrente utilizados nos exemplos deste capítulo, incluindo o 
passo de variação das mesmas. A Tabela 6.16 apresenta os ajustes do relé de sobrecorrente da subestação. As características apresentadas para as unidades instantâneas e temporizadas são válidas tanto para a proteção de fase quanto para proteção de terra. Ressalta-se que na proteção de terra serão empregadas curvas a tempo definido, cujos ajustes de corrente são os mesmos apresentados para a unidade temporizada. Neste caso, a faixa dos ajustes de tempo se inicia em 0 segundo, chegando até 300 segundos, com passo de 0,1 segundo.

Tabela 6.15 - Características dos relés.

\begin{tabular}{|c|c|c|c|c|c|c|c|c|c|c|c|c|c|c|c|c|}
\hline \multirow[t]{2}{*}{ ID } & \multicolumn{3}{|c|}{ TDS (ANSI) } & \multicolumn{3}{|c|}{ TDS (IEC) } & \multicolumn{3}{|c|}{$\begin{array}{l}\text { Corrente de } \\
\text { Ajuste da } \\
\text { Unidade } \\
\text { Temporizada } \\
\text { (A) }\end{array}$} & \multicolumn{3}{|c|}{$\begin{array}{l}\text { Corrente de } \\
\text { Ajuste da } \\
\text { Unidade } \\
\text { Instantânea } \\
\text { (A) }\end{array}$} & \multicolumn{3}{|c|}{$\mathrm{TC}$} & \multirow[t]{2}{*}{$\begin{array}{l}\text { Intervalo de } \\
\text { Coordenação } \\
\quad(\mathrm{ms})\end{array}$} \\
\hline & LI & pas. & LS & LI & pas. & LS & LI & pas. & LS & LI & pas. & LS & $\begin{array}{l}\text { Prim.F } \\
\text { (A) }\end{array}$ & $\begin{array}{l}\text { Prim.T } \\
\text { (A) }\end{array}$ & $\begin{array}{l}\text { Sec. } \\
\text { (A) }\end{array}$ & \\
\hline 1 & 0,5 & 0,01 & 15 & 0,05 & 0,01 & 1 & 0,25 & 0,01 & 16 & 0,25 & 0,01 & 100 & 100 & 100 & 5 & 250 \\
\hline 2 & 0,5 & 0,01 & 15 & 0,05 & 0,01 & 1 & 0,25 & 0,01 & 16 & 0,25 & 0,01 & 100 & 100 & 100 & 5 & 250 \\
\hline 3 & 0,5 & 0,01 & 15 & 0,05 & 0,01 & 1 & 0,25 & 0,01 & 16 & 0,25 & 0,01 & 100 & 600 & 50 & 5 & 250 \\
\hline 4 & 0,5 & 0,01 & 15 & 0,05 & 0,01 & 1 & 0,25 & 0,01 & 16 & 0,25 & 0,01 & 100 & 100 & 100 & 5 & 250 \\
\hline 5 & 0,5 & 0,01 & 15 & 0,05 & 0,01 & 1 & 0,25 & 0,01 & 16 & 0,25 & 0,01 & 100 & 200 & 200 & 5 & 250 \\
\hline 6 & 0,5 & 0,01 & 15 & 0,05 & 0,01 & 1 & 0,25 & 0,01 & 16 & 0,25 & 0,01 & 100 & 200 & 200 & 5 & 250 \\
\hline 7 & 0,5 & 0,01 & 15 & 0,05 & 0,01 & 1 & 0,25 & 0,01 & 16 & 0,25 & 0,01 & 100 & 100 & 100 & 5 & 250 \\
\hline 8 & 0,5 & 0,01 & 15 & 0,05 & 0,01 & 1 & 0,25 & 0,01 & 16 & 0,25 & 0,01 & 100 & 50 & 50 & 5 & 250 \\
\hline 9 & 0,5 & 0,01 & 15 & 0,05 & 0,01 & 1 & 0,25 & 0,01 & 16 & 0,25 & 0,01 & 100 & 50 & 50 & 5 & 250 \\
\hline 10 & 0,5 & 0,01 & 15 & 0,05 & 0,01 & 1 & 0,25 & 0,01 & 16 & 0,25 & 0,01 & 100 & 500 & 50 & 5 & 250 \\
\hline 11 & 0,5 & 0,01 & 15 & 0,05 & 0,01 & 1 & 0,25 & 0,01 & 16 & 0,25 & 0,01 & 100 & 100 & 50 & 5 & 250 \\
\hline 12 & 0,5 & 0,01 & 15 & 0,05 & 0,01 & 1 & 0,25 & 0,01 & 16 & 0,25 & 0,01 & 100 & 50 & 50 & 5 & 250 \\
\hline 13 & 0,5 & 0,01 & 15 & 0,05 & 0,01 & 1 & 0,25 & 0,01 & 16 & 0,25 & 0,01 & 100 & 500 & 50 & 5 & 250 \\
\hline 14 & 0,5 & 0,01 & 15 & 0,05 & 0,01 & 1 & 0,25 & 0,01 & 16 & 0,25 & 0,01 & 100 & 100 & 50 & 5 & 250 \\
\hline 15 & 0,5 & 0,01 & 15 & 0,05 & 0,01 & 1 & 0,25 & 0,01 & 16 & 0,25 & 0,01 & 100 & 100 & 50 & 5 & 250 \\
\hline
\end{tabular}

TDS = multiplicador de ajuste de tempo; LI = limite inferior; LS = limite superior; Prim. F= primário de fase do TC; Prim. $\mathrm{T}=$ primário de terra do TC; Sec.: secundário do TC.

Tabela 6.16 - Ajustes fixos dos relés.

\begin{tabular}{|c|c|c|c|c|c|c|}
\hline ID & Fixo & $\begin{array}{c}\text { Padrão da Curva } \\
\text { de Atuação }\end{array}$ & $\begin{array}{c}\text { Tipo da Curva } \\
\text { de Atuação }\end{array}$ & TDS & $\begin{array}{c}\text { Corrente de Ajuste da } \\
\text { Unidade Temporizada } \\
\text { (A) }\end{array}$ & $\begin{array}{c}\text { Corrente de Ajuste da } \\
\text { Unidade Instantânea } \\
\text { (A) }\end{array}$ \\
\hline 1 & 1 & 2 & 4 & 0,15 & 5 & $0 *$ \\
\hline
\end{tabular}

*0 indica que a unidade instantânea está inoperante ou bloqueada.

\subsubsection{Algoritmo de Busca}

Com todos os dados dos equipamentos e dispositivos de proteção carregados, tratados e verificados, o programa inicia o algoritmo de busca para encontrar a barra eletricamente mais distante da barra da subestação. Em seguida, será demonstrado passo a passo como se 
procede à determinação automática e coordenação dos ajustes dos dispositivos de proteção do sistema elétrico da Figura 6.1.

\subsubsection{Ajuste das Proteções de Fase}

O algoritmo de busca inicia formando a matriz Rede mostrada na Tabela 6.17, composta de todas as barras do sistema elétrico no percurso de cada motor até a barra da subestação.

Tabela 6.17 - Matriz Rede inicial.

\begin{tabular}{|c|c|c|c|c|}
\hline Motor & $\mathrm{B}(1)$ & $\mathrm{B}(2)$ & $\mathrm{B}(3)$ & $\mathrm{B}(4)$ \\
\hline 1 & 07 & 04 & 03 & 01 \\
\hline 2 & 10 & 04 & 03 & 01 \\
\hline 3 & 13 & 03 & 01 & 0 \\
\hline 4 & 13 & 03 & 01 & 0 \\
\hline 5 & 15 & 03 & 01 & 0 \\
\hline 6 & 15 & 03 & 01 & 0 \\
\hline 7 & 17 & 03 & 01 & 0 \\
\hline 8 & 17 & 03 & 01 & 0 \\
\hline
\end{tabular}

Após a primeira execução, o algoritmo de busca retorna os seguintes pares (barra, motor): (B07, M1) e (B10, M2). Em seguida, inicia-se o processamento com o primeiro dos pares relacionados, pois não há o estabelecimento de prioridade entre eles. Então, começando com o par (B07, M1), o algoritmo de ajuste automático procura qual equipamento está associado à Barra B07, sendo o resultado o próprio motor M1. Uma busca nos dados dos dispositivos de proteção indica que o equipamento é protegido pelo disjuntor de baixa tensão, cujo índice (ID) é 1, e o programa verifica se os ajustes desse disjuntor estão adequados à região de ajuste para o motor em questão. Este procedimento está mostrado na Figura 6.2.

Observa-se que a curva de atuação de tempo longo do DBT não respeita a margem mínima de segurança sobre o tempo de aceleração do motor, no entanto não intercepta a curva de partida do motor. Essa violação é admitida, conforme explicado na seção 4.2.2. 


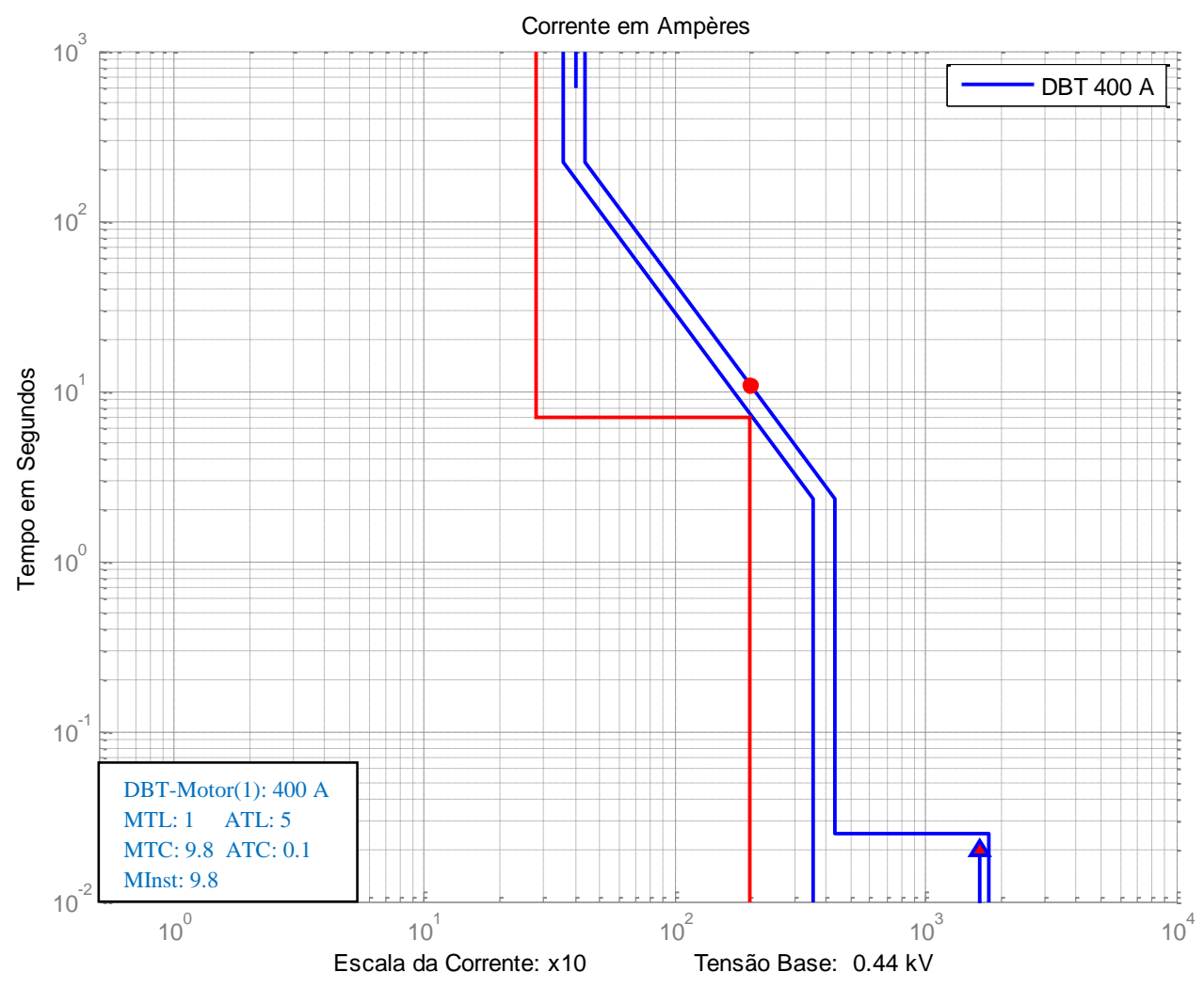

Figura 6.2 - Ajustes do DBT para o motor M1.

Para o par (B10, M2) definido na segunda linha da matriz Rede, o procedimento é o mesmo aplicado ao disjuntor do Motor M1. Como os motores M1 e M2 são idênticos e os ajustes do DBT também são, a verificação dos ajustes do DBT do Motor M2 é tal qual mostrada na Figura 6.2.

Terminada a primeira busca, o programa identifica qual dispositivo de proteção das cargas de cada barra analisada (barras B07 e B10) tem o maior ajuste. Neste caso, como não há mais de um equipamento na mesma barra, então os próprios ajustes recém definidos são os maiores. Logo, o algoritmo exclui da matriz Rede as barras executadas, resultando na nova matriz mostrada na Tabela 6.18. 
Tabela 6.18 - Matriz Rede para o segundo passo.

\begin{tabular}{|c|c|c|c|}
\hline Motor & $\mathrm{B}(1)$ & $\mathrm{B}(2)$ & $\mathrm{B}(3)$ \\
\hline 1 & 04 & 03 & 01 \\
\hline 2 & 04 & 03 & 01 \\
\hline 3 & 13 & 03 & 01 \\
\hline 4 & 13 & 03 & 01 \\
\hline 5 & 15 & 03 & 01 \\
\hline 6 & 15 & 03 & 01 \\
\hline 7 & 17 & 03 & 01 \\
\hline 8 & 17 & 03 & 01 \\
\hline
\end{tabular}

O retorno da nova busca são os pares: (B04, M1); (B04, M2); (B13, M3); (B13, M4); (B15, M5); (B15, M6); (B17, M7); (B17, M8).

Inicia-se o processamento com o par (B04, M1), e o equipamento associado à barra B04 indicado pelo valor 1 na coluna "Motor" é o transformador T2. O dispositivo que protege o transformador T2 é o relé 8 no lado primário e o relé 10 no lado secundário. Com essas informações o programa determina os ajustes dos relés localizados em ambos os lados do transformador T2 considerando os critérios de proteção individual do transformador e os de coordenação com o disjuntor do motor M1. O resultado do algoritmo para o relé no lado primário e secundário do transformador T2 é mostrado na Figura 6.3. Observa-se na caixa de texto que fornece os ajustes dos dispositivos de proteção o emprego dos símbolos "I>" e "I $>>$ ". Estes se referem às correntes de ajuste das unidades temporizada e instantânea, respectivamente. Tal simbologia é comumente empregada quando se está referindo ao padrão de curvas do IEC, no entanto será admitida neste trabalho para representar os ajustes em ambos os padrões de curvas. Além disso, os textos estão coloridos na mesma cor da curva de atuação do dispositivo de proteção correspondente. 


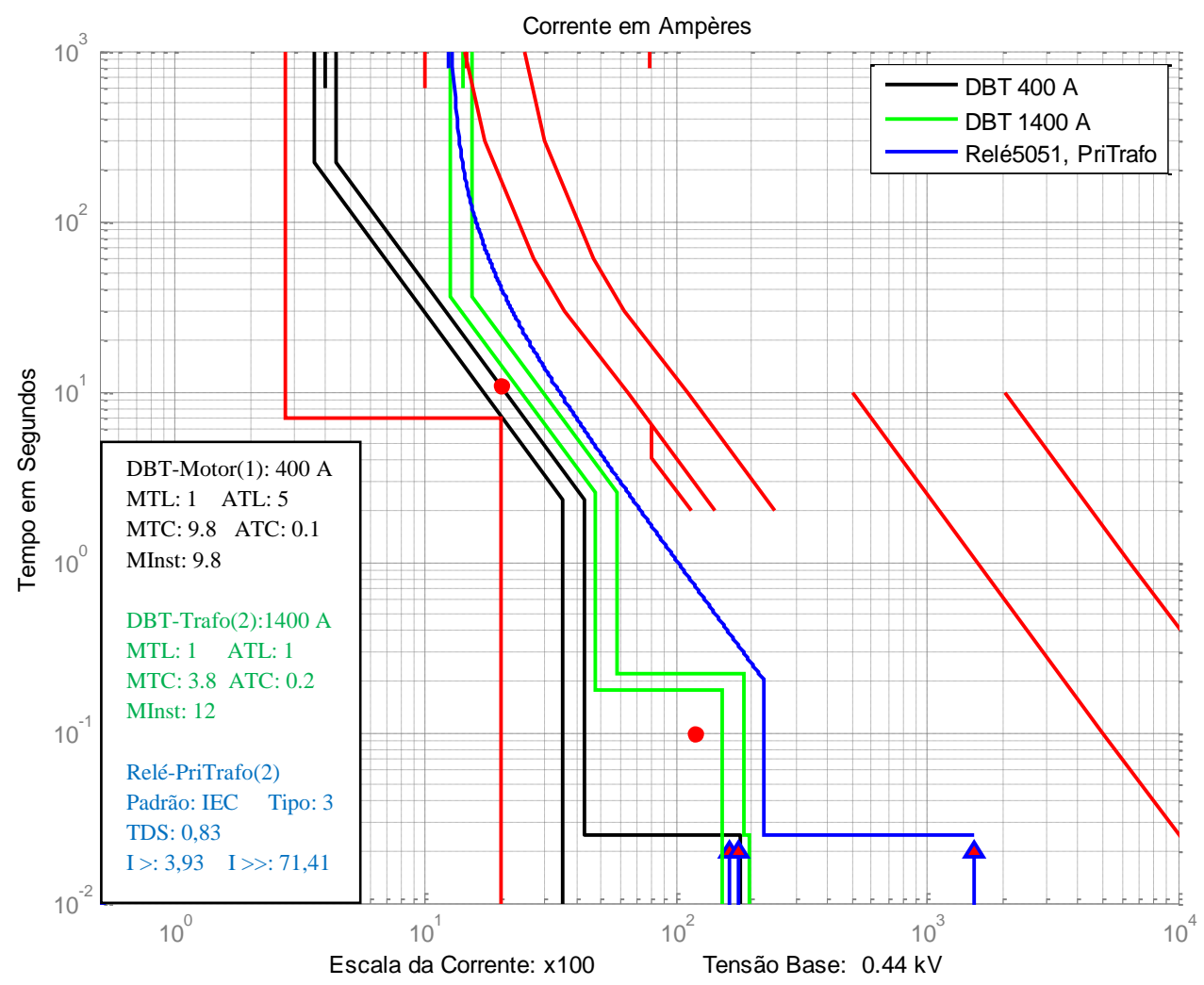

Figura 6.3 - Coordenação entre os dispositivos de proteção do transformador T2 e motor M1.

Para o par (B04, M2) da matriz Rede, o procedimento é idêntico ao do par (B04, M1), sendo o resultado da coordenação para os dispositivos de proteção do transformador T3 e motor M2 igual ao mostrado na Figura 6.3.

Na seqüência, o par (B13, M3) é processado, indicando que o equipamento associado à barra $\mathrm{B} 13$ é o motor M3 e o dispositivo que o protege é o relé 13 e o fusível 1 . O resultado da definição automática do ajuste do relé 13 , considerando o fusível e as características nominais do motor M3 é mostrado na Figura 6.4. 


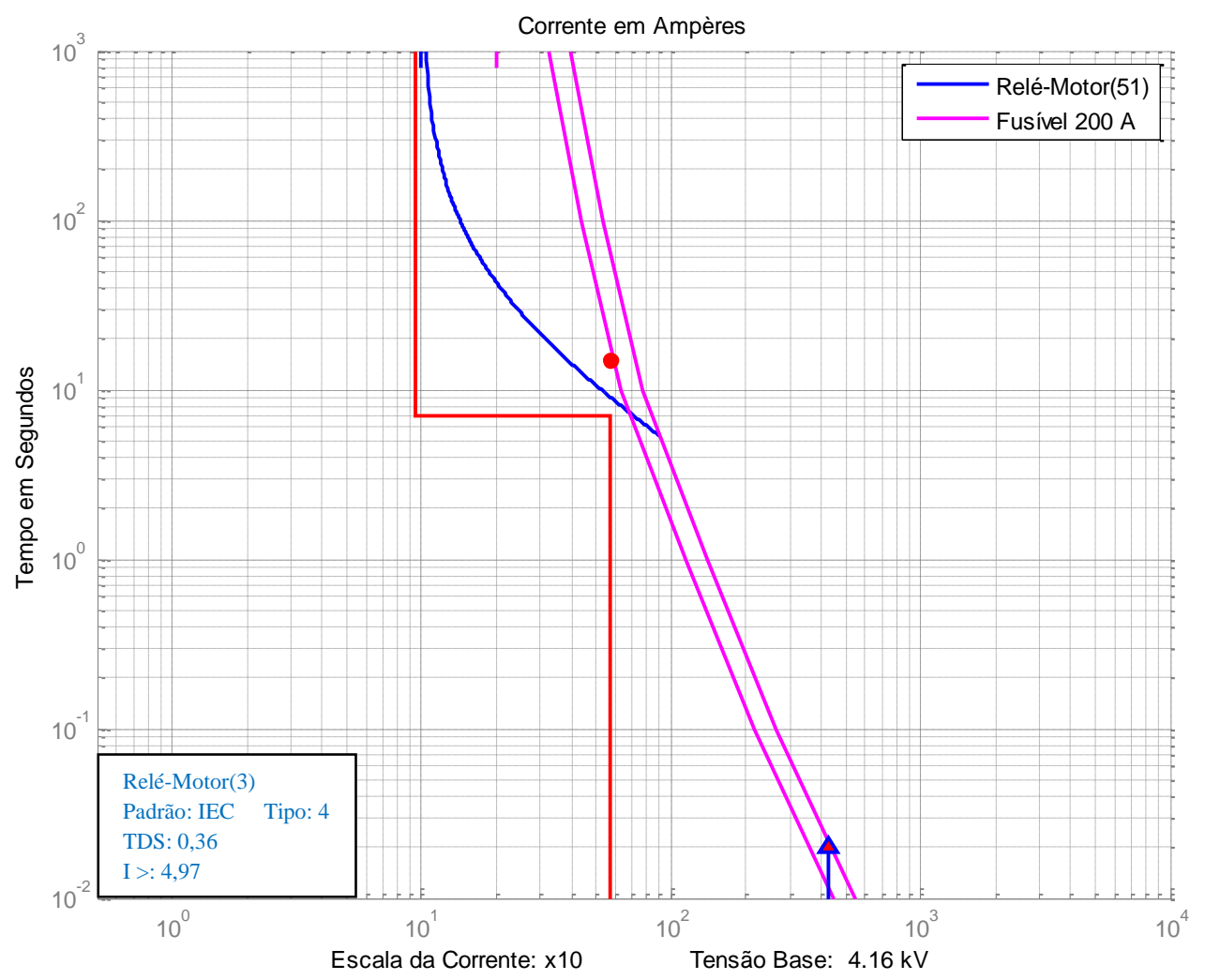

Figura 6.4 - Ajustes para o relé do motor M3.

Para o par (B13, M4), o motor M4 também é protegido por relé e fusível (relé 14 e fusível 2), e o resultado do algoritmo para o relé e o fusível do motor M4 é mostrado na Figura 6.5. 


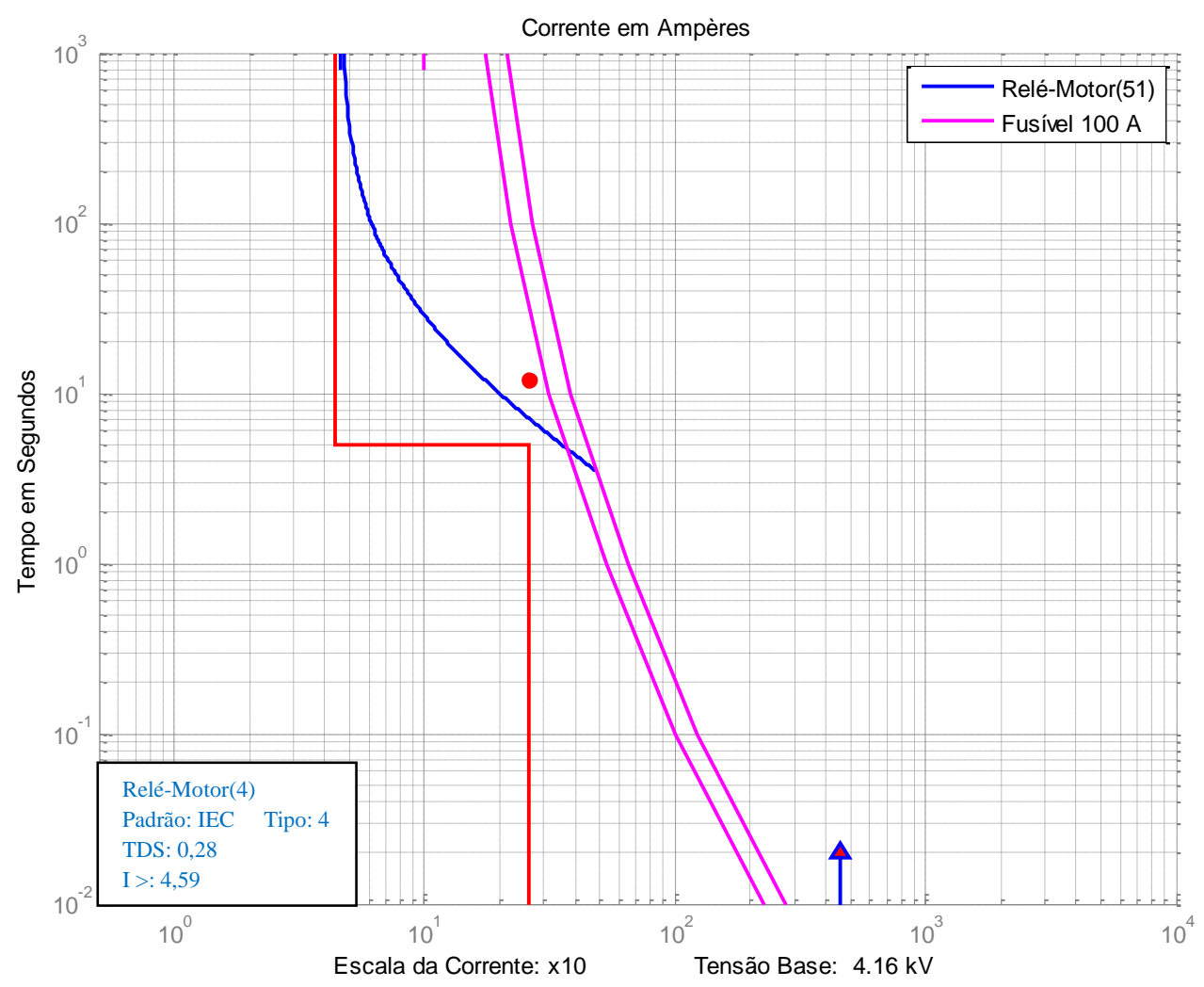

Figura 6.5 - Ajustes para o relé do motor M4.

Para o par (B15, M5), o equipamento associado à barra B15 é o motor M5, protegido pelo relé 16. O resultado do algoritmo para o relé do motor M5 é mostrado na Figura 6.6. 


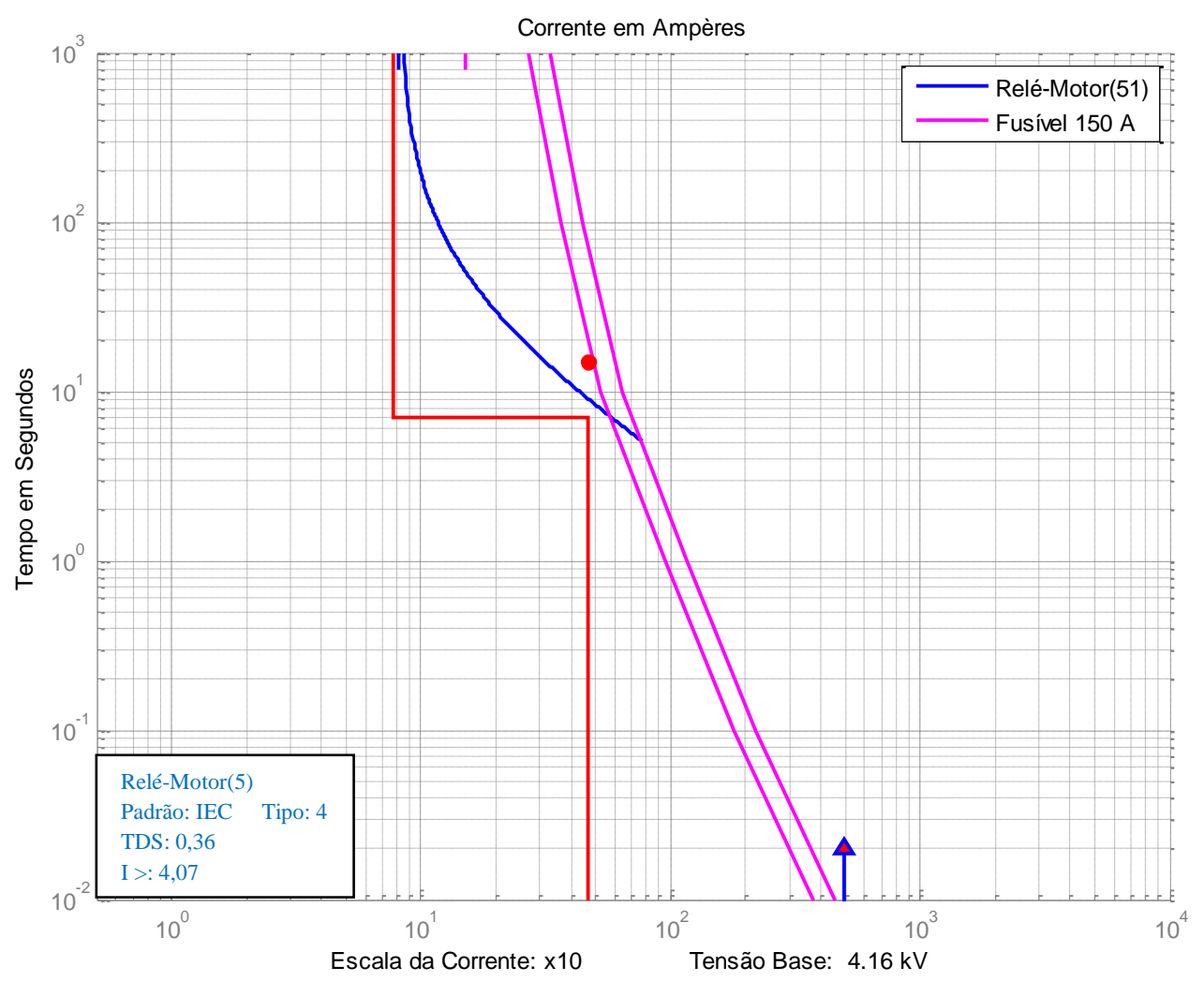

Figura 6.6 - Ajustes para o relé do motor M5.

Seguindo as linhas da matriz Rede (Tabela 6.18), os próximos elementos a serem processados são indicados pelo par (B15, M6), cujo equipamento associado à barra B15 é o motor M6 e seu dispositivo de proteção é o relé 17. O resultado do algoritmo de ajuste do relé do motor M6 é mostrado na Figura 6.7. 


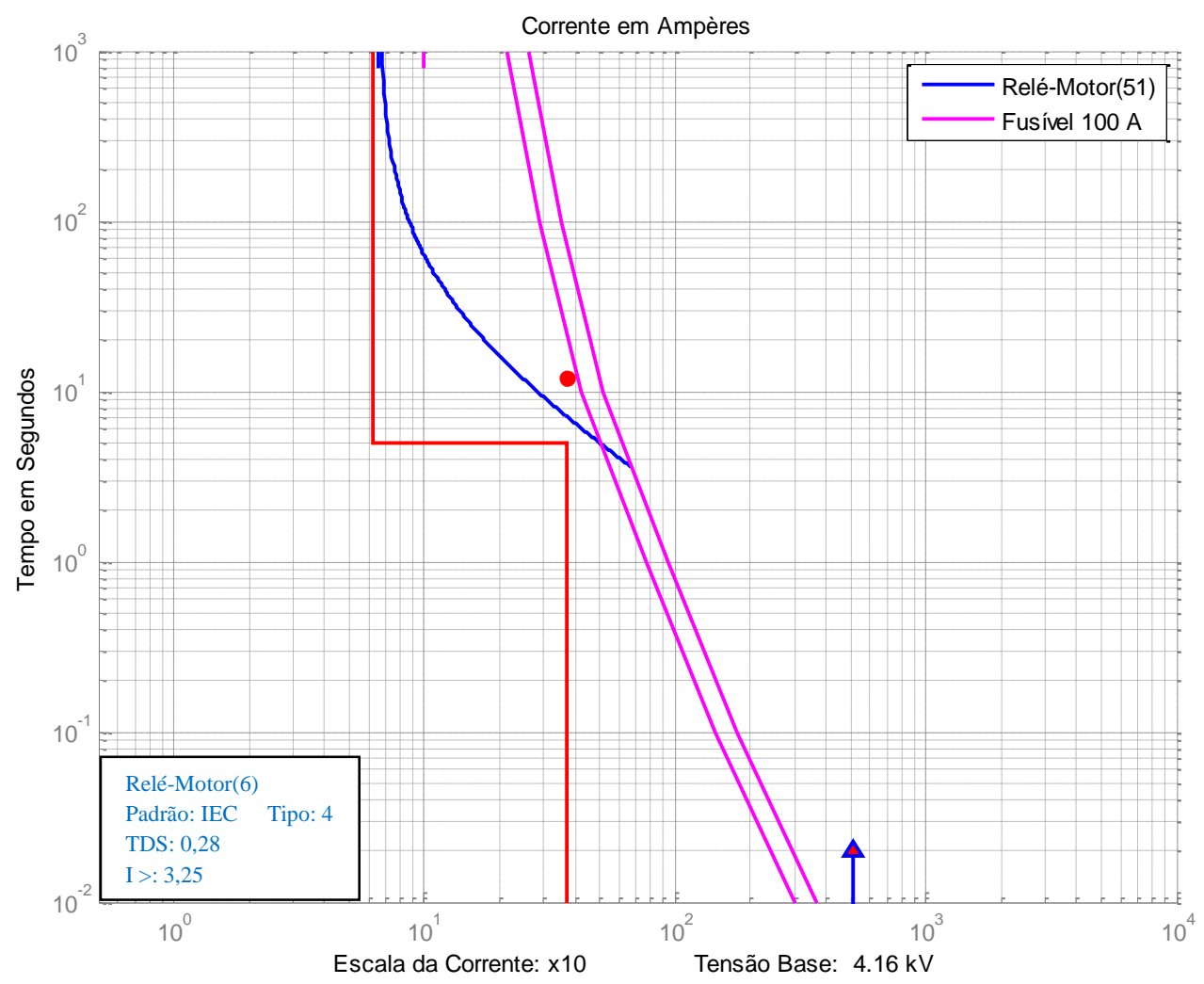

Figura 6.7 - Ajustes para o relé do motor M6.

O par (B17, M7) indica que o equipamento associado à barra B17 é o motor M7, protegido pelo disjuntor de baixa tensão 3. A verificação dos ajustes deste disjuntor é mostrada na Figura 6.8. 


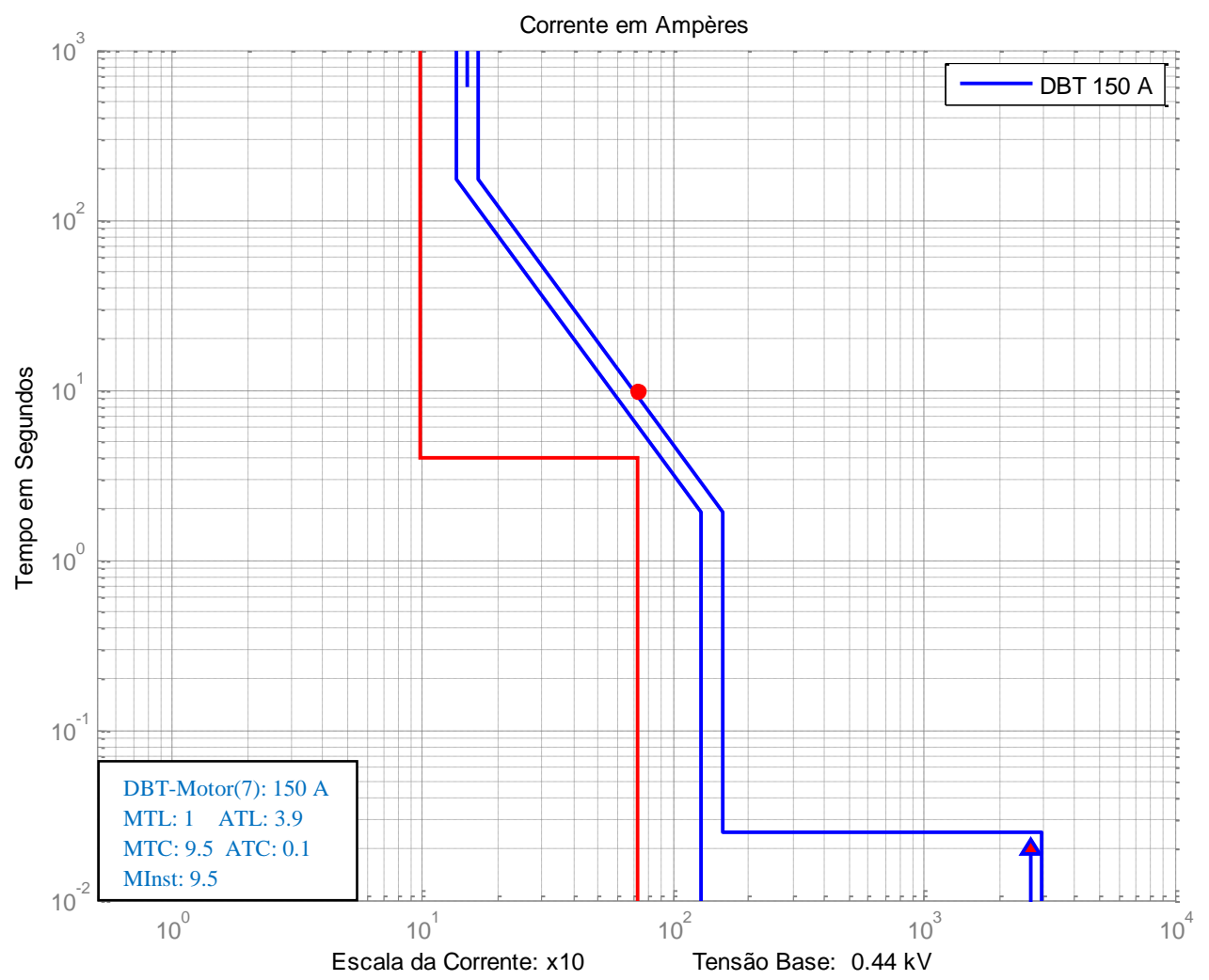

Figura 6.8 - Verificação de ajustes do DBT do motor M7.

Finalmente, o processamento do par (B17, M8) indica o fim do segundo passo do mecanismo de busca e de ajuste do programa. Esse par indica que o equipamento associado à barra B17 é o motor M8, protegido pelo disjuntor de baixa tensão 4 . O resultado do algoritmo de verificação de ajuste para esse disjuntor de baixa tensão é mostrado na Figura 6.9. 


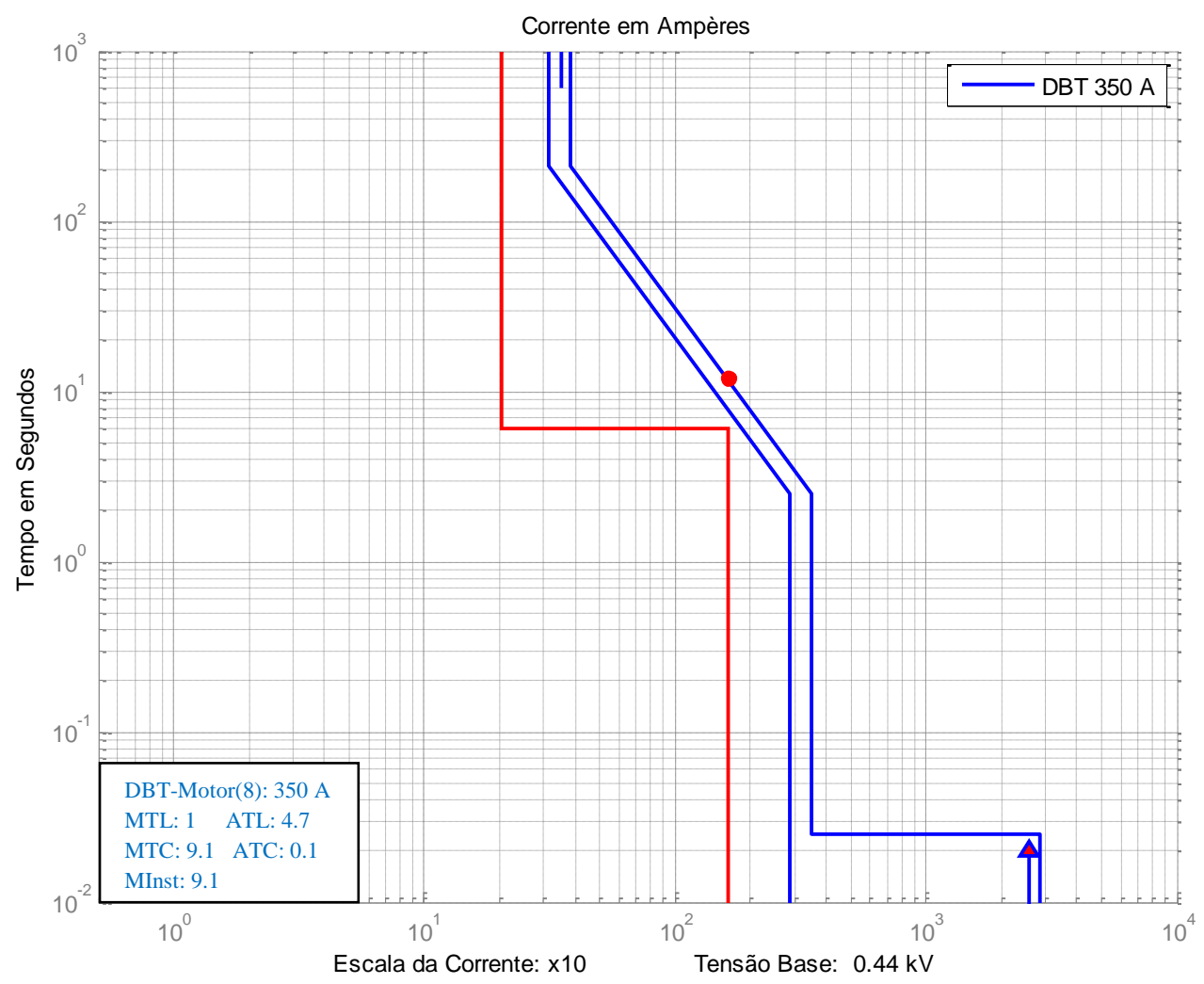

Figura 6.9 - Verificação de ajustes do DBT do motor M8.

Com o término do segundo passo, o programa executa o algoritmo para identificar os dispositivos de maiores ajustes em cada barra recém processada. Identificados esses elementos, as linhas da matriz Rede correspondentes aos dispositivos com menores ajustes são excluídas da matriz Rede juntamente com as barras já processadas, originando uma nova matriz, conforme mostra a Tabela 6.19.

Tabela 6.19 - Matriz Rede para o terceiro passo.

\begin{tabular}{|c|c|c|}
\hline Motor & $\mathrm{B}(1)$ & $\mathrm{B}(2)$ \\
\hline 1 & 03 & 01 \\
\hline 3 & 03 & 01 \\
\hline 5 & 03 & 01 \\
\hline 8 & 03 & 01 \\
\hline
\end{tabular}

Analisando a Tabela 6.19 e Figura 6.1 observa-se que a barra B03 é comum a todos os trechos restantes e o próximo passo é definir os ajustes daqueles dispositivos que ainda não tiveram seus ajustes calculados e que pertençam ao caminho desde o motor indicado na coluna "Motor" até a barra B03. Os motores relacionados na coluna "Motores" são aqueles 
cujos dispositivos de proteção possuem os maiores ajustes. No caso do motor M1, embora o ajuste do DBT que o protege seja idêntico ao DBT do motor M2, ele foi selecionado no processo de busca por ser o primeiro.

Continuando o processamento do programa, o par (B03, M2) indica que o próximo dispositivo de proteção a ter seus ajustes calculados é o relé 4 (ID $=4$ na Tabela 6.14), referido nas figuras como Relé-Painel (B04). O resultado do algoritmo de ajuste para este relé é mostrado na Figura 6.10.

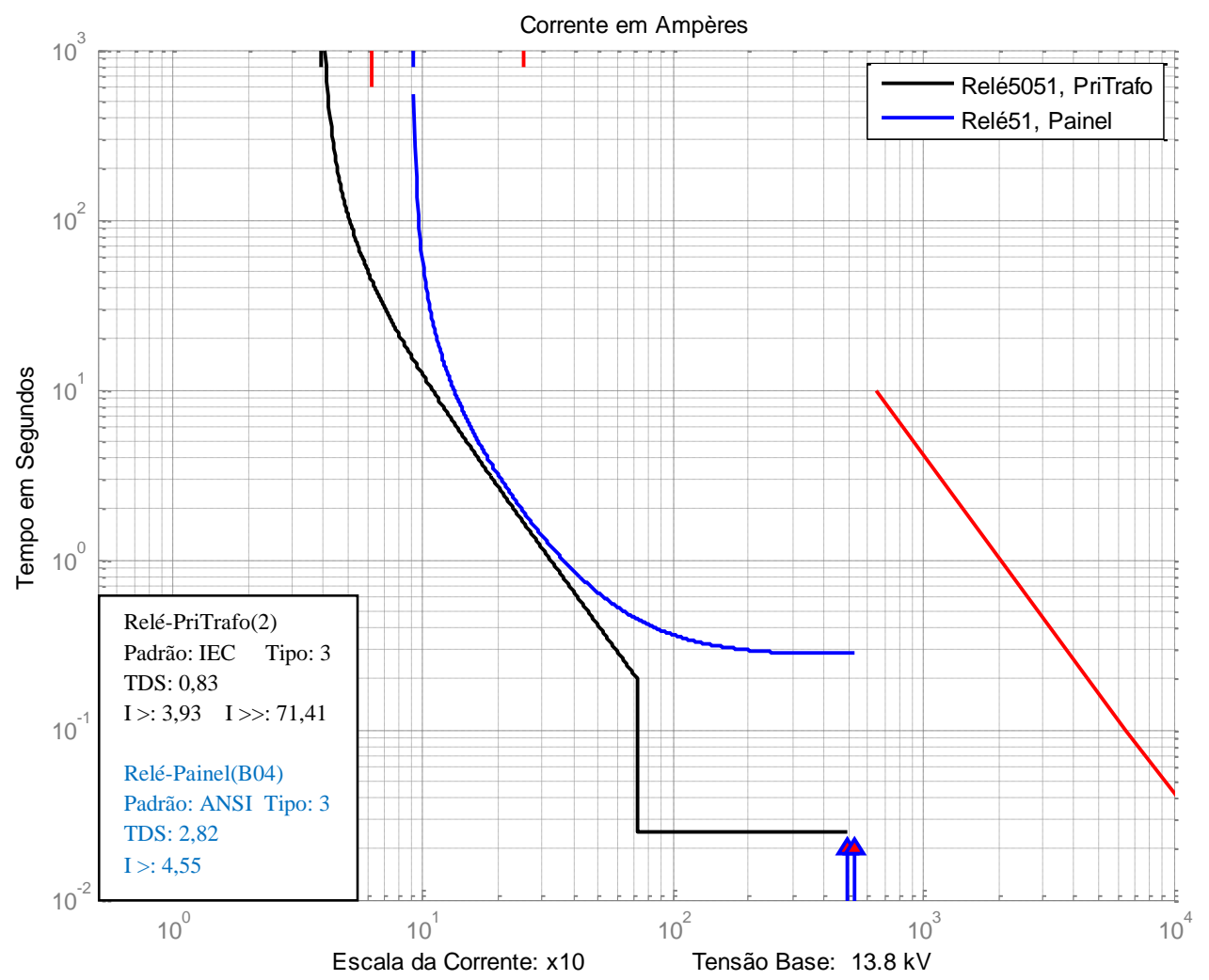

Figura 6.10 - Ajustes para o Relé-Painel(B04).

Para o par (B03, M3), o equipamento associado à barra B03 e indicado pelo motor M3 é o transformador T4, cujo dispositivo de proteção é o relé 5 instalado no lado primário e o relé 12 no lado secundário. O resultado do algoritmo de ajustes para esses relés é mostrado na Figura 6.11. 


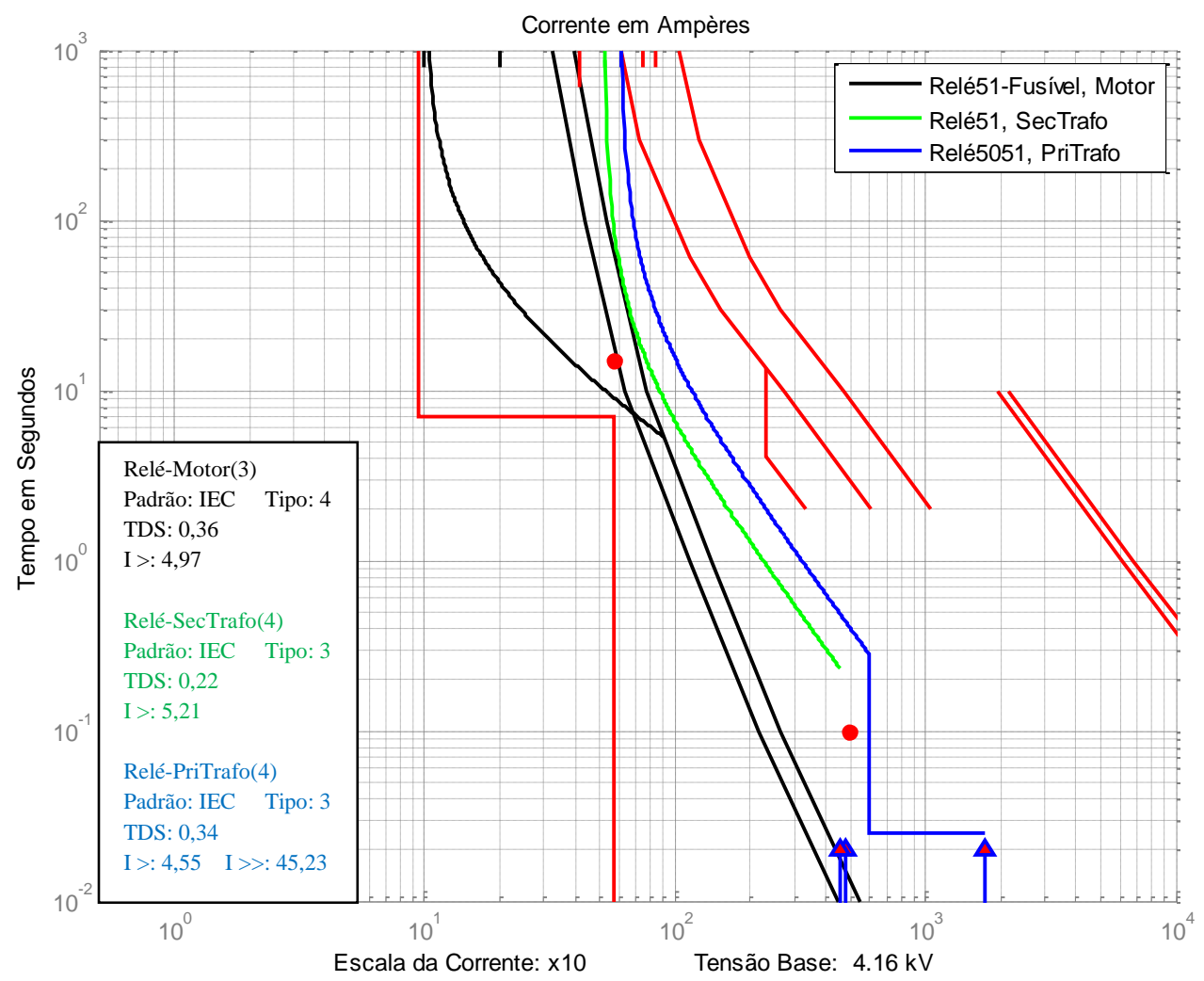

Figura 6.11 - Coordenação entre os dispositivos de proteção do transformador T4 e motor M3.

Para o par (B03, M5), o equipamento associado à barra B03 indicado pelo motor M5 é o transformador T5, cujo dispositivo de proteção é o relé 6 no lado primário e o relé 15 no lado secundário. O resultado do algoritmo de ajustes para esses relés é mostrado na Figura 6.12. 


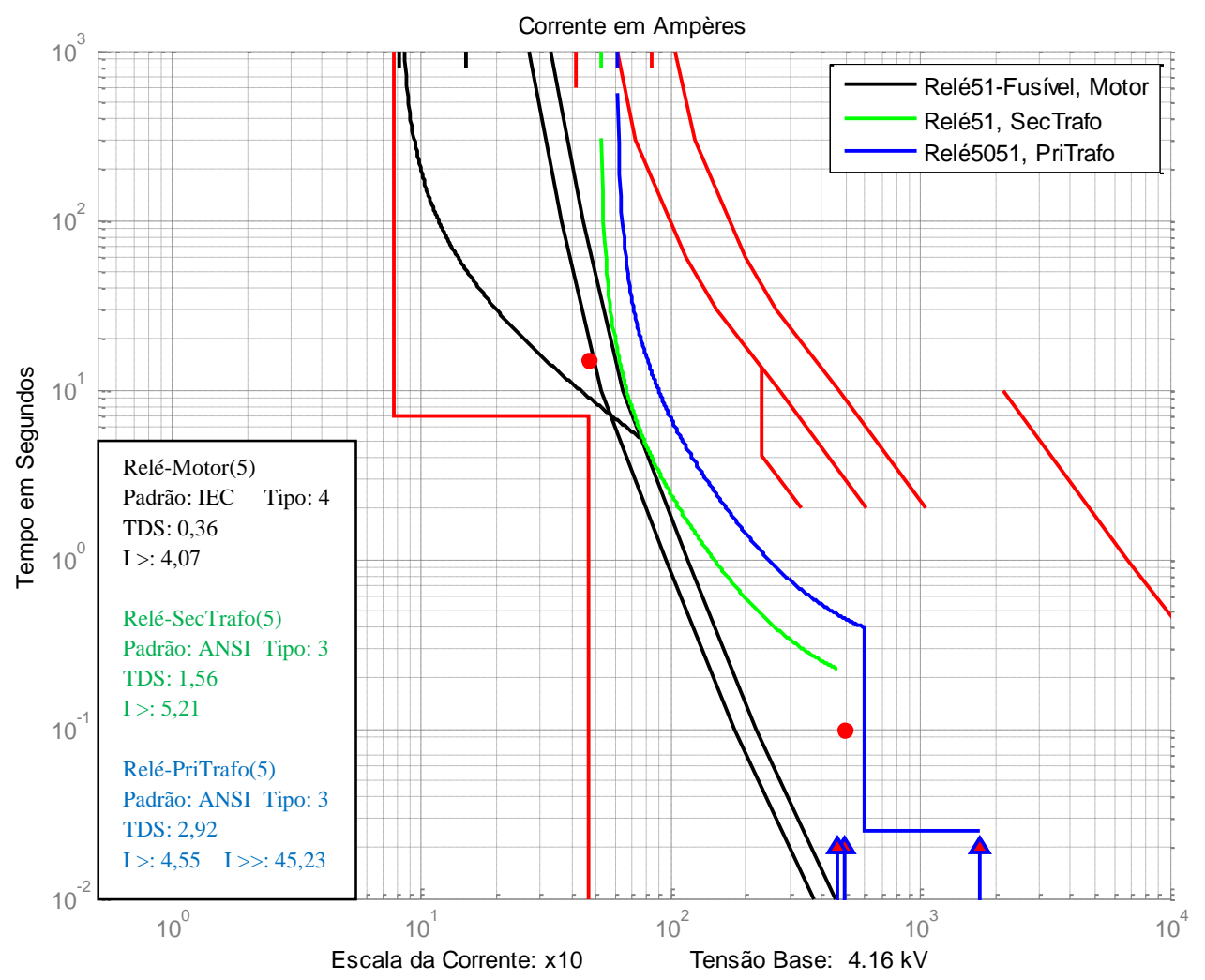

Figura 6.12 - Coordenação entre os dispositivos de proteção do transformador T5 e motor M5.

Finalmente para o par (B03, M8), o equipamento associado à barra B03 indicado pelo motor M8 é o transformador T6, cujo dispositivo de proteção é o relé 7 no lado primário e o relé 18 no lado secundário. O resultado do algoritmo de ajustes para relé no lado primário e secundário do transformador T6 é mostrado na Figura 6.13. 


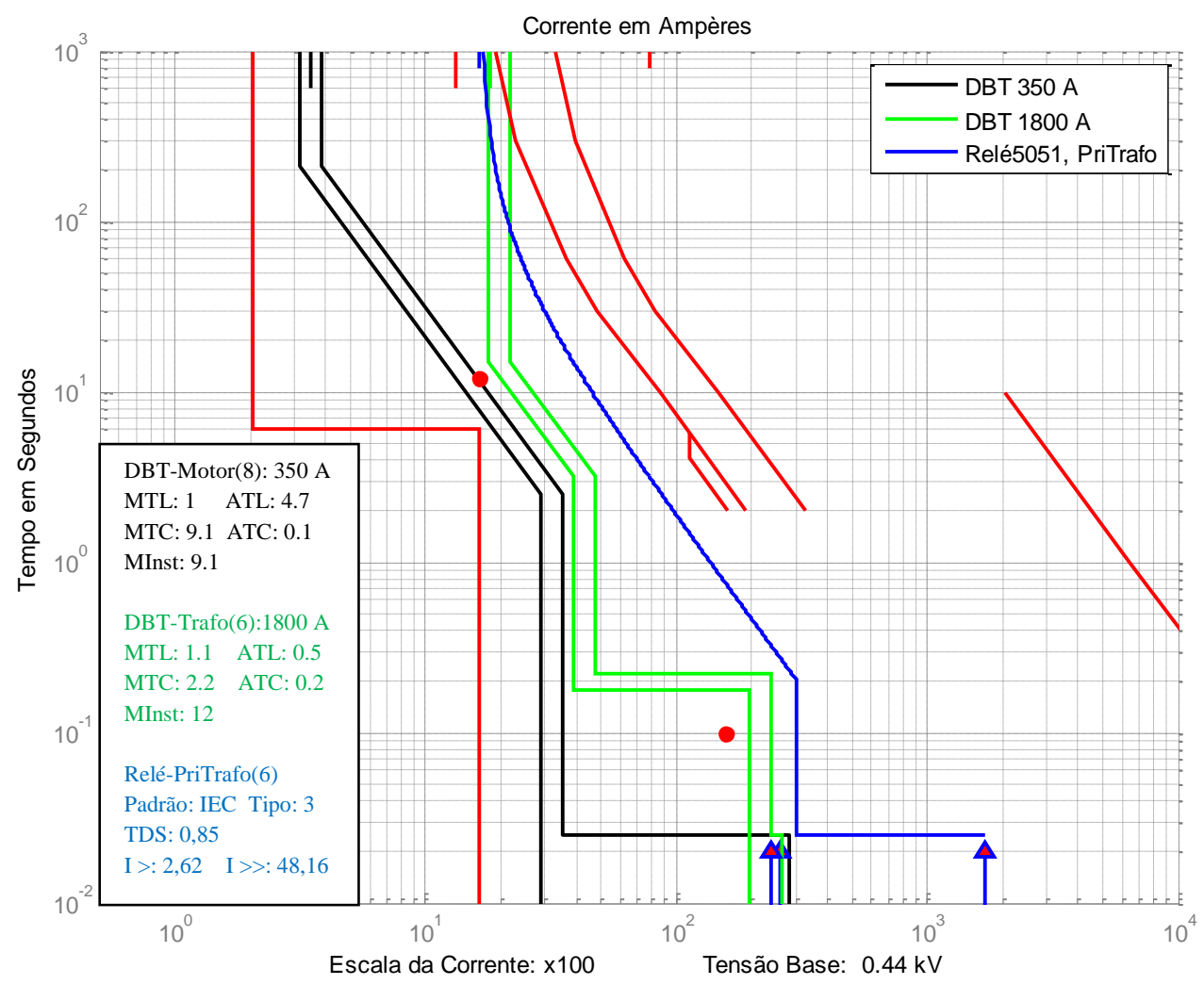

Figura 6.13 - Coordenação entre os dispositivos de proteção do transformador T6 e motor M8.

Findado o processamento da matriz Rede para o terceiro passo, o programa executa o algoritmo de maior ajuste para definir qual dispositivo de proteção conectado nas saídas da barra B03 é o que tem o maior ajuste. Como resultado, é encontrado o par (B01, M5), sendo que o equipamento associado à barra B01 indicado pelo motor M5 é o transformador T1, cujos dispositivos de proteção associados são o relé 2 no lado primário e o relé 3 no lado secundário. Logo, a nova matriz Rede é composta por apenas uma linha conforme mostra a Tabela 6.20, e os ajustes dos relés 2 e 3 são mostrados na Figura 6.14.

Tabela 6.20 - Matriz Rede para o último passo.

\begin{tabular}{|c|c|}
\hline Motor & $\mathrm{B}(1)$ \\
\hline 5 & 01 \\
\hline
\end{tabular}




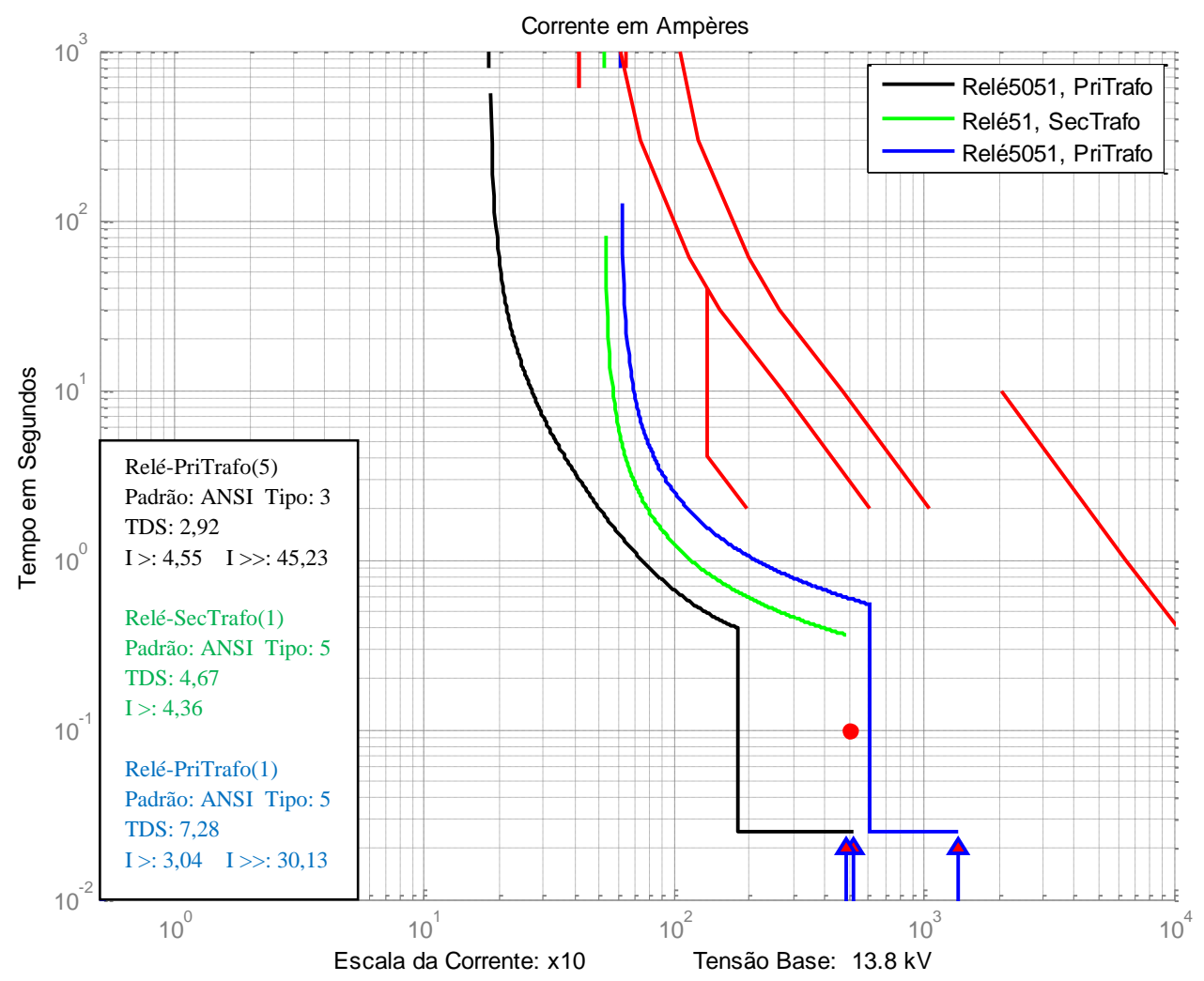

Figura 6.14 - Coordenação entre o relé do primário do transformador T5 e os relés associados ao transformador $\mathrm{T} 1$.

Procedendo a uma nova busca da barra mais distante da barra da subestação, o resultado foi a barra B01, indicando que o percurso das barras da rede elétrica chegou ao fim. O programa então executa o algoritmo de verificação de coordenação do último relé processado com dispositivo de proteção da subestação. O resultado é mostrado na Figura 6.15, observando-se que a coordenação está garantida.

Em todas as situações em que o dispositivo de proteção instalado no secundário dos transformadores era disjuntor de baixa tensão, observa-se que o ajuste do relé do primário do transformador foi automaticamente definido no mesmo valor do ajuste da unidade de tempo longo do disjuntor. Isso foi necessário para que a região de dano do transformador não fosse violada pelo relé instalado no lado primário. 


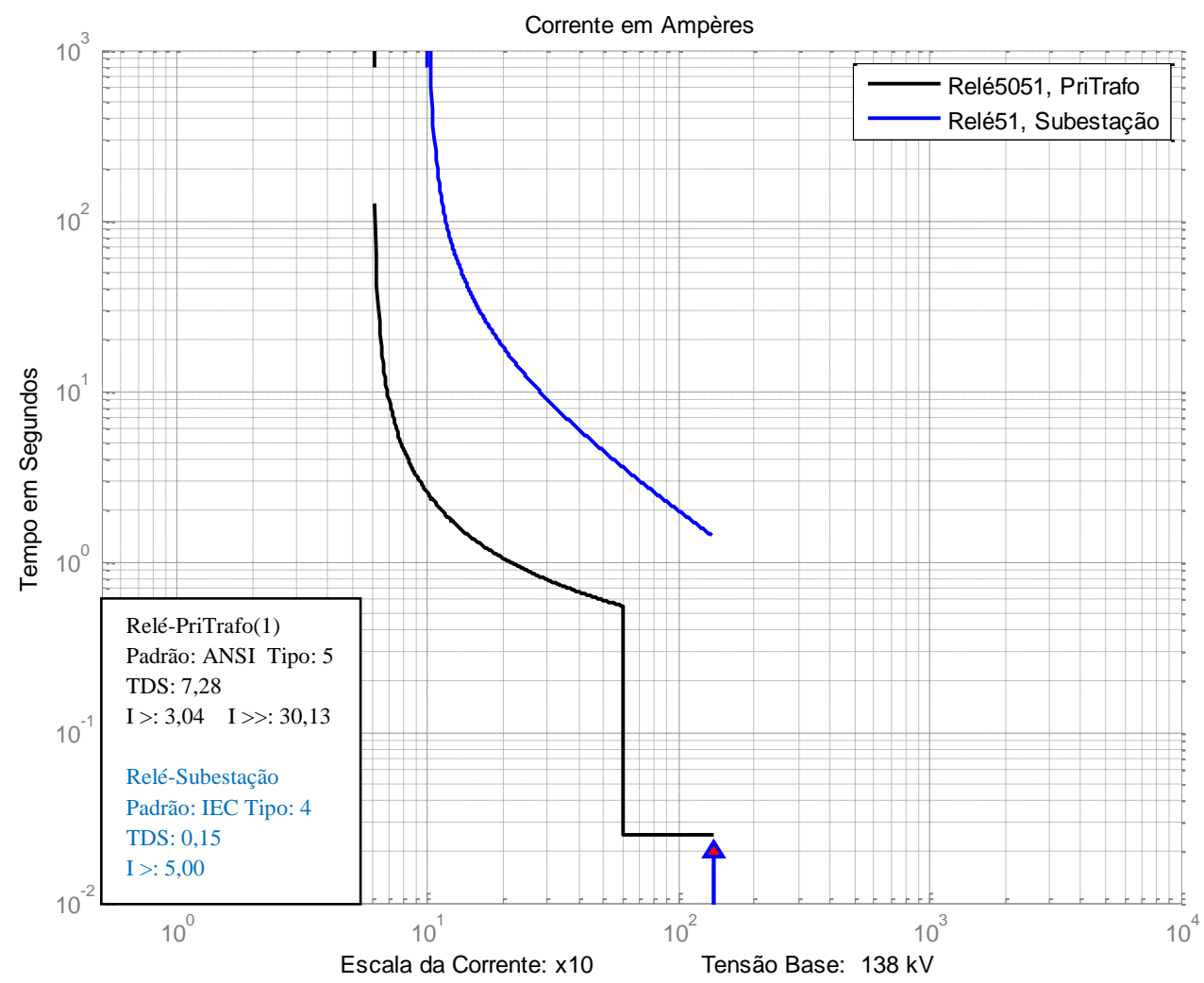

Figura 6.15 - Verificação da coordenação com o relé da subestação.

\subsubsection{Proteção Fase-Terra}

Para proteção fase-terra é necessário formar novamente a matriz Rede mostrada na Tabela 6.21, composta de todas as barras do sistema elétrico, desde cada motor até a barra da subestação.

Tabela 6.21 - Matriz Rede inicial.

\begin{tabular}{|c|c|c|c|c|}
\hline Motor & $\mathrm{B}(1)$ & $\mathrm{B}(2)$ & $\mathrm{B}(3)$ & $\mathrm{B}(4)$ \\
\hline 1 & 07 & 04 & 03 & 01 \\
\hline 2 & 10 & 04 & 03 & 01 \\
\hline 3 & 13 & 03 & 01 & 0 \\
\hline 4 & 13 & 03 & 01 & 0 \\
\hline 5 & 15 & 03 & 01 & 0 \\
\hline 6 & 15 & 03 & 01 & 0 \\
\hline 7 & 17 & 03 & 01 & 0 \\
\hline 8 & 17 & 03 & 01 & 0 \\
\hline
\end{tabular}

Assim como na execução do programa para o ajuste da proteção de fase, o algoritmo de busca retorna os pares (barra, motor). Na primeira execução os pares são: (B07, M1) e 
(B10, M2). Iniciando pelo par (B07, M1), o resultado é mostrado na Figura 6.16, em que se mostra o ajuste da unidade de proteção de terra do disjuntor de baixa tensão que protege o motor M1.

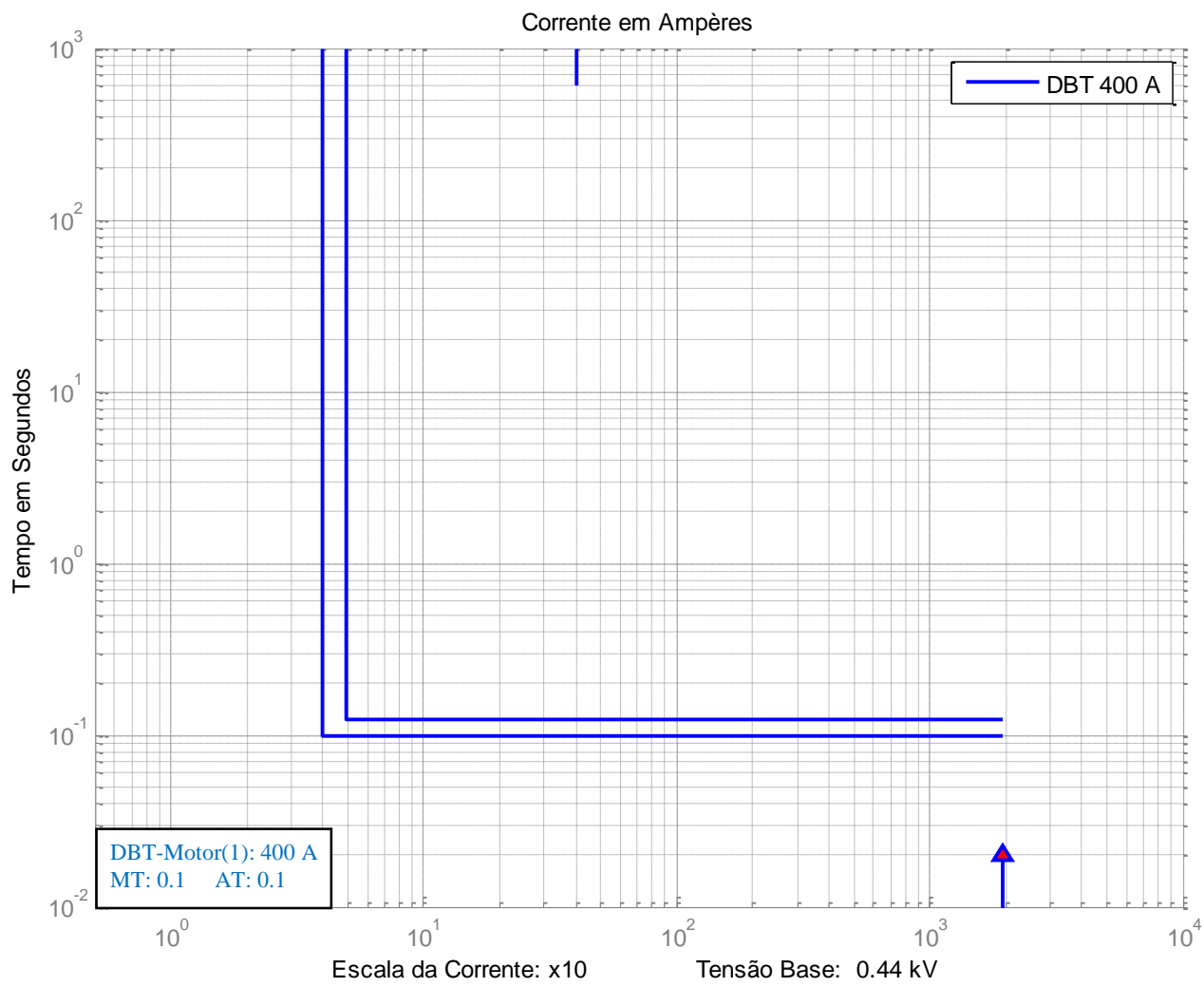

Figura 6.16 - Ajuste da proteção de terra do DBT para o motor M1.

Para o par (B10, M2) definido na segunda linha da matriz Rede, o procedimento é o mesmo aplicado ao disjuntor do motor M1. Como os motores M1 e M2 são idênticos e os ajustes do DBT também são, a verificação dos ajustes do DBT do motor M2 é tal qual mostrada na Figura 6.16.

A eliminação dos elementos da matriz Rede é similar ao algoritmo de proteção de fase. Seguindo com a execução do algoritmo, tem-se a formação da nova matriz Rede mostrada na Tabela 6.22. 
Tabela 6.22 - Matriz Rede para o segundo passo.

\begin{tabular}{|c|c|c|c|}
\hline Motor & $\mathrm{B}(1)$ & $\mathrm{B}(2)$ & $\mathrm{B}(3)$ \\
\hline 1 & 04 & 03 & 01 \\
\hline 2 & 04 & 03 & 01 \\
\hline 3 & 13 & 03 & 01 \\
\hline 4 & 13 & 03 & 01 \\
\hline 5 & 15 & 03 & 01 \\
\hline 6 & 15 & 03 & 01 \\
\hline 7 & 17 & 03 & 01 \\
\hline 8 & 17 & 03 & 01 \\
\hline
\end{tabular}

Para o par (B04, M1), o equipamento associado à barra B04 é o transformador T2. Verificado o tipo de conexão dos enrolamentos do transformador, delta-estrela com neutro solidamente aterrado, primeiro é realizada a coordenação com a proteção de terra do relé do motor M1 e os resultados são mostrados na Figura 6.17. Os ajustes do relé do lado primário são mostrados na Figura 6.18.

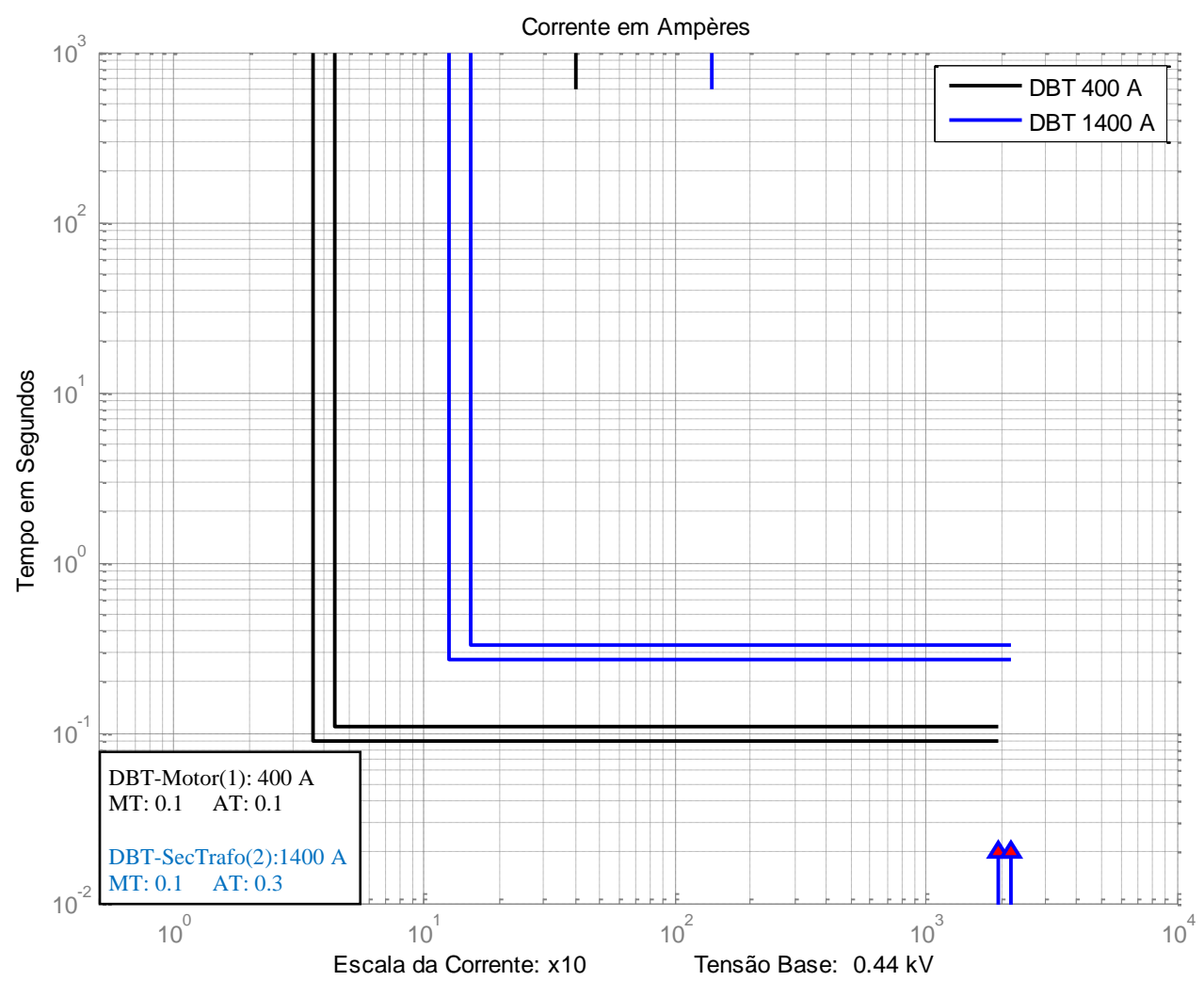

Figura 6.17 - Coordenação da proteção fase-terra do secundário do transformador T2 e motor M1. 


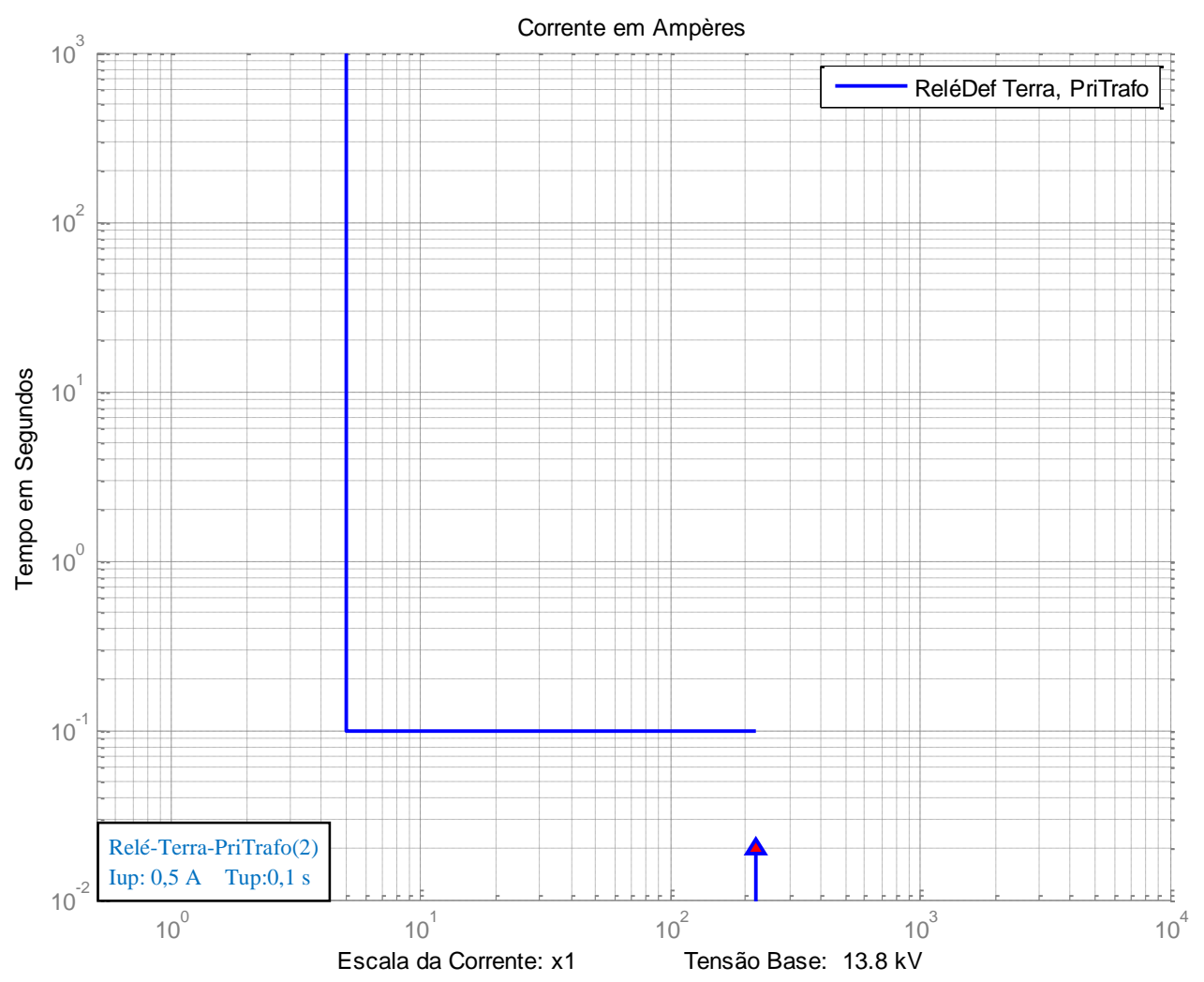

Figura 6.18 - Ajustes para o relé de terra do primário do transformador T2.

Para o par (B04, M2) da matriz Rede, o procedimento é idêntico ao do par (B04, M1), sendo o resultado da coordenação para os dispositivos de proteção do transformador T3 e motor M2 igual ao mostrado na Figura 6.17 e Figura 6.18.

Na seqüência, o resultado do par (B13, M3), referente ao relé de proteção de terra do motor M3, é mostrado na Figura 6.19.

Para os pares (B13, M4); (B15, M5); (B15, M6), que se referem aos motores M4, M5 e M6, respectivamente, os ajustes definidos pelo programa são iguais, pois os TCs e os relés têm as mesmas características. Logo, o resultado da proteção fase-terra desses motores é mostrado na Figura 6.19, representado pelos ajustes do relé do motor M3. 


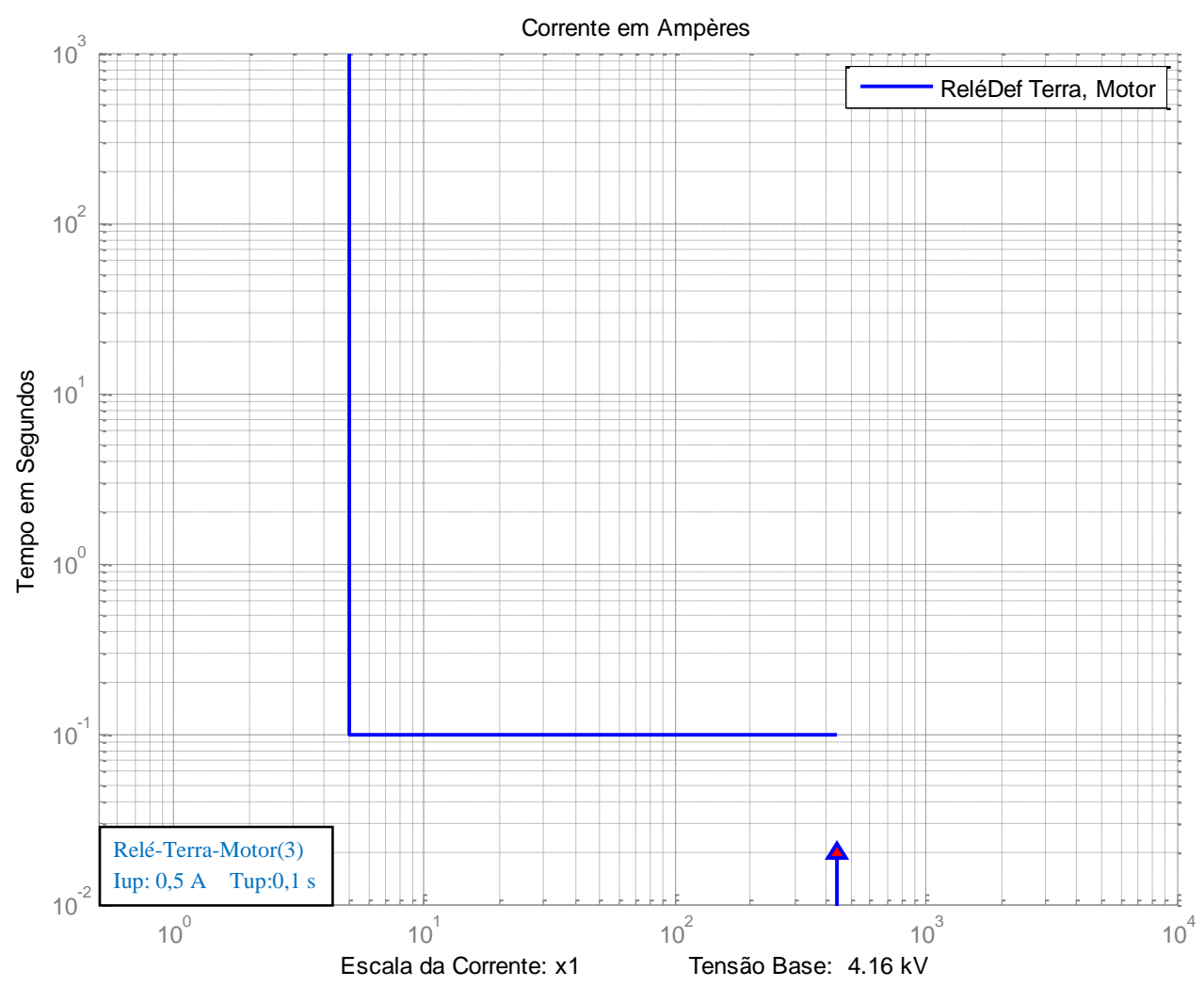

Figura 6.19- Ajustes para o relé de terra do motor M3.

Para o par (B17, M7), referente ao disjuntor do motor M7, o resultado é mostrado na Figura 6.20. 


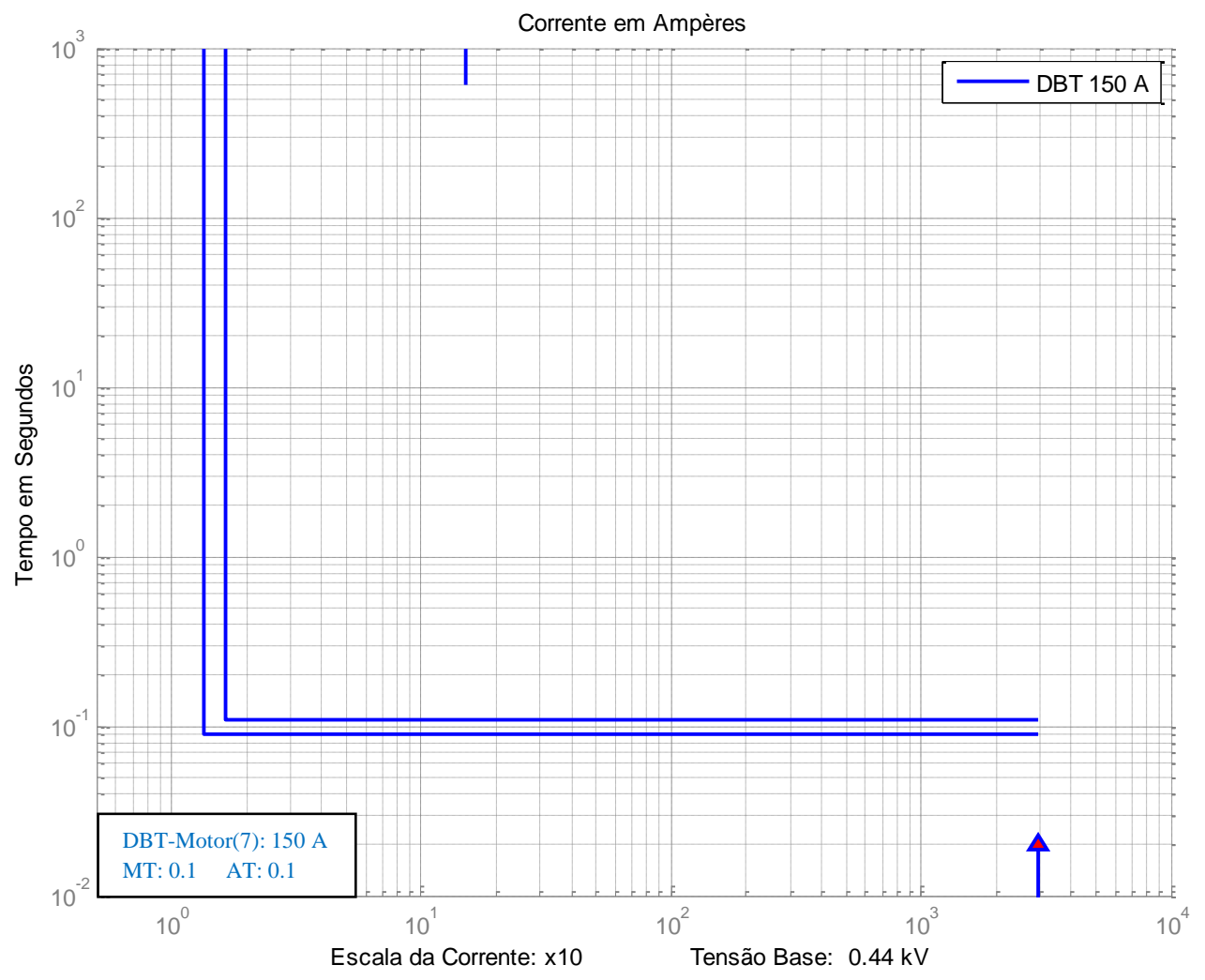

Figura 6.20 - Ajuste do terra do DBT para o motor M7.

Para o par (B17, M8), referente ao disjuntor do Motor M8, o resultado é mostrado na Figura 6.21. 


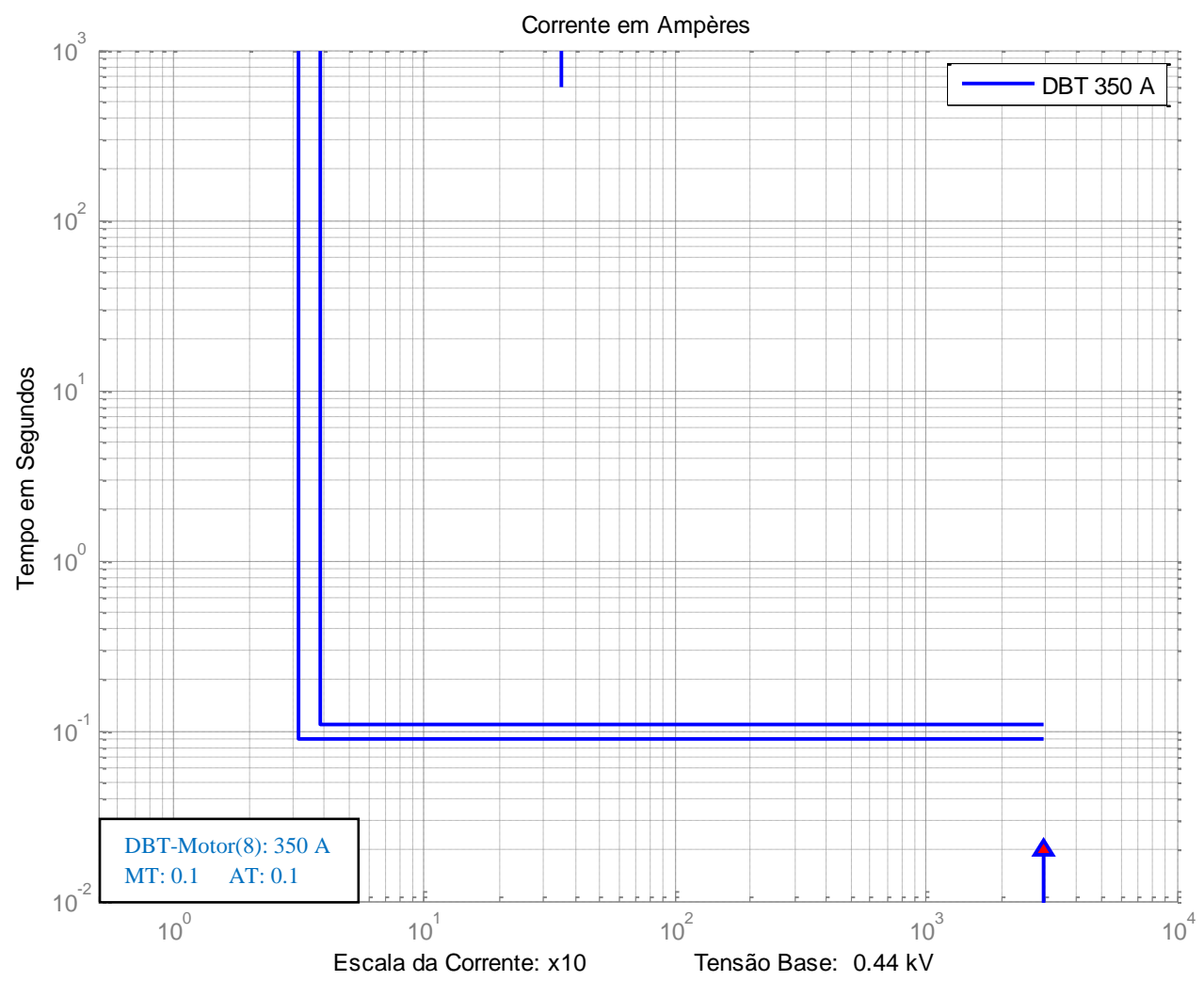

Figura 6.21- Ajuste do terra do DBT para o motor M8.

Novamente é formada uma nova matriz Rede, mostrada na Tabela 6.23, após as devidas eliminações.

Tabela 6.23 - Matriz Rede para o terceiro passo.

\begin{tabular}{|c|c|c|}
\hline Motor & $\mathrm{B}(1)$ & $\mathrm{B}(2)$ \\
\hline 1 & 03 & 01 \\
\hline 3 & 03 & 01 \\
\hline 5 & 03 & 01 \\
\hline 8 & 03 & 01 \\
\hline
\end{tabular}

Analisando a Tabela 6.23, segue a execução para o par (B03, M1) cujo resultado é mostrado na Figura 6.22. 


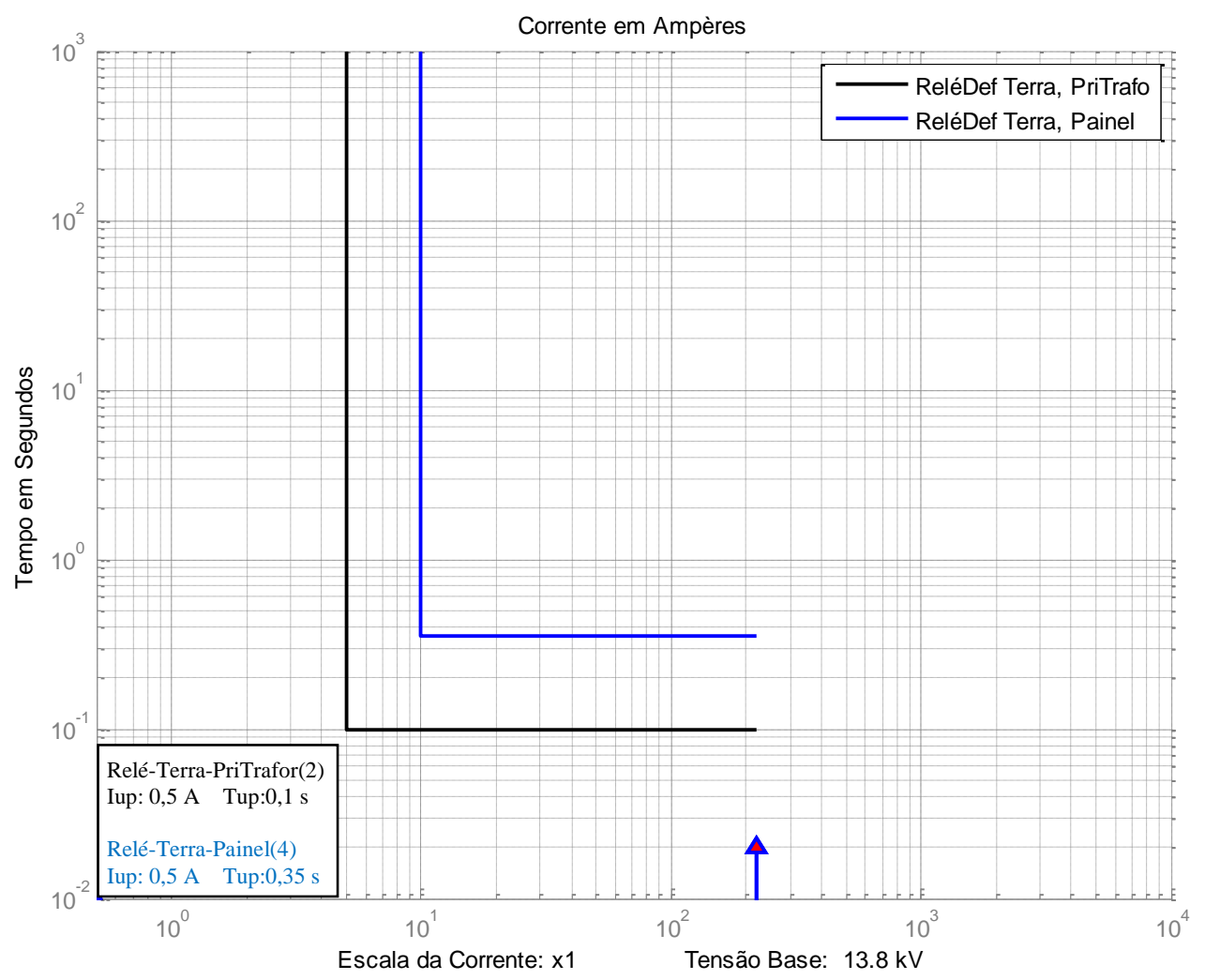

Figura 6.22 - Coordenação da proteção do relé primário do transformador T2 com o relé do painel B04.

Para o par (B03, M3), é verificado o tipo de conexão do enrolamento do transformador T4, delta-estrela com neutro solidamente aterrado, é realizada a coordenação com a proteção de terra do relé do motor M1 e os resultados são mostrados na Figura 6.23. Os ajustes do relé do lado primário são mostrados na Figura 6.24. 


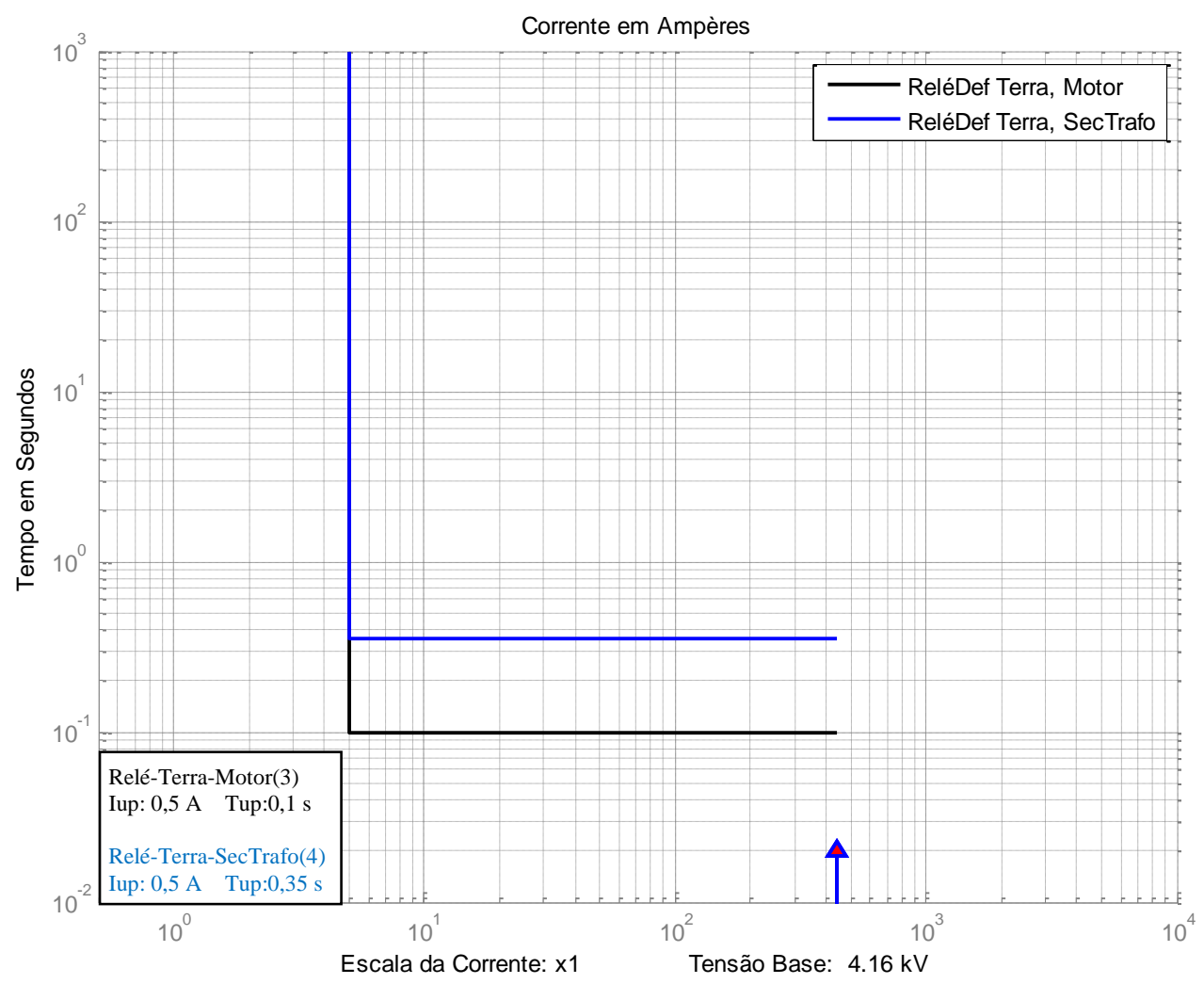

Figura 6.23 - Coordenação da proteção do motor M3 com a do lado secundário do transformador T4.

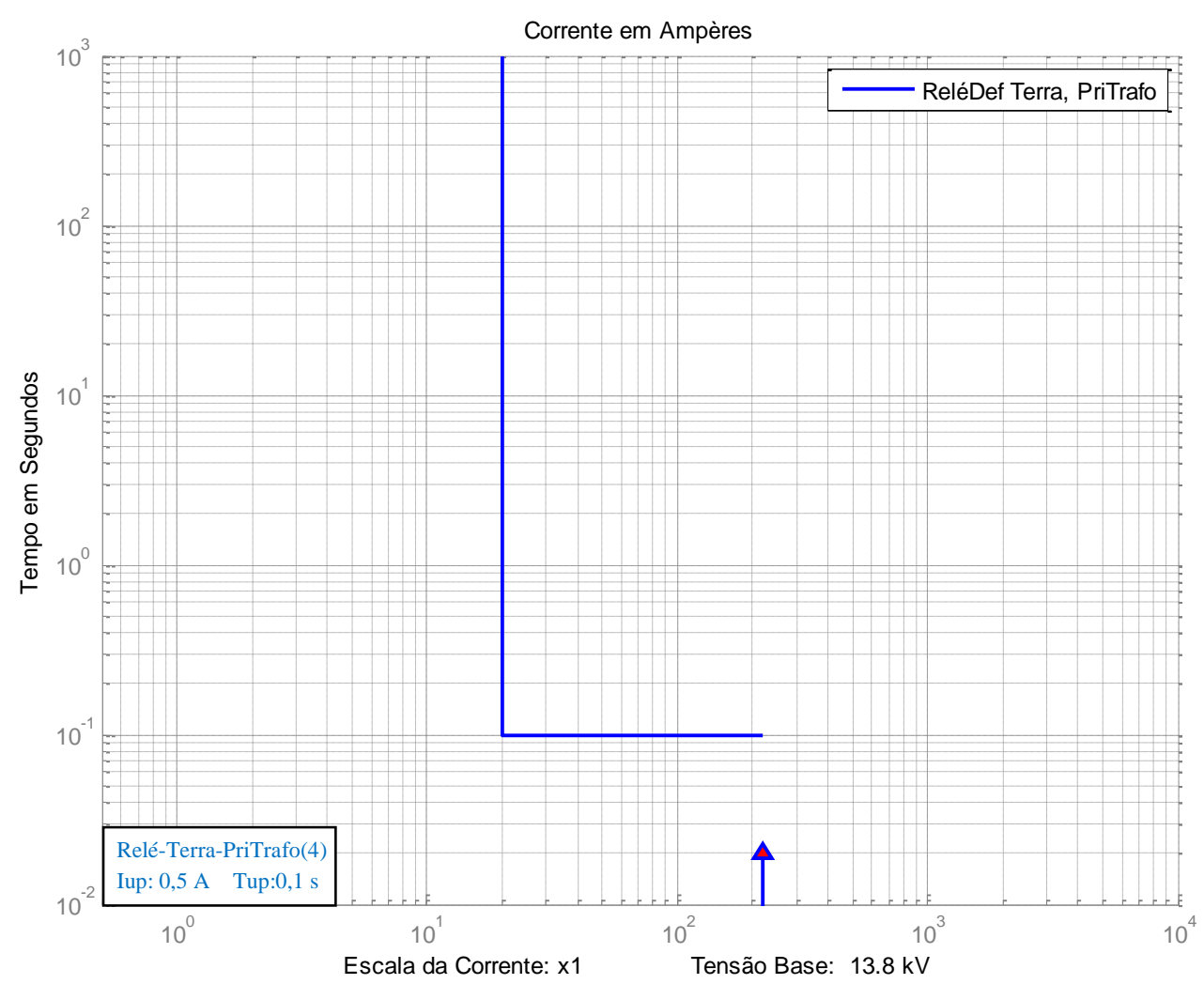

Figura 6.24 - Ajustes do rele de terra do transformador T4. 
Para o par (B03, M5), referentes ao transformador T5 e motor M5, o resultado é idêntico ao par (B03, M3) mostrado na Figura 6.23 e Figura 6.24.

Seguindo a execução do algoritmo, tem-se o par (B03, M8), depois de verificado o tipo de conexão dos enrolamentos do Transformador T6, os resultados dos ajustes para coordenação entre o DBT do secundário do transformador T6 com DBT do motor M8 são mostrados na Figura 6.25 e o ajuste do relé do primário na Figura 6.26.

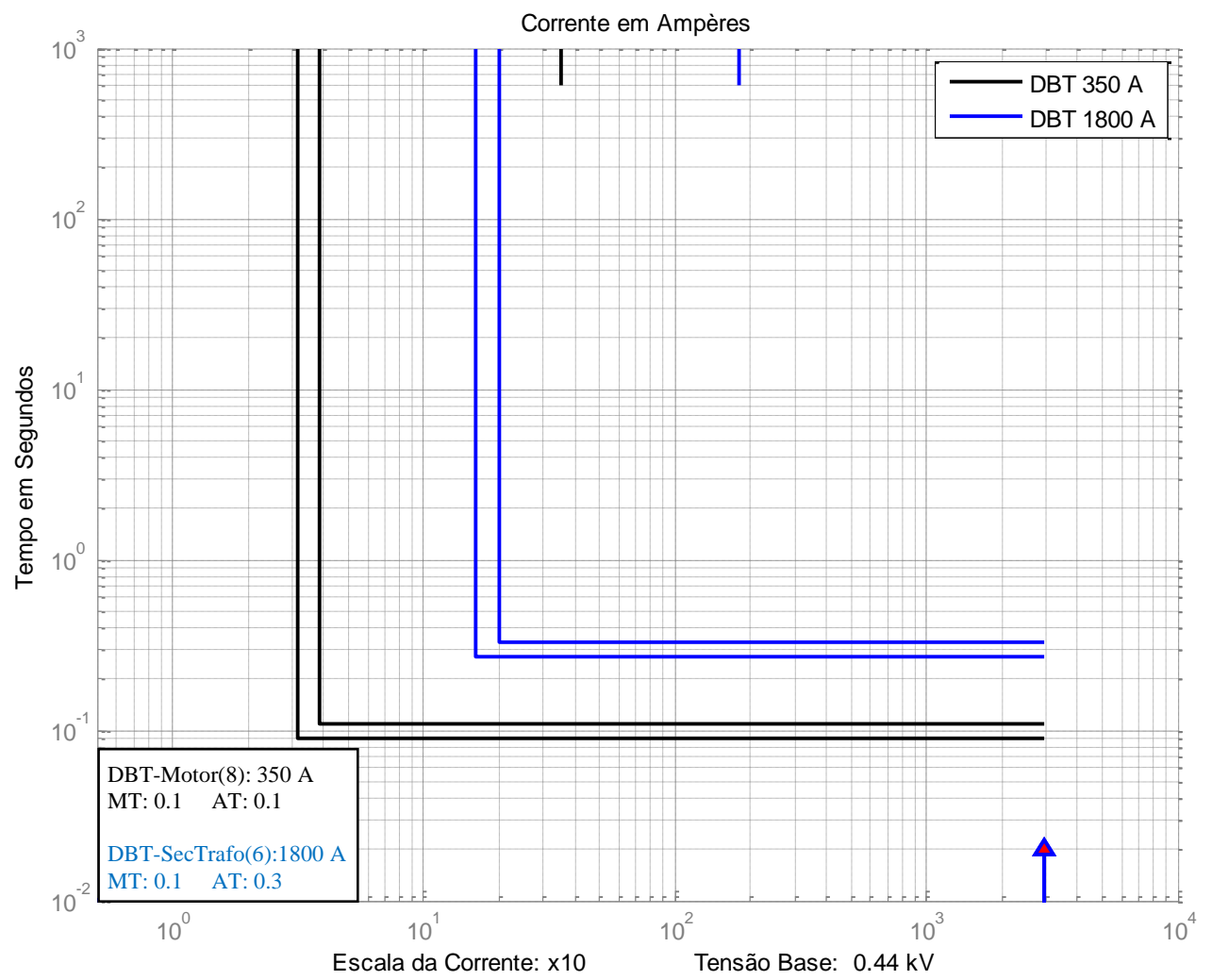

Figura 6.25 - Coordenação da proteção do motor M8 com a do lado secundário do transformador T6. 


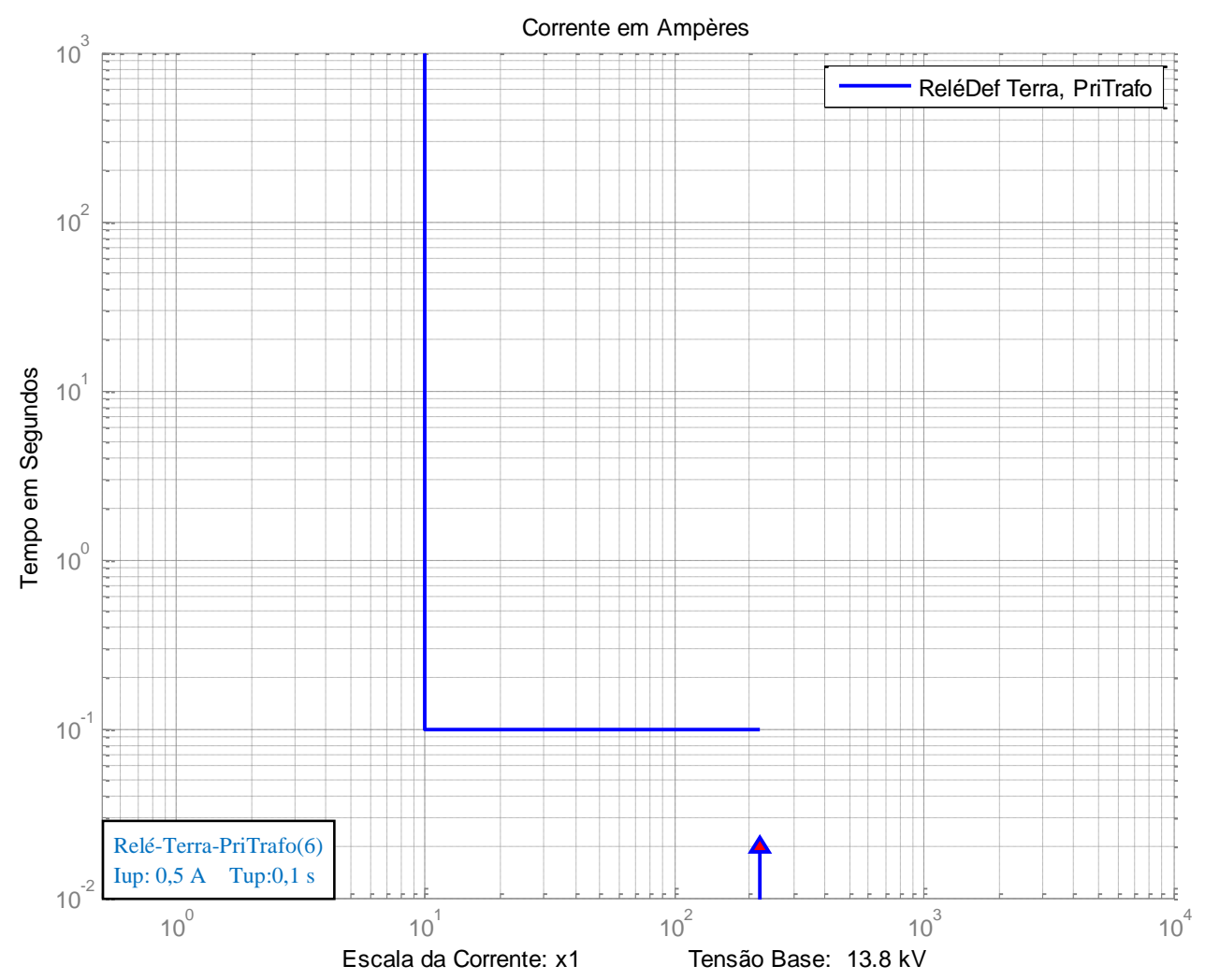

Figura 6.26 - Ajustes do relé de terra do transformador T6.

Finalmente, após todas as eliminações, tem-se a formação da última matriz Rede, mostrada na Tabela 6.24.

Tabela 6.24 - Matriz Rede para o último passo.

\begin{tabular}{|c|c|}
\hline Motor & $\mathrm{B}(1)$ \\
\hline 5 & 01 \\
\hline
\end{tabular}

Para o par (B01, M5), identifica-se o tipo de transformador T1, faz-se a coordenação com o caminho vencedor indicado pelo motor M5, mostrado na Figura 6.27, e o ajuste da proteção de terra do primário na Figura 6.28.

Após todos os ajustes dos dispositivos de proteção do sistema elétrico é necessário verificar se a proteção de terra do relé da subestação está coordenada com a proteção do lado primário do Transformador T1. Neste caso, existe a coordenação, conforme é mostrado na Figura 6.29. 


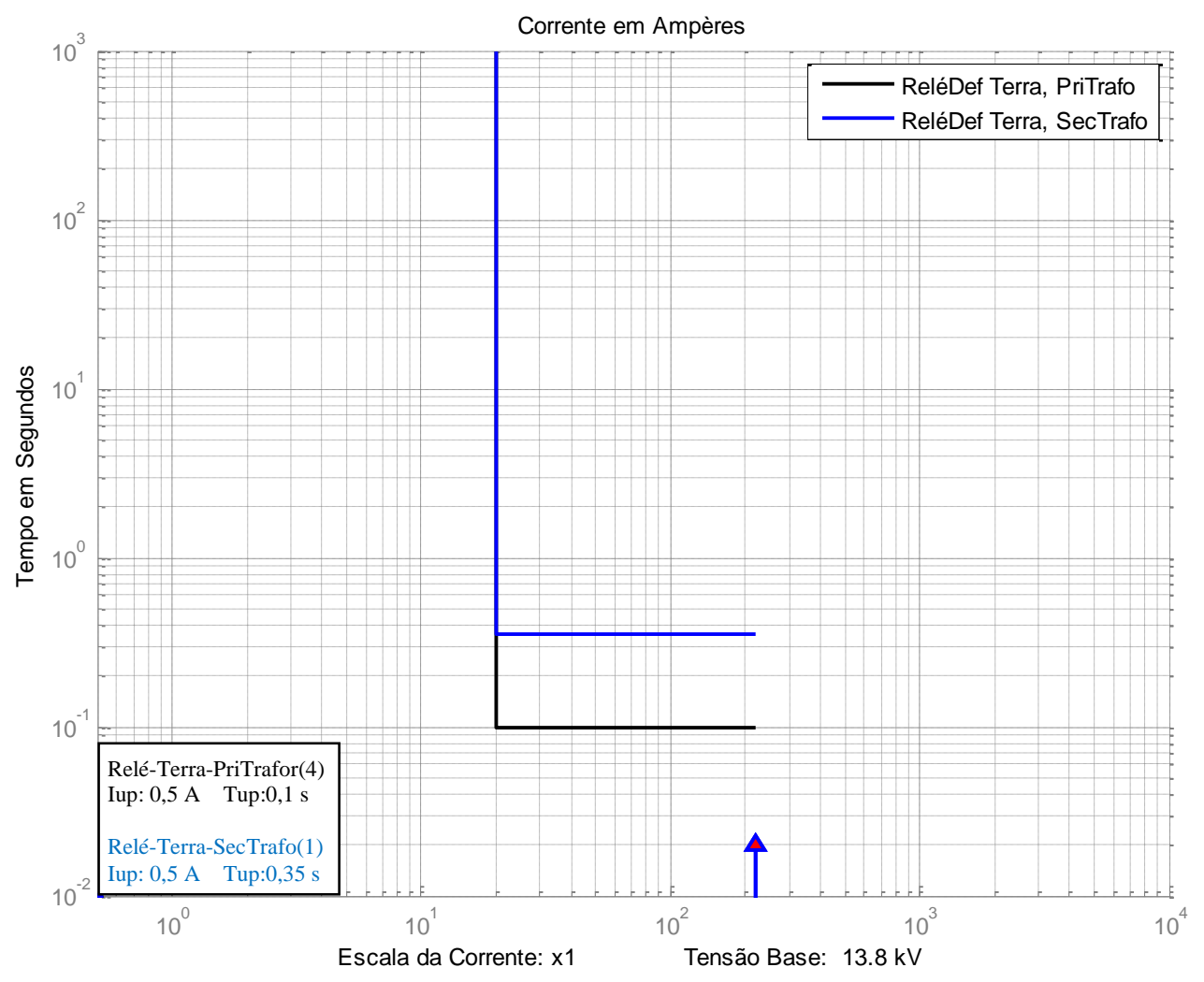

Figura 6.27 - Coordenação da proteção do lado primário do transformador T4 com o lado secundário do transformador $\mathbf{T} 1$.

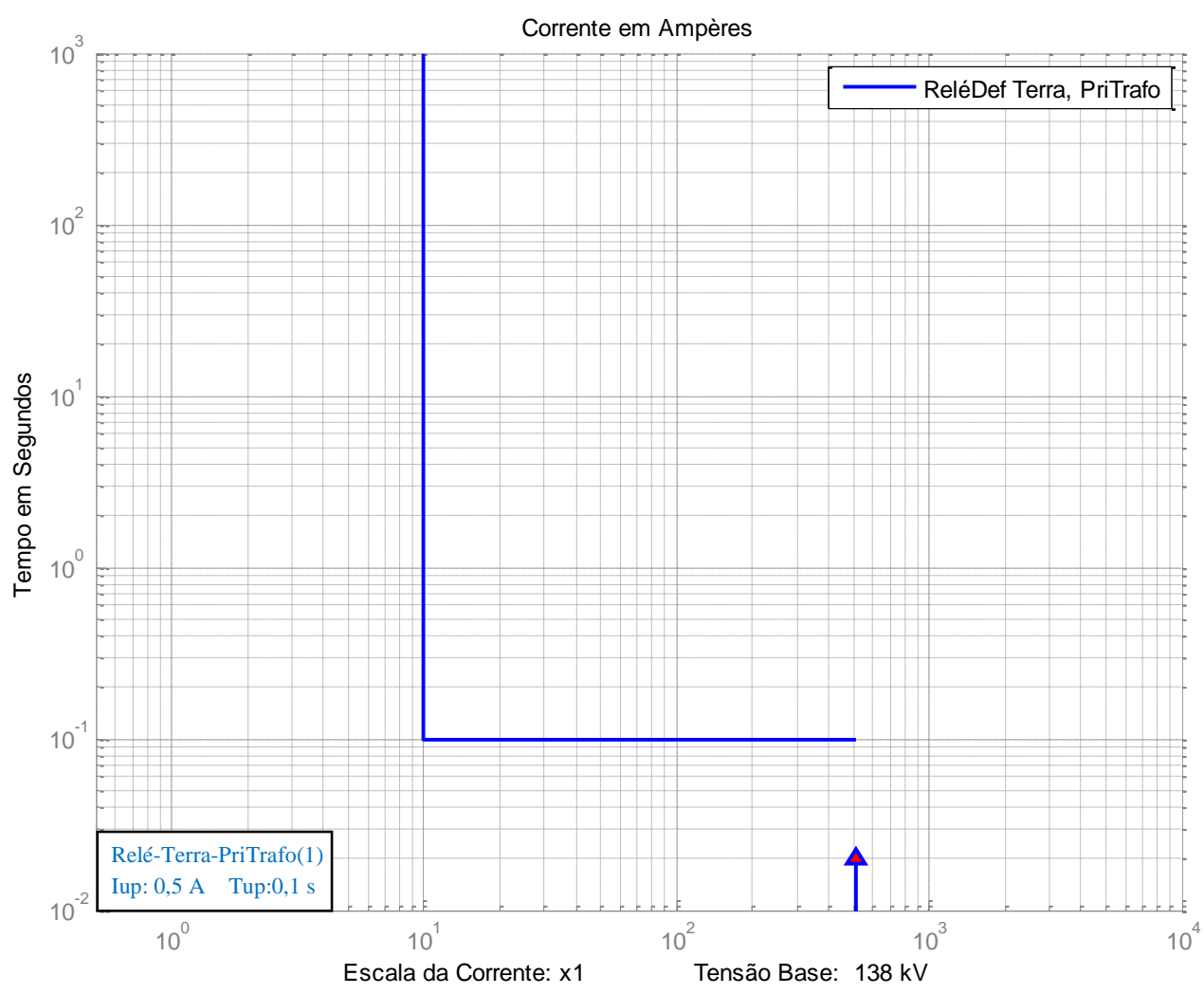

Figura 6.28 - Ajustes do relé de terra do transformador T1. 


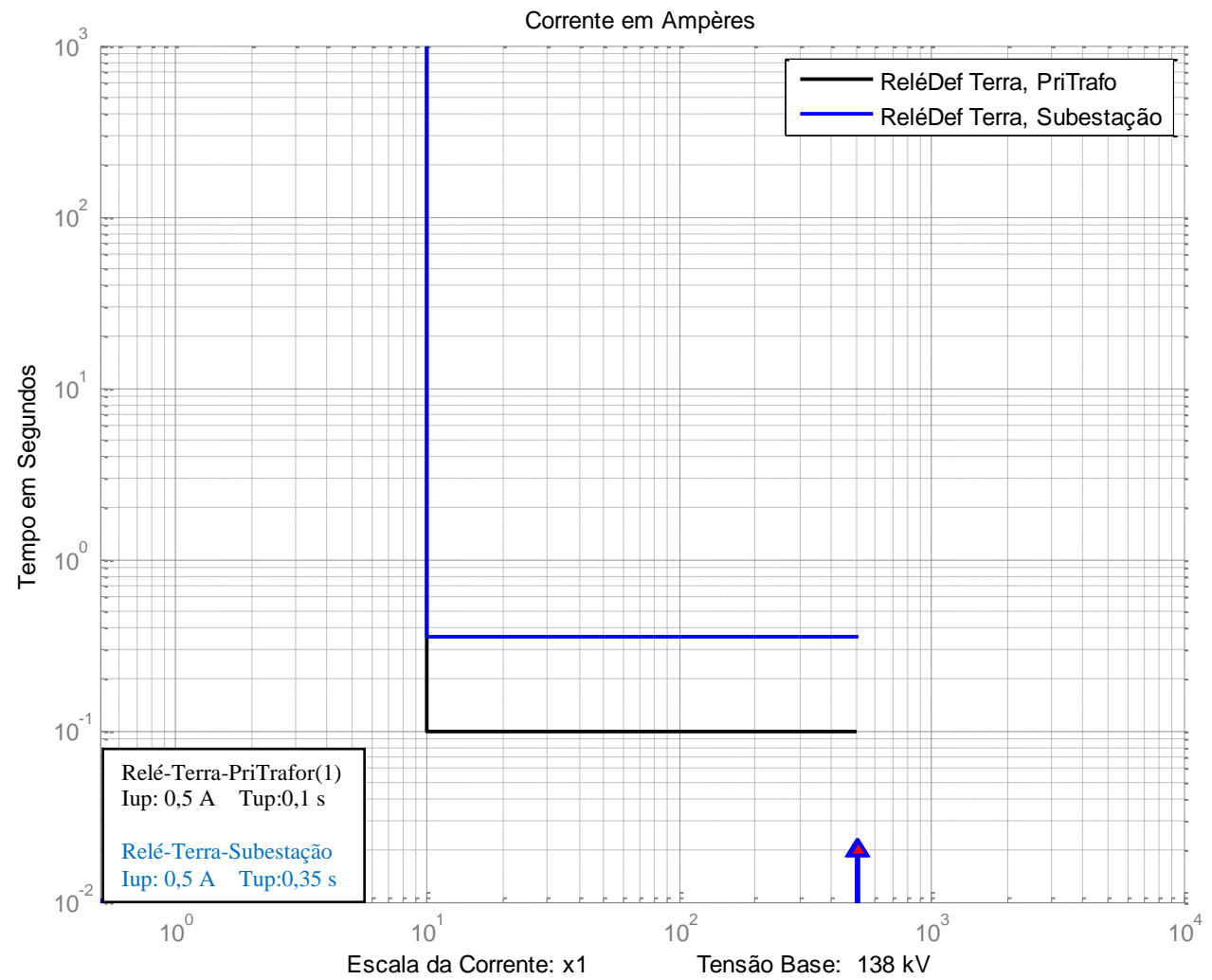

Figura 6.29 - Verificação da proteção de terra primário do transformador T1 com a proteção de terra da subestação.

\subsection{Exemplo 2}

Para o exemplo 2, foi escolhido um sistema elétrico real, mostrado na Figura 6.30, de grande porte e vários ramos. Por esse motivo nesta seção serão apresentados apenas os resultados do maior ramo e do ramo com maior ajuste. Contudo, vale frisar que a metodologia foi aplicada com sucesso no sistema elétrico como um todo. Entenda-se por maior ramo aquele que contém o maior número de elementos (barras e cabos) desde a carga até a subestação.

A escolha do sistema elétrico em questão justifica-se pela sua complexidade em relação aos dispositivos de proteção, pois há fusíveis instalados nos lados primários da maioria dos transformadores e existem equipamentos sem proteção contra curtos-circuitos fase-terra. Todos os dados dos equipamentos e dispositivos de proteção estão no Anexo A. 


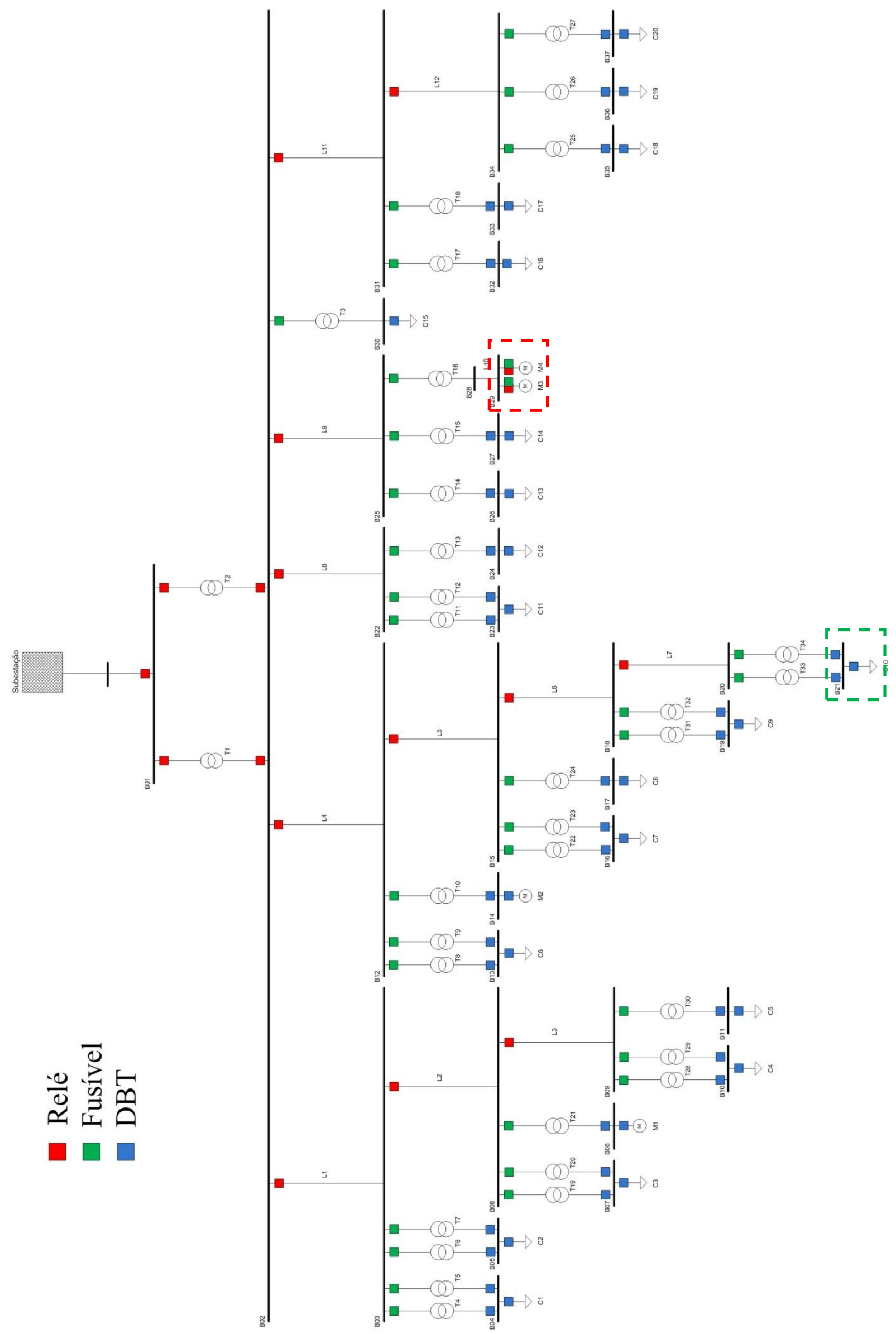

Figura 6.30 - Diagrama unifilar do sistema elétrico do Exemplo 2. 
Na Figura 6.30 o maior ramo é aquele definido pelo circuito que vai desde a barra B21 (destacada em verde na figura) até a barra da subestação. Já o ramo de maior ajuste é aquele que inicia na barra B29 (destacada em vermelho na figura).

\subsubsection{Proteção de Fase}

A Figura 6.31 apresenta a coordenação entre o dispositivo que protege a carga C10 instalada na barra B21, mostrado no gráfico pela linha cheia de cor preta, o disjuntor de baixa tensão instalado no secundário do transformador T33, linha de cor verde, e o fusível de cor azul instalado no primário do mesmo transformador. A linha preta tracejada representa a curva do dispositivo de proteção da carga dividido por 2 para efetivo cálculo de coordenação com o dispositivo a jusante. Este processo ocorre internamente ao programa, posto que a montante da carga existem dois transformadores em paralelo. Há de se verificar ainda a curva do fusível que protege o lado primário do transformador que viola a região de dano do transformador. Em relação a esse problema, a metodologia proposta prevê a emissão de uma mensagem indicando tal violação, mas não indica outro ajuste, visto que o fusível é um dispositivo não ajustável. 


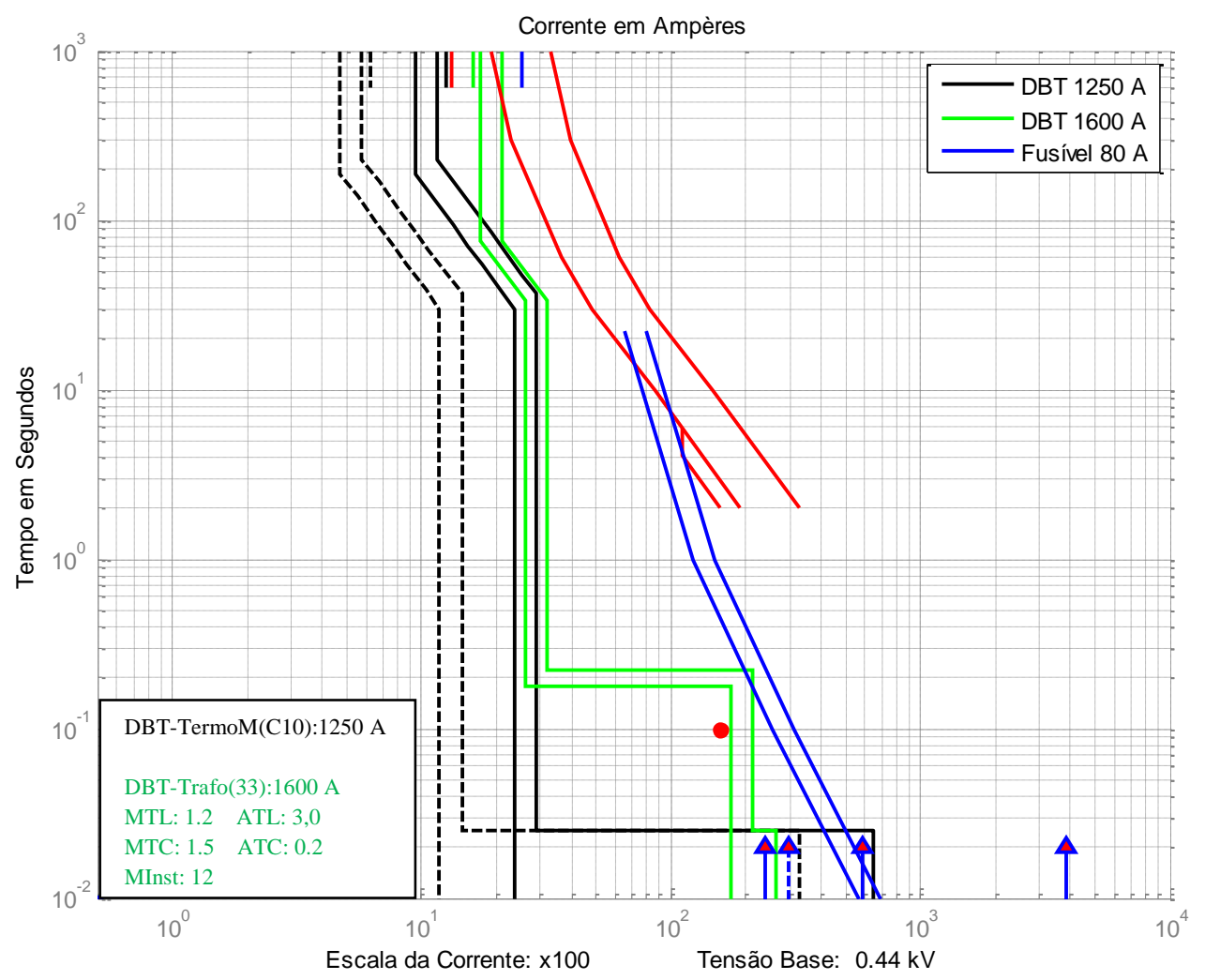

Figura 6.31 - Coordenação entre os dispositivos de proteção do transformador T33 e carga C10.

A Figura 6.32 mostra os ajustes para o relé que protege a barra B20, denominado Relé-Painel(20). Para estes ajustes é necessário verificar a proteção a jusante que é feita por fusível. Para tanto, a corrente de ajuste do relé ficou a $250 \%$ da corrente nominal da soma dos transformadores a jusante. 


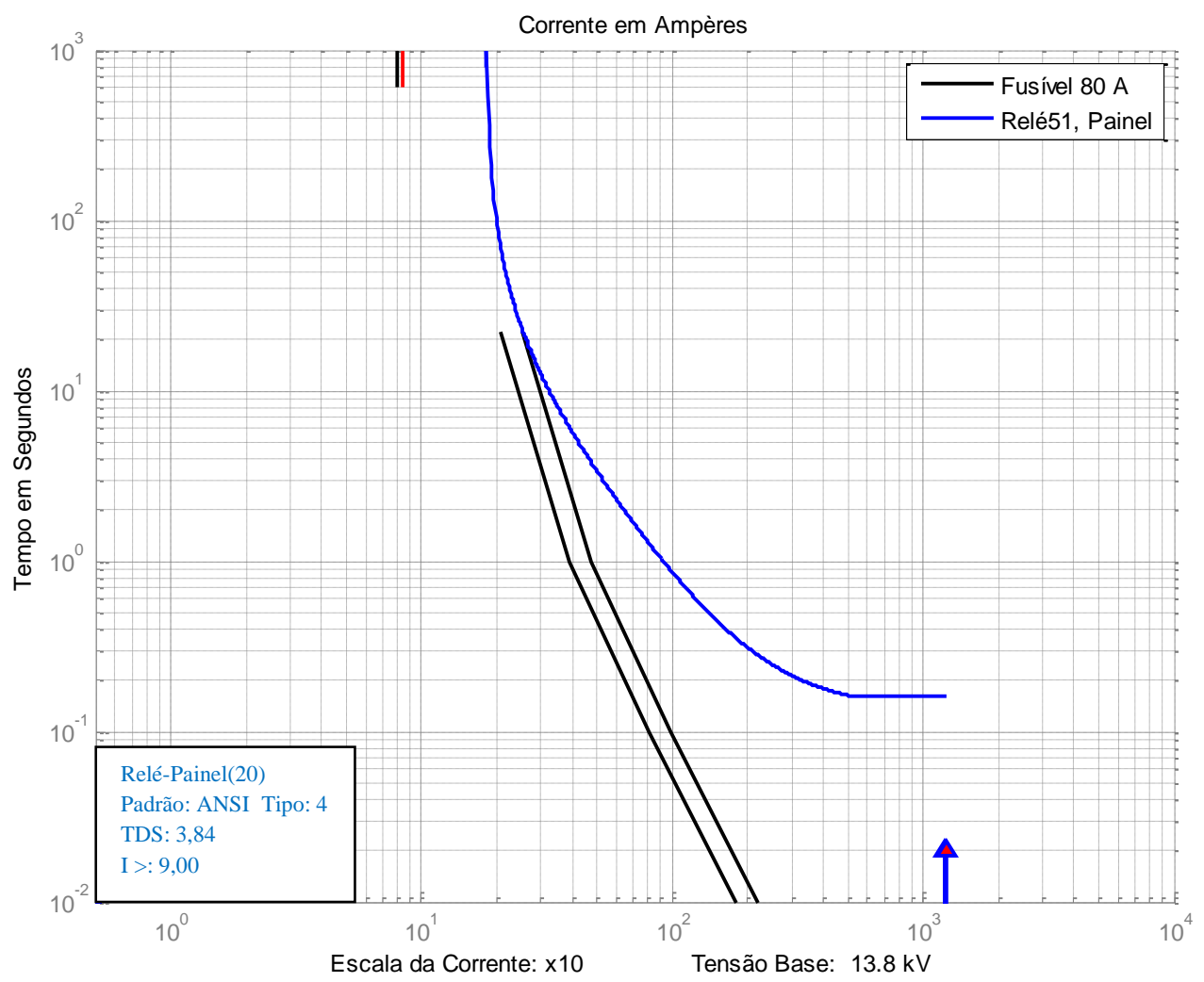

Figura 6.32 - Ajustes do relé da barra B20 coordenado com fusível do primário do transformador T33.

Os ajustes dos relés que protegem as barras a montante do painel B20 são mostrados na Figura 6.33, Figura 6.34 e Figura 6.35, referenciados por Relé-Painel(18), Relé-Painel(15) e Relé-Painel(12). Essas figuras mostram que a metodologia conseguiu ajustar corretamente os dispositivos de proteção de um ramo com várias barras em cascata, comprovando sua eficiência para sistemas elétricos mais complexos do que o apresentado no Exemplo 1. 


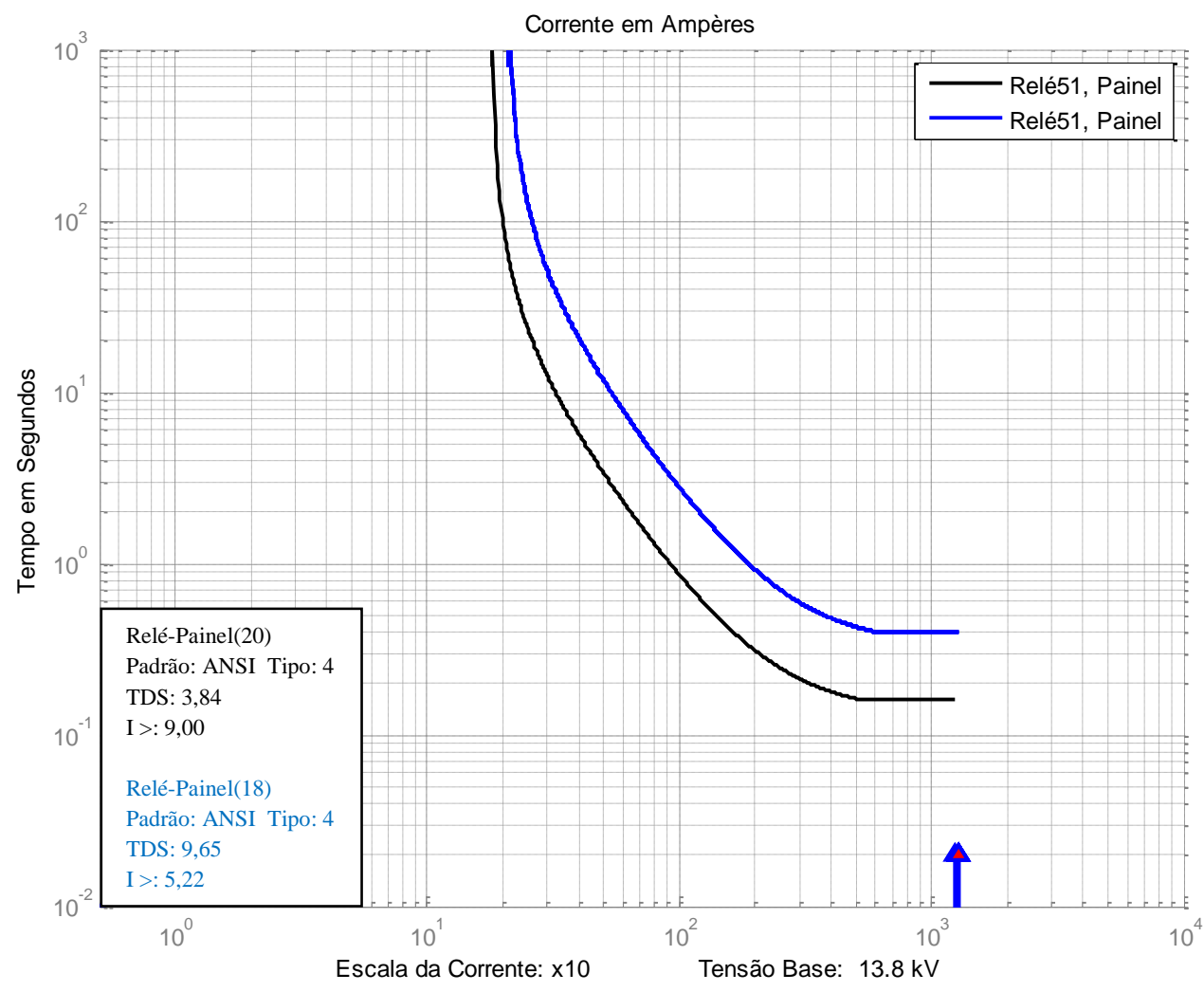

Figura 6.33 - Coordenação entre as proteções da barra B20 e B18.

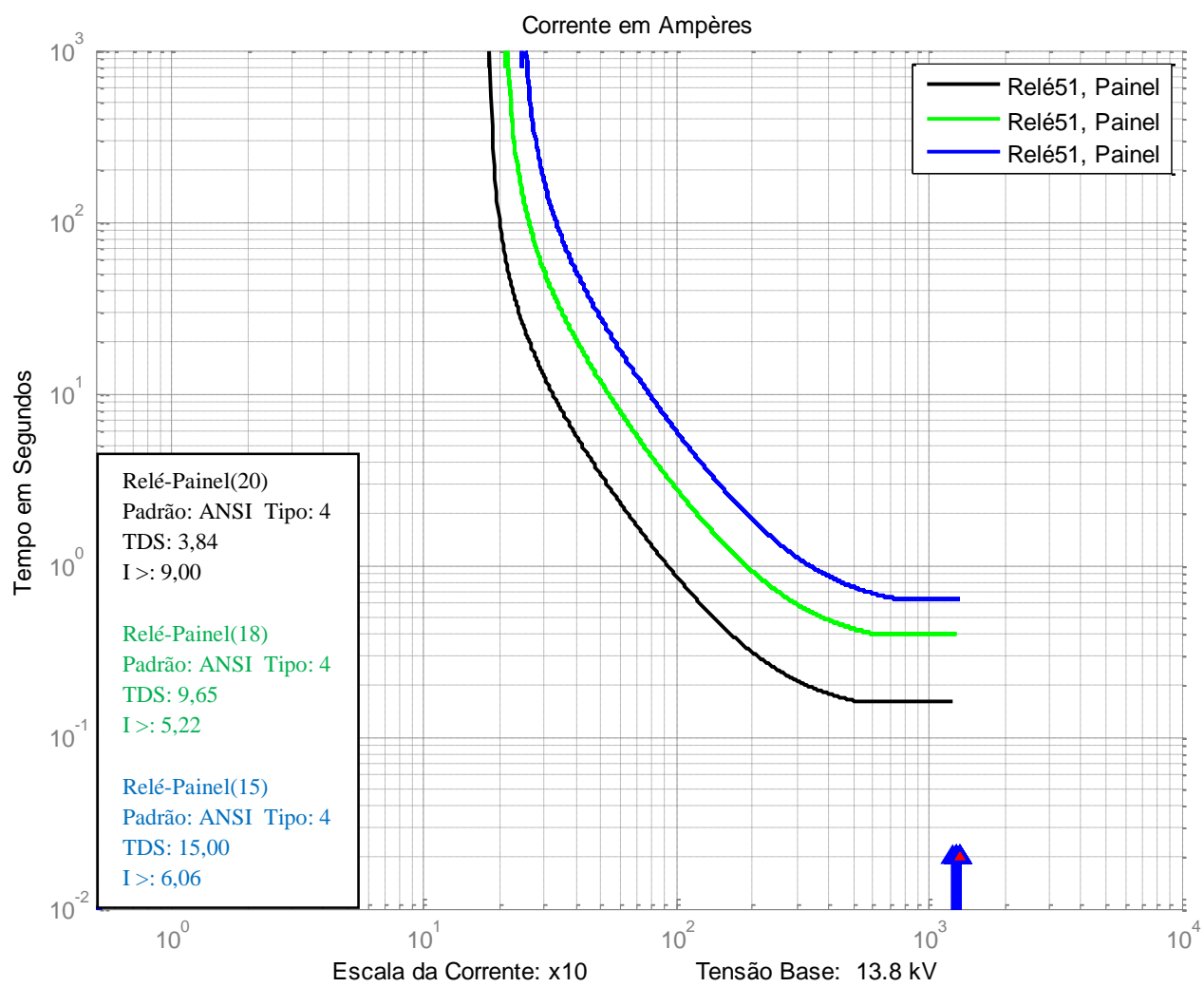

Figura 6.34 - Coordenação entre as proteções das barras B20, B18 e B15. 


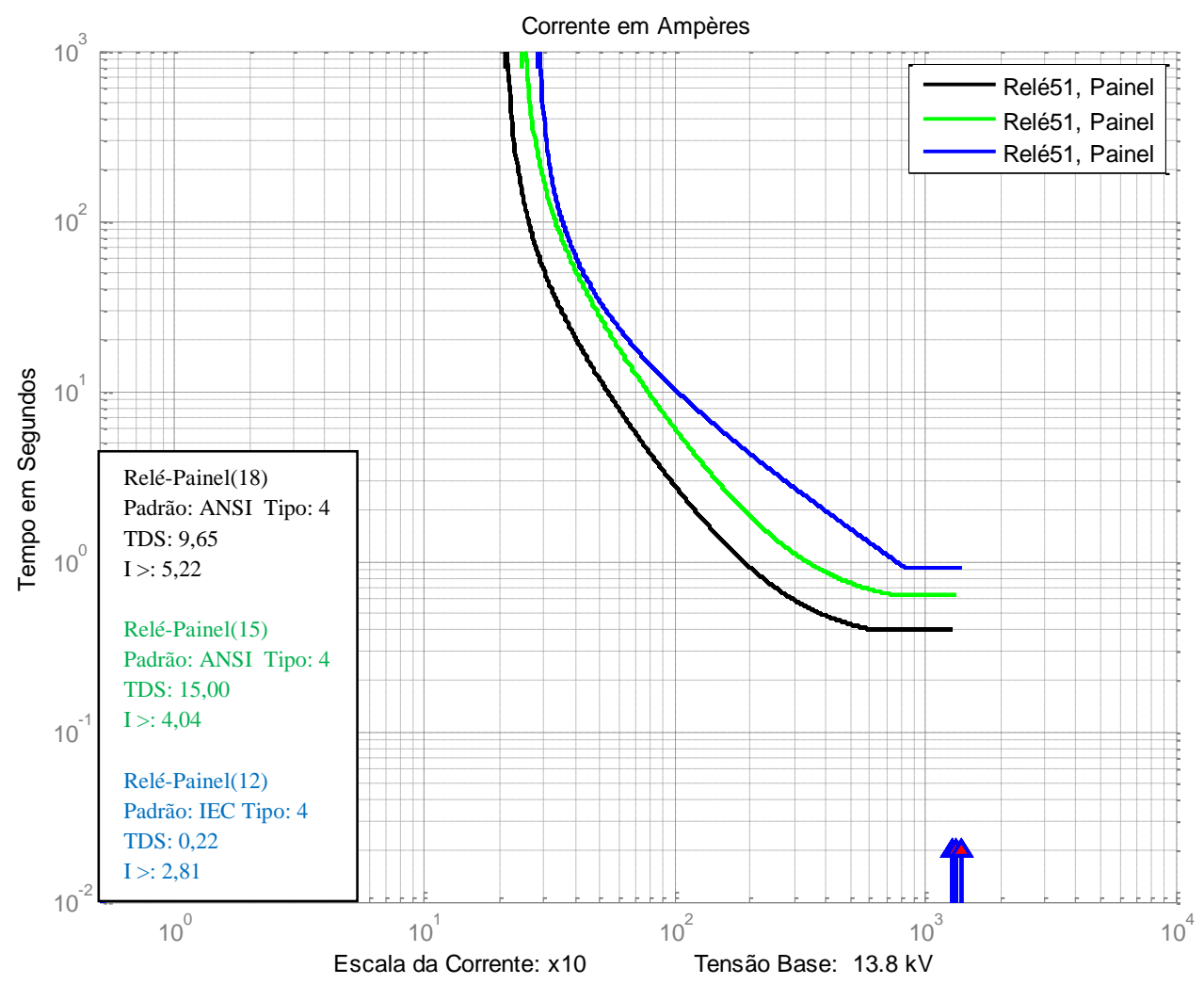

Figura 6.35 - Coordenação entre as proteções das barras B18, B15 e B12.

Para finalizar a definição dos ajustes dos dispositivos de proteção, resta identificar o maior ajuste dos ramos conectados na barra $\mathrm{B} 02$. Os resultados mostraram que este ramo é o definido pelo motor M3, barras B29, transformador T16, barra B25 e cabo L9. Os resultados são mostrados na Figura 6.36, para o relé que protege o motor M3, e na Figura 6.37 e Figura 6.38, para todo o ramo. Na Figura 6.37 tem-se apenas a verificação, posto que nesse ramo não há proteção no lado secundário do transformador, restando ao programa verificar se o fusível protege o lado primário. Verifica-se que o fusível toca a região de dano do transformador, assim para prosseguir a coordenação com os dispositivos a montante, o programa identifica a porção do fusível que efetivamente protege o transformador e desconsidera o restante da curva de atuação, conforme explicado na seção 4.3.3. 


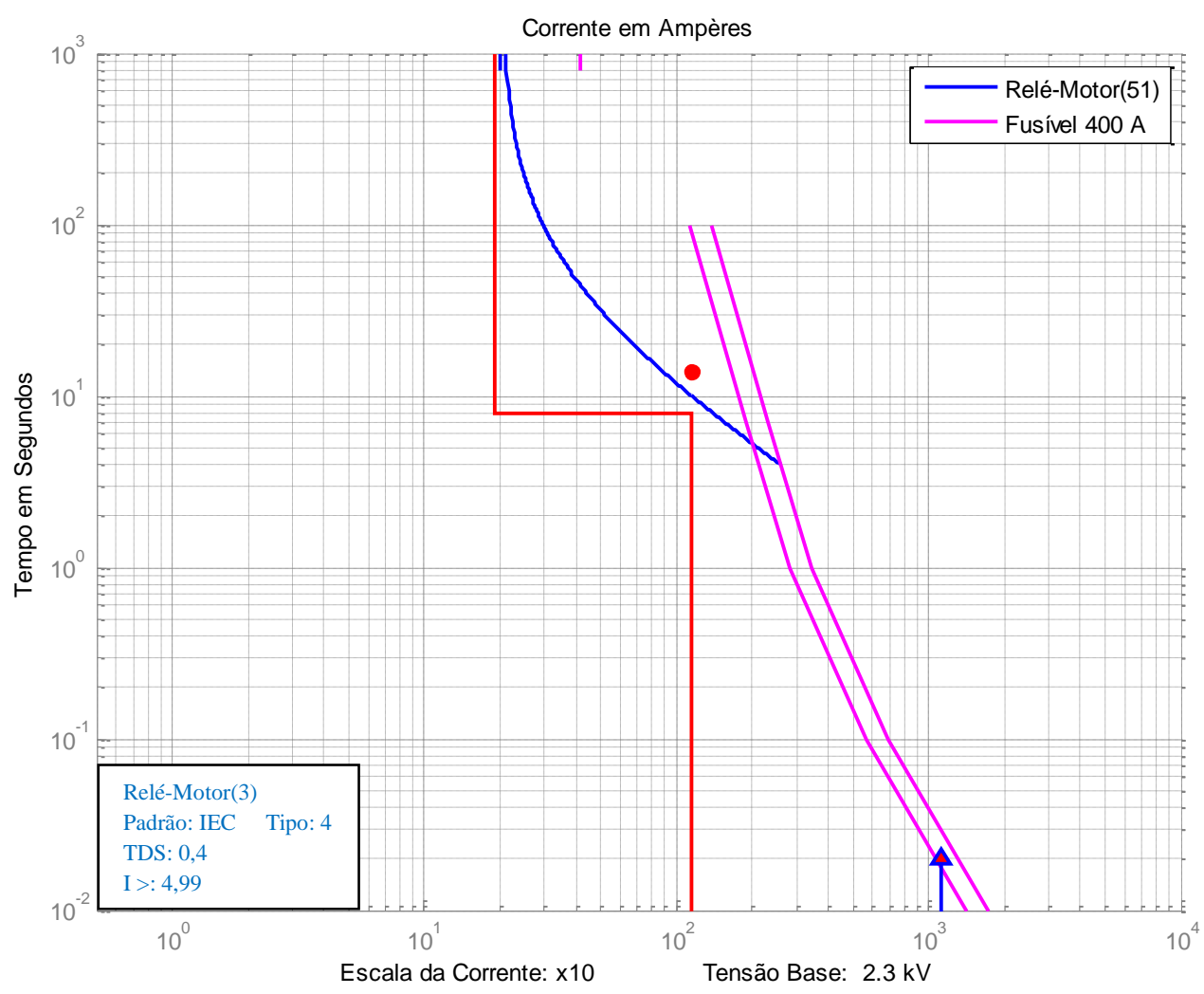

Figura 6.36 - Ajustes para o relé do motor M3.

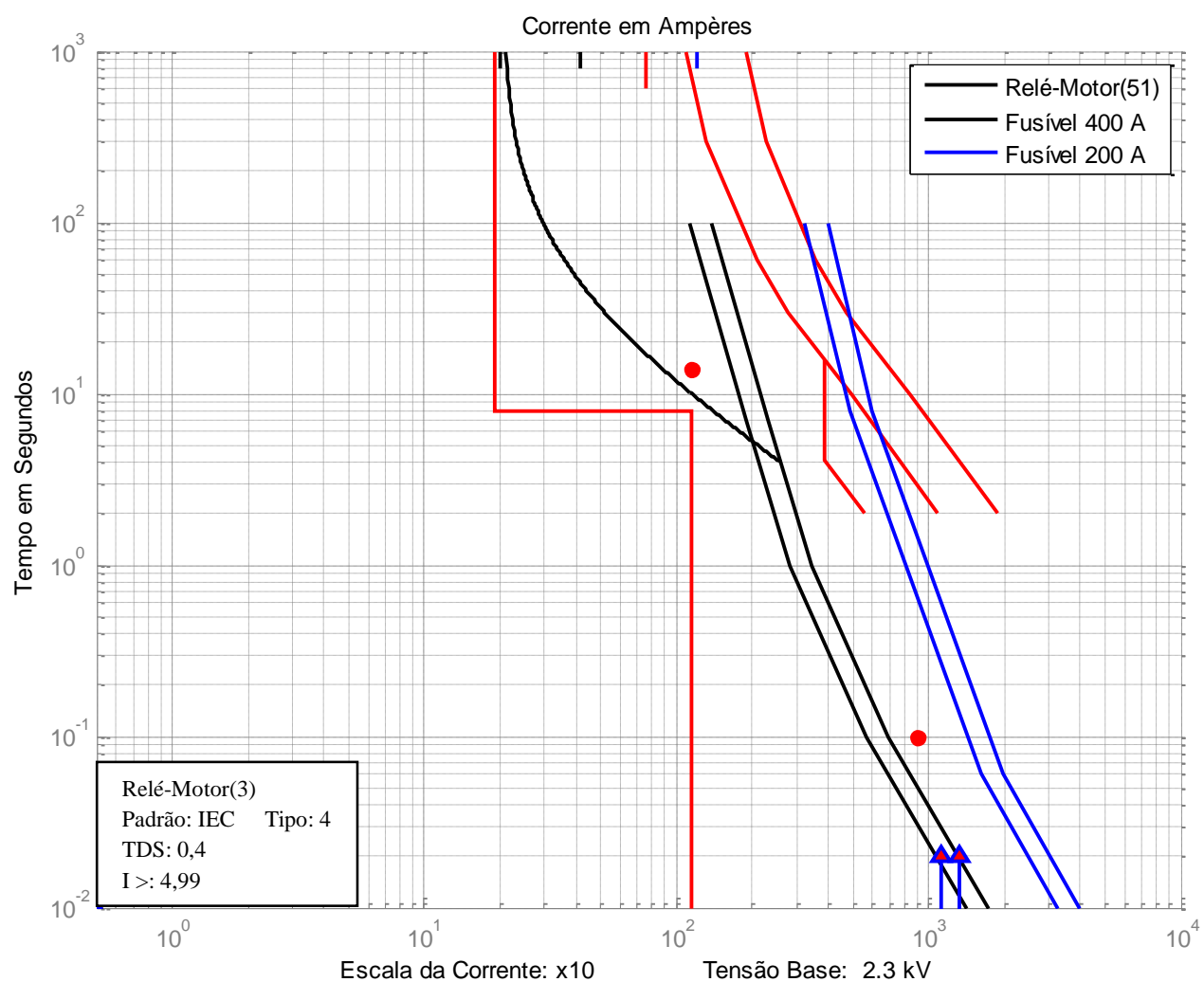

Figura 6.37 - Verificação da coordenação entre os dispositivos do motor M3 e transformador T16. 
A Figura 6.38 mostra os ajustes para o relé que protege a barra B25, coordenado com o fusível que protege o lado primário do transformador T16.

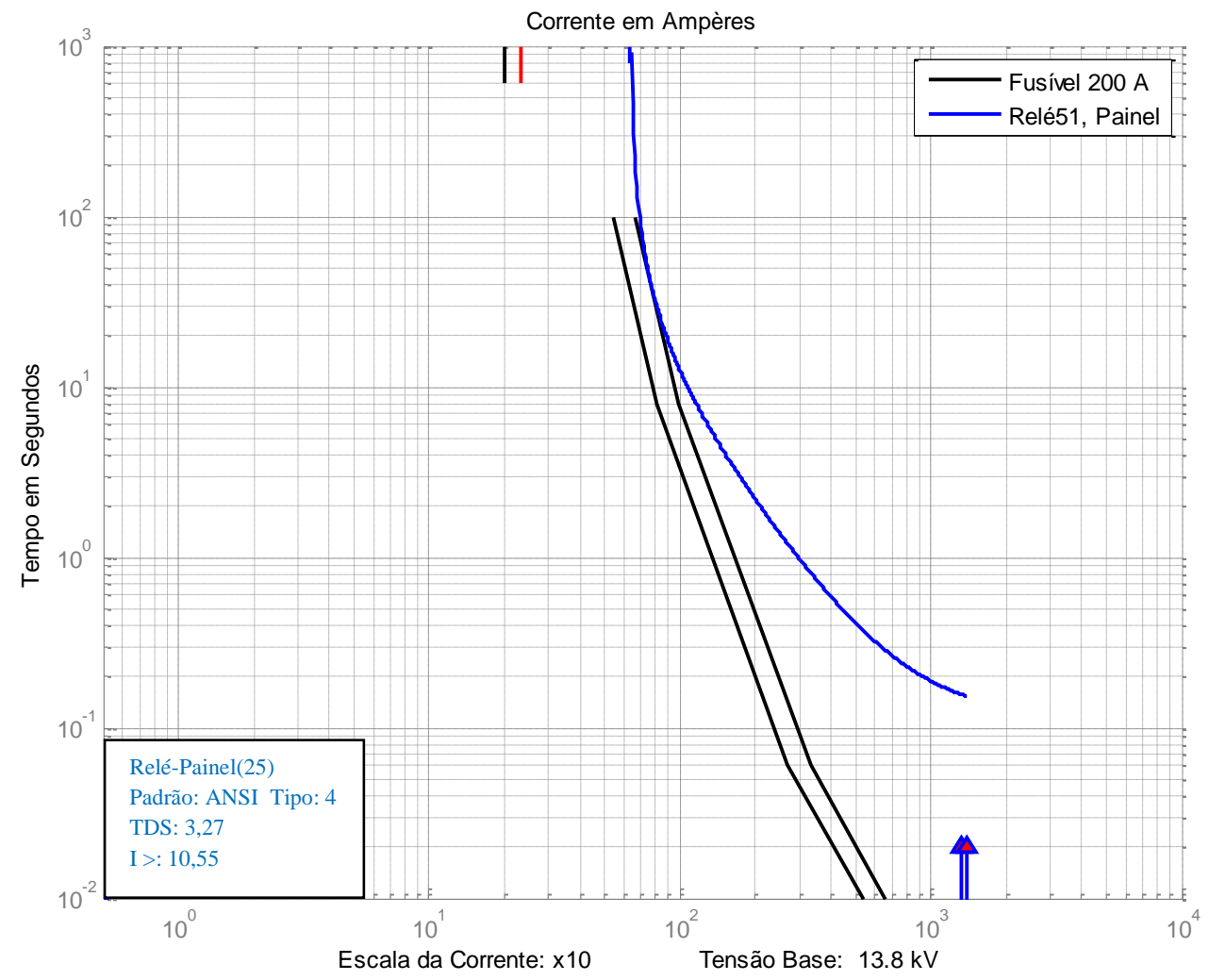

Figura 6.38 - Ajustes do relé da barra B25 coordenados com o fusível do primário do transformador T16.

Seguindo a execução do programa, já verificado o caminho com o maior ajuste, resta ajustar os relés dos dispositivos que protegem os transformadores principais que estão em paralelo. Aplica-se então a estratégia adotada para coordenar transformadores em paralelo, ou seja, os valores de corrente da curva do relé da barra B25 (Relé-Painel(25)) são divididos por 2, sendo o resultado mostrado na Figura 6.39 pela curva tracejada. Observa-se que existe coordenação efetiva entre todos os dispositivos de proteção. 


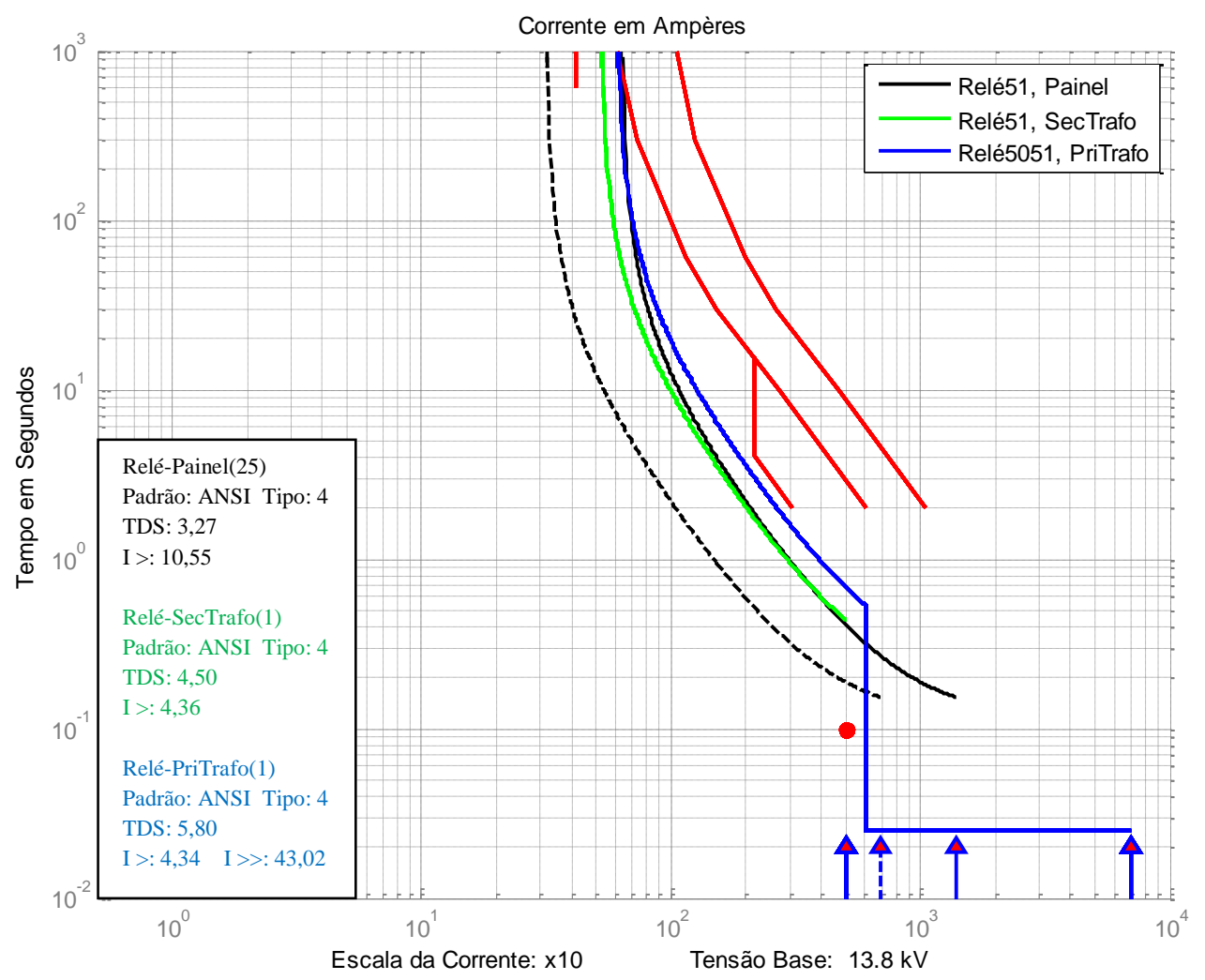

Figura 6.39 - Coordenação entre os dispositivos de proteção do transformador T1 e barra B25.

Realizados todos os ajustes dos dispositivos para curtos-circuitos trifásicos, o programa executa o ajuste automático para curtos-circuitos fase-terra para o sistema elétrico da Figura 6.30. No entanto, apenas serão mostrados os resultados referentes aos mesmos ramos tratados nesta seção.

\subsubsection{Proteção Fase-Terra}

A Figura 6.40 apresenta a coordenação da proteção de terra do disjuntor de baixa tensão instalado no secundário do transformador T33 com a curva do dispositivo de proteção da carga C10. Novamente se observa a divisão por 2 da curva do dispositivo que protege a carga para efeito de coordenação por ter transformadores em paralelo. Nota-se que a carga não tem proteção específica contra curtos-circuitos fase-terra, portanto a estratégia seguida pela metodologia proposta é coordenar a proteção de terra do disjuntor a montante da carga 
com o dispositivo de proteção de fase da carga. Isso é possível, pois a corrente de curtocircuito fase-terra máxima é elevada. Observa-se que os dispositivos de proteção estão efetivamente coordenados.

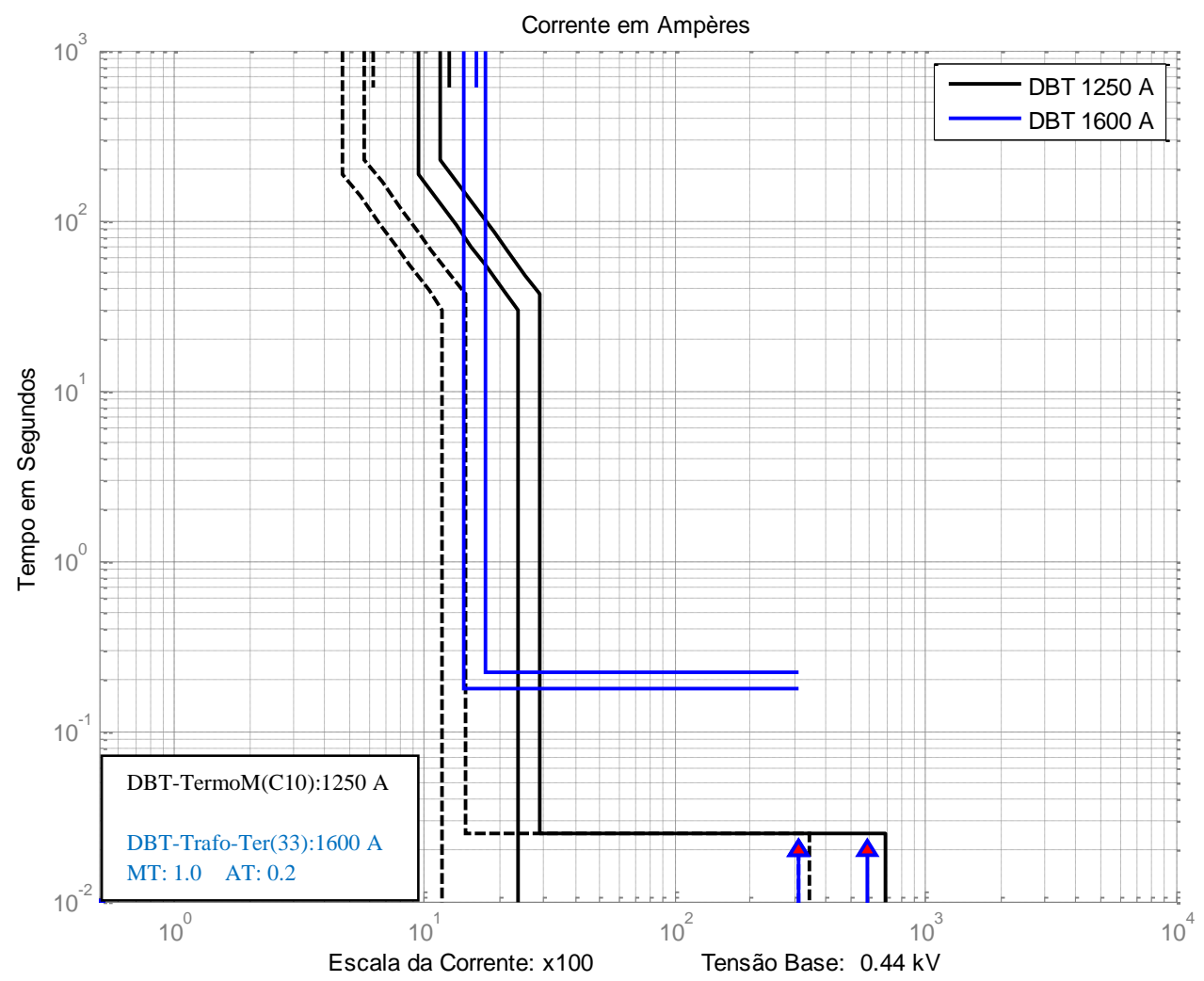

Figura 6.40 - Coordenação entre o terra do DBT do secundário do transformador T33 com a proteção da carga C10.

A Figura 6.41 mostra o ajuste do relé de terra da barra B20 (Relé-Terra-Painel(20)). Neste caso não há como coordenar a curva de terra do relé com o fusível por conta da baixa corrente de curto-circuito fase-terra. Logo, a estratégia prevista é desprezar esta coordenação primando por uma proteção mais rápida. 


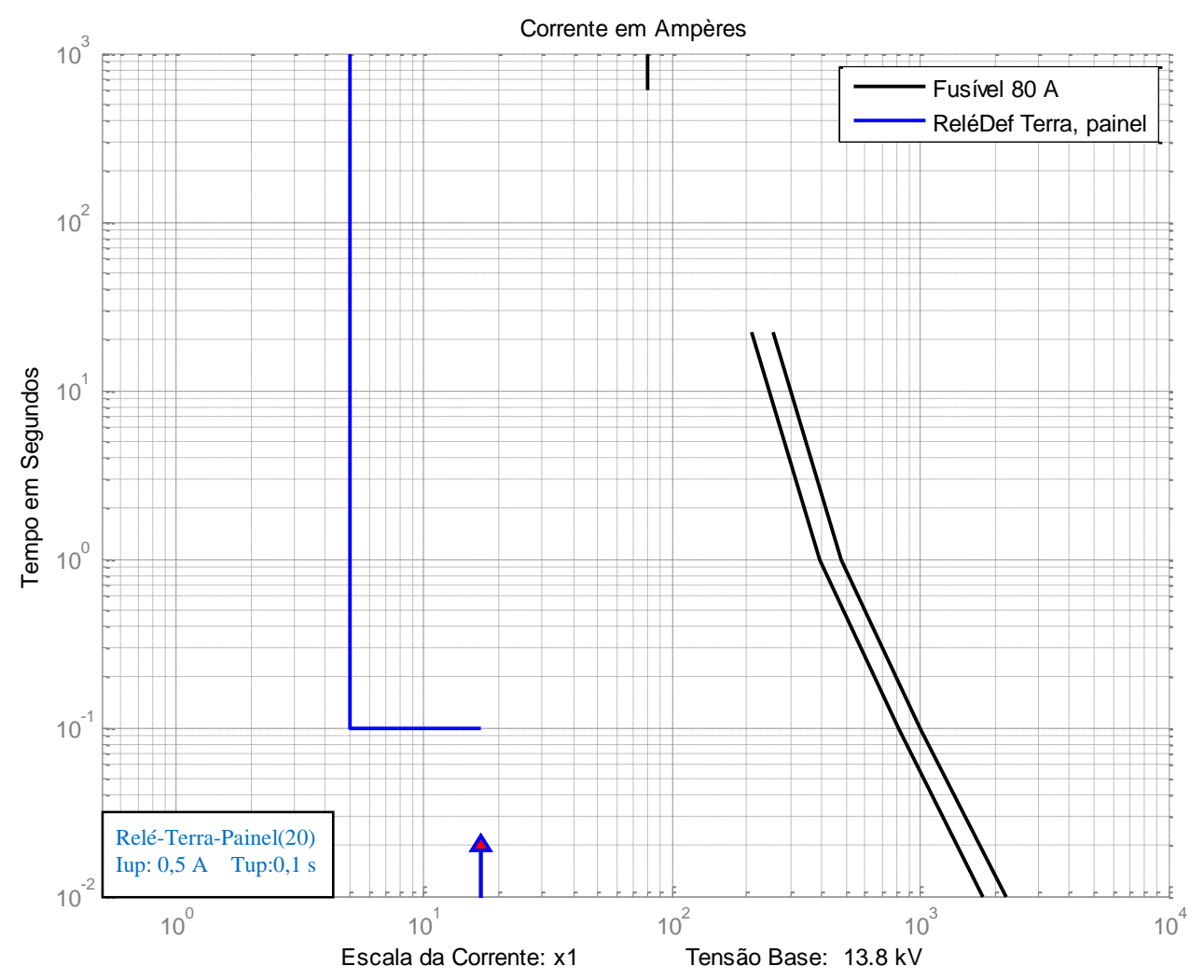

Figura 6.41 - Ajustes do rele de terra da barra B20 com fusível do transformador T33.

Os ajustes dos dispositivos de proteção das barras a montante da barra B20 são mostrados na Figura 6.42, Figura 6.43 e Figura 6.44, todos ajustados na mesma corrente de partida, mas coordenados entre si por tempo. 


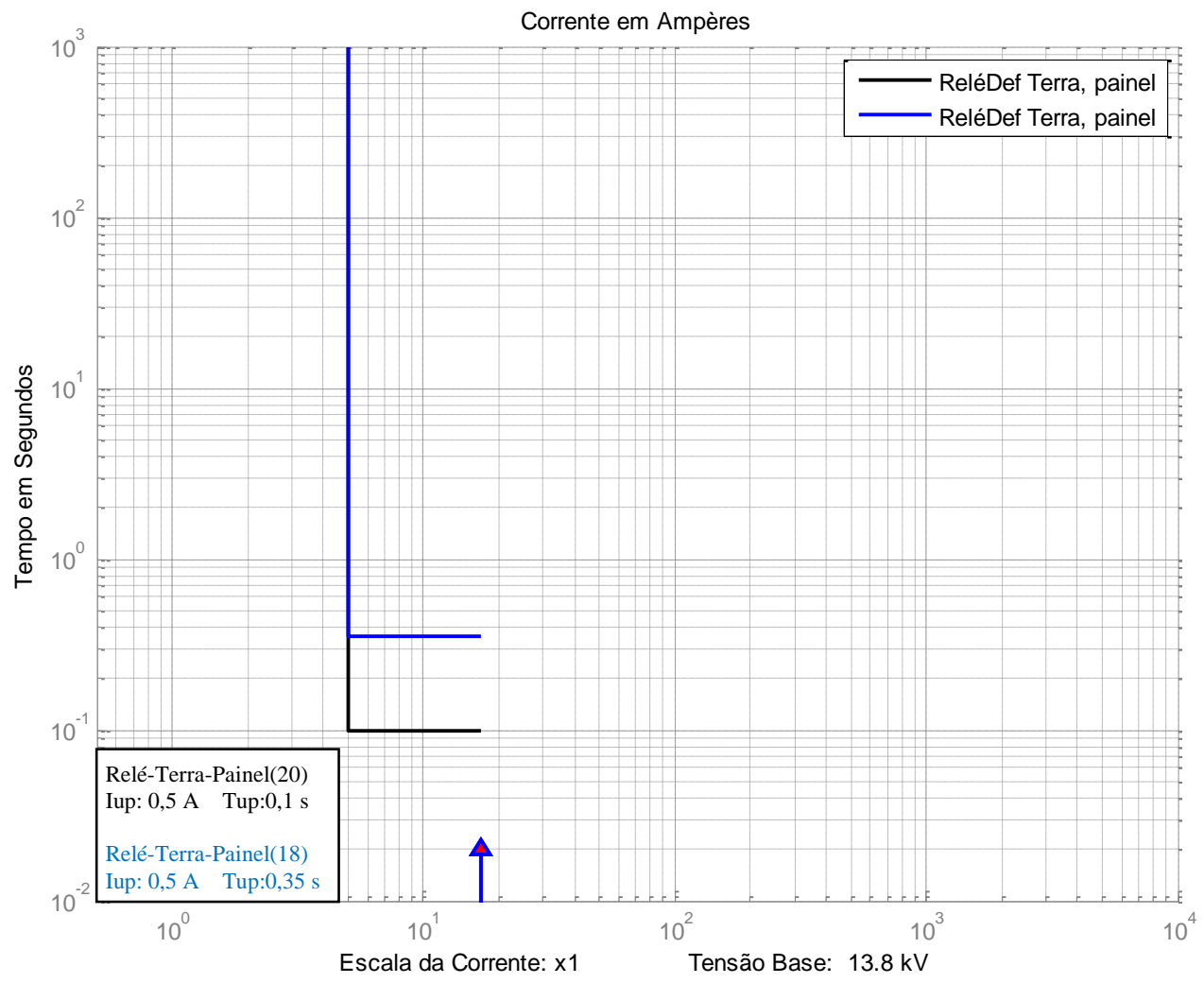

Figura 6.42 - Coordenação entre as proteções de terra das barras B20 e B18.

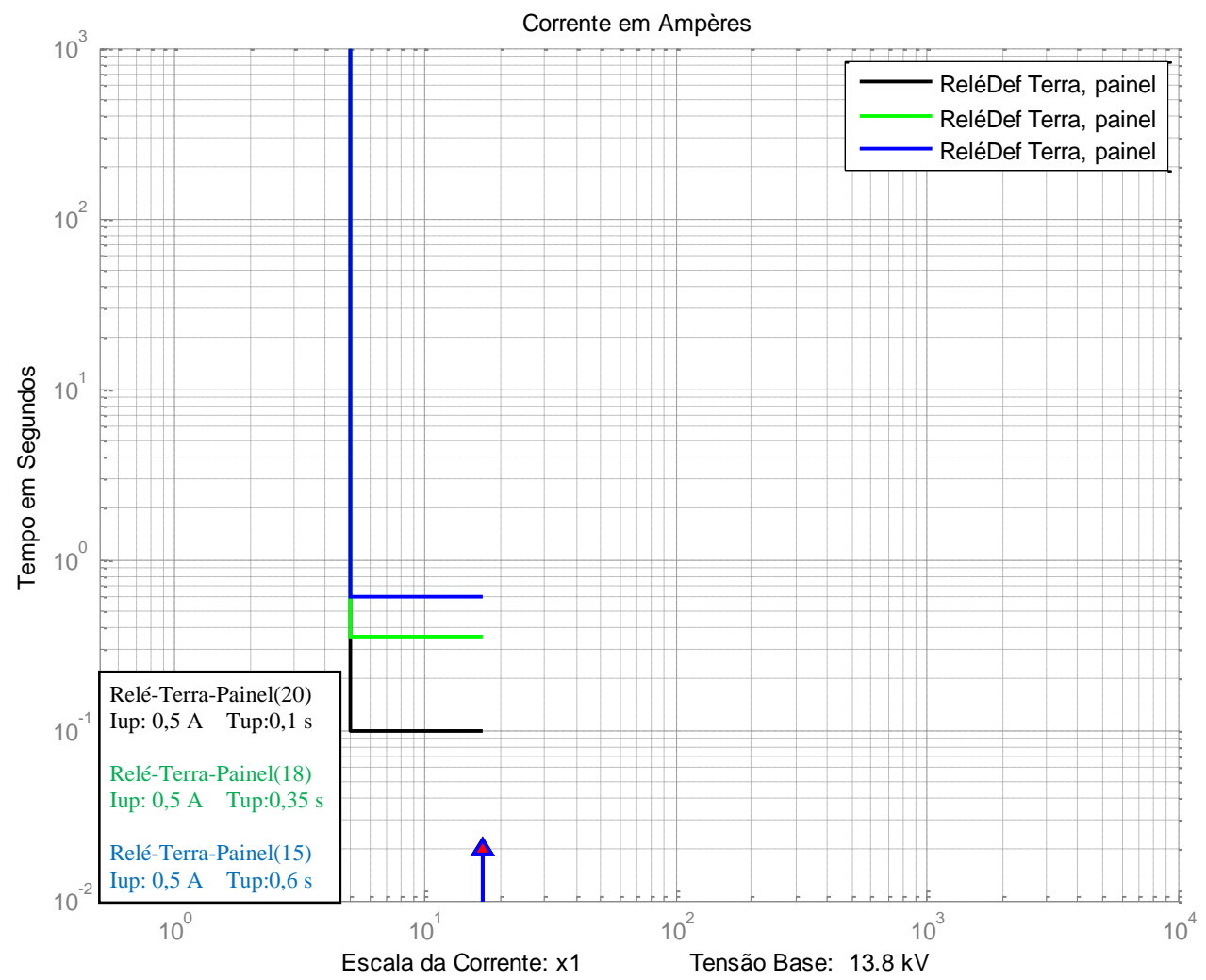

Figura 6.43 - Coordenação entre as proteções de terra das barras B20, B18 e B15. 


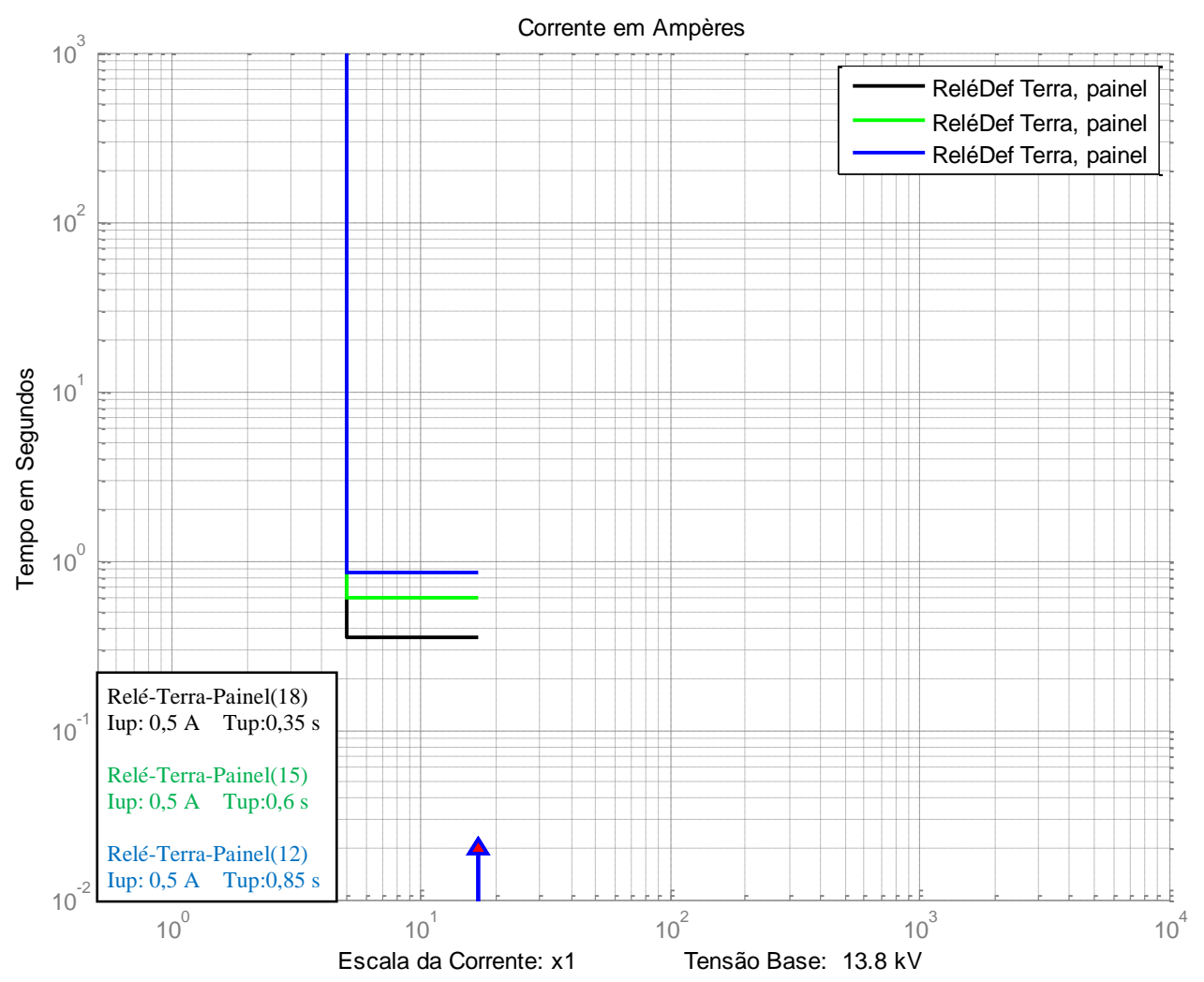

Figura 6.44 - Coordenação entre as proteções de terra das barras B18, B15 e B12.

Para o ramo de maior ajuste, seguindo a execução do programa, tem-se a Figura 6.45 mostrando os ajustes para o relé de terra que protege o motor M3. 


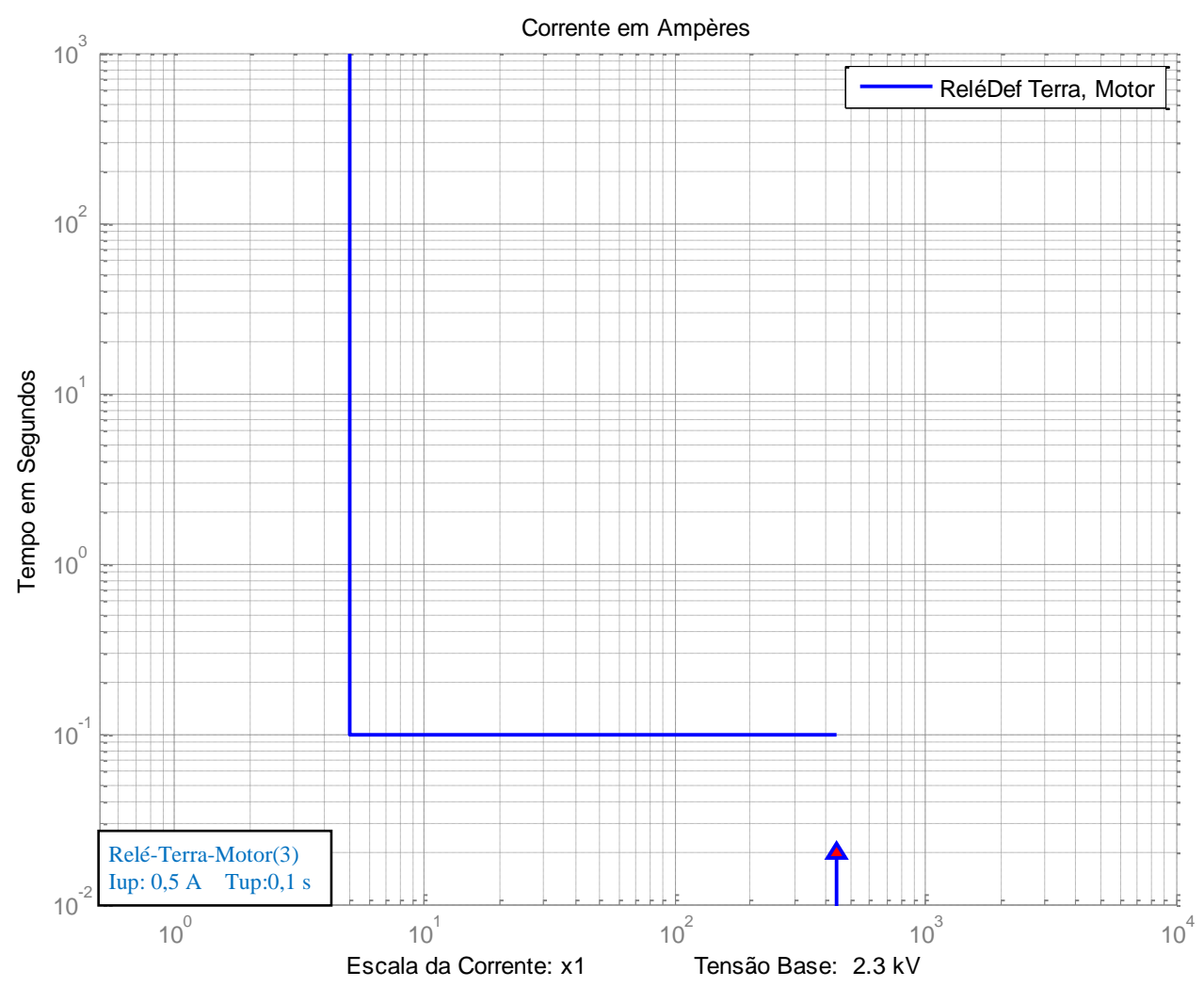

Figura 6.45- Ajustes para a proteção de terra do motor M3.

A Figura 6.46 mostra o ajuste do relé de terra da barra B25. Neste caso não há como coordenar a curva de proteção terra do relé com o fusível por conta a baixa corrente de curto circuito fase-terra. 


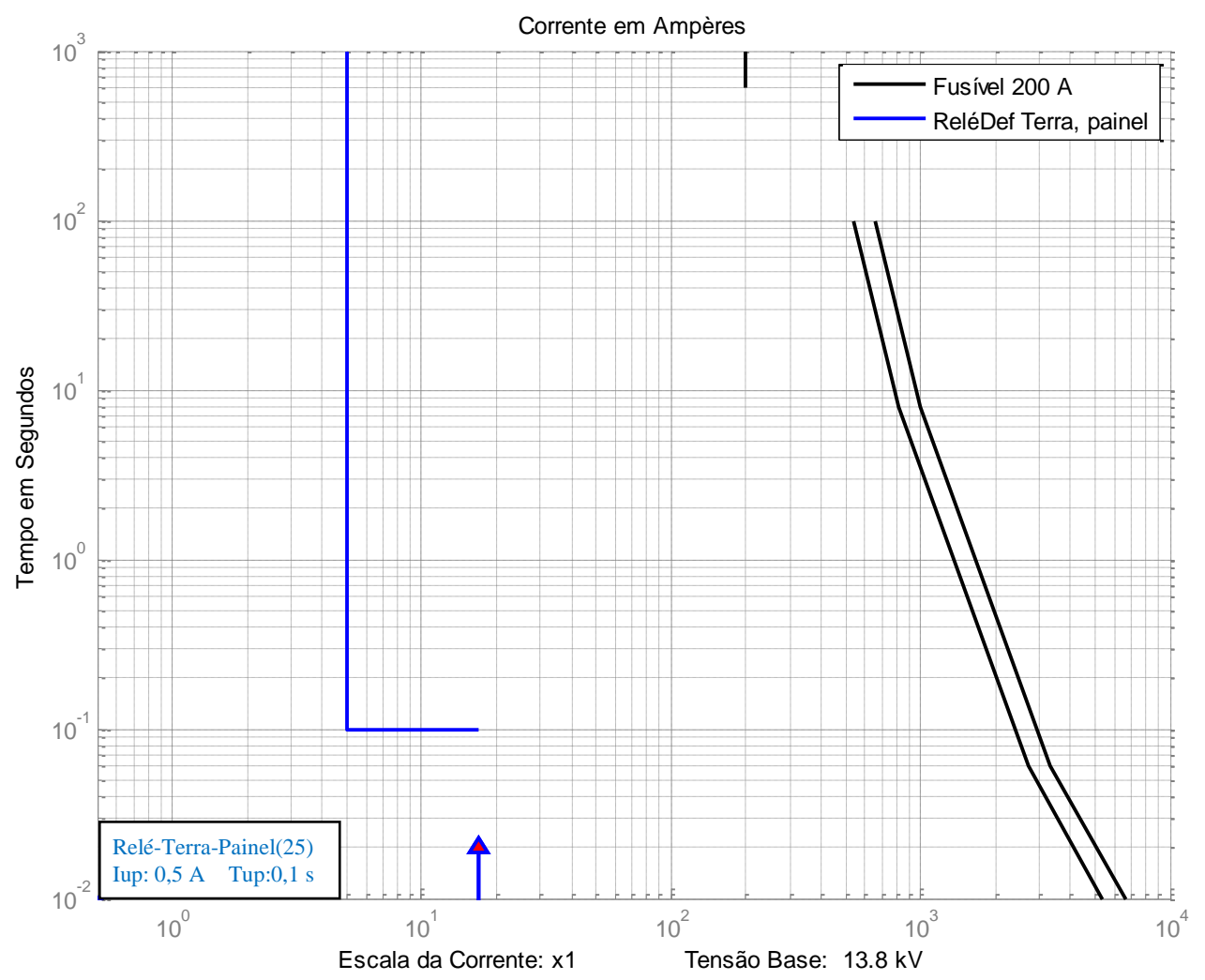

Figura 6.46 - Ajustes do rele de terra da barra B25 com o fusível do transformador T16.

Seguindo a execução do programa, já verificado o caminho com o maior ajuste, resta ajustar os relés de terra dos dispositivos que protegem os transformadores principais.

A Figura 6.47 mostra a coordenação dos dispositivos de terra de maior ajuste com o relé de terra do lado secundário do transformador T1.

A Figura 6.48 mostra o ajuste do relé de terra do lado primário do transformador T1. Por conta do seu tipo de conexão do enrolamento do lado primário (delta) não é necessário haver a coordenação desta com a curva de proteção do dispositivo do lado secundário. 


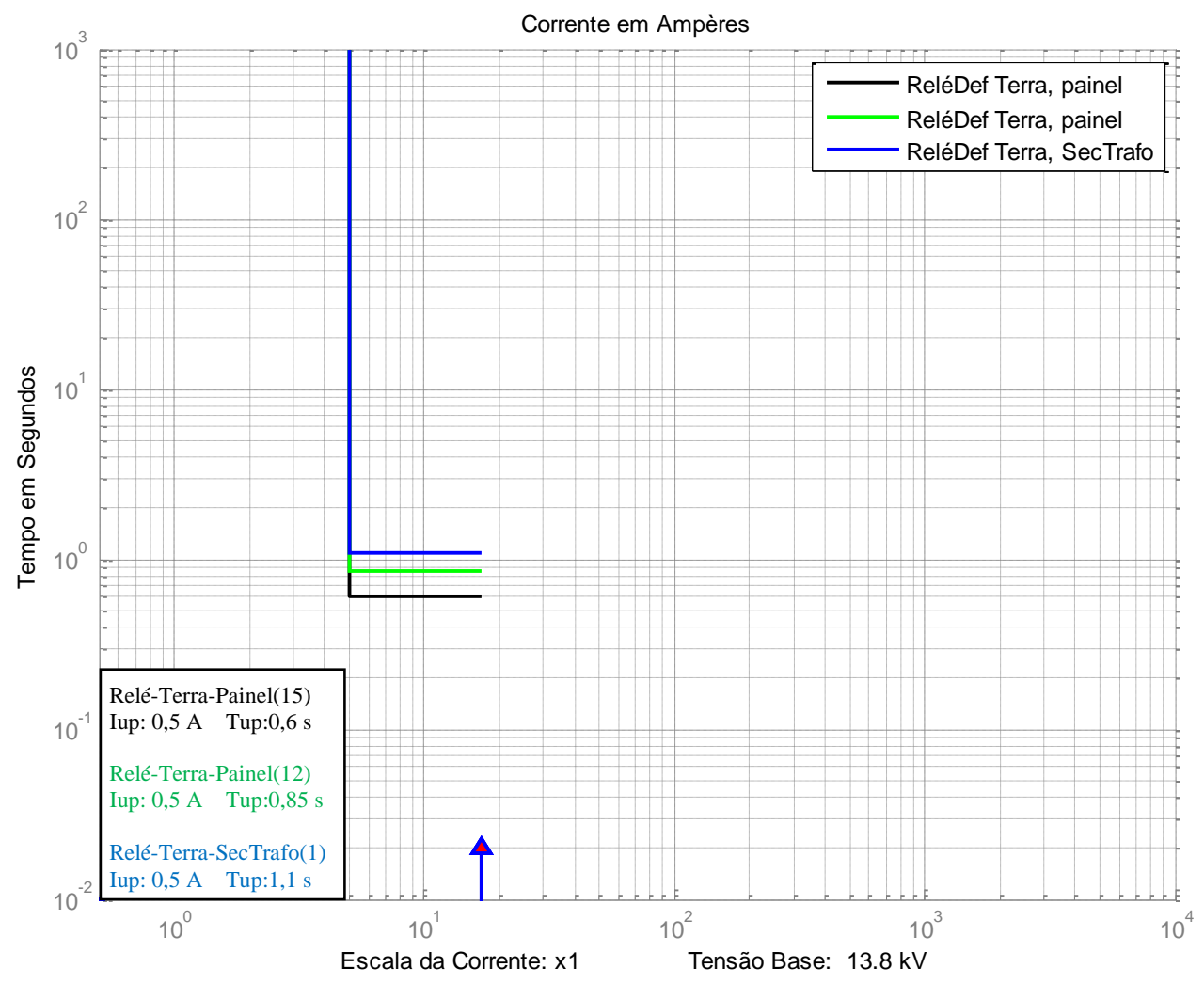

Figura 6.47 - Coordenação entre as proteções de terra das barras B15, B12 do secundário do transformador T1.

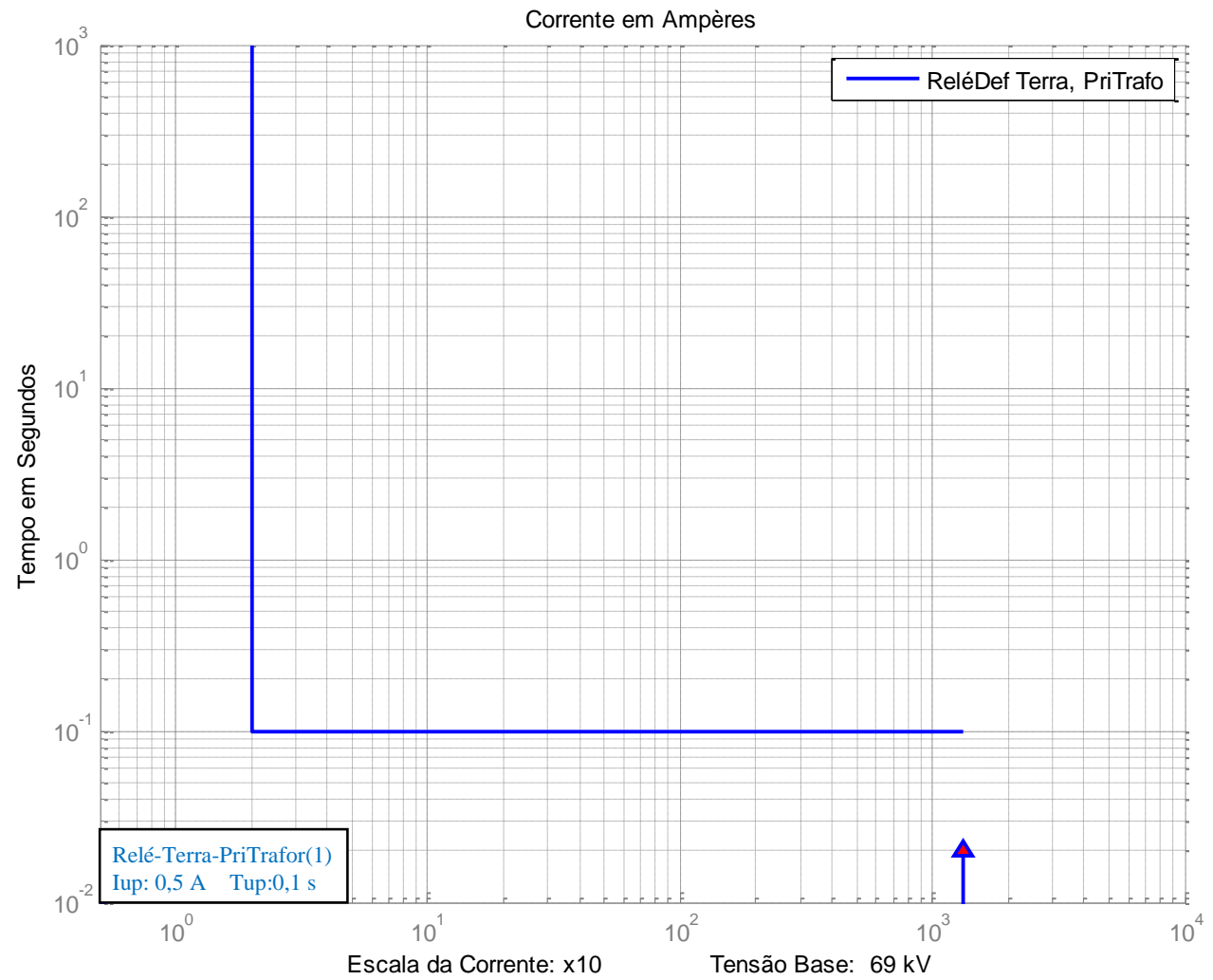

Figura 6.48 - Ajustes do relé de terra do primário do transformador T1. 
Realizados todos os ajustes dos dispositivos de proteção de fase e de terra, resta ao programa executar o algoritmo de verificação de coordenação do último relé processado com o dispositivo de proteção da subestação. O resultado é mostrado na Figura 6.49 e Figura 6.50, em que se observa que a coordenação está garantida para proteção de fase. $\mathrm{O}$ mesmo não ocorre com a proteção de terra, visto que se observa a perda de coordenação para valores de corrente superiores a 1.300 A. Nesta situação, optou-se por manter a temporização do ajuste da proteção de terra em 0,1 segundo conforme estabelecido na metodologia. O procedimento indicado seria solicitar a alteração dos ajustes do relé da subestação a fim de garantir a plena coordenação para os dispositivos de proteção.

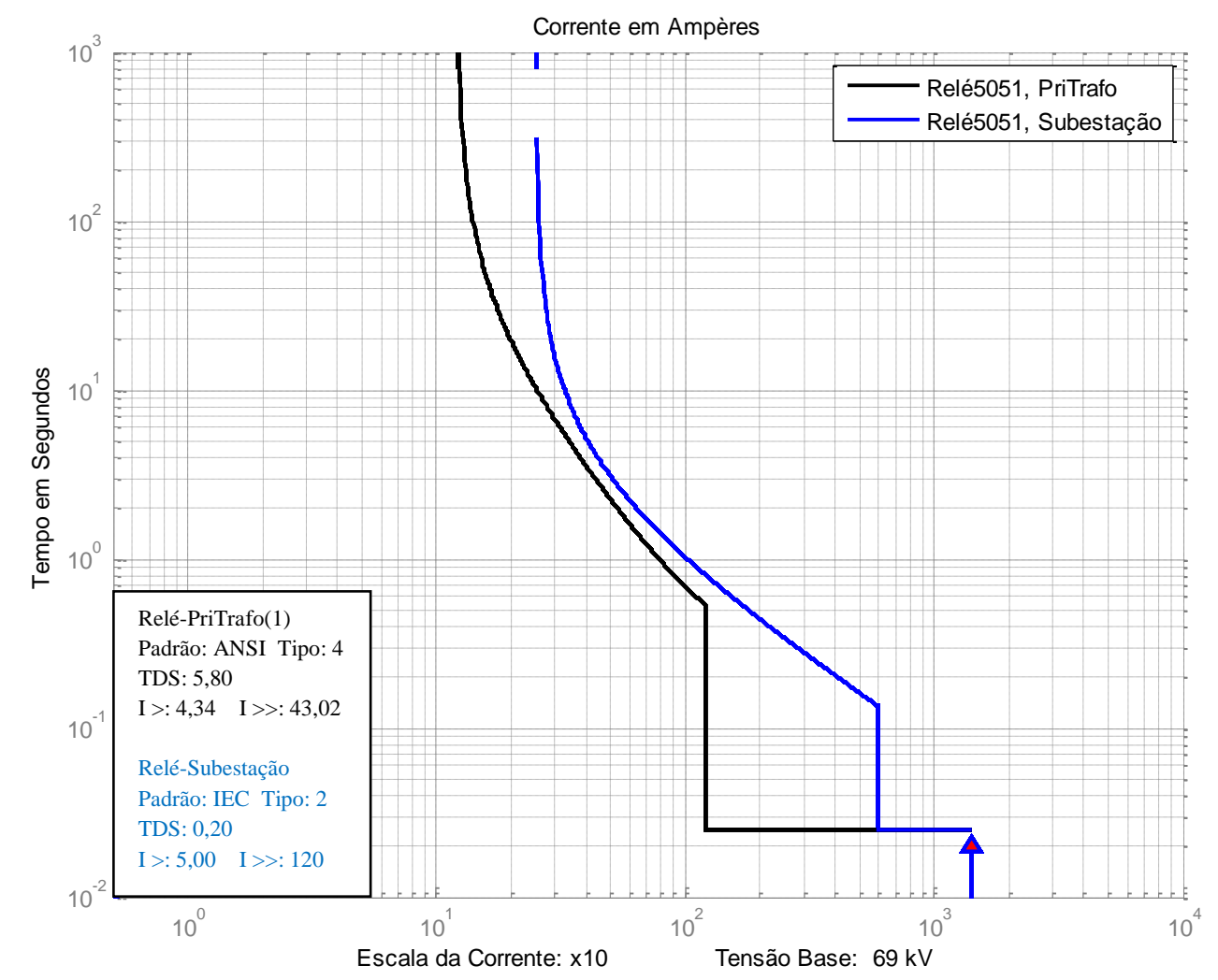

Figura 6.49 - Verificação da proteção do primário do transformador T1 com o relé da subestação. 


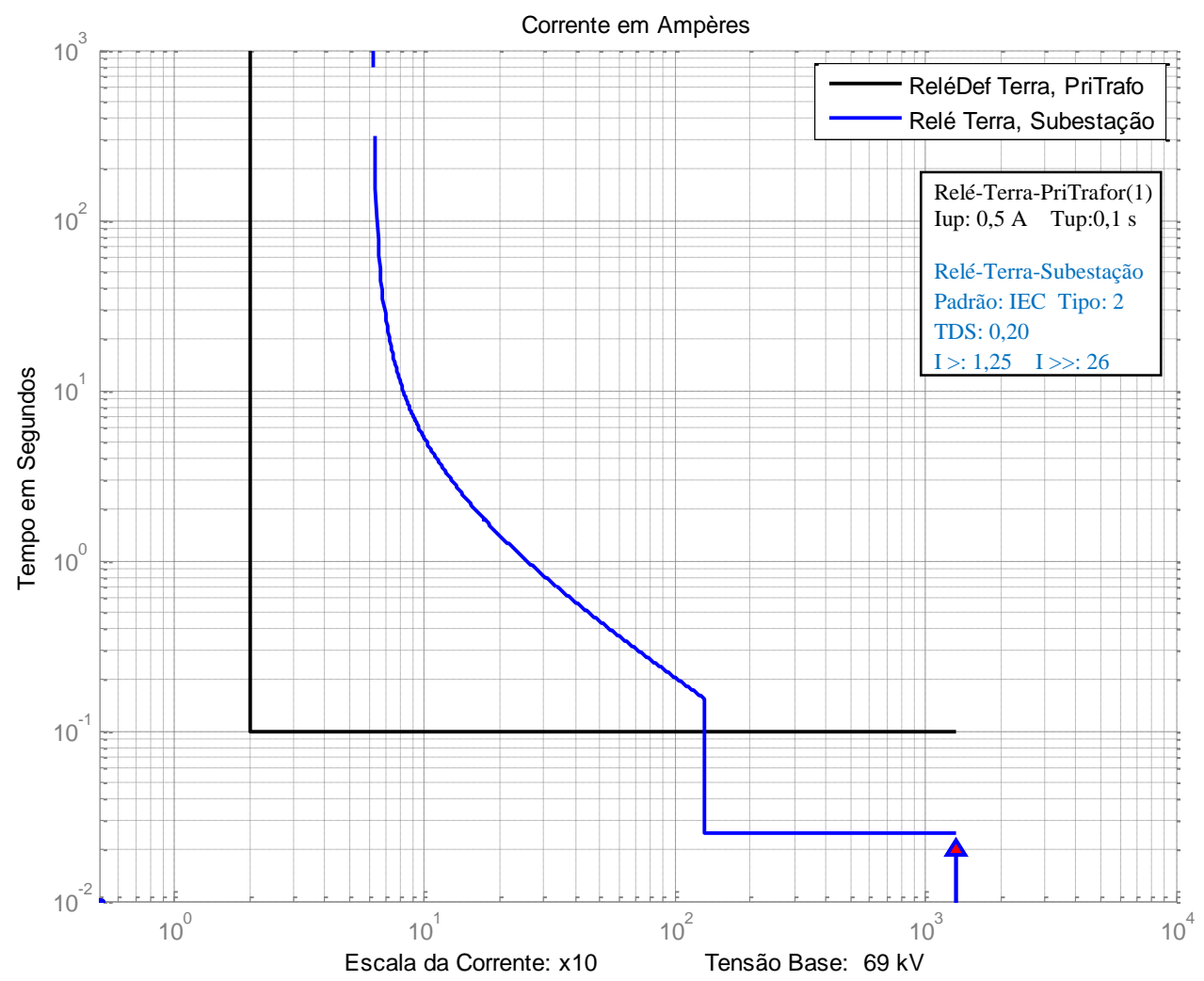

Figura 6.50 - Verificação da proteção de terra primário do transformador T1 com a proteção de terra do relé subestação.

As tabelas apresentando os ajustes dos relés e disjuntores de baixa tensão dos sistemas analisados nos exemplos 1 e 2 encontram-se no Anexo B. 


\section{Capítulo 7}

\section{Conclusões}

O trabalho apresentado mostrou o desenvolvimento de uma metodologia computacional para a coordenação automática de dispositivos de proteção contra sobrecorrente em sistemas elétricos industriais que tem como objetivo acelerar o trabalho do engenheiro de proteção na execução deste tipo de tarefa. No entanto, ressalta-se que os resultados do programa não são definitivos, cabendo ao engenheiro a decisão de utilizá-los ou executar pequenas mudanças. Um ponto forte da estratégia de proteção utilizada neste trabalho é a garantia da coordenação, sempre que possível, dos dispositivos de proteção visando atuação rápida dos mesmos para correntes elevadas de curto-circuito.

Outra vantagem do método é que, em relação ao processo de ajuste manual, ele proporciona uma maior exatidão no cálculo dos ajustes para a coordenação dos dispositivos de proteção, visando sempre selecionar as curvas com menor multiplicador de tempo para prover rapidez na proteção. Além disso, a característica que o distingue em relação a outros métodos existentes é a possibilidade de solucionar automaticamente alguns problemas de má coordenação da proteção, conforme abordado em seções anteriores. 
No trabalho há o desenvolvimento de uma ferramenta computacional que pode ser aplicada para ajuste automático na proteção contra curtos-circuitos trifásicos e fase-terra em sistemas industriais radiais ou em parte de grandes sistemas industriais, um vez que muitos setores possuem configuração radial sem interligações complexas ou geradores.

Agrupar todos os critérios de coordenação e tipos de dispositivos de proteção em uma única ferramenta computacional de análise e prever todos os tipos de situações e problemas que podem ocorrer na coordenação dos mesmos é uma tarefa árdua que deve ser realizada em etapas, analisando-se vários casos diferentes. Neste contexto, a ferramenta desenvolvida apresentou desempenho bastante satisfatório quando aplicado aos sistemas elétricos apresentados no Capítulo 6, com complexidades e esquemas de proteção distintos.

Um procedimento admitido na metodologia proposta foi a possibilidade de coordenar curvas de atuação de relés de padrões diferentes, ou seja, ANSI e IEC. Usualmente, em estudos de coordenação executados manualmente, busca-se sempre manter o mesmo padrão das curvas de atuação em toda a instalação, por razões de simplicidade na análise e padronização. No entanto, após a realização de vários testes nos sistemas elétricos apresentados neste trabalho, verificou-se que, em casos específicos, a proteção poderia ser mais eficiente se houvesse a coordenação entre diferentes padrões de curvas de atuação. Devido a isso, a metodologia proposta permite essa possibilidade, restringindo a utilização de apenas um padrão de curva de atuação para dispositivos que protegem o mesmo ramo, ou seja, relés instalados no lado primário e secundário de transformadores, e início e fim de cabos. Nos demais casos, é permitida a coordenação entre diferentes padrões de curva.

Esta dissertação de Mestrado constitui um avanço significativo em pesquisas na área de coordenação de dispositivos de proteção dentro do Laboratório de Sistemas de Energia Elétrica da EESC/USP. A partir deste trabalho, as seguintes pesquisas podem ser realizadas:

- Inclusão da proteção de geradores síncronos e relés direcionais de corrente; 
- Inclusão da proteção de bancos de capacitores;

- Inclusão de seletividade lógica;

- Elaboração de esquemas de proteção adaptativos para sistemas industriais complexos, em que há diferentes configurações topológicas de operação. 


\section{Referências Bibliográficas}

ALBRECHT, R. E.; NISJA, M. J.; FEERO, W. E.; ROCKEFELLER, G. D.; WAGNER, C. L. Digital Computer Protective Device Co-ordination Program I-General Program Description. IEEE Transactions on Power Apparatus and Systems, vol. 83, no. 4, p. 401410, Apr. 1964.

ALMEIDA M. A. D. Apostila de Proteção de Sistemas Elétricos. Disponível em $<$ http://www.dee.ufrn.br/ marcos/arquivos/Prote\%E7\%E3o/Apost.\%20prot.\%2099\%20\%20capa.pdf $>$.Acesso em: 01 de março de 2009.

ASPEN. Disponível em <http://www.aspeninc.com>. Acesso em 19 de julho de 2009.

BCP SWITZERLAND. Disponível em <http://www.neplan.ch>. Acesso e 19 de julho de 2009.

BROWN, K. A.; PARKER, J. M. A Personal Computer Approach to Overcurrent Protective Device Coordination. IEEE Transactions on Power Delivery, vol. 3, no. 2, p. 509-513, Apr. 1988.

CAMINHA A. C. Introdução à Proteção dos Sistemas Elétricos. São Paulo: Edgard Blücher, 1977, 211 p.

CEE RELAYS Ltd.. Application Guide for the Choice of Protective Relays. Disponível em <http:// www.ceerelays.co.uk/brochures/CEE PRAG.pdf>. Acesso em: 05 de março de 2009.

COMASSETTO L.; BERNARDON, D. P.; CANHA, L. N.; ABAIDE, A. R. Software for Automatic Coordination of Protection Devices in Distribution System. IEEE Transactions on Power Delivery, vol. 23, no. 4, p. 2241-2246, Oct. 2008.

COURY, D. V.; OleSKOVICZ, M.; GIOVAnINI, R. Proteção Digital de Sistemas Elétricos de Potência: dos relés eletromecânicos aos microprocessados inteligentes. São Carlos: EESC-USP, 2007. 378 p.

DIgSILENT. Disponível em <http://www.digsilent.de>. Acesso em: 01 de março de 2009.

EASYPOWER. Disponível em <http://www.easypower.com>. Acesso em: 01 de março de 2009.

FLORES, E. L.; PEREIRA, P. S. Ajuste Computacional Interativo de Dispositivos de

Sobrecorrente para Sistemas Elétricos de Potência. In: SEMINÁRIO TÉCNICO DE PROTEÇÃO E CONTROLE, 5., 1995, Curitiba. Anais..., Curitiba, 1995, vol. 1, p. 165-168.

HEWITSON, L. G.; BROWN, M.; BALAKRISHnAN, R. Practical Power System Protection. Oxford: Newnes, 2004, 288 p. 
INTERNATIONAL ELECTROTECHNICAL COMISSION. IEC 60255-3: electrical relays part 3: single input energizing quantity measuring relays with dependent or independent time", 1989.

INSTITUTE OF ELECTRICAL AND ELECTRONICS ENGINEERS. IEEE Std. 242: IEEE recommended practice for protection and coordination of industrial and commercial power systems. 2001.

IEEE Std. C37.96: IEEE guide for AC motor protection. 2000.

IEEE Std. C37.112: IEEE standard inverse-time characteristic equations for overcurrent relays. 1996.

IEEE Std. C57.109: IEEE guide for liquid-immersed transformer through-faultcurrent duration. 1993 (R2008).

IEEE Std. C57.12.00: IEEE standard for standard general requirements for liquidimmersed distribution, power, and regulating transformers. 2006.

duration. 2001

IEEE Std C57.12.59: IEEE guide for dry-type transformer through-fault current

IEEE Std C57.12.01-2005: IEEE standard general requirements for dry-type distribution and power transformers, including those with solid-cast and/or resin Encapsulated windings. 2005.

KLOCK Jr., O. S. Programa Computacional para a Verificação da Coordenação e Auxílio na Determinação dos Ajustes de Relés Direcionais de Sobrecorrente de Neutro de Linhas de Transmissão. 2002. 85 f. Dissertação (Mestrado em Engenharia Elétrica) Universidade Federal de Santa Catarina, Florianópolis, 2002.

KUNDUR, P. Power System Stability and Control. 1st ed., New York: McGraw-Hill, 1994. $1176 \mathrm{p}$.

LANGHANS, J. D.; E. RONAT. Protective Devices Coordination via Computer Graphics. IEEE Transactions on Industry Applications, vol. IA-16, no. 3, p. 404-412, May/Jun. 1980.

MAMEDE FILHO, J. Manual de Equipamentos Elétricos. $3^{\text {a }}$ ed. Rio de Janeiro: LTC, 2005, 792 p.

MATHWORKS. Disponível em <http://www.mathworks.com>. Acesso em: 15 de março de 2009.

PRYSMIAN CABLES \& SYSTEMS. Média Tensão - Uso Geral: dimensionamento. Disponível em <http:// http://www.prysmian.com.br>. Acesso em: 10 de setembro de 2008. 
SCHWEITZER ENGINEERING LABORATORIES, INC. SEL-351-5, -6, -7 Relay: instruction manual. 2007. Disponível em <http://www.selinc.com.br>. Acesso em: 02 de julho de 2008.

SEN, P. C. Principles of Electric Machines and Power Electronics. $2^{\mathrm{a}}$ ed. John Wiley \& Sons, 1997. $615 \mathrm{p}$.

STEVEnSON Jr., W. D. Elementos de Análise de Sistemas de Potência. Editora McGraw-Hill do Brasil, 1978. 378 p.

SKM. Captor Study Module. Disponível em <http://www.skm.com/products_captor.shtml>. Acesso em: 02 de março de 2009.

YANG, Z.; SHI, D.; XIANZHONG, D; Study on Flexible Power System Protection Relay Coordination Software Based on User-Defined Principle. In: UNIVERSISTIES POWER ENGINEERING CONFERENCE, 2007. Proceedings... 2007, vol. 42, p. 277-282.

YINHONG, L.; DONGYUAN, S.; XIANZHONG, D; An Integrated Power System Relay Coordination Software. In: 2001 IEEE PES SUMMER MEETING, 2001. Proceedings... 2001, vol. 3, p. 1315-1318. 
Anexo A - Dados do Sistema Elétrico do

\author{
Exemplo 2
}


Este anexo contém todos os dados dos equipamentos e dispositivos de proteção utilizados no sistema elétrico da Figura 6.30. Essas informações são apresentadas nas tabelas seguintes, sendo necessárias como dados de entrada para a ferramenta computacional desenvolvida para busca dos ajustes de coordenação dos dispositivos que protegem os equipamentos.

A Tabela A.1 mostra os dados de entrada dos motores, a Tabela A.2 dos transformadores e a Tabela A.3 dos cabos.

Tabela A.1 - Dados dos motores.

\begin{tabular}{|c|c|c|c|c|c|c|c|c|c|}
\hline ID & Barra & $\begin{array}{c}\text { Potência } \\
\text { Nominal } \\
(\mathrm{kVA})\end{array}$ & $\begin{array}{c}\text { Tensão } \\
(\mathrm{kV})\end{array}$ & $\begin{array}{c}\text { Fator de } \\
\text { Serviço }\end{array}$ & Ip/In* & $\begin{array}{c}\text { Tempo de } \\
\text { Aceleração } \\
(\mathrm{s})\end{array}$ & $\begin{array}{c}\text { Tempo de } \\
\text { Rotor } \\
\text { Bloqueado } \\
(\mathrm{s})\end{array}$ & $\begin{array}{c}\text { Margem de } \\
\text { Segurança } \\
\text { sobre o } \\
\text { Tempo de } \\
\text { Aceleração } \\
(\mathrm{s})\end{array}$ & $\begin{array}{c}\text { Fator de } \\
\text { Potência } \\
\text { Nominal }\end{array}$ \\
\hline 1 & 8 & 450 & 0,38 & 1,05 & 6 & 6 & 12 & 2 & 0,83 \\
\hline 2 & 14 & 180 & 0,38 & 1,05 & 6 & 5 & 12 & 2 & 0,83 \\
\hline 3 & 29 & 721 & 2,3 & 1,05 & 6,0 & 8 & 14 & 2 & 0,89 \\
\hline 4 & 29 & 721 & 2,3 & 1,05 & 6,0 & 8 & 14 & 2 & 0,89 \\
\hline
\end{tabular}


Tabela A.2 - Dados dos transformadores.

\begin{tabular}{|c|c|c|c|c|c|c|c|c|c|c|c|}
\hline \multirow{2}{*}{ ID } & \multirow{2}{*}{$\begin{array}{l}\text { Barra } \\
\text { Início }\end{array}$} & \multirow{2}{*}{$\begin{array}{c}\text { Barra } \\
\text { Fim }\end{array}$} & \multirow{2}{*}{$\begin{array}{l}\text { Tipo de } \\
\text { Isolação }\end{array}$} & \multirow{2}{*}{$\begin{array}{c}\text { Potência } \\
\text { (MVA) }\end{array}$} & \multirow{2}{*}{$\begin{array}{c}\text { Tensão } \\
\text { de } \\
\text { Alta } \\
(\mathrm{kV})\end{array}$} & \multirow{2}{*}{$\begin{array}{c}\text { Tensão } \\
\text { de } \\
\text { Baixa } \\
(\mathrm{kV})\end{array}$} & \multirow{2}{*}{$\begin{array}{l}\text { Impedância } \\
(\%)\end{array}$} & \multirow{2}{*}{$\mathrm{M}_{\mathrm{SH}}$} & \multicolumn{2}{|c|}{$\begin{array}{c}\text { Conexão dos } \\
\text { Enrolamentos }\end{array}$} & \multirow{2}{*}{$\begin{array}{c}\text { Frequiência } \\
\text { de Faltas }\end{array}$} \\
\hline & & & & & & & & & Prim & $\mathrm{Sec}$ & \\
\hline 1 & 1 & 2 & 1 & 10 & 69 & 13,8 & 7,89 & 12 & 1 & 4 & 1 \\
\hline 2 & 1 & 2 & 1 & 10 & 69 & 13,8 & 7,82 & 12 & 1 & 4 & 1 \\
\hline 3 & 2 & 30 & 1 & 0,225 & 13,8 & 0,44 & 4,41 & 12 & 1 & 4 & 1 \\
\hline 4 & 3 & 4 & 1 & 0,75 & 13,8 & 0,44 & 4,94 & 12 & 1 & 4 & 1 \\
\hline 5 & 3 & 4 & 1 & 0,75 & 13,8 & 0,44 & 4,96 & 12 & 1 & 4 & 1 \\
\hline 6 & 3 & 5 & 1 & 0,75 & 13,8 & 0,44 & 4,96 & 12 & 1 & 4 & 1 \\
\hline 7 & 3 & 5 & 1 & 0,75 & 13,8 & 0,44 & 4,92 & 12 & 1 & 4 & 1 \\
\hline 8 & 12 & 13 & 1 & 1 & 13,8 & 0,44 & 4,99 & 12 & 1 & 4 & 1 \\
\hline 9 & 12 & 13 & 1 & 1 & 13,8 & 0,44 & 5,02 & 12 & 1 & 4 & 1 \\
\hline 10 & 12 & 14 & 1 & 0,3 & 13,8 & 0,38 & 5,52 & 12 & 1 & 4 & 1 \\
\hline 11 & 22 & 23 & 1 & 1,25 & 13,8 & 0,44 & 5,52 & 12 & 1 & 4 & 1 \\
\hline 12 & 22 & 23 & 1 & 1,25 & 13,8 & 0,44 & 5,52 & 12 & 1 & 4 & 1 \\
\hline 13 & 22 & 24 & 1 & 1,25 & 13,8 & 0,44 & 5,53 & 12 & 1 & 4 & 1 \\
\hline 14 & 25 & 26 & 1 & 1,25 & 13,8 & 0,44 & 5,54 & 12 & 1 & 4 & 1 \\
\hline 15 & 25 & 27 & 1 & 1,25 & 13,8 & 0,44 & 5,54 & 12 & 1 & 4 & 1 \\
\hline 16 & 25 & 28 & 1 & 3 & 13,8 & 2,3 & 7,88 & 12 & 1 & 4 & 1 \\
\hline 17 & 31 & 32 & 1 & 0,75 & 13,8 & 0,44 & 4,96 & 12 & 1 & 4 & 1 \\
\hline 18 & 31 & 33 & 1 & 0,75 & 13,8 & 0,44 & 4,96 & 12 & 1 & 4 & 1 \\
\hline 19 & 6 & 7 & 1 & 0,75 & 13,8 & 0,38 & 5,28 & 12 & 1 & 4 & 1 \\
\hline 20 & 6 & 7 & 1 & 0,75 & 13,8 & 0,38 & 5,2 & 12 & 1 & 4 & 1 \\
\hline 21 & 6 & 8 & 1 & 0,75 & 13,8 & 0,38 & 5,24 & 12 & 1 & 4 & 1 \\
\hline 22 & 15 & 16 & 1 & 1 & 13,8 & 0,44 & 4,85 & 12 & 1 & 4 & 1 \\
\hline 23 & 15 & 16 & 1 & 1 & 13,8 & 0,44 & 4,89 & 12 & 1 & 4 & 1 \\
\hline 24 & 15 & 17 & 1 & 0,3 & 13,8 & 0,38 & 5,62 & 12 & 1 & 4 & 1 \\
\hline 25 & 34 & 35 & 1 & 1,25 & 13,8 & 0,44 & 5,54 & 12 & 1 & 4 & 1 \\
\hline 26 & 34 & 36 & 1 & 1,25 & 13,8 & 0,44 & 5,48 & 12 & 1 & 4 & 1 \\
\hline 27 & 34 & 37 & 1 & 1 & 13,8 & 0,44 & 6,08 & 12 & 1 & 4 & 1 \\
\hline 28 & 9 & 10 & 1 & 1,25 & 13,8 & 0,44 & 5,62 & 12 & 1 & 4 & 1 \\
\hline 29 & 9 & 10 & 1 & 1,25 & 13,8 & 0,44 & 5,59 & 12 & 1 & 4 & 1 \\
\hline 30 & 9 & 11 & 1 & 1,25 & 13,8 & 0,44 & 5,55 & 12 & 1 & 4 & 1 \\
\hline 31 & 18 & 19 & 1 & 1 & 13,8 & 0,44 & 4,9 & 12 & 1 & 4 & 1 \\
\hline 32 & 18 & 19 & 1 & 1 & 13,8 & 0,44 & 4,9 & 12 & 1 & 4 & 1 \\
\hline 33 & 20 & 21 & 1 & 1 & 13,8 & 0,44 & 4,81 & 12 & 1 & 4 & 1 \\
\hline 34 & 20 & 21 & 1 & 1 & 13,8 & 0,44 & 4,78 & 12 & 1 & 4 & 1 \\
\hline
\end{tabular}


Tabela A.3 - Dados dos cabos.

\begin{tabular}{|c|c|c|c|c|c|c|c|c|c|}
\hline ID & $\begin{array}{c}\text { Barra } \\
\text { Início }\end{array}$ & $\begin{array}{c}\text { Barra } \\
\text { Fim }\end{array}$ & $\begin{array}{c}\text { Tipo de } \\
\text { Cabo }\end{array}$ & $\begin{array}{c}\text { Tensão } \\
\text { Nominal } \\
(\mathrm{kV})\end{array}$ & $\begin{array}{c}\text { Número de } \\
\text { Condutores } \\
\text { por Fase }\end{array}$ & $\begin{array}{c}\text { Seção } \\
\text { Transversal } \\
\left(\mathrm{mm}^{2}\right)\end{array}$ & $\begin{array}{c}\text { T1 } \\
\left({ }^{\circ} \mathrm{C}\right)\end{array}$ & $\begin{array}{c}\text { T2 } \\
\left({ }^{\circ} \mathrm{C}\right)\end{array}$ & $\begin{array}{c}\text { Ampacidade } \\
\text { por } \\
\text { Condutor } \\
(\mathrm{A})\end{array}$ \\
\hline 1 & 2 & 3 & 1 & 13,80 & 1 & 95 & 90 & 250 & 0,251 \\
\hline 2 & 3 & 6 & 1 & 13,80 & 1 & 95 & 90 & 250 & 0,251 \\
\hline 3 & 6 & 9 & 1 & 13,80 & 1 & 95 & 90 & 250 & 0,251 \\
\hline 4 & 2 & 12 & 1 & 13,80 & 1 & 95 & 90 & 250 & 0,251 \\
\hline 5 & 12 & 15 & 1 & 13,80 & 1 & 95 & 90 & 250 & 0,251 \\
\hline 6 & 15 & 18 & 1 & 13,80 & 1 & 95 & 90 & 250 & 0,251 \\
\hline 7 & 18 & 20 & 1 & 13,80 & 1 & 95 & 90 & 250 & 0,251 \\
\hline 8 & 2 & 22 & 1 & 13,80 & 1 & 95 & 90 & 250 & 0,251 \\
\hline 9 & 2 & 25 & 1 & 13,80 & 1 & 95 & 90 & 250 & 0,251 \\
\hline 10 & 28 & 29 & 1 & 2,3 & 3 & 125 & 90 & 250 & 0,251 \\
\hline 11 & 2 & 31 & 1 & 13,80 & 1 & 95 & 90 & 250 & 0,241 \\
\hline 12 & 31 & 34 & 1 & 13,80 & 1 & 95 & 90 & 250 & 0,241 \\
\hline
\end{tabular}

As características dos dispositivos de proteção são apresentadas nas tabelas seguintes.

A Tabela A.4 e Tabela A.5 apresentam os dados dos fusíveis.

Tabela A.4 - Tipos de fusíveis.

\begin{tabular}{|c|c|c|c|c|c|c|c|c|c|c|c|c|c|c|}
\hline \multirow{2}{*}{ ID } & \multirow{2}{*}{$\begin{array}{c}\text { Corrente } \\
\text { Nominal } \\
\text { (A) }\end{array}$} & \multirow{2}{*}{$\begin{array}{c}\text { Tensão } \\
\text { Base } \\
(\mathrm{kV})\end{array}$} & \multicolumn{6}{|c|}{ Corrente $(\mathrm{A})$} & \multicolumn{6}{|c|}{ Tempo (s) } \\
\hline & & & $\mathrm{I}(1)$ & $\mathrm{I}(2)$ & $\mathrm{I}(3)$ & $\mathrm{I}(4)$ & $\mathrm{I}(5)$ & $\mathrm{I}(6)$ & $\mathrm{T}(1)$ & $\mathrm{T}(2)$ & $\mathrm{T}(3)$ & $\mathrm{T}(4)$ & $\mathrm{T}(5)$ & $\mathrm{T}(6)$ \\
\hline 1 & 25 & 13,8 & 58 & 70 & 80 & 100 & 200 & 350 & 35 & 8 & 3,2 & 1,2 & 0,065 & 0,01 \\
\hline 2 & 40 & 13,8 & 100 & 200 & 300 & 400 & 500 & 620 & 40 & 1 & 0,2 & 0,055 & 0,025 & 0,01 \\
\hline 3 & 63 & 13,8 & 150 & 200 & 350 & 590 & 1.200 & 1.200 & 50 & 6 & 0,5 & 0,1 & 0,01 & 0,01 \\
\hline 4 & 80 & 13,8 & 230 & 433 & 900 & 2.000 & 2.000 & 2.000 & 22 & 1 & 0,1 & 0,01 & 0,01 & 0,01 \\
\hline 5 & 100 & 13,8 & 340 & 400 & 566 & 1.701 & 2.428 & 2.428 & 100 & 10 & 1 & 0,05 & 0,01 & 0,01 \\
\hline 6 & 100 & 13,8 & 200 & 590 & 700 & 1200 & 2.400 & 2.400 & 50 & 1 & 0,5 & 0,1 & 0,01 & 0,01 \\
\hline 7 & 125 & 13,8 & 300 & 430 & 600 & 1500 & 3000 & 3000 & 100 & 10 & 2 & 0.1 & 0.01 & 0.01 \\
\hline 8 & 125 & 13,8 & 400 & 500 & 700 & 1333 & 1.700 & 5.857 & 100 & 10 & 1 & 0.1 & 0,05 & 0,01 \\
\hline 9 & 200 & 13,8 & 600 & 900 & 3.000 & 6.000 & 6.000 & 6.000 & 100 & 8 & 0,06 & 001 & 0,01 & 0,01 \\
\hline 10 & 400 & 2,4 & 1.200 & 2.000 & 3.000 & 6.000 & 15.000 & 15.000 & 100 & 7 & 1 & 0,1 & 0,01 & 0,01 \\
\hline
\end{tabular}


Tabela A.5 - Identificação dos fusíveis.

\begin{tabular}{|c|c|c|c|}
\hline ID & $\begin{array}{c}\text { Tipo de } \\
\text { Equipamento }\end{array}$ & $\begin{array}{c}\text { Índice do } \\
\text { Equipamento }\end{array}$ & $\begin{array}{l}\text { Tipo de } \\
\text { Fusível }\end{array}$ \\
\hline 1 & 2 & 4 & 3 \\
\hline 2 & 2 & 5 & 4 \\
\hline 3 & 2 & 6 & 4 \\
\hline 4 & 2 & 7 & 4 \\
\hline 5 & 2 & 19 & 3 \\
\hline 6 & 2 & 20 & 3 \\
\hline 7 & 2 & 21 & 3 \\
\hline 8 & 2 & 28 & 5 \\
\hline 9 & 2 & 29 & 5 \\
\hline 10 & 2 & 30 & 5 \\
\hline 11 & 2 & 8 & 4 \\
\hline 12 & 2 & 9 & 4 \\
\hline 13 & 2 & 10 & 2 \\
\hline 14 & 2 & 22 & 4 \\
\hline 15 & 2 & 23 & 4 \\
\hline 16 & 2 & 24 & 2 \\
\hline 17 & 2 & 31 & 4 \\
\hline 18 & 2 & 32 & 4 \\
\hline 19 & 2 & 33 & 4 \\
\hline 20 & 2 & 34 & 4 \\
\hline 21 & 2 & 11 & 5 \\
\hline 22 & 2 & 12 & 5 \\
\hline 23 & 2 & 13 & 5 \\
\hline 24 & 2 & 14 & 7 \\
\hline 25 & 2 & 15 & 6 \\
\hline 26 & 2 & 16 & 9 \\
\hline 27 & 2 & 3 & 1 \\
\hline 28 & 2 & 17 & 3 \\
\hline 29 & 2 & 18 & 3 \\
\hline 30 & 2 & 25 & 8 \\
\hline 31 & 2 & 26 & 5 \\
\hline 32 & 2 & 27 & 3 \\
\hline 33 & 1 & 3 & 10 \\
\hline 34 & 1 & 4 & 10 \\
\hline
\end{tabular}

A Tabela A.6 e Tabela A.7 mostram os dados dos disjuntores termomagnéticos. 
Tabela A.6 - Identificação dos disjuntores termomagnéticos.

\begin{tabular}{|c|c|c|c|}
\hline ID & $\begin{array}{c}\text { Tipo de } \\
\text { Equipamento }\end{array}$ & $\begin{array}{c}\text { Índice do } \\
\text { Equipamento }\end{array}$ & $\begin{array}{c}\text { Corrente } \\
\text { Nominal (A) }\end{array}$ \\
\hline 1 & 7 & 1 & 1600 \\
\hline 2 & 7 & 2 & 1600 \\
\hline 3 & 7 & 3 & 800 \\
\hline 4 & 7 & 4 & 800 \\
\hline 5 & 7 & 5 & 1600 \\
\hline 6 & 7 & 6 & 1250 \\
\hline 7 & 7 & 7 & 1250 \\
\hline 8 & 7 & 8 & 400 \\
\hline 9 & 7 & 9 & 1250 \\
\hline 10 & 7 & 10 & 1250 \\
\hline 11 & 7 & 11 & 1250 \\
\hline 12 & 7 & 12 & 1600 \\
\hline 13 & 7 & 13 & 1600 \\
\hline 14 & 7 & 14 & 1600 \\
\hline 15 & 7 & 15 & 400 \\
\hline 16 & 7 & 16 & 1250 \\
\hline 17 & 7 & 17 & 1250 \\
\hline 18 & 7 & 18 & 1600 \\
\hline 19 & 7 & 19 & 1000 \\
\hline 20 & 7 & 20 & 1000 \\
\hline
\end{tabular}

Tabela A.7 - Dados dos disjuntores termomagnéticos.

\begin{tabular}{|c|c|c|c|c|c|c|c|c|c|c|c|c|}
\hline \multirow{2}{*}{ ID } & \multicolumn{6}{|c|}{ Corrente (A) } & \multicolumn{6}{|c|}{ Tempo (s) } \\
\hline & $\mathrm{I}(1)$ & $\mathrm{I}(2)$ & $\mathrm{I}(3)$ & $\mathrm{I}(4)$ & $\mathrm{I}(5)$ & $\mathrm{I}(6)$ & $\mathrm{T}(1)$ & $\mathrm{T}(2)$ & $\mathrm{T}(3)$ & $\mathrm{T}(4)$ & $\mathrm{T}(5)$ & $\mathrm{T}(6)$ \\
\hline 1 & 1.718 & 1.735 & 1.851 & 2.173 & 3.279 & 4.000 & 1.000 & 600 & 300 & 100 & 60 & 30 \\
\hline 2 & 1.021 & 1.025 & 1.098 & 1.292 & 2.386 & 4.000 & 1.000 & 600 & 300 & 100 & 60 & 16,8 \\
\hline 3 & 671 & 700 & 764 & 868,5 & 2.034 & 3.000 & 1.000 & 400 & 200 & 100 & 30 & 13,58 \\
\hline 4 & 672 & 745 & 813 & 1.040 & 2.082 & 2.240 & 160 & 100 & 70 & 40 & 20 & 9 \\
\hline 5 & 768 & 797,3 & 822 & 850 & 917 & 960 & 20 & 17 & 14,76 & 12,58 & 10,62 & 8 \\
\hline 6 & 1.077 & 1.155 & 1.357 & 1.497 & 3.555 & 8.000 & 1.000 & 300 & 100 & 70 & 40 & 9 \\
\hline 7 & 1.075 & 1.122 & 1.215 & 1.361 & 2.519 & 4.000 & 1.000 & 400 & 200 & 100 & 60 & 17 \\
\hline 8 & 3.54 .1 & 374,8 & 445,3 & 560 & 1.013 & 1.278 & 1.000 & 200 & 100 & 60 & 30 & 12,74 \\
\hline 9 & 1.500 & 2.162 & 2.580 & 3.057 & 3.950 & 5.000 & 208,33 & 100 & 70 & 50 & 40 & 18,56 \\
\hline 10 & 1.050 & 1.224 & 1.484 & 1.712 & 2.304 & 2.625 & 208,33 & 153,16 & 104,25 & 78,38 & 61,08 & 33,32 \\
\hline 11 & 1.503 & 1.660 & 1.812 & 2.100 & 4.673 & 5.000 & 158 & 100 & 70 & 50 & 20 & 8,7 \\
\hline 12 & 1.344 & 1.572 & 1.724 & 2.376 & 4.167 & 4.480 & 160 & 80 & 60 & 30 & 20 & 8,7 \\
\hline 13 & 1.152 & 1.277 & 1.485 & 1.782 & 3.013 & 3.840 & 80 & 50 & 30 & 20 & 10 & 4,37 \\
\hline 14 & 1.152 & 1.277 & 1.485 & 1.782 & 3.013 & 3.840 & 80 & 50 & 30 & 20 & 10 & 4,37 \\
\hline 15 & 573,5 & 616 & 700 & 907 & 2.167 & 2.600 & 1.000 & 600 & 300 & 100 & 40 & 7 \\
\hline 16 & 1.343 & 1.352 & 1.448 & 1.697 & 2.570 & 4.000 & 1.000 & 600 & 300 & 100 & 70 & 22,2 \\
\hline 17 & 1.343 & 1.352 & 1.448 & 1.697 & 2.570 & 4.000 & 1.000 & 600 & 300 & 100 & 70 & 22,2 \\
\hline 18 & 1.536 & 1.705 & 1.861 & 2.726 & 4.750 & 5.108 & 160 & 100 & 70 & 30 & 20 & 8,8 \\
\hline 19 & 1.201 & 1.330 & 1.453 & 1.863 & 3.726 & 4.000 & 160 & 100 & 70 & 40 & 20 & 8,8 \\
\hline 20 & 1.040 & 1.124 & 1.378 & 1.520 & 2.398 & 3.000 & 300 & 200 & 100 & 80 & 60 & 30 \\
\hline
\end{tabular}

A Tabela A.8 e Tabela A.9 apresentam os dados dos disjuntores de baixa tensão. 
Tabela A.8 - Identificação dos disjuntores de baixa tensão.

\begin{tabular}{|c|c|c|c|}
\hline ID & $\begin{array}{c}\text { Tipo de } \\
\text { Equipamento }\end{array}$ & $\begin{array}{c}\text { Índice do } \\
\text { Equipamento }\end{array}$ & $\begin{array}{c}\text { Corrente } \\
\text { Nominal (A) }\end{array}$ \\
\hline 1 & 3 & 4 & 1600 \\
\hline 2 & 3 & 5 & 1600 \\
\hline 3 & 3 & 6 & 1600 \\
\hline 4 & 3 & 7 & 1600 \\
\hline 5 & 3 & 19 & 1600 \\
\hline 6 & 3 & 20 & 1600 \\
\hline 7 & 3 & 21 & 1600 \\
\hline 8 & 1 & 1 & 1000 \\
\hline 9 & 3 & 28 & 2000 \\
\hline 10 & 3 & 29 & 2000 \\
\hline 11 & 3 & 30 & 2000 \\
\hline 12 & 3 & 8 & 1600 \\
\hline 13 & 3 & 9 & 1600 \\
\hline 14 & 3 & 10 & 630 \\
\hline 15 & 1 & 2 & 630 \\
\hline 16 & 3 & 22 & 1600 \\
\hline 17 & 3 & 23 & 1600 \\
\hline 18 & 3 & 24 & 630 \\
\hline 19 & 3 & 31 & 1600 \\
\hline 20 & 3 & 32 & 1600 \\
\hline 21 & 3 & 33 & 1600 \\
\hline 22 & 3 & 34 & 1600 \\
\hline 23 & 3 & 11 & 2000 \\
\hline 24 & 3 & 12 & 2000 \\
\hline 25 & 3 & 13 & 2000 \\
\hline 26 & 3 & 14 & 2000 \\
\hline 27 & 3 & 15 & 2000 \\
\hline 28 & 3 & 17 & 1600 \\
\hline 29 & 3 & 18 & 1600 \\
\hline 30 & 3 & 25 & 2000 \\
\hline 31 & 3 & 26 & 2000 \\
\hline 32 & 3 & 27 & 1600 \\
\hline
\end{tabular}

Tabela A.9 - Parâmetros para todos os disjuntores de baixa tensão.

\begin{tabular}{|c|c|c|c|c|c|c|c|c|c|c|c|c|c|c|c|c|c|c|c|c|}
\hline \multicolumn{3}{|c|}{ MTL } & \multicolumn{3}{|c|}{ ATL } & \multicolumn{3}{|c|}{ MTC } & \multicolumn{3}{|c|}{ ATC } & \multicolumn{3}{|c|}{ MInst } & \multicolumn{3}{|c|}{ MT } & \multicolumn{3}{|c|}{ AT } \\
\hline LI & pas. & LS & LI & pas. & LS & LI & pas. & LS & LI & pas. & LS & LI & pas. & LS & LI & pas. & LS & LI & pas. & LS \\
\hline 0,4 & 0,1 & 1,1 & 0,5 & 0,1 & 30 & 0,1 & 0,1 & 0,1 & 0,1 & 0,1 & 0,4 & 2 & 0,1 & 12 & 0,1 & 0,1 & 1 & 0,1 & 0,1 & 0,4 \\
\hline
\end{tabular}


A Tabela A.10 e a Tabela A.11 mostram os dados dos relés.

Tabela A.10 - Identificação dos relés.

\begin{tabular}{|c|c|c|c|c|c|}
\hline \multirow{2}{*}{ ID } & Tipo de & Índice do & \multicolumn{3}{|c|}{ TC } \\
\cline { 4 - 6 } & Equipamento & Equipamento & Prim.F (A) & Prim.T (A) & Sec (A) \\
\hline 1 & 6 & 1 & 250 & 250 & 5 \\
\hline 2 & 2 & 1 & 200 & 200 & 5 \\
\hline 3 & 2 & 2 & 200 & 200 & 5 \\
\hline 4 & 3 & 1 & 600 & 50 & 5 \\
\hline 5 & 3 & 2 & 600 & 50 & 5 \\
\hline 6 & 4 & 1 & 400 & 50 & 5 \\
\hline 7 & 4 & 4 & 400 & 50 & 5 \\
\hline 8 & 4 & 8 & 400 & 50 & 5 \\
\hline 9 & 4 & 9 & 400 & 50 & 5 \\
\hline 10 & 4 & 11 & 400 & 50 & 5 \\
\hline 11 & 4 & 2 & 300 & 50 & 5 \\
\hline 12 & 4 & 3 & 200 & 50 & 5 \\
\hline 13 & 4 & 5 & 300 & 50 & 5 \\
\hline 14 & 4 & 6 & 200 & 50 & 5 \\
\hline 15 & 4 & 7 & 100 & 50 & 5 \\
\hline 16 & 4 & 12 & 200 & 50 & 5 \\
\hline 17 & 1 & 3 & 200 & 50 & 5 \\
\hline 18 & 1 & 4 & 200 & 50 & 5 \\
\hline
\end{tabular}

Tabela A.11 - Parâmetros para todos os relés.

\begin{tabular}{|c|c|c|c|c|c|c|c|c|c|c|c|}
\hline \multicolumn{2}{|c|}{} & \multicolumn{9}{|c|}{} & \multicolumn{2}{c|}{$\begin{array}{c}\text { Corrente de } \\
\text { Ajuste da } \\
\text { Unidade } \\
\text { Temporizada } \\
\text { TDS (ANSI) }\end{array}$} & \multicolumn{3}{c|}{$\begin{array}{c}\text { Corrente de } \\
\text { Ajuste da } \\
\text { Unidade } \\
\text { Instantânea } \\
\text { (A) }\end{array}$} \\
\hline LI & pas. & LS & LI & pas. & LS & LI & pas. & LS & LI & pas. & LS \\
\hline 0,5 & 0,01 & 15 & 0,05 & 0,01 & 1 & 0,25 & 0,01 & 16 & 0,25 & 0,01 & 100 \\
\hline
\end{tabular}


Anexo B - Resultados Completos dos Exemplos 
Este anexo contém as saídas da ferramenta computacional desenvolvida para os dois exemplos do Capítulo 6.

Da Tabela B.1 à Tabela B.4 são apresentados os resultados correspondentes ao Exemplo 1.

Tabela B.1 - Ajustes dos disjuntores de baixa tensão (Exemplo 1).

\begin{tabular}{|c|c|c|c|c|c|c|c|c|c|}
\hline ID & $\begin{array}{c}\text { Tipo de } \\
\text { Equipamento }\end{array}$ & $\begin{array}{c}\text { Índice do } \\
\text { Equipamento }\end{array}$ & MTL & ATL & MTC & ATC & MInst & MT & AT \\
\hline 1 & 1 & 1 & 1 & 5 & 9,8 & 0,1 & 9,8 & 0,1 & 0,1 \\
\hline 2 & 1 & 2 & 1 & 5 & 9,8 & 0,1 & 9,8 & 0,1 & 0,1 \\
\hline 3 & 1 & 7 & 1 & 3,9 & 9,5 & 0,1 & 9,5 & 0,1 & 0,1 \\
\hline 4 & 1 & 8 & 1 & 4,7 & 9,1 & 0,1 & 9,1 & 0,1 & 0,1 \\
\hline 5 & 3 & 2 & 1 & 1 & 3,8 & 0,2 & 12 & 0,1 & 0,3 \\
\hline 6 & 3 & 3 & 1 & 1 & 3,8 & 0,2 & 12 & 0,1 & 0,3 \\
\hline 7 & 3 & 6 & 1,1 & 0,5 & 2,2 & 0,2 & 12 & 0,1 & 0,3 \\
\hline
\end{tabular}

MTL = multiplicador de tempo longo; ATL = atraso de tempo longo; MTC = multiplicador de tempo curto; ATC = atraso de tempo curto; MInst = multiplicador de instantâneo; MT = multiplicador de corrente da unidade de proteção de terra; AT = atraso da unidade de proteção de terra.

Tabela B.2 - Identificação dos relés (Exemplo 1).

\begin{tabular}{|c|c|c|}
\hline ID & $\begin{array}{c}\text { Tipo de } \\
\text { Equipamento }\end{array}$ & $\begin{array}{c}\text { Índice do } \\
\text { Equipamento }\end{array}$ \\
\hline 1 & 6 & 1 \\
\hline 2 & 2 & 1 \\
\hline 3 & 3 & 1 \\
\hline 4 & 4 & 2 \\
\hline 5 & 4 & 9 \\
\hline 6 & 4 & 10 \\
\hline 7 & 4 & 3 \\
\hline 8 & 4 & 5 \\
\hline 9 & 4 & 4 \\
\hline 10 & 3 & 3 \\
\hline 11 & 1 & 4 \\
\hline 12 & 1 & 5 \\
\hline 13 & 3 & 5 \\
\hline 14 & 1 & 6 \\
\hline 15 & 1 & \\
\hline
\end{tabular}


Tabela B.3 - Ajustes dos relés para proteção de fase (Exemplo 1).

\begin{tabular}{|c|c|c|c|c|c|c|c|}
\hline ID & $\begin{array}{c}\text { Corrente de } \\
\text { Ajuste (tempo } \\
\text { definido) (A) }\end{array}$ & $\begin{array}{c}\text { Tempo de } \\
\text { Ajuste (tempo } \\
\text { definido) (s) }\end{array}$ & $\begin{array}{c}\text { Padrão da } \\
\text { Curva de } \\
\text { Atuação }\end{array}$ & $\begin{array}{c}\text { Tipo da } \\
\text { Curva de } \\
\text { Atuação }\end{array}$ & TDS & $\begin{array}{c}\text { Corrente de } \\
\text { Ajuste da } \\
\text { Unidade } \\
\text { Temporizada } \\
\text { (A) }\end{array}$ & $\begin{array}{c}\text { Corrente de } \\
\text { Ajuste da } \\
\text { Unidade } \\
\text { Instantânea } \\
\text { (A) }\end{array}$ \\
\hline 1 & $0^{*}$ & $0^{*}$ & 2 & 4 & 0,15 & 5 & $0^{*}$ \\
\hline 2 & $0^{*}$ & $0^{*}$ & 1 & 5 & 7,28 & 3,04 & 30,13 \\
\hline 3 & $0^{*}$ & $0^{*}$ & 1 & 5 & 4,67 & 4,36 & $0^{*}$ \\
\hline 4 & $0^{*}$ & $0^{*}$ & 1 & 3 & 2,82 & 4,55 & $0^{*}$ \\
\hline 5 & $0^{*}$ & $0^{*}$ & 2 & 3 & 0,34 & 4,55 & 45,23 \\
\hline 6 & $0^{*}$ & $0^{*}$ & 1 & 3 & 2,92 & 4,55 & 45,23 \\
\hline 7 & $0^{*}$ & $0^{*}$ & 2 & 3 & 0,85 & 2,62 & 48,16 \\
\hline 8 & $0^{*}$ & $0^{*}$ & 2 & 3 & 0,83 & 3,93 & 71,41 \\
\hline 9 & $0^{*}$ & $0^{*}$ & 2 & 3 & 0,83 & 3,93 & 71,41 \\
\hline 10 & $0^{*}$ & $0^{*}$ & 2 & 3 & 0,22 & 5,21 & $0^{*}$ \\
\hline 11 & $0^{*}$ & $0^{*}$ & 2 & 4 & 0,36 & 4,97 & $0^{*}$ \\
\hline 12 & $0^{*}$ & $0^{*}$ & 2 & 4 & 0,28 & 4,59 & $0^{*}$ \\
\hline 13 & $0^{*}$ & $0^{*}$ & 1 & 3 & 1,56 & 5,21 & $0^{*}$ \\
\hline 14 & $0^{*}$ & $0^{*}$ & 2 & 4 & 0,36 & 4,07 & $0^{*}$ \\
\hline 15 & $0^{*}$ & $0^{*}$ & 2 & 4 & 0,28 & 3,25 & $0^{*}$ \\
\hline
\end{tabular}

*0 indica que a unidade instantânea está inoperante ou bloqueada.

Tabela B.4 - Ajustes dos relés para proteção de terra (Exemplo 1).

\begin{tabular}{|c|c|c|c|c|c|c|c|}
\hline ID & $\begin{array}{c}\text { Corrente de } \\
\text { Ajuste (tempo } \\
\text { definido) (A) }\end{array}$ & $\begin{array}{c}\text { Tempo de } \\
\text { Ajuste (tempo } \\
\text { definido) (s) }\end{array}$ & $\begin{array}{c}\text { Padrão da } \\
\text { Curva de } \\
\text { Atuação }\end{array}$ & $\begin{array}{c}\text { Tipo da } \\
\text { Curva de } \\
\text { Atuação }\end{array}$ & $\begin{array}{c}\text { Corrente de } \\
\text { Ajuste da } \\
\text { Unidade } \\
\text { Temporizada } \\
\text { (A) }\end{array}$ & $\begin{array}{c}\text { Corrente de } \\
\text { Ajuste da } \\
\text { Unidade } \\
\text { Instantânea } \\
\text { (A) }\end{array}$ \\
\hline 1 & 0,5 & 0,35 & $0^{*}$ & $0^{*}$ & $0^{*}$ & $0^{*}$ & $0^{*}$ \\
\hline 2 & 0,5 & 0,1 & $0^{*}$ & $0^{*}$ & $0^{*}$ & $0^{*}$ & $0^{*}$ \\
\hline 3 & 0,5 & 0,35 & $0^{*}$ & $0^{*}$ & $0^{*}$ & $0^{*}$ & $0^{*}$ \\
\hline 4 & 0,5 & 0,35 & $0^{*}$ & $0^{*}$ & $0^{*}$ & $0^{*}$ & $0^{*}$ \\
\hline 5 & 0,5 & 0,1 & $0^{*}$ & $0^{*}$ & $0^{*}$ & $0^{*}$ & $0^{*}$ \\
\hline 6 & 0,5 & 0,1 & $0^{*}$ & $0^{*}$ & $0^{*}$ & $0^{*}$ & $0^{*}$ \\
\hline 7 & 0,5 & 0,1 & $0^{*}$ & $0^{*}$ & $0^{*}$ & $0^{*}$ & $0^{*}$ \\
\hline 8 & 0,5 & 0,1 & $0^{*}$ & $0^{*}$ & $0^{*}$ & $0^{*}$ & $0^{*}$ \\
\hline 9 & 0,5 & 0,1 & $0^{*}$ & $0^{*}$ & $0^{*}$ & $0^{*}$ & $0^{*}$ \\
\hline 10 & 0,5 & 0,35 & $0^{*}$ & $0^{*}$ & $0^{*}$ & $0^{*}$ & $0^{*}$ \\
\hline 11 & 0,5 & 0,1 & $0^{*}$ & $0^{*}$ & $0^{*}$ & $0^{*}$ & $0^{*}$ \\
\hline 12 & 0,5 & 0,1 & $0^{*}$ & $0^{*}$ & $0^{*}$ & $0^{*}$ & $0^{*}$ \\
\hline 13 & 0,5 & 0,35 & $0^{*}$ & $0^{*}$ & $0^{*}$ & $0^{*}$ & $0^{*}$ \\
\hline 14 & 0,5 & 0,1 & $0^{*}$ & $0^{*}$ & $0^{*}$ & $0^{*}$ & $0^{*}$ \\
\hline 15 & 0,5 & 0,1 & $0^{*}$ & $0^{*}$ & $0^{*}$ & $0^{*}$ & $0^{*}$ \\
\hline
\end{tabular}

*0 indica que a unidade instantânea está inoperante ou bloqueada. 
As tabelas seguintes correspondem ao Exemplo 2.

Tabela B.5 - Ajustes dos disjuntores de baixa tensão (Exemplo 2).

\begin{tabular}{|c|c|c|c|c|c|c|c|c|c|}
\hline ID & $\begin{array}{c}\text { Tipo de } \\
\text { Equipamento }\end{array}$ & $\begin{array}{c}\text { Índice do } \\
\text { Equipamento }\end{array}$ & MTL & ATL & MTC & ATC & MInst & MT & AT \\
\hline 1 & 3 & 4 & 0,9 & 9,8 & 3,8 & 0,2 & 12 & 1 & 0,2 \\
\hline 2 & 3 & 5 & 0,9 & 9,8 & 3,8 & 0,2 & 12 & 1 & 0,2 \\
\hline 3 & 3 & 6 & 0,9 & 5,5 & 3,8 & 0,2 & 12 & 1 & 0,2 \\
\hline 4 & 3 & 7 & 0,9 & 5,5 & 3,8 & 0,2 & 12 & 1 & 0,2 \\
\hline 5 & 3 & 19 & 1 & 2,6 & 2,6 & 0,2 & 12 & 1 & 0,2 \\
\hline 6 & 3 & 20 & 1 & 2,6 & 2,6 & 0,2 & 12 & 1 & 0,2 \\
\hline 7 & 3 & 21 & 1 & 3,7 & 7,2 & 0,2 & 12 & 0,1 & 0,3 \\
\hline 8 & 1 & 1 & 0,9 & 4,1 & 9,4 & 0,1 & 8,4 & 0,1 & 0,1 \\
\hline 9 & 3 & 28 & 1,1 & 0,9 & 1,5 & 0,2 & 12 & 1 & 0,2 \\
\hline 10 & 3 & 29 & 1,1 & 0,9 & 1,5 & 0,2 & 12 & 1 & 0,2 \\
\hline 11 & 3 & 30 & 1,1 & 0,8 & 1,5 & 0,2 & 12 & 0,6 & 0,2 \\
\hline 12 & 3 & 8 & 0,9 & 11,7 & 5,7 & 0,2 & 12 & 1 & 0,2 \\
\hline 13 & 3 & 9 & 0,9 & 11,7 & 5,7 & 0,2 & 12 & 1 & 0,2 \\
\hline 14 & 3 & 10 & 1,1 & 3,4 & 6,6 & 0,2 & 12 & 0,2 & 0,3 \\
\hline 15 & 1 & 2 & 0,6 & 1,5 & 9 & 0,1 & 5,4 & 0,1 & 0,1 \\
\hline 16 & 3 & 22 & 1,1 & 5,8 & 2,9 & 0,2 & 12 & 1 & 0,2 \\
\hline 17 & 3 & 23 & 1,1 & 5,8 & 2,9 & 0,2 & 12 & 1 & 0,2 \\
\hline 18 & 3 & 24 & 1,1 & 2,7 & 2,5 & 0,2 & 12 & 1 & 0,2 \\
\hline 19 & 3 & 31 & 1,1 & 9,7 & 3,6 & 0,2 & 12 & 1 & 0,2 \\
\hline 20 & 3 & 32 & 1,1 & 9,7 & 3,6 & 0,2 & 12 & 1 & 0,2 \\
\hline 21 & 3 & 33 & 1,1 & 3 & 1,5 & 0,2 & 12 & 1 & 0,2 \\
\hline 22 & 3 & 34 & 1,1 & 3 & 1,5 & 0,2 & 12 & 1 & 0,2 \\
\hline 23 & 3 & 11 & 1,1 & 3 & 2,9 & 0,2 & 12 & 1 & 0,2 \\
\hline 24 & 3 & 12 & 1,1 & 3 & 2,9 & 0,2 & 12 & 1 & 0,2 \\
\hline 25 & 3 & 13 & 1,1 & 0,9 & 2,2 & 0,2 & 12 & 1 & 0,2 \\
\hline 26 & 3 & 14 & 1,1 & 0,9 & 2,2 & 0,2 & 12 & 1 & 0,2 \\
\hline 27 & 3 & 15 & 1,1 & 0,9 & 2,2 & 0,2 & 12 & 1 & 0,2 \\
\hline 28 & 3 & 17 & 1,1 & 1,9 & 2,3 & 0,2 & 12 & 1 & 0,2 \\
\hline 29 & 3 & 18 & 1,1 & 5,9 & 2,2 & 0,2 & 12 & 1 & 0,2 \\
\hline 30 & 3 & 25 & 1,1 & 3 & 2,9 & 0,2 & 12 & 1 & 0,2 \\
\hline 31 & 3 & 26 & 1,1 & 1,9 & 2,3 & 0,2 & 12 & 1 & 0,2 \\
\hline 32 & 3 & 27 & 1,1 & 5,9 & 2,2 & 0,2 & 12 & 1 & 0,2 \\
\hline
\end{tabular}

MTL = multiplicador de tempo longo; $\mathrm{ATL}=$ atraso de tempo longo; $\mathrm{MTC}=$ multiplicador de tempo curto; $\mathrm{ATC}=$ atraso de tempo curto; MInst = multiplicador de instantâneo; MT = multiplicador de corrente da unidade de proteção de terra; $\mathrm{AT}=$ atraso da unidade de proteção de terra. 
Tabela B.6 - Identificação dos relés (Exemplo 2).

\begin{tabular}{|c|c|c|}
\hline ID & $\begin{array}{c}\text { Tipo de } \\
\text { Equipamento }\end{array}$ & $\begin{array}{c}\text { Índice do } \\
\text { Equipamento }\end{array}$ \\
\hline 1 & 6 & 1 \\
\hline 2 & 2 & 1 \\
\hline 3 & 2 & 2 \\
\hline 4 & 3 & 1 \\
\hline 5 & 3 & 2 \\
\hline 6 & 4 & 1 \\
\hline 7 & 4 & 4 \\
\hline 8 & 4 & 8 \\
\hline 9 & 4 & 9 \\
\hline 10 & 4 & 11 \\
\hline 11 & 4 & 2 \\
\hline 12 & 4 & 3 \\
\hline 13 & 4 & 5 \\
\hline 14 & 4 & 6 \\
\hline 15 & 4 & 7 \\
\hline 16 & 4 & 12 \\
\hline 17 & 1 & 3 \\
\hline 18 & 1 & 4 \\
\hline
\end{tabular}

Tabela B.7 - Ajustes dos relés para proteção de fase (Exemplo 2).

\begin{tabular}{|c|c|c|c|c|c|c|c|}
\hline ID & $\begin{array}{c}\text { Corrente de } \\
\text { Ajuste (tempo } \\
\text { definido) (A) }\end{array}$ & $\begin{array}{c}\text { Tempo de } \\
\text { Ajuste (tempo } \\
\text { definido) (s) }\end{array}$ & $\begin{array}{c}\text { Padrão da } \\
\text { Curva de } \\
\text { Atuação }\end{array}$ & $\begin{array}{c}\text { Tipo da } \\
\text { Curva de } \\
\text { Atuação }\end{array}$ & TDS & $\begin{array}{c}\text { Corrente de } \\
\text { Ajuste da } \\
\text { Unidade } \\
\text { Temporizada } \\
\text { (A) }\end{array}$ & $\begin{array}{c}\text { Corrente de } \\
\text { Ajuste da } \\
\text { Unidade } \\
\text { Instantânea } \\
\text { (A) }\end{array}$ \\
\hline 1 & $0^{*}$ & $0^{*}$ & 2 & 2 & 0,2 & 5 & 120 \\
\hline 2 & $0^{*}$ & $0^{*}$ & 1 & 4 & 5,8 & 4,34 & 43,02 \\
\hline 3 & $0^{*}$ & $0^{*}$ & 1 & 4 & 5,8 & 4,34 & 43,02 \\
\hline 4 & $0^{*}$ & $0^{*}$ & 1 & 4 & 4,5 & 4,36 & $0^{*}$ \\
\hline 5 & $0^{*}$ & $0^{*}$ & 1 & 4 & 4,5 & 4,36 & $0^{*}$ \\
\hline 6 & $0^{*}$ & $0^{*}$ & 1 & 4 & 15 & 4,12 & $0^{*}$ \\
\hline 7 & $0^{*}$ & $0^{*}$ & 2 & 4 & 0,22 & 2,81 & $0^{*}$ \\
\hline 8 & $0^{*}$ & $0^{*}$ & 1 & 4 & 3,69 & 7,26 & $0^{*}$ \\
\hline 9 & $0^{*}$ & $0^{*}$ & 2 & 4 & 3,27 & 10,55 & $0^{*}$ \\
\hline 10 & $0^{*}$ & $0^{*}$ & 1 & 4 & 3,59 & 6,38 & $0^{*}$ \\
\hline 11 & $0^{*}$ & $0^{*}$ & 1 & 4 & 9,65 & 5,92 & $0^{*}$ \\
\hline 12 & $0^{*}$ & $0^{*}$ & 1 & 4 & 3,66 & 7,65 & $0^{*}$ \\
\hline 13 & $0^{*}$ & $0^{*}$ & 1 & 4 & 15 & 6,06 & $0^{*}$ \\
\hline 14 & $0^{*}$ & $0^{*}$ & 1 & 4 & 9,65 & 5,22 & $0^{*}$ \\
\hline 15 & $0^{*}$ & $0^{*}$ & 1 & 4 & 3,84 & 9 & $0^{*}$ \\
\hline 16 & $0^{*}$ & $0^{*}$ & 1 & 4 & 3,59 & 8,24 & $0^{*}$ \\
\hline 17 & $0^{*}$ & $0^{*}$ & 1 & 4 & 0,4 & 4,99 & $0^{*}$ \\
\hline 18 & $0^{*}$ & $0^{*}$ & 1 & 4 & 0,4 & 4,99 & $0^{*}$ \\
\hline
\end{tabular}

*0 indica que a unidade instantânea está inoperante ou bloqueada. 
Tabela B.8 - Ajustes dos relés para proteção de terra (Exemplo 2).

\begin{tabular}{|c|c|c|c|c|c|c|c|}
\hline ID & $\begin{array}{l}\text { Corrente de } \\
\text { Ajuste (tempo } \\
\text { definido) (A) }\end{array}$ & $\begin{array}{c}\text { Tempo de } \\
\text { Ajuste (tempo } \\
\text { definido) (s) }\end{array}$ & $\begin{array}{c}\text { Padrão da } \\
\text { Curva de } \\
\text { Atuação }\end{array}$ & $\begin{array}{l}\text { Tipo da } \\
\text { Curva de } \\
\text { Atuação }\end{array}$ & TDS & $\begin{array}{l}\text { Corrente de } \\
\text { Ajuste da } \\
\text { Unidade } \\
\text { Temporizada } \\
\text { (A) }\end{array}$ & $\begin{array}{l}\text { Corrente de } \\
\text { Ajuste da } \\
\text { Unidade } \\
\text { Instantânea } \\
\text { (A) }\end{array}$ \\
\hline 1 & $0 *$ & $0 *$ & 2 & 2 & 0,2 & 1,25 & 26 \\
\hline 2 & 0,5 & 0,1 & $0 *$ & 0* & $0 *$ & 0* & $0 *$ \\
\hline 3 & 0,5 & 0,1 & $0^{*}$ & $0 *$ & $0^{*}$ & $0 *$ & $0^{*}$ \\
\hline 4 & 0,5 & 1,1 & $0 *$ & $0 *$ & $0 *$ & 0* & $0 *$ \\
\hline 5 & 0,5 & 1,1 & 0* & $0 *$ & $0 *$ & 0* & $0 *$ \\
\hline 6 & 0,5 & 0,6 & 0* & 0* & 0 * & 0* & 0* \\
\hline 7 & 0,5 & 0,85 & 0* & $0 *$ & $0 *$ & $0 *$ & $0 *$ \\
\hline 8 & 0,5 & 0,1 & $0 *$ & $0 *$ & $0^{*}$ & 0* & 0* \\
\hline 9 & 0,5 & 0,1 & $0 *$ & $0 *$ & $0 *$ & $0 *$ & $0 *$ \\
\hline 10 & 0,5 & 0,35 & $0^{*}$ & $0 *$ & $0^{*}$ & 0* & 0* \\
\hline 11 & 0,5 & 0,35 & $0 *$ & $0 *$ & $0 *$ & $0 *$ & $0 *$ \\
\hline 12 & 0,5 & 0,1 & $0 *$ & $0 *$ & $0 *$ & 0* & $0 *$ \\
\hline 13 & 0,5 & 0,6 & $0 *$ & $0 *$ & $0 *$ & $0 *$ & $0 *$ \\
\hline 14 & 0,5 & 0,35 & $0 *$ & $0 *$ & $0 *$ & $0 *$ & $0 *$ \\
\hline 15 & 0,5 & 0,1 & $0 *$ & $0 *$ & $0 *$ & 0* & $0 *$ \\
\hline 16 & 0,5 & 0,1 & $0 *$ & $0 *$ & $0 *$ & 0* & $0 *$ \\
\hline 17 & 0,5 & 0,1 & $0 *$ & $0 *$ & $0 *$ & $0 *$ & $0 *$ \\
\hline 18 & 0,5 & 0,1 & $0 *$ & $0 *$ & $0 *$ & 0* & $0 *$ \\
\hline
\end{tabular}

*0 indica que a unidade instantânea está inoperante ou bloqueada. 


\section{Anexo C - Publicações}


$\mathrm{O}$ seguinte artigo resultante desta dissertação de mestrado foi aceito para $08^{\circ}$ Congresso Latino-Americano de Geração e Transmissão de Energia:

- H. M. Soares e J. C. M. Vieira, Programa Computacional para Definição Automática dos Ajustes dos Dispositivos de Proteção contra Sobrecorrente em Motores de Média e de Baixa Tensão. Artigo submetido para o $8^{\circ}$ Congresso Latino Americano de Geração e Transmissão de Energia Elétrica (CLAGTEE 2009). 